Facultad de Ingeniería Industrial

Carrera de Ingeniería Industrial

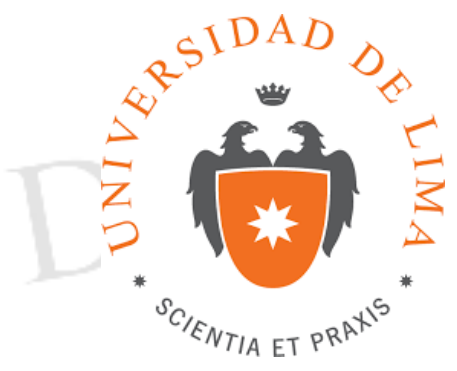

\title{
ESTUDIO DE PREFACTIBILIDAD PARA LA INSTALACIÓN DE UNA PLANTA DE PRODUCCIÓN DE HARINA DE LÚCUMA (Pouteria obovata) PARA SU EXPORTACIÓN
}

Trabajo de investigación para optar el título profesional de Ingeniero Industrial

\author{
Ximena Teresa Gutiérrez Sedano \\ Código 20090509 \\ Joseph Harold Rafael Blas \\ Código 20091818
}

\section{Asesor}

Luis Enrique Chávez Gurmendi

Lima - Perú

Diciembre de 2015 


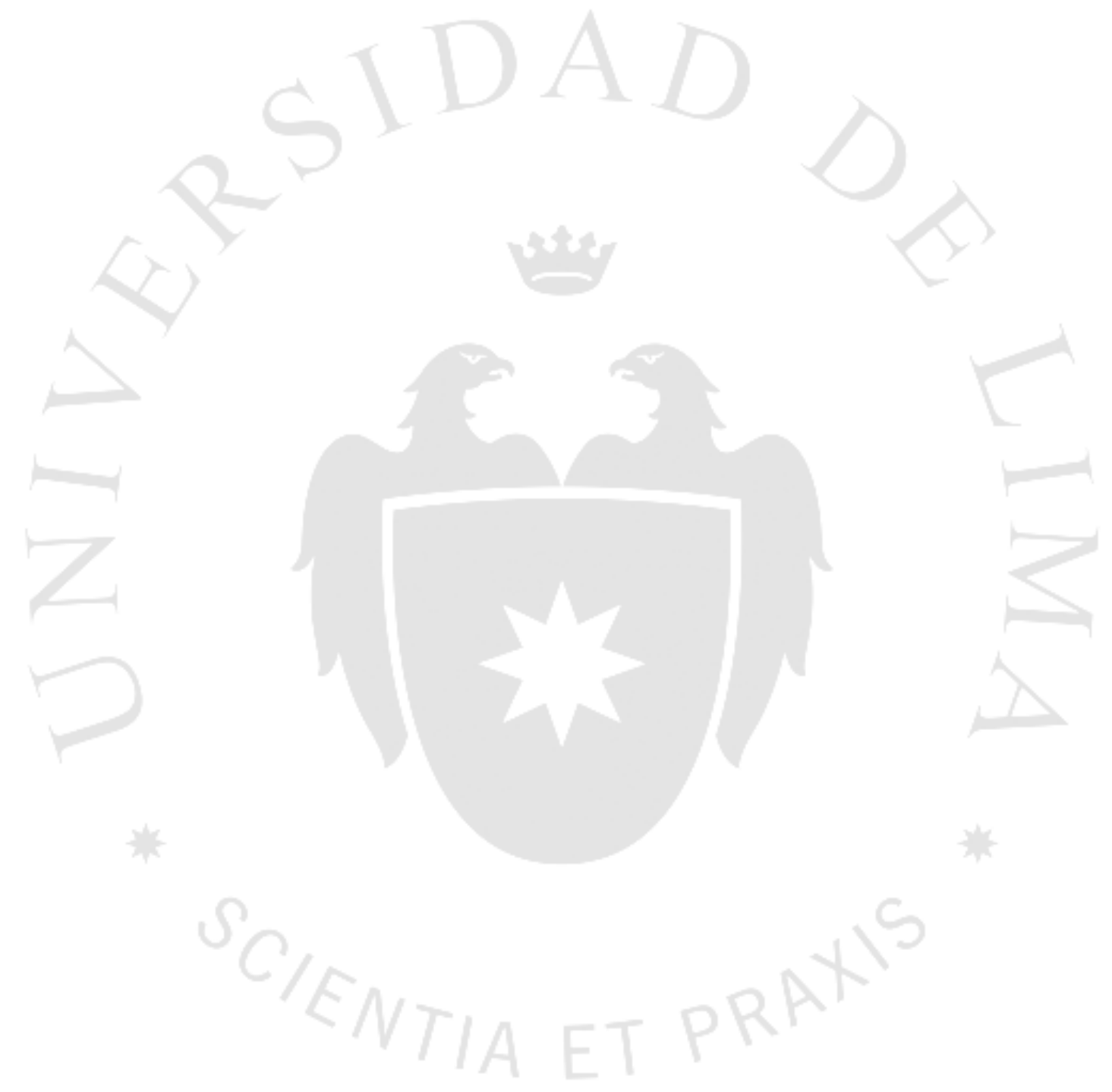




\section{ESTUDIO DE PREFACTIBILIDAD PARA LA INSTALACIÓN DE UNA PLANTA DE PRODUCCIÓN DE HARINA DE LÚCUMA (Pouteria obovata) PARA SU EXPORTACIÓN}




\section{TABLA DE CONTENIDO}

CAPÍTULO I: ASPECTOS GENERALES.

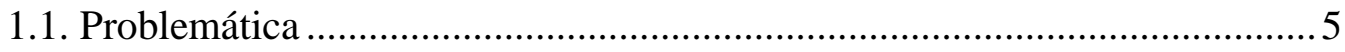

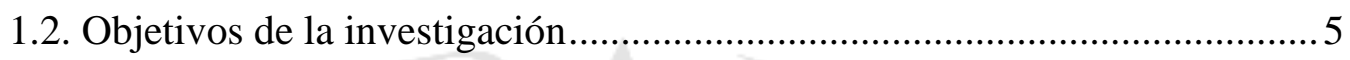

1.3 Alcance y limitaciones de la investigación............................................... 6

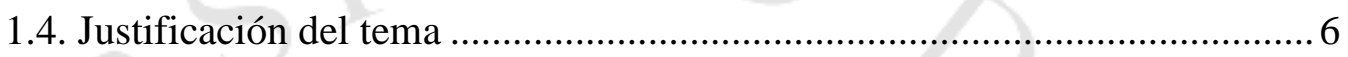

1.5. Hipótesis de trabajo ......................................................................... 7

1.6. Marco referencial de la investigación..................................................... 7

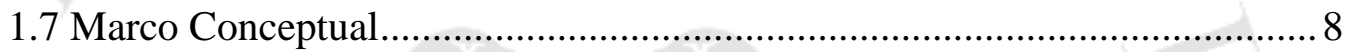

CAPÍTULO II: ESTUDIO DE MERCADO ...................................................................9

2.1. Aspectos generales del estudio de mercado ......................................... 9

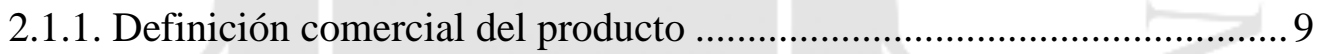

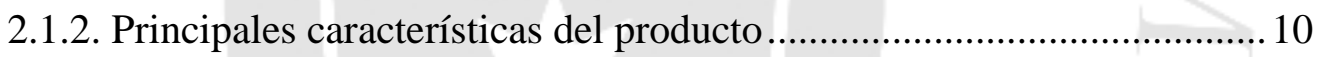

2.1.3. Determinación del área geográfica que abarbará el estudio ................. 11

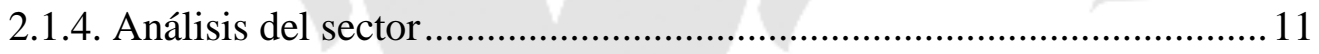

2.1.5. Determinación de la metodología que se empleará en la investigación de

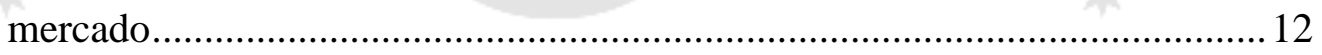

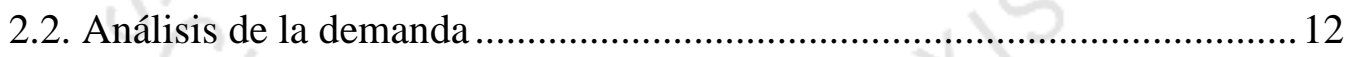

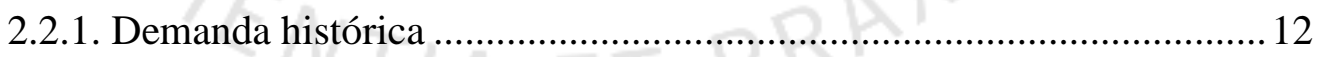

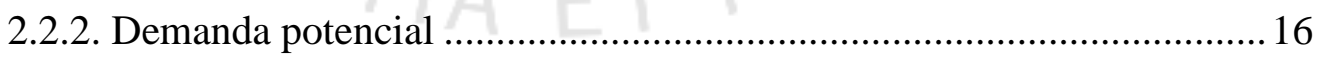

2.2.3 Demanda mediante fuentes primarias ............................................. 18

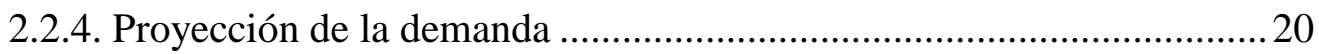

2.2.5 Consideraciones sobre la vida útil del proyecto ..................................24

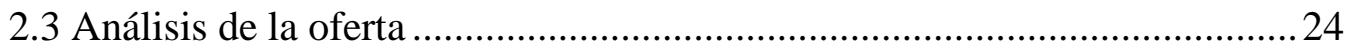

2.3.1. Empresas productoras, importadoras y comercializadoras ..................25 
2.4. Determinación de la Demanda para el proyecto........................................26

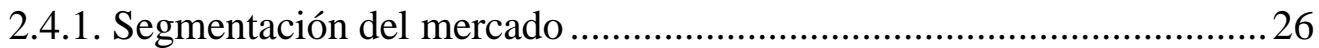

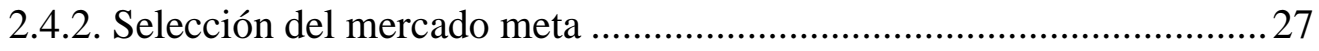

2.4.3. Demanda Específica para el Proyecto ...............................................2 28

2.5. Definición de la Estrategia de Comercialización .......................................229

2.5.1. Políticas de comercialización y distribución ......................................29

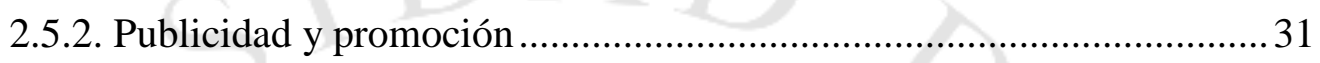

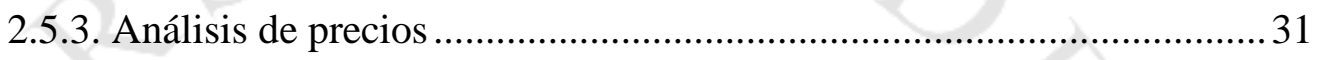

2.6. Análisis de la disponibilidad de los insumos principales .......................... 32

2.6.1. Características principales de la materia prima ...................................32

2.6.2. Disponibilidad de la materia prima..................................................... 33

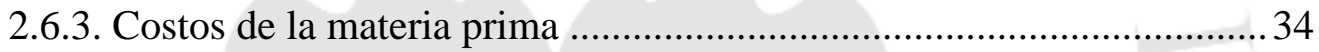

\section{CAPÍTULO III: LOCALIZACIÓN DE PLANTA.........................................................36}

3.1. Identificación y análisis detallado de los factores de localización ..............36

3.2. Identificación y descripción de las alternativas de localización...................37

3.3. Evaluación y selección de localización .................................................. 37

3.3.1. Evaluación y selección de la macro localización ..................................3 37

3.3.2. Evaluación y selección de la micro localización .................................. 40

CAPÍTULO IV: TAMAÑO DE PLANTA ................................................................4 43

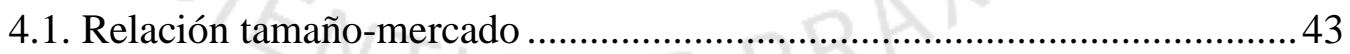

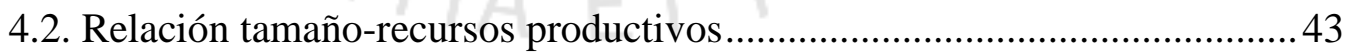

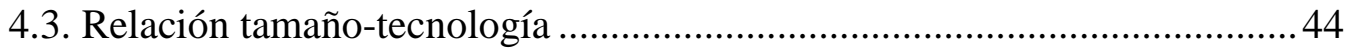

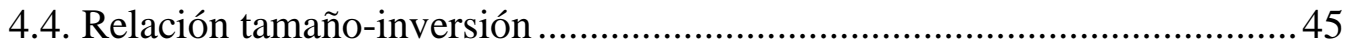

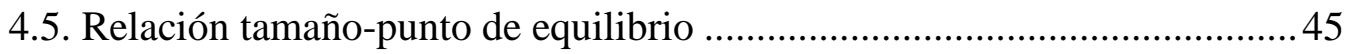

4.6. Selección del tamaño de planta ............................................................ 48 
5.1. Definición técnica del producto

5.1.1. Especificaciones técnicas del producto ..................................................49

5.1.2. Composición del producto ............................................................ 50

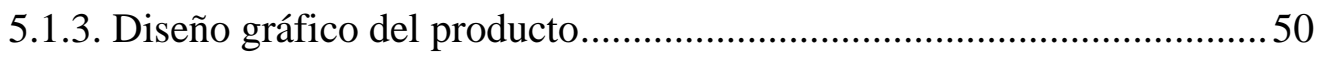

5.1.4. Regulaciones técnicas al producto.................................................51

5.2. Tecnologías existentes y procesos de producción ......................................52

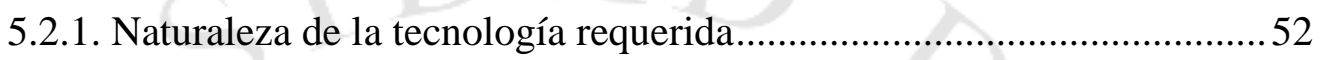

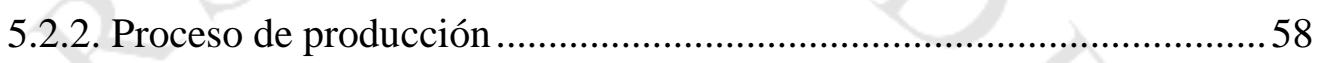

5.3. Características de las instalaciones y equipos ........................................6 63

5.3.1. Selección de la maquinaria y equipos............................................... 63

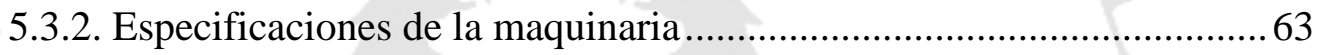

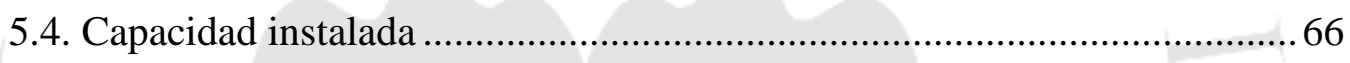

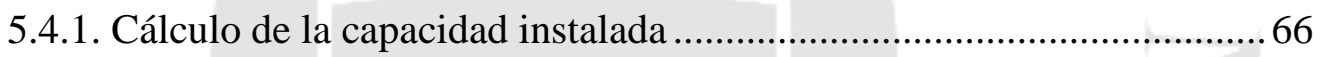

5.4.2. Cálculo detallado del número de máquinas requeridas .......................69 69

5.5 Resguardo de la calidad y/o inocuidad del producto .................................6 69

5.5.1. Calidad de la materia prima, de los insumos, del proceso y del

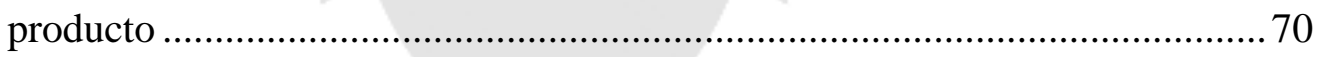

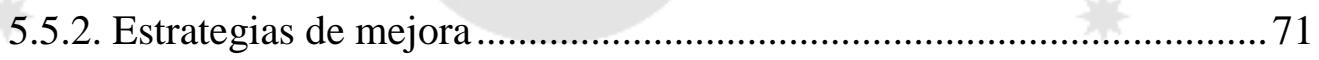

5.6. Estudio de Impacto Ambiental .......................................................... 75

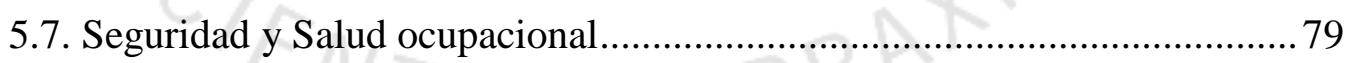

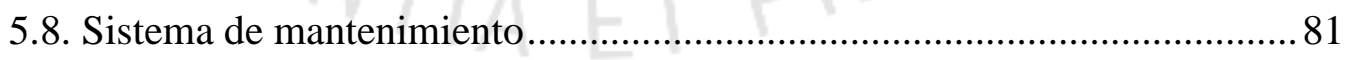

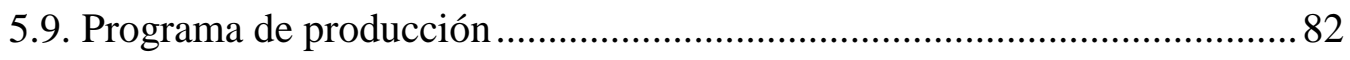

5.9.1. Factores para la programación de la producción ................................. 82

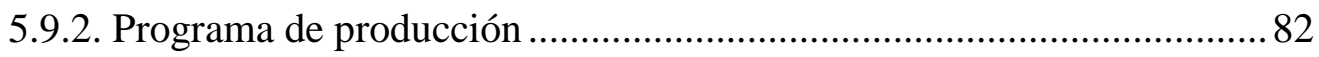

5.10. Requerimiento de insumos, servicios y personal...................................8 83

5.10.1. Materia prima, insumos y otros materiales ...................................... 83 
5.10.2. Servicios: energía eléctrica, agua, vapor, combustible, etc. 84

5.10.3. Determinación del número de operarios y trabajadores indirectos ....87

5.10.4. Servicios de terceros .89

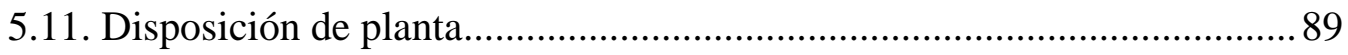

5.11.1. Características físicas del proyecto.............................................. 89

5.11.2. Determinación de las zonas físicas requeridas .................................90

5.11.3. Cálculo de áreas para cada zona ................................................ 90

5.11.4. Dispositivos de seguridad industrial y señalización ..........................94

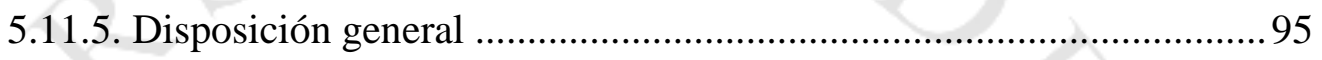

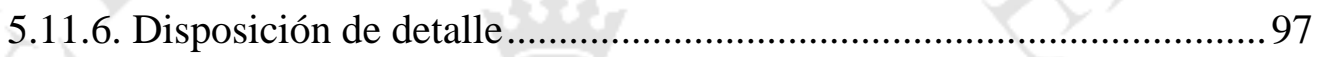

5.12. Cronograma de implementación del proyecto ......................................... 101

CAPÍTULO VI: ORGANIZACIÓN Y ADMINISTRACIÓN..................................103

6.1. Formación de la Organización empresarial ............................................. 103

6.2. Requerimientos de personal directivo, administrativo y de servicios ...... 104

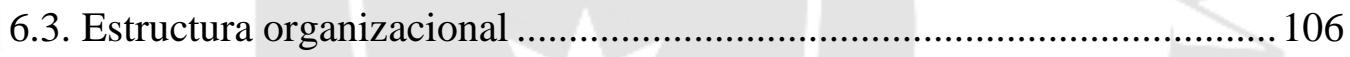

CAPÍTULO VII: ASPECTOS ECONÓMICOS Y FINANCIEROS.......................108

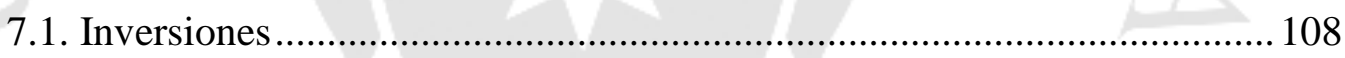

7.1.1. Estimación de las inversiones de largo plazo ................................... 108

7.1.2. Estimación de las inversiones de corto plazo (Capital de trabajo) ...... 111

7.2. Costos de producción.......................................................................... 111

7.2.1. Costos de la materia prima …....................................................... 112

7.2.2. Costo de la mano de obra directa......................................................... 112

7.2.3. Costo Indirecto de Fabricación (materiales indirectas, mano de obra indirecta y costos generales de planta) .................................................... 113

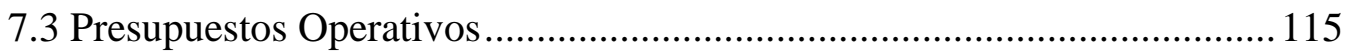

7.3.1. Presupuesto de ingreso por ventas ................................................. 115

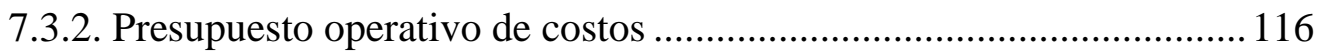


7.3.3. Presupuesto operativo de gastos

7.4 Presupuestos Financieros.

7.4.1. Presupuesto de Servicio de Deuda

7.4.2. Presupuesto de Estado Resultados

7.4.3. Presupuesto de Estado de Situación Financiera

7.4.4. Flujo de caja de corto plazo

7.5 Flujo de fondos netos.....

7.5.1. Flujo de fondos económicos

7.5.2. Flujo de fondos financieros

\section{CAPÍTULO VIII: EVALUACIÓN ECONÓMICA Y FINANCIERA DEL}

8.1. Evaluación económica: VAN, TIR, B/C, PR

8.2. Evaluación financiera: VAN, TIR, B/C, PR

8.3. Análisis de ratios (liquidez, solvencia, rentabilidad) e indicadores económicos y financieros del proyecto

8.4. Análisis de sensibilidad del proyecto 126

CAPÍTULO IX: EVALUACIÓN SOCIAL DEL PROYECTO 128

9.1. Identificación de las zonas y comunidades de influencia del proyecto .... 128

9.2. Análisis de indicadores sociales (valor agregado, densidad de capital, intensidad de capital, generación de divisas) 


\section{ÍNDICE DE TABLAS}

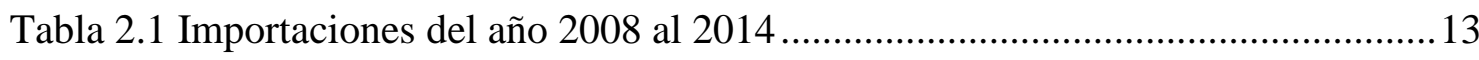

Tabla 2.2 Exportaciones del 2008 al 2014 en kilogramos ........................................ 13

Tabla 2.3 Exportaciones peruanas de harina de lúcuma por países del 2007 al 2014 en

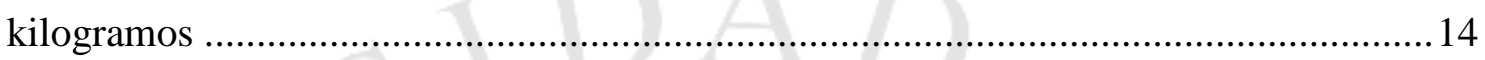

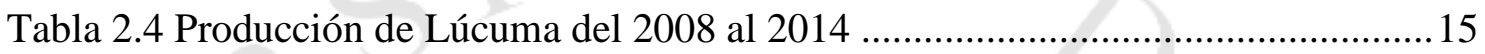

Tabla 2.5 Lúcuma destinada a la producción de Harina de Lúcuma ............................ 15

Tabla 2.6 Producción de harina de lúcuma del 2008 al 2014 ....................................... 16

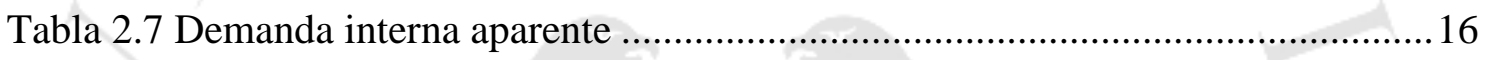

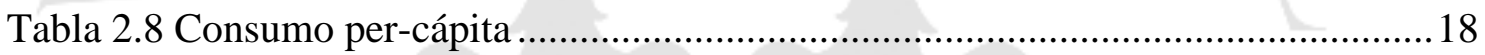

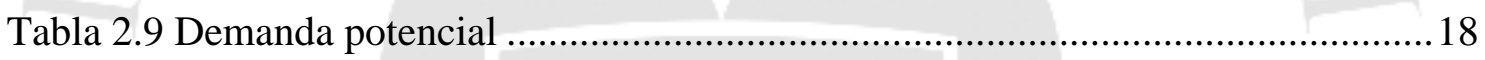

Tabla 2.10 Demanda del mercado .......................................................................... 20

Tabla 2.11 Proyección de la demanda con regresión lineal...........................................21

Tabla 2.12 Proyección de la demanda con regresión exponencial ................................22

Tabla 2.13 Proyección de la demanda con regresión logarítmica .................................23

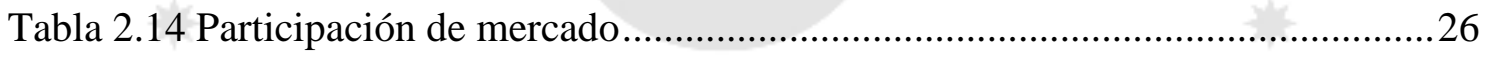

Tabla 2.15 Exportaciones del 2007 al 2014 en kilogramos .......................................26

Tabla 2.16 Participación de empresas exportadoras en los últimos 8 años ...................28

Tabla 2.17 Demanda especifica del proyecto ........................................................29

Tabla 2.18 Evolución del precio por kilo entre 2007 y 2014 (Dólares) .......................... 32

Tabla 2.19 Producción, superficie cosechada y rendimiento de Lúcuma del año 2014.34

Tabla 2.20 Precio de la lúcuma en el Perú por región ...................................................35

Tabla 3.1 Matriz de enfrentamiento de factores de macro localización ..........................38

Tabla 3.2 Información de los factores por departamento ........................................... 39 
Tabla 3.3 Escala de evaluación para la macro localización .39

Tabla 3.4 Matriz de evaluación de la macro localización .40

Tabla 3.5 Matriz de enfrentamiento de factores de micro localización ..........................40

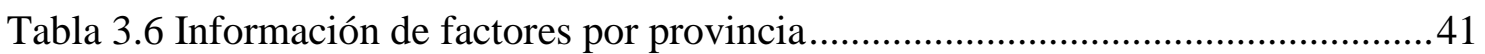

Tabla 3.7 Escala de evaluación para micro localización ...............................................4 41

Tabla 3.8 Matriz de evaluación de la micro localización ............................................42

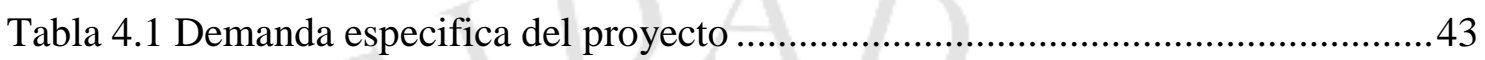

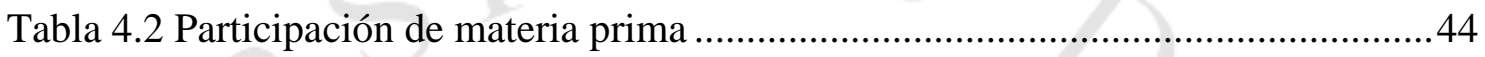

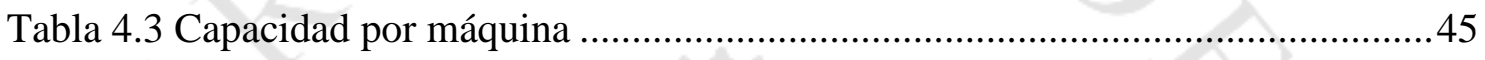

Tabla 4.4 Tarifario de luz de la empresa Edelnor para la zona de Huaral......................46

Tabla 4.5 Tarifario de servicio de agua potable de la empresa Emapa Huaral..............47

Tabla 5.1 Ficha técnica de la harina de lúcuma .........................................................49

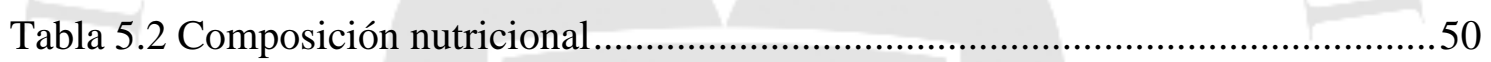

Tabla 5.3 Requisitos microbiológicos según DIGESA, R.M. 591 - 2008 .....................52

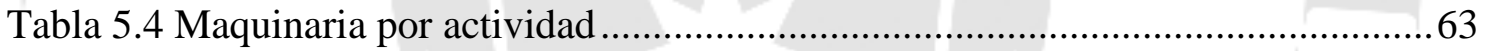

Tabla 5.5 Ficha descriptiva de la balanza de plataforma ..........................................63

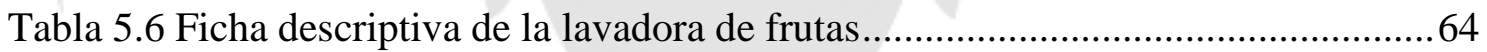

Tabla 5.7 Ficha descriptiva del secador de bandejas ...................................................64

Tabla 5.8 Ficha descriptiva del molino de martillos .....................................................65

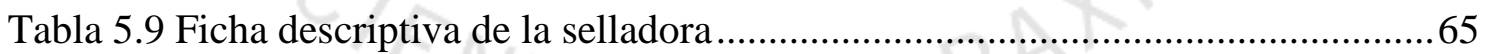

Tabla 5.10 Ficha descriptiva de la embolsadora.....................................................6

Tabla 5.11 Cálculo de la capacidad instalada por actividad ........................................ 68

Tabla 5.12 Cálculo del número de máquinas.......................................................69

Tabla 5.13 Características de la harina de lúcuma..................................................... 70

Tabla 5.14 Descripción del producto y uso presunto.................................................. 73 
Tabla 5.15 Análisis de los peligros en las etapas del proceso para la elaboración de harina de lúcuma

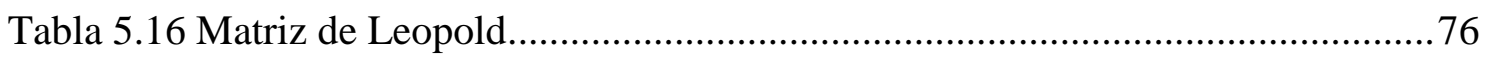

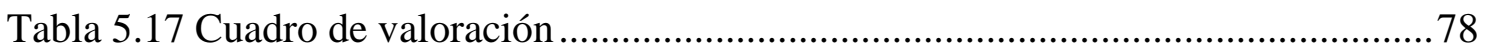

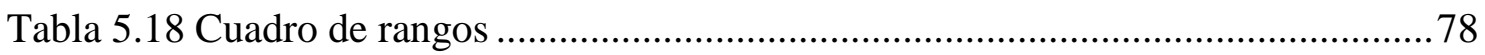

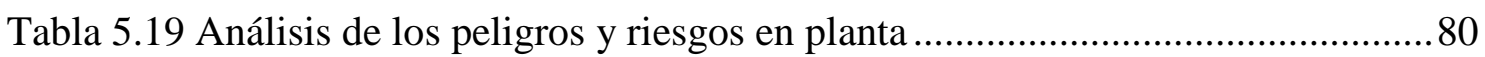

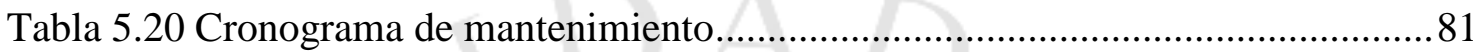

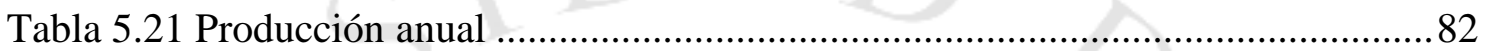

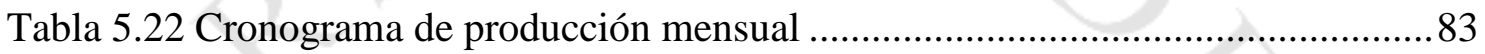

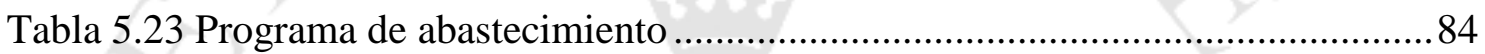

Tabla 5.24 Consumo de horas por máquina y por año ……....................................... 85

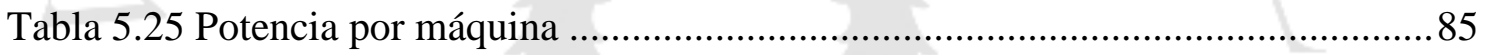

Tabla 5.26 Demanda de potencia anual por máquina en $\mathrm{kW} \mathrm{hr} \mathrm{...................................} 85$

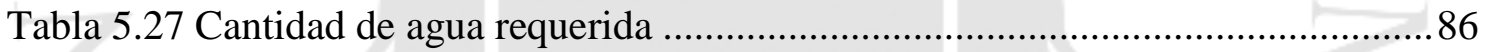

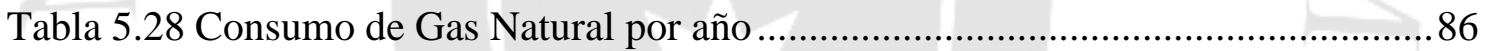

Tabla 5.29 Requerimiento de H-H por actividad por año.......................................... 87

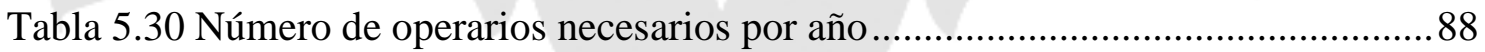

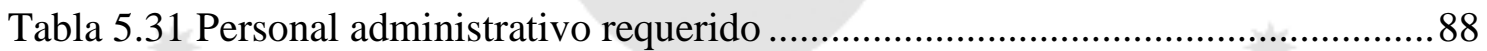

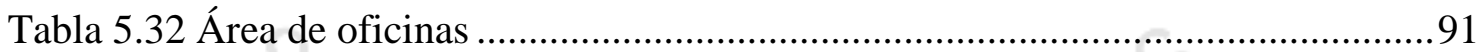

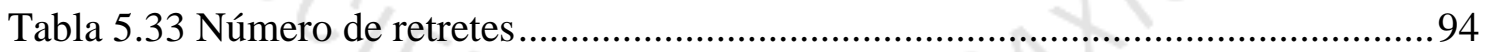

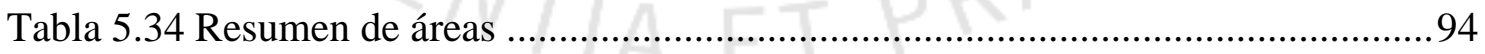

Tabla 5.35 Significado general de colores de seguridad ...........................................95

Tabla 5.36 Tabla de códigos de proximidades ............................................................ 95

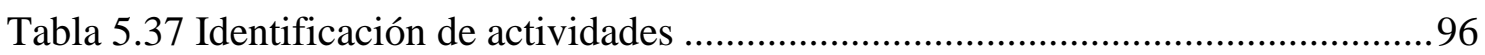

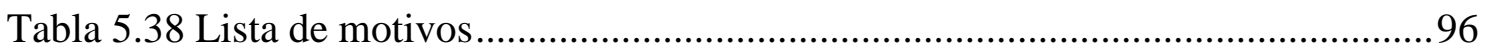

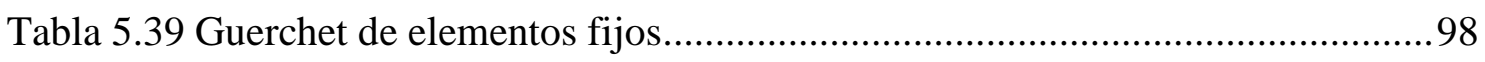


Tabla 5.40 Guerchet de elementos móviles .99

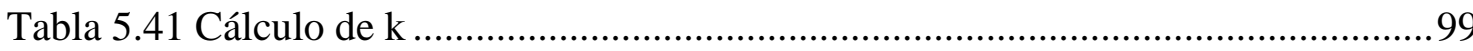

Tabla 5.42 Estructura de desglose de trabajo ........................................................... 101

Tabla 6.1 Requerimiento de personal para actividades administrativas .......................104

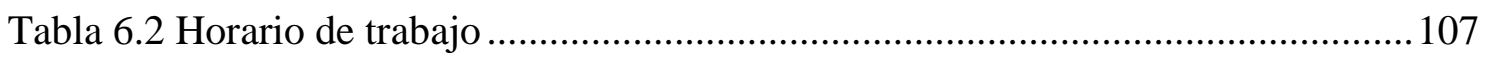

Tabla 7.1 Inversión en edificaciones de oficinas administrativas, almacenes y comedor 109

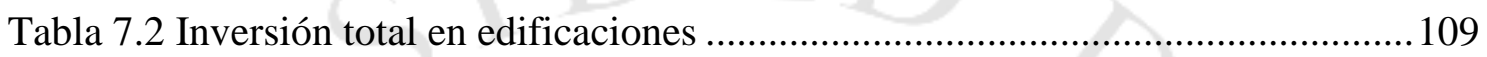

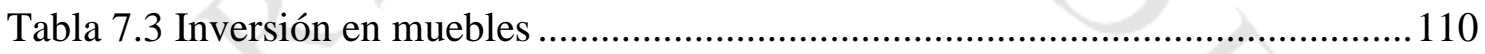

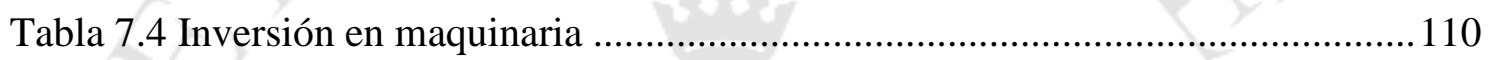

Tabla 7.5 Inversión en instrumentos de control y medición .......................................... 110

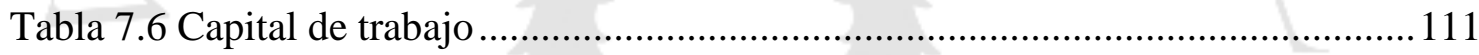

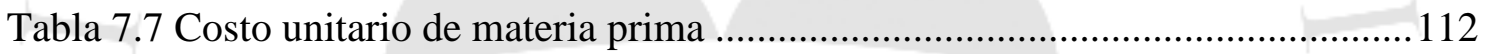

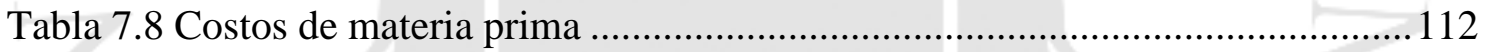

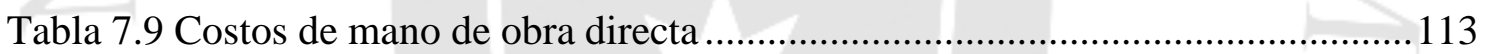

Tabla 7.10 Remuneraciones de puestos administrativos ......................................... 113

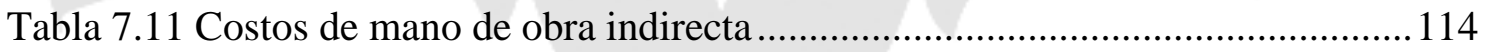

Tabla 7.12 Costo del agua potable, energía eléctrica y gas natural en planta ............... 114

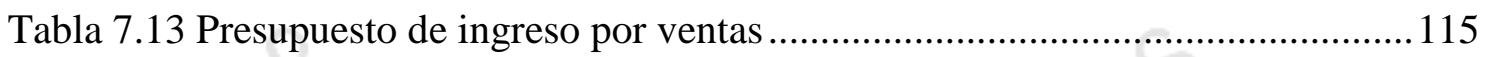

Tabla 7.14 Presupuesto operativo de costos (en nuevos soles) ................................... 116

Tabla 7.15 Presupuesto operativo de gastos (en nuevos soles) ..................................116

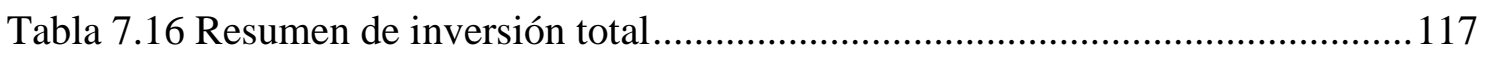

Tabla 7.17 Cuadro de Servicio de deuda (en nuevos soles) ..................................... 117

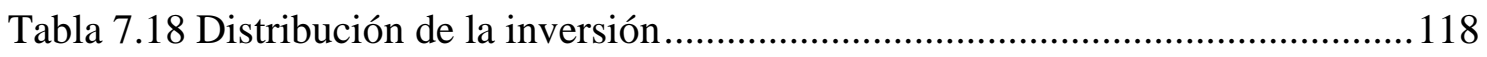

Tabla 7.19 Presupuesto de Estado de Resultados (en nuevos soles) ...........................119

Tabla 7.20 Presupuesto de Estado de Situación Financiera (en nuevos soles)............. 120 
Tabla 7.21 Flujo de Caja de Corto Plazo (en nuevos soles)

Tabla 7.22 Flujo de fondos económicos (en nuevos soles) ........................................ 122

Tabla 7.23 Flujo de fondos financieros (en nuevos soles)......................................... 123

Tabla 8.1 Indicadores económicos del proyecto.......................................................... 124

Tabla 8.2 Indicadores financieros del proyecto ............................................................. 125

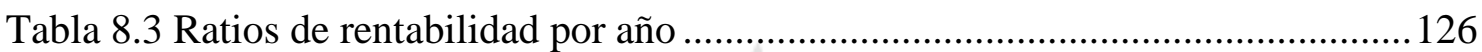

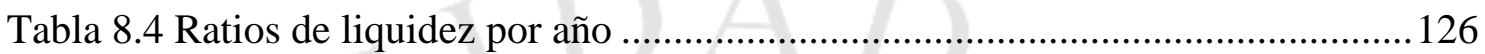

Tabla 8.5 Análisis de sensibilidad por variación del precio ........................................ 127

Tabla 8.6 Análisis de sensibilidad por variación de costos de producción.....................127

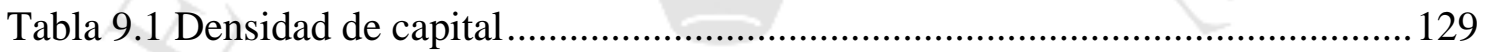

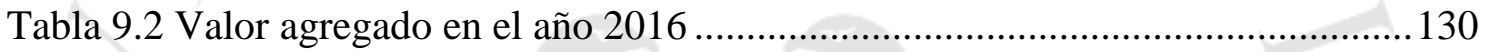

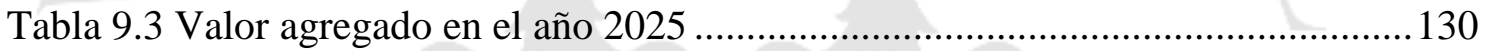

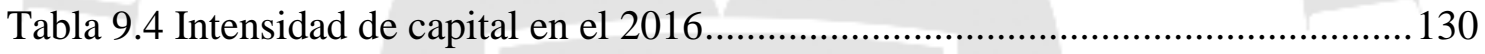

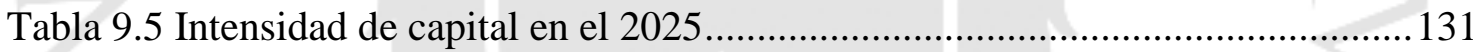




\section{ÍNDICE DE FIGURAS}

Figura 2.1 Imagen del producto básico

Figura 2.2 Tendencia de las exportaciones del 2007 al 2014 en kilogramos ................. 14

Figura 2.3 Características de un comprador estadounidense ..................................... 17

Figura 2.4 Estacionalidad de las ventas del 2007 al 2014 en kilogramos ..................... 17

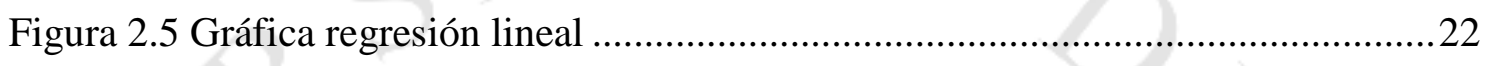

Figura 2.6 Gráfica regresión exponencial ..........................................................23

Figura 2.7 Gráfica regresión logarítmica .................................................................. 24

Figura 2.8 Exportaciones del 2007 al 2014 de harina de lúcuma (kg) a los principales

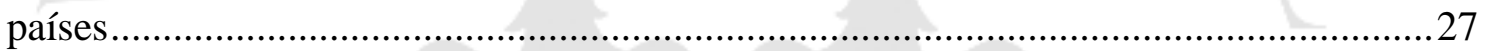

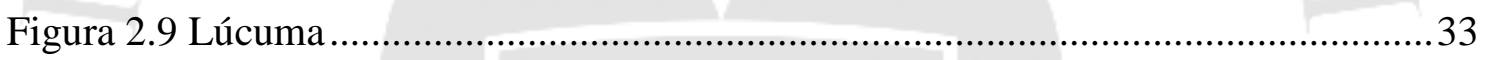

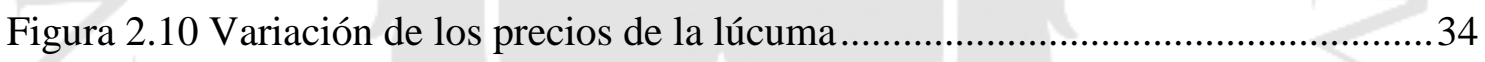

Figura 4.1 Fórmula para el cálculo del punto de equilibrio .......................................46

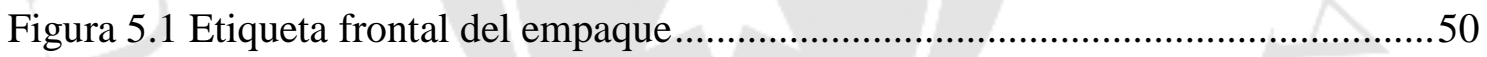

Figura 5.2 Etiqueta posterior del empaque ........................................................ 51

Figura 5.3 Máquina de liofilización.......................................................................53

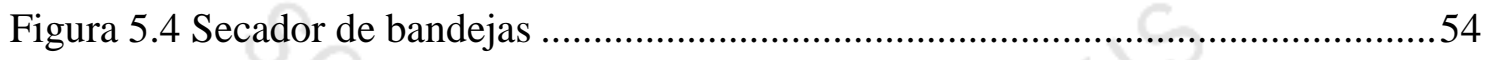

Figura 5.5 Esquema del secado por Ventana Refractante .........................................55

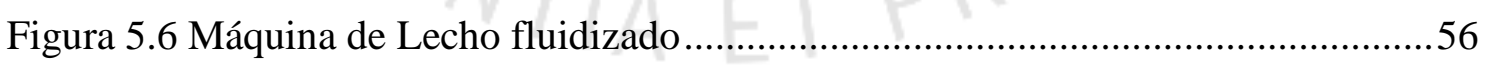

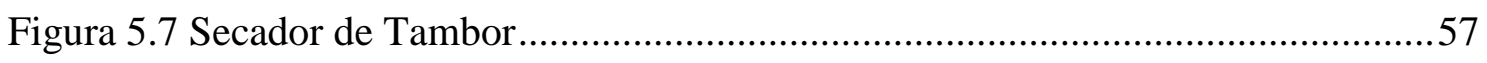

Figura 5.8 Diagrama de operaciones del proceso .................................................. 61

Figura 5.9 Balance de materia de la producción de harina de lúcuma ..........................62

Figura 5.10 Pasos para la implementación de HACCP ............................................. 72

Figura 5.11 Distribución de parihuelas .................................................................. 92 
Figura 5.12 Distribución de cajas en una parihuela....................................................93

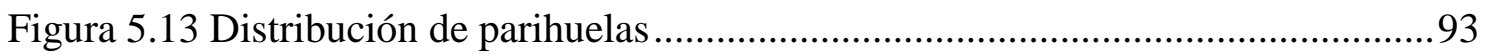

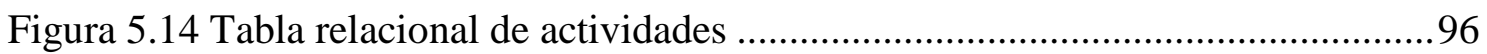

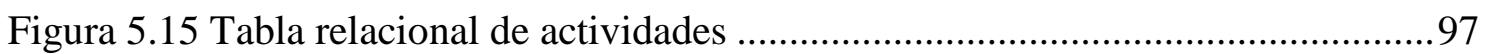

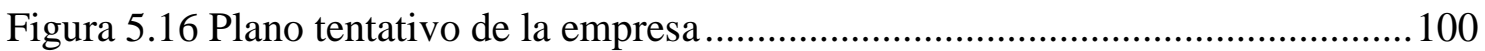

Figura 5.17 Cronograma de implementación del proyecto.........................................102

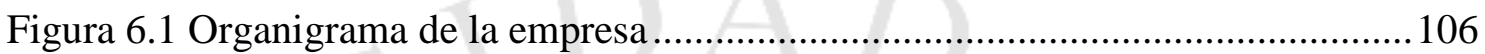

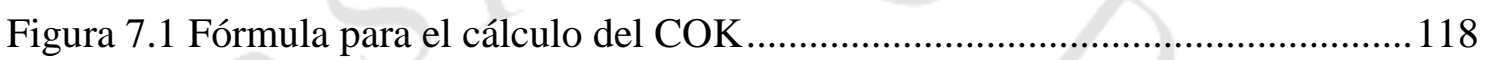

Figura 9.1 Mapa del departamento de Lima ..................................................... 128 


\section{ÍNDICE DE ANEXOS}

Anexo 1 - Propuesta económica - Lavadora de frutas ................................................... VI

Anexo 2 - Propuesta económica - Secador de bandejas y Molino de martillos ............ VII

Anexo 3 - Propuesta económica - Carretilla hidráulica ................................................... 


\section{RESUMEN}

En nuestro país estamos viviendo una época de crecimiento económico sin precedentes. El dinamismo de las actividades productivas y de comercio internacional ha hecho que el país tenga un crecimiento constante durante los últimos 16 años (INEI, 2015).

Este crecimiento ha generado oportunidades para miles de empresarios que, con el soporte necesario, son capaces de colocar un producto aceptado por el mercado al que se dirigen ya sea nacional o internacionalmente. Tal es el caso del aumento de empresas que se dedican a la exportación de productos alimenticios, ya sean para su consumo directo o como insumos, a los países llamados desarrollados como Estados Unidos y algunos países de Europa y Asia.

La presente investigación propone la instalación de una planta productora de harina de lúcuma para la exportación, producto utilizado ampliamente en la industria heladera, repostera y pandera en el mercado internacional, así también como para el consumo directo debido a que es visto como un producto natural y sin preservantes.

El desarrollo abarca varias perspectivas, las cuales comprenden la de mercado, tecnológica, económica, financiera y social del proyecto.

En el estudio de mercado, hemos identificado que el mercado interno, si bien hay un consumo importante por parte de empresas como Alicorp y Gloria, no es tan significativo si se compara con el consumo externo. La relación de la cantidad de harina de lúcuma consumida en el país y consumida externamente va de 1 a 3 . Es por ello que la presente investigación contempla la producción y exportación del producto a países como Estados Unidos, Reino Unido, Alemania y Holanda, consumidores importantes de la harina de lúcuma peruana.

Bajo la perspectiva tecnológica determinamos las especificaciones técnicas del producto, la maquinaria y equipos a utilizar, el personal y los servicios a contratar, así como también los requisitos que debemos de cumplir para asegurar un producto bajo los más altos estándares de calidad que exige el mercado internacional. 
En el aspecto económico y financiero se determinaron las inversiones necesarias para dar inicio al proyecto, los ingresos, los costos de producción, gastos administrativos y financieros. Con esto se obtuvieron los indicadores económicos y financieros, los cuales nos indican que el proyecto es rentable con un periodo de recupero de 6 años.

Finalmente, en el último capítulo se realiza la evaluación social del proyecto, identificando las zonas y comunidades de influencia del proyecto. Se analizaron los indicadores sociales tales como valor agregado, densidad de capital e intensidad de capital. 


\section{SUMMARY}

In our country we are living in an era of unprecedented economic growth. The dynamism of productive activities and international trade has made the country has a steady growth over the past 16 years (INEI, 2015).

This growth has created opportunities for thousands of entrepreneurs that, with the necessary support, are capable of placing a product accepted by the national or international market. Such is the case of the increasing number of companies engaged in the export of food products, either for direct consumption or as inputs, to the countries called developed like the United States and some countries in Europe and Asia.

This research proposes the installation of a factory of lucuma flour for the exportation, product widely used in the ice cream industry, pastry and baking in the international market, as well as for direct consumption because it is seen as a natural product without preservatives.

The development of this research covers multiple perspectives, which include market, technological, economic, financial and social project.

In the market study, we have identified that the domestic market, although there is a significant consumption by companies as Alicorp and Gloria, is not as significant when is compared with external consumption. The ratio of the amount of lucuma flour consumed in the country and externally consumed is 1 to 3 . That is why this research involves the production and export of the product to countries like the US, UK, Germany and the Netherlands, consumers important Peruvian lucuma flour.

Under the technological perspective we determined the technical specifications of the product, machinery and equipment used, staff and services to hire, as well as the requirements that we must meet to ensure a product under the highest quality standards required by the market international.

In the economic and financial aspect, the investments needed to start the project, revenues, production costs, administrative and financial expenses were determined. With this information the economic and financial indicators were obtained indicating that the project is profitable with a period of recovery of 6 years. 
Finally in the last chapter the social aspect of the project is evaluated, identifying the areas and communities affected by the project. Social indicators such as value-added, capital intensity and capital intensity were analyzed.

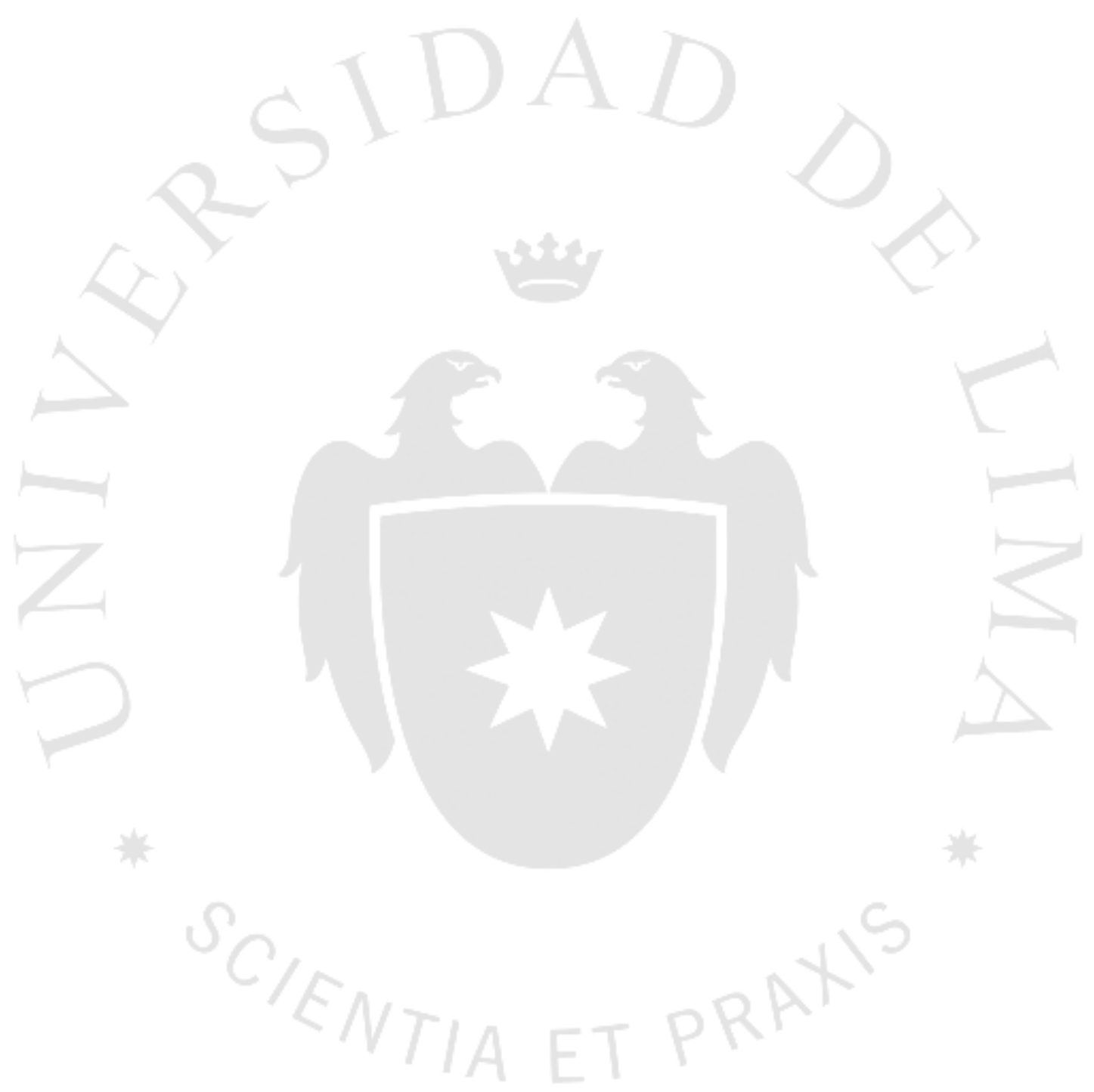




\section{CAPÍTULO I: ASPECTOS GENERALES}

\subsection{Problemática}

En los 15 últimos años, la exportación de productos "No Tradicionales" ha crecido año tras año, con tasas de crecimiento de exportación positivas, a excepción del año 2009, año en el que se presentó una caída en las exportaciones debido a la crisis internacional. (INEI, 2015) ${ }^{1}$. Entre estos productos se encuentra la harina de lúcuma, producto demandado principalmente por las empresas productoras de helado, yogures, postres y por empresas comercializadoras de productos naturales. La ventaja competitiva que el Perú tiene frente a los demás países es la calidad de la lúcuma que se produce en el interior del país y que permite obtener harina de lúcuma de mejores propiedades y composición. Al ser un producto que se puede almacenar por un periodo prolongado de tiempo ( 2 años) y que se puede transportar fácilmente, los costos de transporte y almacenaje son bajos, ventaja sobre otros derivados de la lúcuma.

Son estas razones por las cuales la presente investigación es acerca de la producción de harina de lúcuma para su exportación a los principales países de la Unión Europea y Estados Unidos.

\subsection{Objetivos de la investigación}

$\underline{\text { Objetivo general }}$

- Determinar la viabilidad de mercado, tecnológica, económica y financiera para la instalación de una planta productora de harina de lúcuma.

\section{$\underline{\text { Objetivos específicos }}$}

- Realizar un estudio de mercado sobre el consumo de harina de lúcuma para identificar su oferta, demanda y precio de venta en el mercado internacional.

- Analizar los factores para determinar la localización y el tamaño de la planta de producción.

\footnotetext{
${ }^{1}$ Entre los años 2002 y 2014 el valor de las exportaciones FOB del sector agropecuario aumentó en $662 \%$ con una tasa de crecimiento promedio anual de $18.4 \%$. (INEI, 2015).
} 
- Evaluar las tecnológicas existentes y procesos de producción de harina de lúcuma para la elección y aplicación de la metodología más conveniente.

- Determinar si el proyecto es económica y financieramente viable analizando los indicadores de inversión.

- Evaluar el impacto social del proyecto analizado los indicadores como valor agregado o densidad de capital.

\subsection{Alcance y limitaciones de la investigación}

\section{$\underline{\text { Alcance }}$}

La presente investigación abarca el estudio de mercado para la comercialización de la harina de lúcuma en el mercado internacional, además del estudio de localización y tamaño de la planta, la determinación de la localización de la planta, el estudio técnico del proyecto, la organización y administración de la empresa y el estudio y análisis económico-financiero. En base a los estudios y análisis ya mencionados se procederá a verificar la viabilidad del proyecto.

\section{$\underline{\text { Limitaciones }}$}

El presente estudio no abarca la comercialización del producto en el mercado peruano.

\subsection{Justificación del tema}

Justificación técnica

El proyecto es técnicamente factible debido a que se cuenta con la metodología para el proceso de producción de la harina de lúcuma. El proceso principal a utilizar es el de secado por bandejas. Por otro lado se cuenta con los equipos, utensilios y mobiliario, para la ejecución del proyecto.

Justificación económica

El proyecto es económicamente viable debido a que se generaría una utilidad neta positiva. Las ganancias se obtendrán de la venta a empresas comercializadoras de suplementos naturales en el mercado internacional, principalmente a los siguientes países: Estados Unidos, Reino Unido, Alemania y Holanda. 
Justificación social

El proyecto es socialmente viable, ya que la planta de producción de harina de lúcuma brindará oportunidades de trabajo. Además los productores de lúcuma se verán beneficiados con el incremento en la demanda de su producto (insumo principal de la harina de lúcuma). Por otro lado el consumo de productos saludables combatiría la obesidad y demás enfermedades nutricionales.

\subsection{Hipótesis de trabajo}

La instalación de una planta procesadora de harina de lúcuma para su exportación es factible, pues existe el mercado internacional que va a aceptar el producto y además es tecnológica, económica y financieramente viable.

\subsection{Marco referencial de la investigación}

Existen referencias sobre proyectos similares existentes:

- Perfil de Mercado y Competitividad Exportadora de la lúcuma

- Estudio Técnico de la Producción de Harina de Lúcuma en la Sierra de Piura Universidad de Piura.

- Seminario de Agro Negocios - Universidad del Pacífico.

- Estudio de rendimiento de harina de lúcuma a partir del fruto fresco. - Revista de la Facultad de Ingeniería Industrial - Universidad Nacional Mayor de San Marcos.

- Estudio tecnológico para la obtención de harina de lúcuma por liofilización Universidad de Lima.

- Plan de negocios para la puesta en marcha de una empresa productora/comercializadora de harina, pulpa y demás derivados de la lúcuma EXPROPAK S.R. L. - para el mercado nacional e internacional - Universidad de Lima. 
Por otro lado programas del estado o privados desarrollan proyecto en este tema:

- PROLUCUMA: Asociación de Productores de Lúcuma, agrupa empresarios agrarios con gran potencial de exportación.

- PROMPERU/PROMPEX: Guía para la exportación de la harina de lúcuma.

- Programa PAEN-GTZ: Proyecto Productivo de Harina de Lúcuma. Municipalidad de Chalaco y el Programa Desarrollo Sostenible de Ecosistemas de Montaña en el Perú (PDSEMP).

- Entidades del estado como el Ministerio de Agricultura, Ministerio de Comercio Exterior y Turismo realizan concursos para invertir en proyectos para exportación.

\subsection{Marco Conceptual}

En el presente marco conceptual, colocamos algunas definiciones técnicas del producto en base a la NTP 011.0422012 Norma técnica Peruana de Harina de Lúcuma (INDECOPI):

- Harina de lúcuma: Producto obtenido a través de un proceso de molienda de la pulpa secada o deshidratada del fruto de la lúcuma Pouteria lúcuma (R. \& P.) asegurando su inocuidad y calidad. ${ }^{2}$

Así mismo, utilizaremos como base teórica las normas sanitarias que establecen los criterios microbiológicos de calidad sanitaria e inocuidad para los alimentos y bebidas de consumo humano (RM N 591 - 2008/MINSA y Comisión del Codex Alimentarius).

\footnotetext{
${ }^{2}$ La Norma Técnica Peruana establece los requisitos de calidad e inocuidad que debe cumplir la harina de lúcuma destinada al consumo directo o al uso industrial.
} 


\section{CAPÍTULO II: ESTUDIO DE MERCADO}

\subsection{Aspectos generales del estudio de mercado}

En esta sección definiremos y describiremos aspectos esenciales como la definición del producto en sus tres niveles (básico, real y aumentado), sus características, el alcance geográfico del proyecto, el análisis del sector al que estamos incursionando y la metodología utilizada para desarrollar el proyecto.

\subsubsection{Definición comercial del producto}

El producto propuesto es una harina elaborada en base a la lúcuma. De acuerdo a la Norma Técnica Peruana 011.0422012 la harina de lúcuma es un producto obtenido a través de un proceso de molienda de la pulsa seca o deshidratada del fruto de la lúcuma (Pouteria Obovata) asegurando su inocuidad y calidad.

\section{$\underline{\text { Producto básico }}$}

La harina de lúcuma es un polvo de color amarillo con una humedad máxima de 7.5\% y una densidad de 0,79+- 0,10. El sabor y olor son característicos de la lúcuma (Figura 2.1). Figura 2.1

Imagen del producto básico

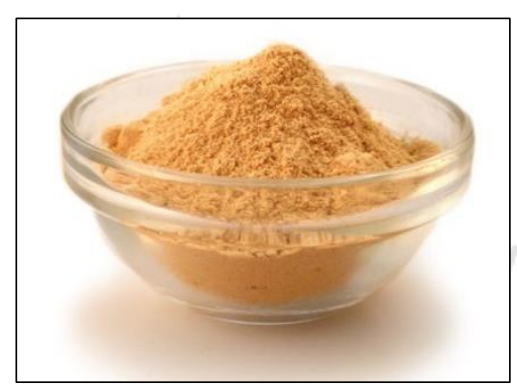

Fuente: Zebra Organics Inc, (2016)

\section{$\underline{\text { Producto real }}$}

El producto real es una harina de lúcuma que cumple con todos los requisitos y controles de calidad requeridos por el Ministerio de Comercio Exterior y Turismo (MINCETUR) para comercializar productos orgánicos en el exterior. Todos los insumos y el proceso de producción cumplen con los requisitos controlados por los organismos de certificación 
autorizados por el Servicio Nacional de Sanidad Agraria (SENASA). El producto es empacado en bolsas de polietileno de $10 \mathrm{~kg}$ previa validación de su inocuidad y de su adecuación al producto mediante un control de calidad. El producto es envasado herméticamente bajo estas condiciones de salubridad y las bolsas son colocadas en cajas de cartón de 5 bolsas cada una.

Cada bolsa lleva adherida dos etiquetas (frontal y posterior) en las que se encuentra el logo, código de barras, peso neto, información nutricional, ingredientes, fecha de elaboración, fecha de vencimiento, lote, teléfono de contacto, dirección y país de origen. También va impreso el logo de la certificación adquirida para su comercialización, provista por la empresa certificadora autorizada mencionada anteriormente.

\section{Producto aumentado}

El producto aumentado considera un servicio de atención a consultas y solución de dudas y reclamos recibidos por parte de nuestros clientes y público en general a una central telefónica y a una página web. También consideramos el envío de pequeñas muestras (30 g) a clientes potenciales para su degustación.

\subsubsection{Principales características del producto}

\subsubsection{Usos y características del producto}

La harina de lúcuma en el mercado internacional es utilizada principalmente como insumo para la preparación de batidos, suplementos alimenticios, así como en la industria heladera y repostera.

\subsubsection{Bienes sustitutos y complementarios}

Los productos sustitutos de la harina de lúcuma en la preparación de batidos, son otros suplementos como la maca y quinua. Así mismo, en la elaboración de postres y helados, los principales sustitutos son la harina de trigo y las harinas de otras frutas.

En la preparación de batidos, los productos complementarios son los alimentos que intervienen en una dieta balanceada. En la industria heladera y repostera, los productos complementarios son los demás insumos como la leche, huevos, azúcar y esencias. 


\subsubsection{Determinación del área geográfica que abarbará el estudio}

El presente estudio se realizara analizando el mercado internacional, principalmente Estados Unidos y algunos países de la Unión Europea como Reino Unido, Alemania y Holanda, ya que estos son los países a los cuáles el Perú exporta la mayor cantidad de harina de lúcuma.

\subsubsection{Análisis del sector}

Amenaza de nuevos competidores

Dentro de los requisitos indispensables para ingresar a la industria de producción y comercialización de harina de lúcuma, los posibles competidores deben cumplir con los requisitos legales que demandan la producción y venta de un producto alimenticio en el mercado internacional. Dichos requisitos son la autorización de comercialización de aditivos emitida por una empresa certificadora de productos orgánicos, licencias municipales, trámites contables, etc. Dichos requisitos no son considerados difíciles de cumplir ya que los organismos encargados brindan las facilidades para su obtención. Las certificaciones necesarias para ingresar al mercado internacional son la USDA Organic y la UE de la unión europea.

En conclusión la amenaza de nuevos ingresos es considerada fuerte debido a la alta posibilidad de que los posibles competidores entren al mercado.

$\underline{\text { Amenaza de productos sustitutos }}$

Para analizar la amenaza de los productos sustitutos de la harina de lúcuma, se consideraron aquellos productos que cumplen con la misma función básica como la harina de trigo o harina de otra fruta. También son sustitutos los productos utilizados como suplementos alimenticios. Esto se puede considerar como una amenaza alta debido a que fácilmente sustituye el bien que se planea producir.

\section{$\underline{\text { Poder de negociación de los clientes }}$}

Dentro de la negociación de los clientes se consideró si nuestros posibles clientes son mayoristas o minoristas. En el caso sean mayoristas el poder de negociación es bajo porque realizan la compra por volúmenes, sin embargo con clientes minoristas el poder de negociación es alto. 


\section{$\underline{\text { Poder de negociación de los proveedores }}$}

En cuanto al poder de negociación de los proveedores, a estos los podemos encontrar en mayor concentración en los departamentos de Lima y Piura. Actualmente los productores de lúcuma comercializan la fruta en los mercados mayoristas de frutas, sin embargo el precio en estos mercados es mayor al precio en chacra. Al comprar la fruta directamente en donde se cosecha, concluimos que el poder de negociación es alto, ya que la cantidad de productores es alta y podríamos cambiar de proveedor fácilmente.

\section{$\underline{\text { Rivalidad entre competidores }}$}

Actualmente son muchas las empresas exportadoras de la harina de lúcuma ( 94 empresas en el 2014), pero son alrededor de 4 empresas que concentran cerca del $80 \%$ de participación del mercado, por lo que concluimos que la rivalidad entre competidores es alta.

\subsubsection{Determinación de la metodología que se empleará en la investigación de} mercado

Para el estudio de mercado utilizaremos dos tipos de fuentes de información: primeras y secundarias.

- Fuentes primarias: Entrevistas y opinión de expertos.

- Fuentes secundarias: MINAG, MINCETUR, Prolucuma, SUNAT y ADEX.

\subsection{Análisis de la demanda}

En esta sección se analizará y calculará la demanda interna aparente, demanda del mercado, demanda potencial y su proyección con el objetivo de tener un punto de referencia sobre el cual determinar la demanda específica de nuestro proyecto en la sección 2.4.

\subsubsection{Demanda histórica}

\subsubsection{Importaciones/exportaciones}

Para hallar las importaciones de la harina de lúcuma, se utilizó como fuente la SUNAT, con partida arancelaria 1106.30.20.00 Harina de lúcuma (Lúcuma Obovata). El resumen 
de las importaciones de los últimos 8 años se encuentra en la tabla 2.1. Cabe mencionar que las importaciones en casi todos los años, es cero.

Tabla 2.1

Importaciones del año 2008 al 2014

\begin{tabular}{|c|c|c|}
\hline Año & Valor FOB $\mathbf{( \$ )}$ & Peso neto $(\mathbf{k g})$ \\
\hline 2008 & 0 & 0 \\
\hline 2009 & $12.615,75$ & $2.170,00$ \\
\hline 2010 & 0 & 0 \\
\hline 2011 & 0 & 0 \\
\hline 2012 & 0 & 0 \\
\hline 2013 & 0 & 0 \\
\hline 2014 & 0 & 0 \\
\hline
\end{tabular}

Fuente: Superintendencia Nacional de Aduanas y de Administración Tributaria, (2015)

Así mismo, para obtener las exportaciones se recurrió a las bases de datos de la SUNAT y se obtuvieron los datos desde el año 2007. En la tabla 2.2 se aprecian las exportaciones desde ese año hasta el 2014 con tasas de crecimiento positivas a acepción del 2009, año de la crisis internacional.

Tabla 2.2

Exportaciones del 2008 al 2014 en kilogramos

\begin{tabular}{|c|c|c|c|}
\hline Año & Valor FOB (\$) & Peso neto (kg) & Tasa de Crecimiento (kg) \\
\hline 2008 & $134.674,00$ & $14.549,00$ & \\
\hline 2009 & $218.108,00$ & $21.100,00$ & $45,03 \%$ \\
\hline 2010 & $226.324,00$ & $20.604,00$ & $-2,35 \%$ \\
\hline 2011 & $353.801,00$ & $32.826,00$ & $59,32 \%$ \\
\hline 2012 & $646.418,00$ & $58.612,00$ & $78,55 \%$ \\
\hline 2013 & $1.100 .334,00$ & $93.142,00$ & $58,91 \%$ \\
\hline 2014 & $1.373 .352,00$ & $116.498,00$ & $25,08 \%$ \\
\hline
\end{tabular}

Fuente: Superintendencia Nacional de Aduanas y de Administración Tributaria, (2015)

En la tabla 2.3 y en la figura 2.2 se observa que el país de destino al que más se exporta es Estados Unidos con un 40\% de participación respecto del total en el 2014, seguido por Reino Unido con $27,30 \%$. Además, el primer país latinoamericano al que le exportamos es Chile. 
Tabla 2.3

Exportaciones peruanas de harina de lúcuma por países del 2007 al 2014 en kilogramos

\begin{tabular}{|l|c|c|c|c|c|c|c|c|}
\hline \multicolumn{1}{|c|}{ País } & $\mathbf{2 0 0 7}$ & $\mathbf{2 0 0 8}$ & $\mathbf{2 0 0 9}$ & $\mathbf{2 0 1 0}$ & $\mathbf{2 0 1 1}$ & $\mathbf{2 0 1 2}$ & $\mathbf{2 0 1 3}$ & $\mathbf{2 0 1 4}$ \\
\hline Estados Unidos & $3.654,00$ & $5.391,00$ & $13.738,00$ & $10.500,00$ & $15.154,00$ & $27.106,00$ & $35.791,00$ & $34.146,00$ \\
\hline Reino Unido & 830,00 & $1.850,00$ & $4.022,00$ & $4.020,00$ & $7.670,00$ & $17.926,00$ & $28.365,00$ & $34.050,00$ \\
\hline Australia & 141,00 & 350,00 & 865,00 & $1.453,00$ & $1.594,00$ & $3.100,00$ & $7.025,00$ & $4.354,00$ \\
\hline Alemania & & & 403,00 & 210,00 & $3.397,00$ & $4.452,00$ & 369,00 & $7.720,00$ \\
\hline Holanda & 120,00 & $1.500,00$ & 500,00 & $1.550,00$ & $1.350,00$ & $2.010,00$ & $2.301,00$ & $6.056,00$ \\
\hline Canadá & 167,00 & 17,00 & 7,00 & 106,00 & 398,00 & $1.229,00$ & $3.361,00$ & $7.493,00$ \\
\hline Portugal & & & & & & & $1.990,00$ & $5.050,00$ \\
\hline Bélgica & & & 37,00 & & & 30,00 & 750,00 & $5.465,00$ \\
\hline Chile & & 800,00 & 720,00 & & 960,00 & $1.327,00$ & $1.180,00$ & $1.200,00$ \\
\hline Sudáfrica & & 10,00 & & 725,00 & 60,00 & 730,00 & $2.070,00$ & $1.960,00$ \\
\hline Ecuador & & $4.351,00$ & & & & & & 240,00 \\
\hline Francia & 249,00 & 147,00 & 195,00 & 122,00 & 836,00 & 13,00 & $1.137,00$ & $1.556,00$ \\
\hline Nueva Zelanda & & & & & & & $2.087,00$ & $1.076,00$ \\
\hline Republica Checa & & & 8,00 & & 216,00 & & $1.475,00$ & $1.050,00$ \\
\hline Bolivia & & & & & & & $2.320,00$ & \\
\hline Finlandia & & & 200,00 & $1.100,00$ & 150,00 & & 300,00 & 450,00 \\
\hline México & & & & & 50,00 & 6,00 & 540,00 & $1.450,00$ \\
\hline España & & & 218,00 & 113,00 & 340,00 & 170,00 & 316,00 & 416,00 \\
\hline
\end{tabular}

Fuente: Superintendencia Nacional de Aduanas y de Administración Tributaria, (2015)

\section{Figura 2.2}

Tendencia de las exportaciones del 2007 al 2014 en kilogramos

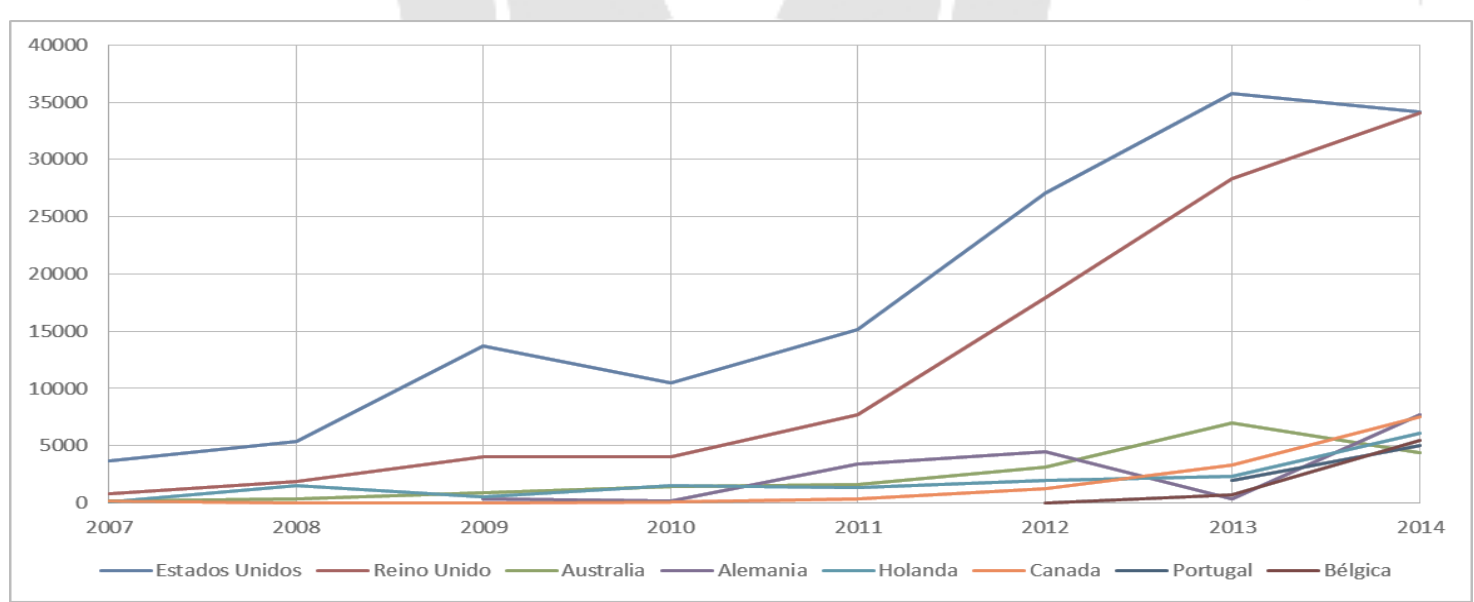

Fuente: Superintendencia Nacional de Aduanas y de Administración Tributaria, (2015)

\subsubsection{Producción Nacional}

Para realizar los cálculos de producción de harina de lúcuma, nos guiaremos de la producción de lúcuma en el Perú. En la tabla 2.4 se encuentra la información de dicha producción del 2008 al 2014, de acuerdo con el Sistema Integrado de Estadísticas Agrarias (SEIA). 
Tabla 2.4

Producción de Lúcuma del 2008 al 2014

\begin{tabular}{|c|c|}
\hline Año & Peso neto $(\mathbf{k g})$ \\
\hline 2008 & $23.741 .000,00$ \\
\hline 2009 & $12.069 .208,00$ \\
\hline 2010 & $12.497 .938,00$ \\
\hline 2011 & $12.792 .626,00$ \\
\hline 2012 & $13.776 .216,00$ \\
\hline 2013 & $14.415 .323,00$ \\
\hline 2014 & $15.553 .475,00$ \\
\hline
\end{tabular}

Fuente: Sistema Integrado de Estadísticas Agrarias, (2015)

De acuerdo a la Asociación de Productores de Lúcuma (PROLUCUMA), se sabe que de la producción total de lúcuma, aproximadamente el $10 \%$ es destinado a la producción de harina de lúcuma. En la tabla 2.5 se encuentra dicha información sobre los últimos 6 años calculada en base a la tabla 2.4.

Tabla 2.5

Lúcuma destinada a la producción de Harina de Lúcuma

\begin{tabular}{|c|c|}
\hline Año & Peso neto $(\mathbf{k g})$ \\
\hline 2008 & $2.374 .100,00$ \\
\hline 2009 & $1.206 .920,80$ \\
\hline 2010 & $1.249 .793,80$ \\
\hline 2011 & $1.279 .262,60$ \\
\hline 2012 & $1.377 .621,60$ \\
\hline 2013 & $1.441 .532,30$ \\
\hline 2014 & $1.555 .347,50$ \\
\hline
\end{tabular}

Elaboración propia

Adicionalmente, se conoce que aproximadamente por cada 5 kilogramos de lúcuma se obtiene 1 kilogramo de harina de lúcuma ${ }^{3}$, es decir, en una proporción de 5 a 1. En la tabla 2.6 se ha calculado la producción de harina de lúcuma de los últimos 6 años en base a la cantidad de lúcuma destinada a la producción de harina de lúcuma calculada en la tabla 2.5 .

\footnotetext{
${ }^{3}$ Este dato se obtuvo a través de opinión de expertos, mediante la entrevista con el representante de la empresa Complementos y Suplementos Orgánicos del Perú, Luis Torres.
} 
Tabla 2.6

Producción de harina de lúcuma del 2008 al 2014

\begin{tabular}{|c|c|}
\hline Año & Peso neto $(\mathbf{k g})$ \\
\hline 2008 & $474.820,00$ \\
\hline 2009 & $241.384,16$ \\
\hline 2010 & $249.958,76$ \\
\hline 2011 & $255.852,52$ \\
\hline 2012 & $275.524,32$ \\
\hline 2013 & $288.306,46$ \\
\hline 2014 & $311.069,50$ \\
\hline
\end{tabular}

Elaboración propia

2.2.1.3. Demanda Interna Aparente (DIA)

Para poder hallar la Demanda Interna Aparente se utilizó la siguiente fórmula:

$$
\text { DIA = Producción }+ \text { Importación }- \text { Exportación }
$$

El resultado de la demanda interna aparente por año, se encuentra en la tabla 2.7.

Tabla 2.7

Demanda interna aparente

\begin{tabular}{|c|c|}
\hline Año & DIA $(\mathbf{k g})$ \\
\hline 2008 & $460.271,00$ \\
\hline 2009 & $222.454,16$ \\
\hline 2010 & $229.354,76$ \\
\hline 2011 & $223.026,52$ \\
\hline 2012 & $216.912,32$ \\
\hline 2013 & $195.164,46$ \\
\hline 2014 & $194.571,50$ \\
\hline
\end{tabular}

Elaboración propia

\subsubsection{Demanda potencial}

2.2.2.1. Patrones de consumo: incremento poblacional, consumo per cápita, estacionalidad

Para poder definir los patrones del consumo, se debe definir el proceso de compra de un comprador extranjero. Tomamos como referencia el consumo en Estados Unidos. Según la revista Información Estratégica y Económica de Mercados de la PUCP, las características son las siguientes: 
Figura 2.3

Características de un comprador estadounidense

\begin{tabular}{|c|}
\hline Comprador mejor informado \\
\hline Mayor cuidado de la salud \\
Creciente conciencia ecológica \\
\hline
\end{tabular}

Fuente: Información Estratégica y Económica de Mercados, PUCP (2014)

Por otro lado analizando la estacionalidad de las ventas, no se observa una tendencia definida, cabe resaltar que en los meses de febrero y agosto las ventas disminuyen.

Figura 2.4

Estacionalidad de las ventas del 2007 al 2014 en kilogramos

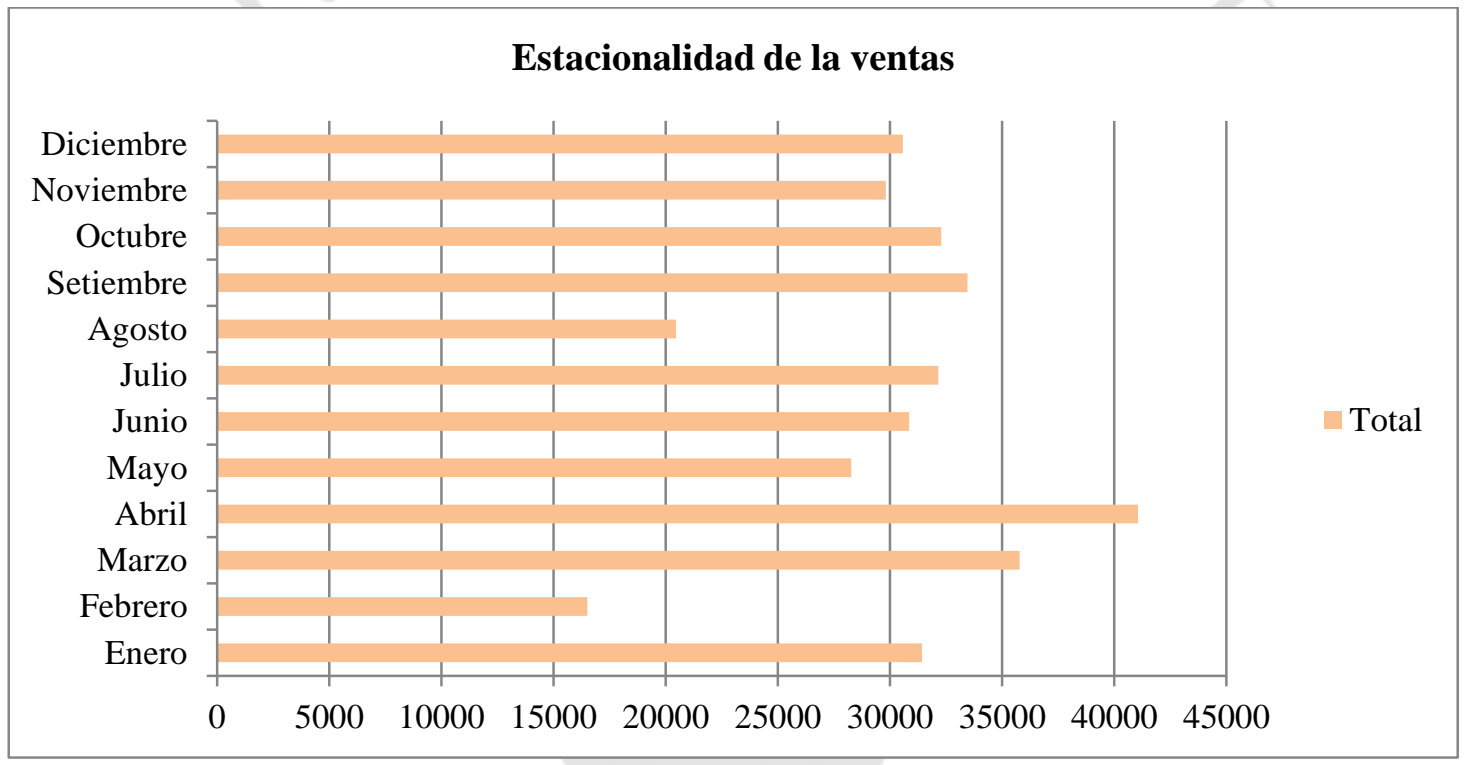

Fuente: Superintendencia Nacional de Aduanas y de Administración Tributaria, (2015)

\subsubsection{Determinación de la demanda potencial}

La demanda potencial es la demanda máxima posible que podrá obtener nuestro producto en el futuro. Para determinar la demanda potencial de nuestro producto hemos tomado como base de datos las exportaciones de harina de lúcuma del 2014. Para esto hallaremos el consumo per cápita de los países más representativos a los que se exporta, mostrado en la tabla 2.8. 
Tabla 2.8

Consumo per-cápita

\begin{tabular}{|l|c|c|c|}
\hline \multicolumn{1}{|c|}{ País } & $\begin{array}{c}\text { Exportaciones } \\
\mathbf{2 0 1 4}(\mathbf{k g})\end{array}$ & $\begin{array}{c}\text { Población 2014 } \\
\text { (habitantes) }\end{array}$ & $\begin{array}{c}\text { Consumo Per-cápita } \\
\text { (g/habitante) }\end{array}$ \\
\hline Estados Unidos & 34.146 & 319.047 .000 & 0,107 \\
\hline Reino Unido & 34.050 & 64.511 .000 & 0,528 \\
\hline Alemania & 7.720 & 80.889 .505 & 0,095 \\
\hline Holanda & 6.056 & 16.864 .000 & 0,359 \\
\hline
\end{tabular}

Fuente: Superintendencia Nacional de Aduanas y de Administración Tributaria, (2015)

A continuación, en la tabla 2.9, se ha escogido el consumo per-cápita mayor, el de Reino Unido, y se multiplicó por el total de población de los 4 países elegidos. Obteniendo así nuestra demanda potencial.

Tabla 2.9

Demanda potencial

\begin{tabular}{|c|c|c|}
\hline $\begin{array}{c}\text { Consumo Per-cápita Reino Unido } \\
\text { (kg/habitante) }\end{array}$ & Población total 2014 & $\begin{array}{c}\text { Demanda potencial } \\
\text { (kg) }\end{array}$ \\
\hline 0,000528 & 481.311 .505 & $254.132,47$ \\
\hline
\end{tabular}

Elaboración propia

\subsubsection{Demanda mediante fuentes primarias}

\subsubsection{Diseño y Aplicación de Encuestas u otras técnicas}

Para el presente proyecto se ha realizado entrevistas a una de las 4 principales empresas que exportan harina de lúcuma, de la cual se extraerá algunos patrones e información para la producción de harina de lúcuma.

\section{Entrevista}

Organización: Complementos y Suplementos Orgánicos del Perú

Entrevistado: Luis Torres, Representante de la empresa "Complementos y Suplementos Andinos del Perú".

Preguntas:

1) ¿Por qué tomaron la decisión de exportar lúcuma?

Cuando iniciamos el negocio de exportación de lúcuma en el 2009, empezamos exportando maca, poco a poco los clientes nos solicitaban harina de lúcuma. Es entonces cuando decidimos elaborar harina de lúcuma. 
2) ¿Qué derivados de lúcuma son los que comercializan?

En un inicio, se comercializó harina de lúcuma. Poco después el negocio se abrió a lo que son lúcuma chips. Sin embargo; hubo algunos inconvenientes con los chips así que decidimos solo comercializar harina de lúcuma.

3) ¿No comercializan pulpa de lúcuma? ¿Por qué?

No, no la comercializamos. Más por el giro de negocios en el que estamos. Vendemos suplementos alimenticios y casi la mayoría de estos son en polvo. Y las empresas nos compran para combinarlas con otros productos.

4) ¿Está asociado a alguna organización como PRO-LÚCUMA?

No, no estamos asociados a ninguna organización de ese tipo.

5) ¿Cómo contactan a sus clientes?

Uno de los principales medios para contactarlos son las ferias internacionales, de ese modo nos expandimos en el medio. En el Perú la feria Expo alimentaria es una de las principales, otras de las ferias a las cuales asistimos son la feria Natural Products Expo West que se realiza en Estados Unidos y la feria Biofach en Alemania. Otro de los medios es a través de la página web.

6) ¿Qué uso final le dan sus clientes a la harina de lúcuma?

El cliente final se encuentra en el exterior. Existe variedad de productos que exportamos que son naturales. Es común ahora comprar quinua o maca en polvo. Nuestros clientes los venden en retail o los combinan con otros productos para elaborar suplementos más complejos.

7) ¿Qué certificaciones les exigen los países a los que exportan? ¿Es difícil tener esa certificación?

En el medio que estamos que son los alimentos orgánicos, nos solicitan certificaciones orgánicas. Para exportar a Estados Unidos nos piden la certificación USDA Organic, en cambio para Japón es el JAS.

No es difícil tener las certificaciones, hay varias modalidades que existen. Una de las empresas que certifican es Control Union con la que trabajamos. 
8) ¿Cómo se hacen los envíos? ¿Qué cuidado se tienen?

Nosotros somos exportadores el 90\% a granel. Nuestra presentación es en bolsas de $10 \mathrm{~kg}$. Y las enviamos en una caja, en la cual entran 2 bolsas de $10 \mathrm{~kg}$. Hemos hecho algunas veces bolsas de una libra. Generalmente hacemos bolsas de 10 kilogramos. Los envíos se hacen vía aérea o marítima, de acuerdo a lo que indique el cliente.

9) ¿De dónde se extrae la materia prima?

En un inicio nuestros principales proveedores de lúcuma fueron el norte y el sur chico. Y luego nos avocamos a la zona de Ayacucho. Eso sí, siempre verificando que los campos sean orgánicos y cuenten con su certificación.

\subsubsection{Determinación de la Demanda}

De acuerdo a PROLUCUMA, del total del mercado para exportación, el Perú abarca el $88 \%$ y lo que resta lo exporta Ecuador, Colombia y Chile. Para estimar la demanda del mercado de los últimos 8 años, se utilizará como base de datos las exportaciones, si estas son el $88 \%$, el $100 \%$ es la demanda del mercado.

Tabla 2.10

Demanda del mercado

\begin{tabular}{|c|c|}
\hline Año & Demanda del mercado (kg) \\
\hline 2007 & $6.062,50$ \\
\hline 2008 & $16.532,95$ \\
\hline 2009 & $23.977,27$ \\
\hline 2010 & $23.413,64$ \\
\hline 2011 & $37.302,27$ \\
\hline 2012 & $66.604,55$ \\
\hline 2013 & $105.843,18$ \\
\hline 2014 & $132.384,09$ \\
\hline
\end{tabular}

Fuente: Superintendencia Nacional de Aduanas y de Administración Tributaria, (2015)

\subsubsection{Proyección de la demanda}

Para determinar la proyección de la demanda utilizaremos distintos tipos de regresiones, para así saber que coeficiente de correlación es mayor. La regresión con el coeficiente de correlación mayor será la elegida puesto que será en esa en la que la demanda proyectada se encuentre más fuertemente relacionada al tiempo. Se tomará como referencia solo el 
periodo comprendido entre los años del 2010 al 2014 dado que el porcentaje de crecimiento es más uniforme.

\section{$\underline{\text { Regresión Lineal }}$}

Con la regresión lineal se obtiene la siguiente fórmula y el siguiente coeficiente de correlación

$$
\begin{aligned}
& y=28648 x-98780 \\
& R^{2}=0.9795
\end{aligned}
$$

Tabla 2.11

Proyección de la demanda con regresión lineal

\begin{tabular}{|c|c|}
\hline Año & Demanda proyectada $(\mathbf{k g})$ \\
\hline 2016 & 159.052 \\
\hline 2017 & 187.700 \\
\hline 2018 & 216.348 \\
\hline 2019 & 244.996 \\
\hline 2020 & 273.644 \\
\hline 2021 & 302.292 \\
\hline 2022 & 330.940 \\
\hline 2023 & 359.588 \\
\hline 2024 & 388.236 \\
\hline 2025 & 416.884 \\
\hline
\end{tabular}

Elaboración propia 
Figura 2.5

Gráfica regresión lineal

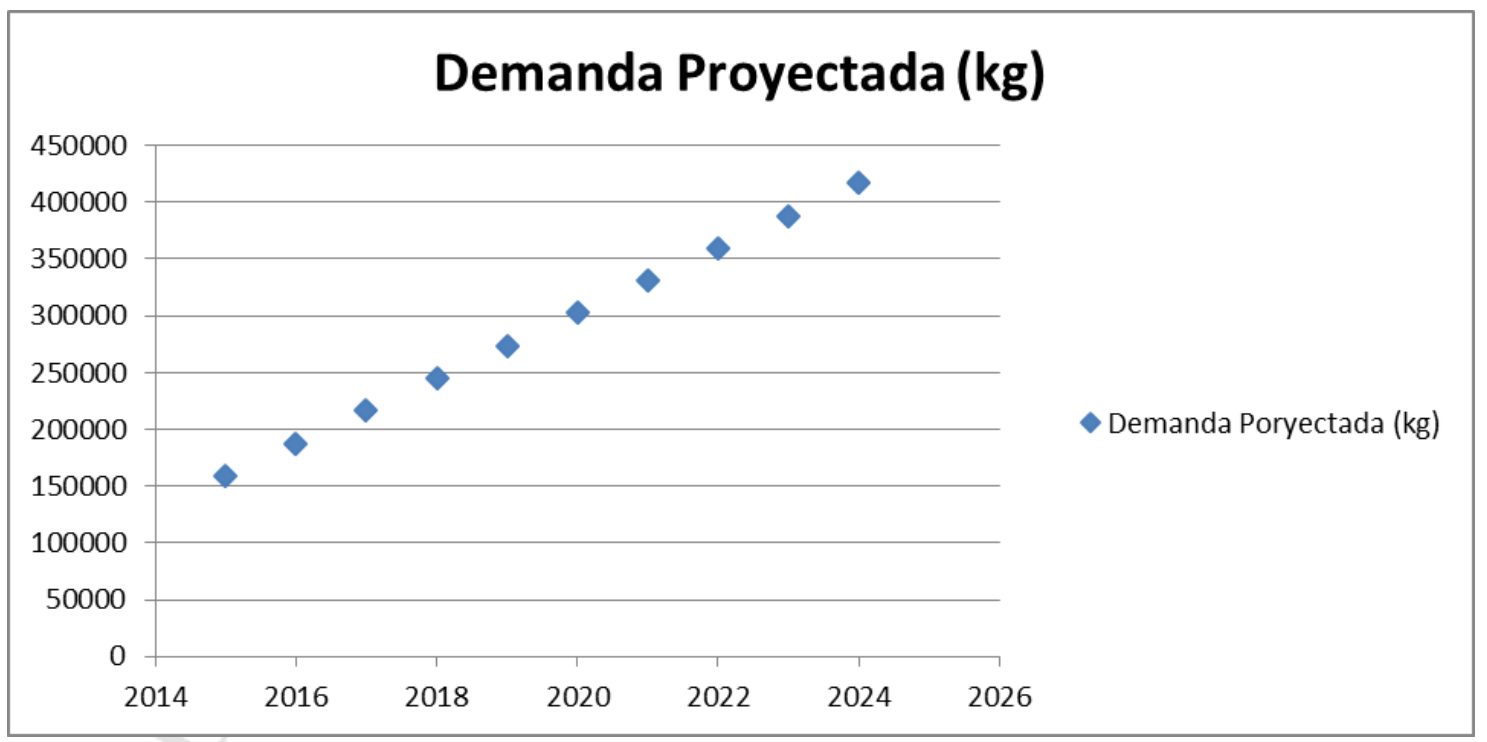

Elaboración propia

$\underline{\text { Regresión Exponencial }}$

Utilizando una regresión exponencial se obtiene la formula y el siguiente coeficiente de correlación.

$$
\begin{gathered}
y=4051.8 e^{0.4508 x} \\
R^{2}=0.9814
\end{gathered}
$$

Tabla 2.12

Proyección de la demanda con regresión exponencial

\begin{tabular}{|c|c|}
\hline Año & Demanda proyectada $(\mathbf{k g})$ \\
\hline 2016 & $231.361,46$ \\
\hline 2017 & $362.638,21$ \\
\hline 2018 & $568.402,68$ \\
\hline 2019 & $890.919,93$ \\
\hline 2020 & $1.396 .436,63$ \\
\hline 2021 & $2.188 .788,45$ \\
\hline 2022 & $3.430 .728,46$ \\
\hline 2023 & $5.377 .357,39$ \\
\hline 2024 & $8.428 .522,64$ \\
\hline 2025 & $13.210 .948,94$ \\
\hline
\end{tabular}

Elaboración propia 
Figura 2.6

Gráfica regresión exponencial

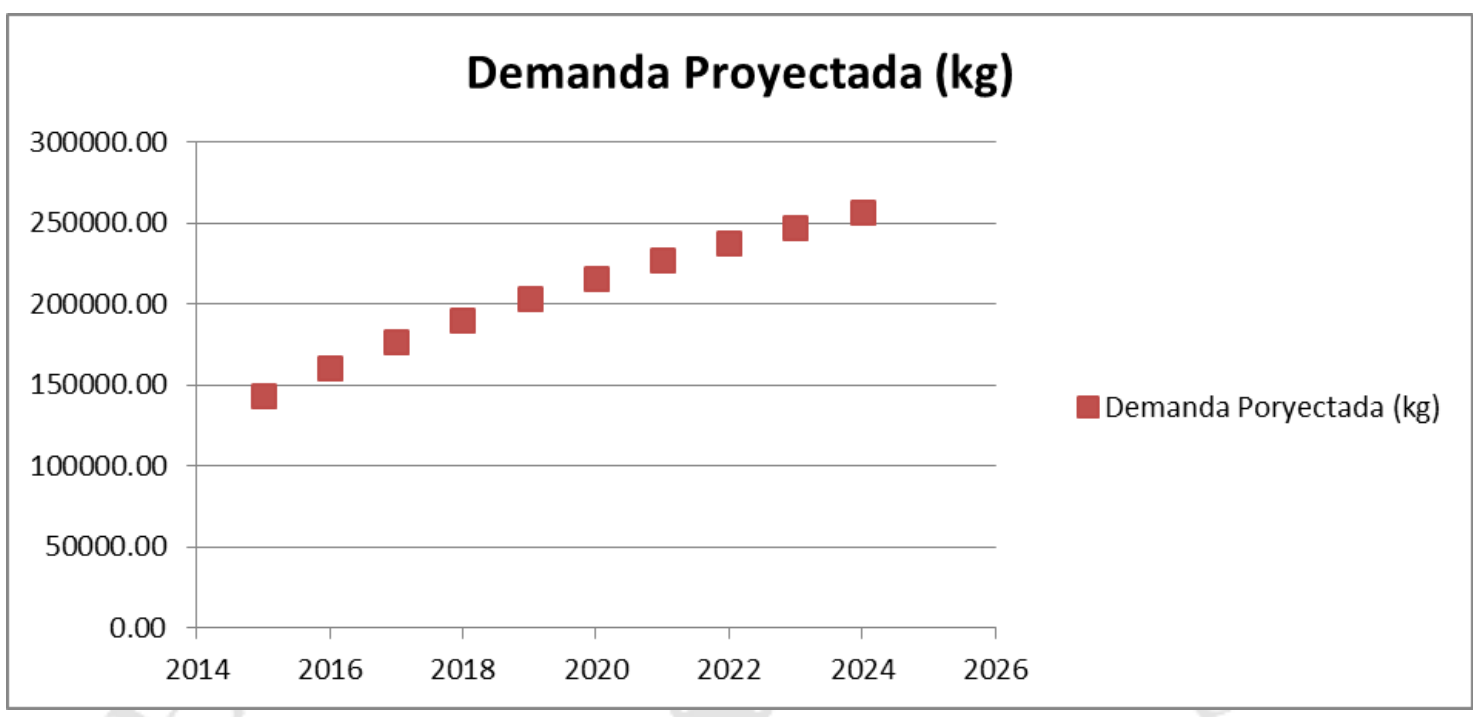

Elaboración propia

\section{$\underline{\text { Regresión Logarítmica }}$}

Finalmente utilizando una regresión logarítmica, se obtiene lo siguiente:

$$
\begin{gathered}
y=162639 \ln (x)-213554 \\
R^{2}=0.9468
\end{gathered}
$$

Tabla 2.13

Proyección de la demanda con regresión logarítmica

\begin{tabular}{|c|c|}
\hline Año & Demanda proyectada $(\mathbf{k g})$ \\
\hline 2016 & $143.800,41$ \\
\hline 2017 & $160.936,14$ \\
\hline 2018 & $176.437,29$ \\
\hline 2019 & $190.588,73$ \\
\hline 2020 & $203.606,80$ \\
\hline 2021 & $215.659,65$ \\
\hline 2022 & $226.880,58$ \\
\hline 2023 & $237.377,06$ \\
\hline 2024 & $247.236,99$ \\
\hline 2025 & $256.533,17$ \\
\hline
\end{tabular}

Elaboración propia 
Figura 2.7

Gráfica regresión logarítmica

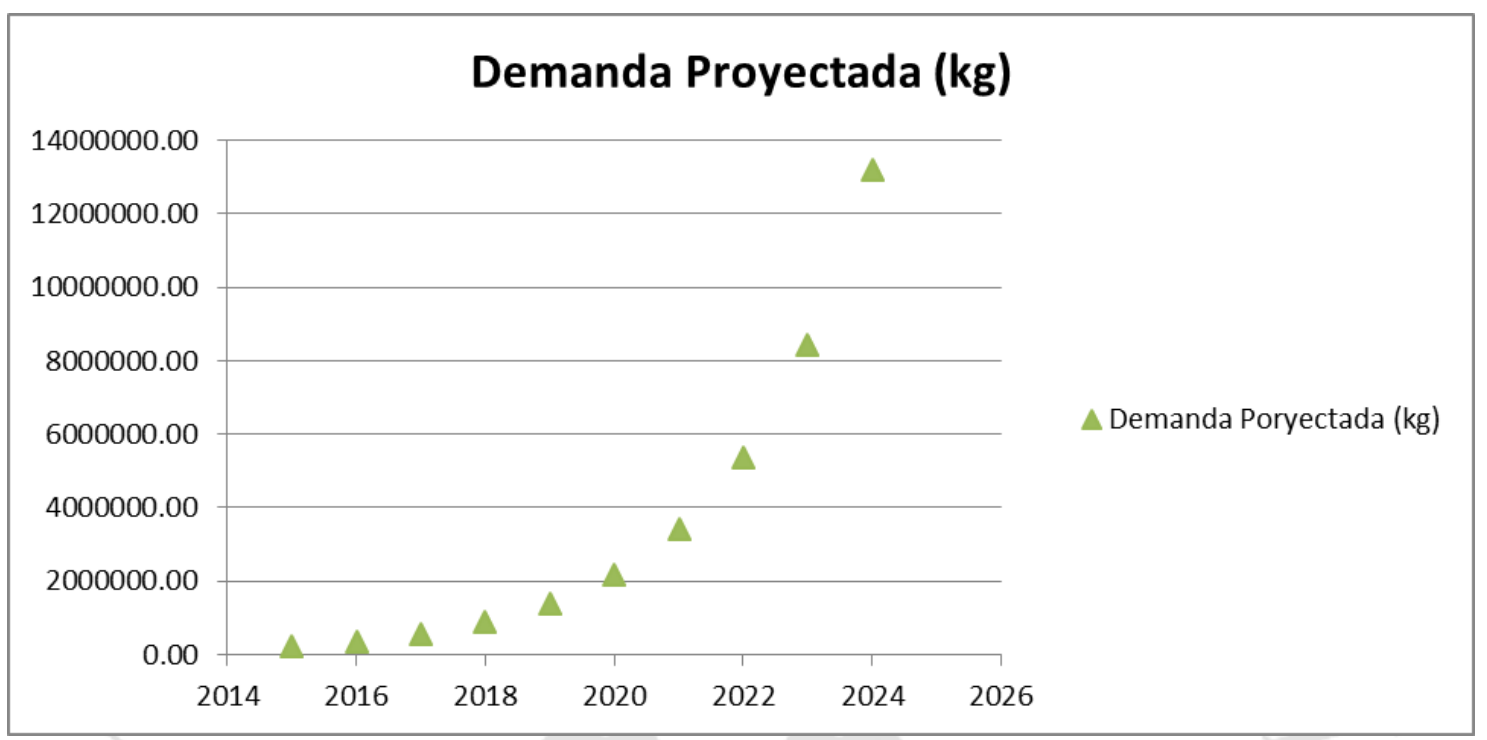

Elaboración propia

En conclusión, la correlación mayor es la obtenida por la regresión lineal, lo que indica que los valores tienen una mayor relación bajo esa regresión.

\subsubsection{Consideraciones sobre la vida útil del proyecto}

Acerca de la vida útil, se debe mencionar que según los cuadros analizados de las exportaciones, las empresas que están posicionadas más años, son las que se han mantenido y las que tienen mayor exportación de este producto. Es por eso que hemos determinado que la vida útil del proyecto es de 10 años, tiempo necesario para que nuestra empresa se consolide en el mercado. ${ }^{4}$

\subsection{Análisis de la oferta}

En esta sección describiremos cuales son nuestros principales competidores a nivel local e internacional.

${ }^{4}$ El tiempo aproximado para que la empresa pase por las fases de introducción, crecimiento y llegue a una fase de madurez es de 10 años. 


\subsubsection{Empresas productoras, importadoras y comercializadoras}

Según el análisis de la producción de harina de lúcuma, se observa que en los últimos años la producción ha incrementado constantemente. Esto se puede explicar gracias a la fuerte demanda del producto en el exterior; así como el crecimiento de las áreas cultivadas lo que decanta en una mayor producción del producto.

En el ámbito internacional según PYMEX, comunidad de exportadores, Chile, Ecuador y Colombia son los principales ofertantes de lúcuma. Esto se da debido a que las condiciones climáticas hacen favorable el cultivo de lúcuma. Adicionalmente a esto, se conoce que el $12 \%$ de la demanda del mercado de harina de lúcuma es producido por estos países.

De acuerdo al análisis de la producción y exportación de la harina de lúcuma, se puede observar que del total producido en el país en los años 2012, 2013 y 2014, lo exportado corresponde al $20 \%, 28 \%$ y $36 \%$ respectivamente.

En la zona de Lima se pueden encontrar tres principales empresas productoras y exportadoras de harina de lúcuma, estas son: Algarrobos Orgánicos de Perú S.A.C, Complementos y Suplementos Orgánicos S.R.L y Peruvian Natures.S.A.C. En el interior del país la empresa Ecoandino S.A.C es la más importante.

\subsubsection{Competidores actuales y potenciales}

A nivel local se sabe que la competencia es alta, tal y como se determinó en el punto 2.1.4 (Análisis del sector). Adicionalmente, hemos visto en el punto anterior que son cuatro las principales empresas que comercializan harina de lúcuma en grandes dimensiones.

Se debe resaltar que este sector está en crecimiento y el mercado mundial está en busca de nuevas empresas que cubran con la demanda. La tabla 2.14 nos muestra como estuvo repartida la participación del mercado de las empresas exportadoras de harina de lúcuma en los años 2013 y 2014. 
Tabla 2.14

Participación de mercado

\begin{tabular}{|l|c|c|}
\hline \multicolumn{1}{|c|}{ Empresas } & $\mathbf{2 0 1 3}$ & $\mathbf{2 0 1 4}$ \\
\hline Algarrobos Orgánicos del Perú S.A.C. & $16,71 \%$ & $28,77 \%$ \\
\hline Complementos y Suplementos Orgánicos del Perú S.R.L. & $27,99 \%$ & $22,47 \%$ \\
\hline Ecoandino S.A.C. & $27,98 \%$ & $22,24 \%$ \\
\hline Peruvian Nature S \& S S.A.C. & $11,28 \%$ & $18,14 \%$ \\
\hline Nutry Body S.A.C. & $2,83 \%$ & $1,43 \%$ \\
\hline Inspection \& Quality Total Services S.A.C. & $0,00 \%$ & $1,27 \%$ \\
\hline Otros & $13,20 \%$ & $5,68 \%$ \\
\hline
\end{tabular}

Fuente: Superintendencia Nacional de Aduanas y de Administración Tributaria, (2015)

\subsection{Determinación de la Demanda para el proyecto}

\subsubsection{Segmentación del mercado}

Para el presente proyecto, la segmentación del mercado se ha realizado escogiendo los 4 países que han sido los principales importadores de la harina de lúcuma durante los últimos 8 años. Estos países son Estados Unidos, Reino Unido, Alemania y Holanda. En esta segmentación se asumió que los consumidores en dichos países tienen el mismo perfil de consumo.

Como se puede apreciar en la tabla 2.15 y la figura 2.8, de los 4 países escogidos para la segmentación de mercado, Estados Unidos y Reino Unido son los países a los que se exporta la mayor cantidad de harina de lúcuma. Dichos países son los que se han escogido para la determinación de la demanda de nuestro proyecto.

Tabla 2.15

Exportaciones del 2007 al 2014 en kilogramos

\begin{tabular}{|l|c|c|c|c|c|c|c|c|}
\hline \multicolumn{1}{|c|}{ País } & $\mathbf{2 0 0 7}$ & $\mathbf{2 0 0 8}$ & $\mathbf{2 0 0 9}$ & $\mathbf{2 0 1 0}$ & $\mathbf{2 0 1 1}$ & $\mathbf{2 0 1 2}$ & $\mathbf{2 0 1 3}$ & $\mathbf{2 0 1 4}$ \\
\hline Estados Unidos & 3.654 & 5.391 & 13738 & 10.500 & 15.154 & 27.106 & 35.791 & 34.146 \\
\hline Reino Unido & 830 & 1.850 & 4.022 & 4.020 & 7.670 & 17.926 & 28365 & 34.050 \\
\hline Alemania & - & - & 403 & 210 & 3.397 & 4.452 & 369 & 7.720 \\
\hline Holanda & 120 & 1.500 & 500 & 1.550 & 1.350 & 2.010 & 2301 & 6.056 \\
\hline
\end{tabular}

Elaboración propia 
Figura 2.8

Exportaciones del 2007 al 2014 de harina de lúcuma (kg) a los principales países

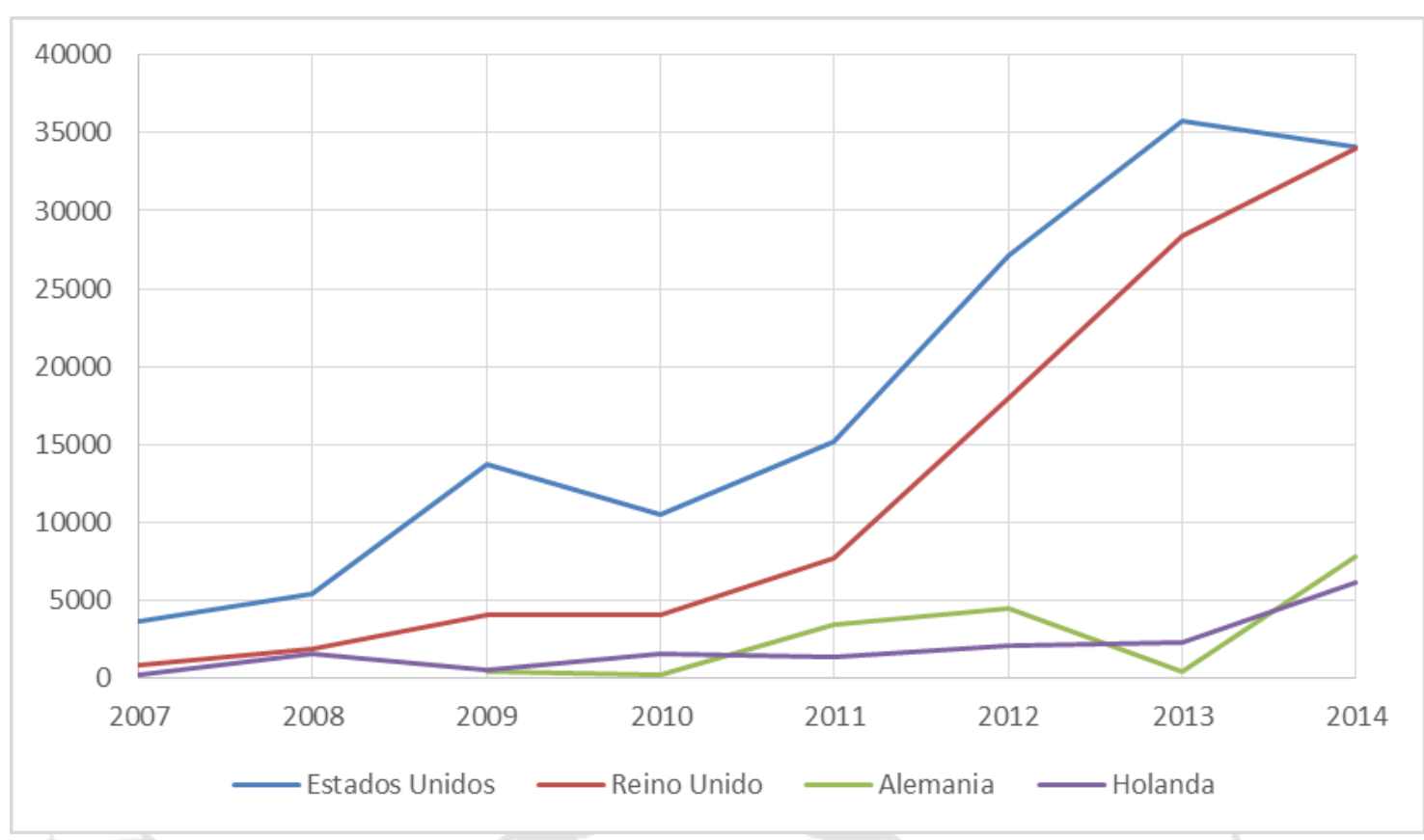

Elaboración propia

\subsubsection{Selección del mercado meta}

Segmentación geográfica

El producto propuesto está dirigido finalmente al mercado internacional, a países como Estados Unidos y Reino Unido. Es utilizado por empresas comercializadoras de productos orgánicos para la elaboración de batidos y también por empresas heladeras y reposteras.

La ventaja para los países importadores de la harina de lúcuma es la capacidad de este producto para ser fácilmente transportado y almacenado por 2 años. La harina de lúcuma puede ser embarcada hacia destinos que impliquen largas distancias, lo que facilita su exportación a los países mencionados anteriormente.

\section{$\underline{\text { Segmentación demográfica }}$}

La harina de lúcuma destinada al mercado internacional, busca introducirse en el mercado de las personas en el rango de edad comprendido entre 18 y 40 años, hombres y mujeres. Si bien las empresas intermediadoras de este producto son nuestros clientes, es importante mencionar que nuestro público final son este grupo de personas y de ellos depende nuestra demanda. 
Según una encuesta de 30.000 personas, realizada en Estados Unidos y publicada en la revista "Psycology Today", un 93\% de mujeres y un $82 \%$ de varones están preocupadas por su apariencia y dispuestos a adquirir un producto natural como el nuestro.

\section{$\underline{\text { Segmentación psicográfica }}$}

Nuestro producto está dirigido, desde el punto de vista psicográfico, a personas con un estilo de vida enfocado en el desarrollo de una vida sana, actividad física regular, dieta y nutrición apropiada. Este estilo de vida no solo incluye el ejercicio continuo, sino una alimentación sana sostenible en el tiempo, es ahí en donde nace la necesidad de este tipo de personas de consumir productos naturales orgánicos como el nuestro.

\subsubsection{Demanda Específica para el Proyecto}

Para el cálculo de la demanda específica para el proyecto, hemos calculado el promedio de la participación de las empresas en sus primeros años. En la tabla 2.16 se puede observar a las empresas que han exportado los últimos 8 años de manera continua. En base a sus participaciones de mercado se ha pronosticado la participación de mercado que obtendríamos.

Tabla 2.16

Participación de empresas exportadoras en los últimos 8 años

\begin{tabular}{|l|c|}
\hline \multicolumn{1}{|c|}{ Empresa } & Participación en el primer año \\
\hline Ecoandino S.A.C. & $32,82 \%$ \\
\hline Agroind.Serv.Y Neg.Internacionales Sac & $16,49 \%$ \\
\hline Agro Export Topara S.A.C. & $10,66 \%$ \\
\hline Complementos Y Suplementos Orgánicos Del Perú S.R.L. & $6,26 \%$ \\
\hline Comercializadora Internacional Del Perú S.A.C & $6,00 \%$ \\
\hline Industrias Ecológicas S.A.C. & $3,73 \%$ \\
\hline Productos Del País SA - Productos Del Pais S.A. & $3,30 \%$ \\
\hline Sideral Group SAC & $2,57 \%$ \\
\hline Algarrobos Organicos Del Peru SAC & $2,15 \%$ \\
\hline Peruvian Nature S \& S S.A.C. & $1,23 \%$ \\
\hline Importadora Y Exportadora Dođa Isabel EIRL & $0,70 \%$ \\
\hline Corporacion Naturalsol S.A.C. & $0,36 \%$ \\
\hline Inkanatura World Peru Export SAC & $0,32 \%$ \\
\hline Natural Perú SAC & $0,30 \%$ \\
\hline Inversiones 2A SRL & $0,03 \%$ \\
\hline Participación promedio & $\mathbf{5 , 7 9 \%}$ \\
\hline
\end{tabular}

Fuente: Superintendencia Nacional de Aduanas y de Administración Tributaria, (2015) 
Tomando en cuenta la participación calculada, 5.79\%, y la demanda proyectada calculada en el punto 2.2.4, se calculó la demanda especifica del proyecto, tal y como lo muestra la tabla 2.17.

Tabla 2.17

Demanda especifica del proyecto

\begin{tabular}{|c|c|c|}
\hline Año & Demanda proyectada $(\mathbf{k g})$ & Demanda específica del proyecto (5.79\%) \\
\hline 2016 & 159.052 & $9.216,08$ \\
\hline 2017 & 187.700 & $10.876,06$ \\
\hline 2018 & 216.348 & $12.536,03$ \\
\hline 2019 & 244.996 & $14.196,01$ \\
\hline 2020 & 273.644 & $15.855,98$ \\
\hline 2021 & 302.292 & $17.515,96$ \\
\hline 2022 & 330.940 & $19.175,93$ \\
\hline 2023 & 359.588 & $20.835,91$ \\
\hline 2024 & 388.236 & $22.495,88$ \\
\hline 2025 & 416.884 & $24.155,86$ \\
\hline
\end{tabular}

Elaboración propia

\subsection{Definición de la Estrategia de Comercialización}

\subsubsection{Políticas de comercialización y distribución}

Políticas de comercialización

Entre los aspectos en la política de comercialización que se adoptará en el presente proyecto para la introducción de la harina de lúcuma al mercado internacional, se tomó en cuenta las políticas relacionadas con el precio, el pago, la venta, el servicio y la garantía.

\section{$\underline{\text { Políticas de precio }}$}

El precio de introducción o de lanzamiento de nuestro producto estará por debajo del precio de mercado. Para ello nos basaremos en los precios que analizaremos en el punto 2.5.3.1. A lo largo del proyecto utilizaremos la estrategia de liderazgo en costos ya que el producto al ser muy estándar trataremos de ofrecerles a los posibles compradores los mejores precios del mercado, sin dejar de enfocarnos en la calidad del producto.

\section{$\underline{\text { Políticas de pago }}$}

Entre las políticas de pago consideraremos el ofrecer a nuestros clientes la opción de pago a 30 días o pago contra entrega. 


\section{$\underline{\text { Políticas de ventas }}$}

En las políticas de ventas ofreceremos a nuestros futuros compradores la opción de hacer órdenes de compra por compras pequeñas (50 gr.) a manera de muestra. Adicionalmente consideraremos un $2 \%$ de descuento por cada $30 \mathrm{~kg}$ solicitados.

\section{$\underline{\text { Políticas de servicios }}$}

Nos enfocaremos en un servicio de respuesta inmediata, en el que absolveremos las dudas de nuestros clientes a través de nuestra página web y nuestro correo electrónico corporativo proporcionado en la etiqueta del producto. Adicionalmente enviaremos propuestas de nuestros productos en caso los clientes nos la soliciten adjuntando también la ficha técnica de la harina de lúcuma (Punto 5.1).

$\underline{\text { Políticas de garantía }}$

Nuestra empresa brindará todas las garantías asegurando que el producto llegue en perfecto estado hasta el lugar convenido con el cliente.

Políticas de distribución

Los canales de distribución que ofreceremos para la venta de la harina de lúcuma en el mercado internacional, previo acuerdo con el cliente, serán los siguientes:

- Exportación directa bajo incoterm FAS-FOB: Bajo esta modalidad asumimos los costos hasta que la mercadería se encuentre estibada, es decir a bordo del barco o del avión.

- Exportación bajo incoterm CIF: Bajo la modalidad CIF asumimos los costos, el seguro y el flete y nos hacemos responsables de la mercadería hasta que esta sobrepase la borda del buque en el puerto de destino.

- Exportación directa bajo incoterm EXW: Bajo esta modalidad asumimos todos los costos hasta dejar en las instalaciones del cargador.

- Exportación a través de un bróker / representante comercial / distribuidor / acopiador independiente / cooperativa de exportación: Bajo estas modalidades utilizaremos un intermediador para poder agilizar las exportaciones y en algunos casos disminuir los costos de los mismos. 
- Joint Venture o colaboración empresarial: Bajo esta modalidad nos asociaremos con otros productores para poder atender un pedido de un solo cliente por un tiempo determinado.

\subsubsection{Publicidad y promoción}

La presentación de nuestro producto se hará en bolsas plásticas de capacidad de $10 \mathrm{~kg}^{5}$ Así mismo las bolsas serán enviadas en cajas con el logo de la empresa y del producto impreso a un lado de la caja.

El objetivo fundamental de nuestra publicidad es crear una imagen de marca para nuestro producto, recordar, informar o persuadir al público para mantener su fidelidad e incrementar las ventas de la harina de lúcuma ofertada. La oferta se realizará a través de:

- Internet, páginas web y correo electrónico

- Cadenas de tiendas de alimentos nutritivos

- Publicidad en tiendas de aeropuertos internacionales y hoteles

- La asistencia a feria de alimentos y otros eventos internacionales

○ Feria Expo Alimentaria - Perú

- Natural Products Expo West

- Feria BioFach - Alemania

- Publicaciones en revistas especializadas

\subsubsection{Análisis de precios}

2.5.3.1. Tendencia histórica de los precios

En los últimos 10 años la cotización de precios de harina de lúcuma ha ido fluctuando, alcanzando los mejores precios en los últimos años. En la tabla 2.18 se detalla los precios en los últimos 8 años.

${ }^{5}$ Se determinó una presentación del producto de 10 kg en base a la opinión de expertos mediante la entrevista con el representante de la empresa Complementos y Suplementos Orgánicos del Perú, Luis Torres. 
Tabla 2.18

Evolución del precio por kilo entre 2007 y 2014 (Dólares)

\begin{tabular}{|c|c|c|}
\hline Año & Promedio anual de precio por kilo & T.C. \\
\hline 2007 & 9,13 & 3,129 \\
\hline 2008 & 11,82 & 2,926 \\
\hline 2009 & 11,58 & 3,012 \\
\hline 2010 & 11,73 & 2,83 \\
\hline 2011 & 12,23 & 2,75 \\
\hline 2012 & 12,98 & 2,64 \\
\hline 2013 & 12,54 & 2,70 \\
\hline 2014 & 12,81 & 2,84 \\
\hline
\end{tabular}

Fuente: Superintendencia Nacional de Aduanas y de Administración Tributaria, (2014)

\subsubsection{Precio actuales}

El precio aproximado de la harina de lúcuma actualmente es de 12,80 dólares. Es a ese precio al cual vamos a comercializar nuestro producto.

\subsection{Análisis de la disponibilidad de los insumos principales}

\subsubsection{Características principales de la materia prima}

La materia prima para la elaboración de nuestro producto es la lúcuma. Esta fruta es originaria de los valles interandinos del Perú, Ecuador, Colombia y Chile, y se caracteriza por ser un cultivo cuya principal cualidad es tener un especial y exquisito sabor.

Es un fruto semi-caducifolio de amplia adaptabilidad, que se encuentra desde el nivel del mar hasta los 3000 metros sobre el nivel del mar. Se trata de un árbol que alcanza 15 a $20 \mathrm{~m}$ de altura, 1,5 m de diámetro en la base y con diámetro de copa de 6 a $10 \mathrm{~m}$. El lúcumo es un frutal de follaje siempre verde, muy vigoroso, de gran longevidad. Se desarrolla en climas tropicales y subtropicales; tolera lluvias temporales, más no precipitaciones constantes. Su hábitat natural es la sierra baja. El rango de temperatura donde se desarrolla comprende de 8 a $27{ }^{\circ} \mathrm{C}$ y humedad de $80 \%$ a $90 \%$, siendo el rango óptimo de 14 a $24^{\circ} \mathrm{C}$. Se adapta a climas fríos constantes pero no tolera fuertes heladas, pudiendo morir con temperaturas menores de $5^{\circ} \mathrm{C}$.

Tradicionalmente la lúcuma es empleada en el Perú tanto para consumo fresco como industrial, en cuyo caso es comúnmente convertida en pulpa o harina. La mayor demanda nacional e internacional proviene del sector de helados, que la requiere en forma de harina y pulpa. 
En los últimos años, tanto la fruta fresca como la industrializada, se está utilizando también en la elaboración de mermeladas, yogures, pastas, papillas, batido de leche, tortas, torta de lúcuma, ravioles, bombones, pudines, galletas, licor de lúcuma, pastas, comidas y conservas.

Según cronistas e historiadores, el uso de la lúcuma proviene de épocas anteriores al incanato, habiéndose encontrado representaciones del fruto de lúcumo en huacos y tejidos en la tumbas de las culturas pre- incas. Esto demuestra el aprovechamiento ancestral como parte de la dieta alimenticia en las poblaciones que se ubicaron en la costa y sierra del Perú.

Para efectos de nuestro proyecto, la lúcuma que adquiriremos debe ser en un $95 \%$ orgánica, ya que con un porcentaje menor a ese no podremos comercializar el producto en el exterior. Adicionalmente esta no debe haber sido modificada genéticamente. Estos son algunos de los requisitos a cumplir y que serán explicados en el punto 5.1.4.

\section{Figura 2.9}

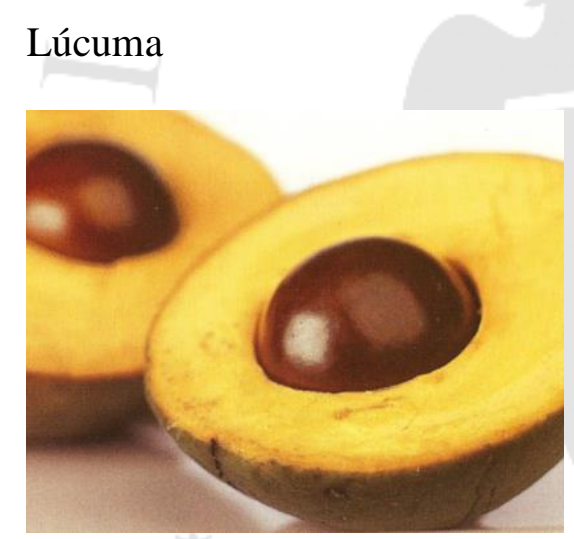

Fuente: Ministerio de Agricultura y Riego, (2014)

\subsubsection{Disponibilidad de la materia prima}

De acuerdo al Anuario hortofrutícola del Ministerio de Agricultura, Lima es el departamento con mayor producción de lúcuma. En la tabla 2.19 se muestra la producción, superficie cosechada y rendimiento por departamento. Cabe resaltar que el departamento que tiene mayor rendimiento en kilogramos por hectárea es Ancash, seguido de Lima. Adicionalmente se obtiene que de la producción nacional, el 73\% corresponde a Lima y Lima Metropolitana. 
Tabla 2.19

Producción, superficie cosechada y rendimiento de Lúcuma del año 2014

\begin{tabular}{|l|c|c|c|}
\hline \multicolumn{1}{|c|}{ Región } & Producción (Ton) & Superficie (Ha) & Rendimiento (Ton/Ha) \\
\hline Piura & 253 & 74 & 3,42 \\
\hline Lambayeque & 23 & 11 & 2,09 \\
\hline La Libertad & 1.201 & 133 & 9,03 \\
\hline Ancash & 168 & 15 & 11,17 \\
\hline Lima & 7.188 & 653 & 11,01 \\
\hline Lima Metropolitana & 2.174 & 226 & 9,62 \\
\hline Ica & 1.670 & 158 & 10,57 \\
\hline Huánuco & 63 & 7 & 9,33 \\
\hline Pasco & 165 & 22 & 7,49 \\
\hline Junín & 98 & 18 & 5,42 \\
\hline Huancavelica & 49 & 7 & 6,95 \\
\hline Arequipa & 624 & 87 & 7,17 \\
\hline Moquegua & 105 & 15 & 7,01 \\
\hline Ayacucho & 453 & 69 & 6,57 \\
\hline Apurímac & 85 & 21 & 4,04 \\
\hline Loreto & 97 & 20 & 4,85 \\
\hline
\end{tabular}

Fuente: Ministerio de Agricultura y Riego, (2014)

\subsubsection{Costos de la materia prima}

De acuerdo al boletín mensual de precios del MINAGRI, en el mercado de frutas el promedio de precio de la lúcuma es de 4,63 soles por kilogramo desde Enero del 2013. En la figura 2.10 se observa la variación de los precios, la cual se ha mantenido fluctuante entre S/. 3,50 y S/. 5,80.

Figura 2.10

Variación de los precios de la lúcuma

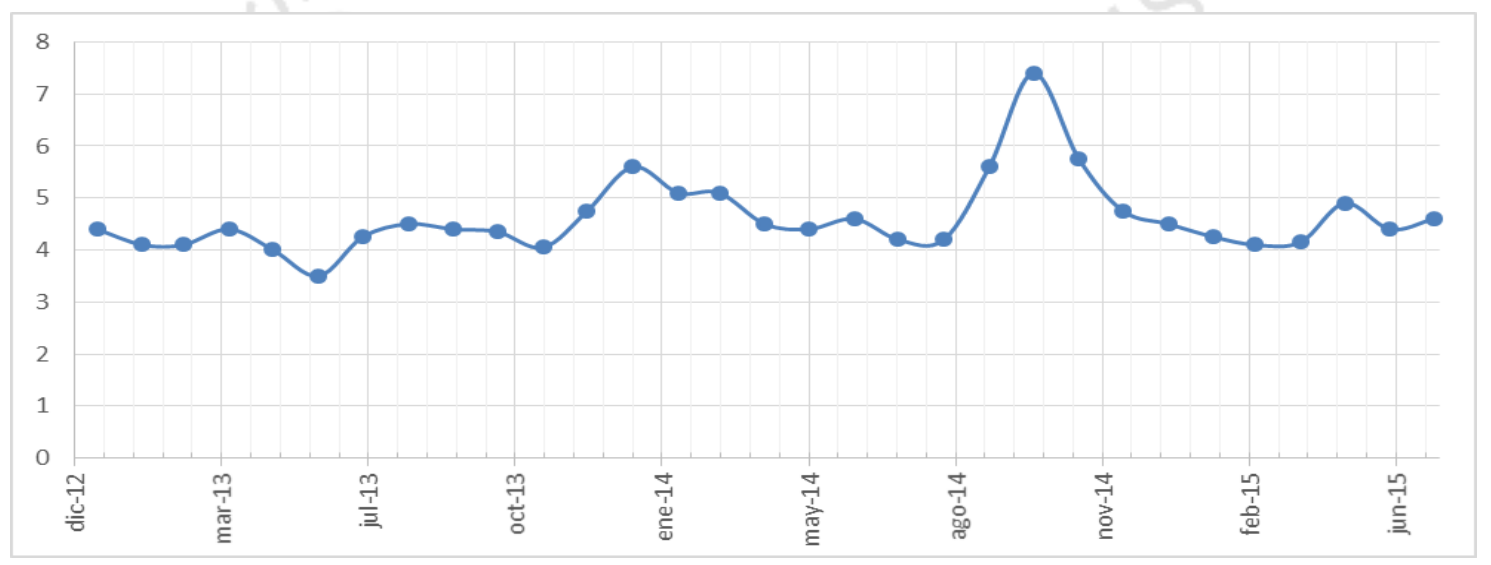

Fuente: Ministerio de Agricultura y Riego, (2015)

Por otro lado, el precio de la lúcuma en chacra la mostramos en la tabla 2.20. 
Tabla 2.20

Precio de la lúcuma en el Perú por región

\begin{tabular}{|l|c|}
\hline \multicolumn{1}{|c|}{ Región } & Precio (S/. / kg) \\
\hline Piura & 0,56 \\
\hline Lambayeque & 1,64 \\
\hline La Libertad & 3,17 \\
\hline Ancash & 2,60 \\
\hline Lima & 2,30 \\
\hline Lima Metropolitana & 2,78 \\
\hline Ica & 2,17 \\
\hline Huánuco & 2,40 \\
\hline Pasco & 3,05 \\
\hline Junín & 1,85 \\
\hline Huancavelica & 1,14 \\
\hline Arequipa & 3,09 \\
\hline Moquegua & 3,61 \\
\hline Ayacucho & 2,12 \\
\hline Apurímac & 1,44 \\
\hline Loreto & 0,42 \\
\hline
\end{tabular}

Fuente: Ministerio de Agricultura y Riego, (2015)

Analizando ambos precios, tanto en el Mercado Mayorista de Frutas $\mathrm{N}^{\circ} 2$ y el precio en chacra, concluimos que es más conveniente comprar el fruto directamente en chacra. El precio referencial del departamento de Lima, S/. 2.30 por kilo de lúcuma, será el precio al que compremos la lúcuma. 


\section{CAPÍTULO III: LOCALIZACIÓN DE PLANTA}

\subsection{Identificación y análisis detallado de los factores de localización}

Para identificar los factores de localización de la planta productora de harina de lúcuma, se cuenta con tres grandes enfoques de localización, los cuales son:

- Localización orientada al producto

- Localización orientada al proceso

- Localización orientada al mercado

Dentro de estos enfoques se pueden encontrar diversos criterios a considerar:

- Clientes

- Medios de transporte

- Materia prima

- Mano de obra

- Suministro básico

- Calidad de vida

- Condiciones climatológicas

- Impuestos

- Terreno y construcción.

Para este proyecto nos hemos basado en una alternativa orientada al proceso y hemos considerado la disponibilidad de la materia prima como el factor principal.

La materia prima para nuestro producto es la lúcuma. Según el portal frutícola, Perú tiene una capacidad productiva de 2000 hectáreas, de las cuales el $65 \%$ se encuentran en Lima, el $21 \%$ en Ayacucho y el resto se encuentran en La Libertad, Ancash, Cajamarca e Ica. Por otro lado el rendimiento aproximado es de 10 toneladas por hectárea.

A continuación definiremos los factores que hemos considerado para nuestro proyecto.

a) Disponibilidad de mano de obra: Para la elaboración de la harina de lúcuma se debe aplicar esfuerzo físico y mental en cada una de las actividades tanto del 
proceso productivo como de las actividades administrativas. Sin este recurso no podremos cumplir los objetivos trazados.

b) Disponibilidad de terreno: En la producción de la harina de lúcuma es necesario contar con áreas en donde ubicar nuestra planta al precio más económico.

c) Proximidad a la materia prima: Dado que nuestro producto es la lúcuma es prioritario estar cerca de la producción de esta.

d) Suministro de energía eléctrica: Es necesaria la instalación y consideraciones de electricidad en una planta de producción de harina de lúcuma, para así operar las máquinas involucradas en el proceso.

e) Facilidad de transporte: Dado que nuestro producto está destinado a la exportación, es importante tener todas las facilidades para transportarlo considerando la distancia al puerto del Callao.

\subsection{Identificación y descripción de las alternativas de localización}

Dado que nos orientaremos a la disponibilidad de materia prima, según PROLÚCUMA la mayor cantidad de producción se da en Lima, Ayacucho y La Libertad. Estas serán nuestras tres posibles ubicaciones.

\subsection{Evaluación y selección de localización}

\subsubsection{Evaluación y selección de la macro localización}

El método a utilizar para el siguiente análisis será ranking de factores. Los factores subjetivos son los siguientes: disponibilidad de mano de obra, disponibilidad de terreno, proximidad a la materia prima, suministro de energía eléctrica y facilidad de transporte. Debemos resaltar que el factor más importante es el de la disponibilidad de materia prima seguido por la facilidad de transporte. Finalmente los factores de disponibilidad de mano de obra, disponibilidad de terreno y suministro de energía eléctrica, se considerarán con igual importancia. Los pesos de cada factor se calculan en la tabla 3.1. 
Tabla 3.1

Matriz de enfrentamiento de factores de macro localización

\begin{tabular}{|c|c|c|c|c|c|c|c|}
\hline Factor & DMO & DT & DMP & SEE & FT & Conteo & Ponderación (\%) \\
\hline DMO & & 1 & 0 & 1 & 0 & 2 & $15,38 \%$ \\
\hline DT & 1 & & 0 & 1 & 0 & 2 & $15,38 \%$ \\
\hline DMP & 1 & 1 & & 1 & 1 & 4 & $30,78 \%$ \\
SEE & 1 & 1 & 0 & & 0 & 2 & $15,38 \%$ \\
FT & 1 & 1 & 0 & 1 & & 3 & $23,08 \%$ \\
\hline
\end{tabular}

Elaboración propia

Leyenda:

DMO: Disponibilidad de Mano de Obra

DT: Disponibilidad de Terrenos

DMP: Disponibilidad de materia prima

SEE: Suministro de energía eléctrica

FT: Facilidad de transporte

En la tabla 3.2 brindamos información acerca de los factores en cada departamento. 
Tabla 3.2

Información de los factores por departamento

\begin{tabular}{|c|c|c|c|}
\hline Factor & Lima & Ayacucho & La Libertad \\
\hline DMO & $\begin{array}{l}\text { La población en Lima ( } 43 \\
\text { distritos) es de } 8 \text { millones } \\
751 \text { mil } 741 \text { habitantes. } \\
\text { Según datos del INEI existen } \\
352.000 \text { personas que se } \\
\text { encuentran desempleadas. }\end{array}$ & $\begin{array}{l}\text { La población de Ayacucho } \\
\text { es de } 681 \text { mil } 149 \text { habitantes. } \\
\text { Además se sabe que la } \\
\text { población } \\
\begin{array}{l}\text { desempleada es de } 22.575 \\
\text { personas. }\end{array}\end{array}$ & $\begin{array}{l}\text { La población de La Libertad } \\
\text { es de } 1 \text { millón } 836 \text { mil } 960 \\
\text { habitantes. Por otro lado la } \\
\text { población } \\
\begin{array}{lr}\text { desempleada es } \\
\text { aproximadamente } \\
\text { personas. }\end{array}\end{array}$ \\
\hline $\mathrm{D}^{\prime}$ & $\begin{array}{l}\text { Se sabe que en el } 2011 \\
\text { aproximadamente se tiene } \\
70.464 .938 \mathrm{~m} 2 \text { en Lima y } \\
\text { Callao con zonificación } \\
\text { industrial. }\end{array}$ & $\begin{array}{l}\text { Se conoce que existe poca } \\
\text { disponibilidad de terrenos y } \\
\text { que el sector construcción } \\
\text { está más orientado a la } \\
\text { edificación de conjuntos } \\
\text { habitacionales que de zonas } \\
\text { industriales (Diario Gestión, } \\
2014 \text { ) }\end{array}$ & $\begin{array}{l}\text { Se conoce que el sector } \\
\text { construcción está orientado a } \\
\text { la edificación de viviendas y } \\
\text { centros comerciales. }\end{array}$ \\
\hline DM & $\begin{array}{l}\text { Según MINAGRI, se sabe } \\
\text { que en Lima se concentra } \\
653 \text { hectáreas para la } \\
\text { plantación de lúcuma. }\end{array}$ & $\begin{array}{l}\text { Según MINAGRI, se sabe } \\
\text { que en Ayacucho existen } 69 \\
\text { hectáreas para el cultivo de } \\
\text { lúcuma }\end{array}$ & $\begin{array}{l}\text { Según MINAGRI, se sabe } \\
\text { que en La Libertad existen } \\
133 \text { hectáreas destinadas al } \\
\text { cultivo de lúcuma. }\end{array}$ \\
\hline SEE & $\begin{array}{l}\text { El acceso a energía eléctrica } \\
\text { es del } 94,70 \% \text { según } \\
\text { Osinergmin. }\end{array}$ & $\begin{array}{l}\text { El acceso a energía eléctrica } \\
\text { es del } 76 \%\end{array}$ & $\begin{array}{l}\text { El acceso a energía eléctrica } \\
\text { es del } 87 \% \text {. }\end{array}$ \\
\hline FT & $\begin{array}{l}\text { Se tiene buena disposición } \\
\text { de vehículos para carga en la } \\
\text { provincia de Lima. }\end{array}$ & $\begin{array}{l}\text { Los kilómetros de Ayacucho } \\
\text { a Lima son } 520 .\end{array}$ & $\begin{array}{l}\text { Los kilómetros de La } \\
\text { Libertad (específicamente } \\
\text { Trujillo) a Lima son } 570 .\end{array}$ \\
\hline
\end{tabular}

Fuente: Instituto Nacional de Estadística e Informática, (2015); Ministerio de Agricultura y Riego,

(2015); Organismo Supervisor de la Inversión en Energía y Minería, (2015).

Elaboración propia

Tabla 3.3

Escala de evaluación para la macro localización

\begin{tabular}{|c|c|}
\hline Descripción & Puntuación \\
\hline Muy bueno & 8 \\
\hline Bueno & 6 \\
\hline Regular & 4 \\
\hline Deficiente & 2 \\
\hline
\end{tabular}

Elaboración propia 
Tabla 3.4

Matriz de evaluación de la macro localización

\begin{tabular}{|c|c|c|c|c|c|c|c|}
\hline \multirow{2}{*}{ Factor } & \multirow{2}{*}{$\begin{array}{c}\text { Conteo } \\
(\boldsymbol{\%})\end{array}$} & \multicolumn{2}{|c|}{ Lima } & \multicolumn{2}{c|}{ Ayacucho } & \multicolumn{2}{c|}{ La Libertad } \\
\cline { 3 - 8 } & Calif. & Puntaje & Calif. & Puntaje & Calif. & Puntaje \\
\hline DMO & 15,38 & 8 & 123,04 & 4 & 61,52 & 6 & 92,28 \\
\hline DT & 15,38 & 8 & 123,04 & 6 & 92,28 & 4 & 61,52 \\
\hline DMP & 30,78 & 8 & 246,24 & 6 & 184,68 & 4 & 123,12 \\
\hline SEE & 15,38 & 6 & 92,28 & 2 & 30,76 & 4 & 61,52 \\
\hline FT & 23,08 & 8 & 184,64 & 6 & 138,48 & 4 & 92,32 \\
\hline \multicolumn{3}{c}{ Suma } & $\mathbf{7 6 9 , 2 4}$ & & 507,72 & & 430,76 \\
\hline
\end{tabular}

Elaboración propia

De acuerdo al método de Ranking de factores realizado, el departamento escogido es Lima.

\subsubsection{Evaluación y selección de la micro localización}

Para la elección de micro localización se utilizará el método de ranking de factores. Cabe resaltar que los factores serán los siguientes: disponibilidad de mano de obra, disponibilidad de terreno, suministro de energía eléctrica y facilidad de transporte. Los pesos de cada factor son calculados en la tabla 3.5.

Tabla 3.5

Matriz de enfrentamiento de factores de micro localización

\begin{tabular}{|c|c|c|c|c|c|c|c|}
\hline Factor & DMO & DT & DMP & SEE & FT & Conteo & Pond. (\%) \\
\hline DMO & & 1 & 0 & 1 & 0 & 2 & $15,38 \%$ \\
\hline DT & 1 & & 0 & 1 & 0 & 2 & $15,38 \%$ \\
\hline DMP & 1 & 1 & & 1 & 1 & 4 & $30,78 \%$ \\
\hline SEE & 1 & 1 & 0 & & 0 & 2 & $15,38 \%$ \\
\hline FT & 1 & 1 & 0 & 1 & & 3 & $23,08 \%$ \\
\hline
\end{tabular}

Elaboración propia

Leyenda:

DMO: Disponibilidad de Mano de Obra

DT: Disponibilidad de Terrenos

DMP: Disponibilidad de materia prima

SEE: Suministro de energía eléctrica

FT: Facilidad de transporte 
Dado que el departamento elegido en la macro localización fue Lima, se escogieron las siguientes provincias de dicho departamento: Huaral, Huaura y Huacho.

En la tabla 3.6 brindamos información acerca de los factores en cada una de ellas.

Tabla 3.6

Información de factores por provincia

\begin{tabular}{|c|c|c|c|}
\hline & Huaral & Huaura & Huacho \\
\hline D & $\begin{array}{l}\text { La PEA desocupada de } \\
\text { Huaura, de acuerdo a } \\
\text { estadísticas del INEI, es de } \\
43 \text { mil personas. }\end{array}$ & $\begin{array}{l}\text { La PEA desocupada de } \\
\text { Huaura, de acuerdo a } \\
\text { estadísticas del INEI, es de } \\
52 \text { mil personas. }\end{array}$ & $\begin{array}{l}\text { La PEA desocupada de } \\
\text { Huacho, de acuerdo a } \\
\text { estadísticas del INEI, es de } \\
35 \text { mil personas. }\end{array}$ \\
\hline $\mathrm{D}^{\prime}$ & $\begin{array}{l}\text { Según publicaciones } \\
\text { recientes, Huaral cuenta con } \\
\text { alta disponibilidad de } \\
\text { terrenos para zonas } \\
\text { industriales. }\end{array}$ & $\begin{array}{l}\text { Según publicaciones, son } \\
\text { pocos los terrenos que se } \\
\text { venden para fin industrial. }\end{array}$ & $\begin{array}{l}\text { Las publicaciones muestran } \\
\text { la poca existencia de } \\
\text { terrenos, algunos con } \\
\text { disponibilidad inmediata. }\end{array}$ \\
\hline & $\begin{array}{l}\text { Según estadísticas Huaral es } \\
\text { la ciudad que concentra } \\
\text { mayor producción de } \\
\text { lúcuma de la región Lima. }\end{array}$ & $\begin{array}{l}\text { Se encuentran cultivos de } \\
\text { lúcuma; sin embargo no en } \\
\text { gran proporción. }\end{array}$ & $\begin{array}{l}\text { Es la segunda ciudad con } \\
\text { cultivos de lúcuma, según } \\
\text { estadísticas. }\end{array}$ \\
\hline & $\begin{array}{l}\text { En Huaral el suministro de } \\
\text { energía eléctrica es brindado } \\
\text { por distintas concesionarias } \\
\text { Luz del Sur, Edelnor, } \\
\text { ELECTO, ETOSA. Se } \\
\text { estima según } \\
\text { OSINERGMIN un aumento } \\
\text { de la tarifa en } 0,1 \% \text {. }\end{array}$ & $\begin{array}{l}\text { En Huaura también se estima } \\
\text { un incremento en la tarifa } \\
\text { eléctrica. Sin embargo, la } \\
\text { instalación de la } \\
\text { hidroeléctrica } \\
\text { entregará anualmente } 837 \\
\text { Gw/hora al Sistema } \\
\text { Eléctrico Interconectado } \\
\text { Nacional lo que supone una } \\
\text { buena disponibilidad de } \\
\text { energía. }\end{array}$ & $\begin{array}{l}\text { En Huacho precio de la tarifa } \\
\text { eléctrica subiría en } 1.7 \% \\
\text { correspondiente a S/.1.30, } \\
\text { según OSINERGMIN, Por } \\
\text { otro lado se sabe que con la } \\
\text { apertura de una oficina de } \\
\text { OSINERGMIN se tendrá } \\
\text { más control de reclamos } \\
\text { contra la empresa } \\
\text { EDELNOR. }\end{array}$ \\
\hline FT & $\begin{array}{l}\text { La distancia de Huaral a } \\
\text { Lima es de } 78,8 \text { kilómetros. } \\
\text { Por otro lado existe } \\
\text { transporte que va desde } \\
\text { Huaral a Lima. }\end{array}$ & $\begin{array}{l}\text { Huaura se encuentra a } 150 \\
\text { kilómetros de Lima. Existe } \\
\text { transporte hacia Lima. }\end{array}$ & $\begin{array}{l}\text { La distancia en kilómetros } \\
\text { de Lima a Huacho es de } 139 . \\
\text { Existe transporte hacia } \\
\text { Lima. }\end{array}$ \\
\hline
\end{tabular}

Fuente: Instituto Nacional de Estadística e Informática, (2015); Ministerio de Agricultura y Riego, (2015); Organismo Supervisor de la Inversión en Energía y Minería, (2015).

Elaboración propia

Tabla 3.7

Escala de evaluación para micro localización

\begin{tabular}{|c|c|}
\hline Descripción & Puntuación \\
\hline Muy bueno & 8 \\
\hline Bueno & 6 \\
\hline Regular & 4 \\
\hline Deficiente & 2 \\
\hline
\end{tabular}

Elaboración propia 
Tabla 3.8

Matriz de evaluación de la micro localización

\begin{tabular}{|c|c|c|c|c|c|c|c|}
\hline \multirow{2}{*}{ Factor } & \multirow{2}{*}{$\begin{array}{c}\text { Conteo } \\
(\boldsymbol{\%})\end{array}$} & \multicolumn{2}{|c|}{ Huaral } & \multicolumn{2}{c|}{ Huaura } & \multicolumn{2}{c|}{ Huacho } \\
\cline { 3 - 8 } & Calif. & Puntaje & Calif. & Puntaje & Calif. & Puntaje \\
\hline DMO & 15,38 & 8 & 123,04 & 4 & 61,52 & 6 & 92,28 \\
\hline DT & 15,38 & 6 & 92,28 & 4 & 61,52 & 4 & 61,52 \\
\hline PMP & 30,78 & 8 & 246,24 & 6 & 184,68 & 4 & 123,12 \\
\hline SEE & 15,38 & 6 & 92,28 & 2 & 30,76 & 4 & 61,52 \\
\hline FT & 23,08 & 8 & 184,64 & 6 & 138,48 & 4 & 92,32 \\
\hline \multicolumn{3}{r}{ Suma } & 738,48 & & 476,96 & & 430,76 \\
\hline
\end{tabular}

Elaboración propia

Por lo tanto, según el análisis de micro localización el distrito elegido para la instalación de nuestra planta es Huaral. 


\section{CAPÍTULO IV: TAMAÑO DE PLANTA}

\subsection{Relación tamaño-mercado}

La relación tamaño - mercado nos indica la capacidad de planta mínima que debemos tener para poder cubrir la demanda del proyecto. Para calcular el tamaño de planta en base al mercado, utilizaremos la demanda del proyecto que se calculó en el punto 2.4.3. La tabla 4.1 muestra dicha demanda desde el 2016, año en que iniciara nuestro proyecto, hasta el año 2025. El tamaño que utilizaremos como referencia será la del año 2025, cuya demanda es de 24.155,86 kg de harina de lúcuma. Nuestro tamaño de planta deberá responder a esta demanda, es decir debe ser mayor o igual a esa cantidad.

Tabla 4.1

Demanda especifica del proyecto

\begin{tabular}{|c|c|}
\hline Año & $\begin{array}{c}\text { Demanda del proyecto (kg de harina } \\
\text { de lúcuma) }\end{array}$ \\
\hline 2016 & $9,216.08$ \\
\hline 2017 & $10,876.06$ \\
\hline 2018 & $12,536.03$ \\
\hline 2019 & $14,196.01$ \\
\hline 2020 & $15,855.98$ \\
\hline 2021 & $17,515.96$ \\
\hline 2022 & $19,175.93$ \\
\hline 2023 & $20,835.91$ \\
\hline 2024 & $22,495.88$ \\
\hline $\mathbf{2 0 2 5}$ & $\mathbf{2 4 , 1 5 5 . 8 6}$ \\
\hline
\end{tabular}

Elaboración propia

\subsection{Relación tamaño-recursos productivos}

Para poder cumplir con la demanda del proyecto nos debemos asegurar que los recursos necesarios para la elaboración de la harina de lúcuma se encuentren disponibles en el momento y lugar que lo requiramos y que estos cumplan con la cantidad y calidad prevista.

\section{$\underline{\text { Materia prima e insumos }}$}

Para el cálculo de la relación tamaño - recursos productivos, se asumió la disponibilidad aproximada de la materia prima en Lima, es decir la lúcuma, de los siguientes 10 años. 
Adicionalmente se conoce que para elaborar un kilo de harina de lúcuma se necesitan $4,96 \mathrm{~kg}$ de lúcuma, por lo que multiplicamos la demanda especifica del proyecto (punto 2.4.3) por 4,96 para obtener la demanda de lúcuma para el proyecto. Como se observa en la tabla 4.2, la materia prima no es una limitante para nuestro proyecto.

Tabla 4.2

Participación de materia prima

\begin{tabular}{|c|c|c|c|}
\hline Año & $\begin{array}{c}\text { Demanda de lúcuma para el } \\
\text { proyecto (kg) }\end{array}$ & $\begin{array}{c}\text { Disponibilidad de lúcuma } \\
\text { (TM) }\end{array}$ & Participación de lúcuma \\
\hline 2016 & $45.711,77$ & $7.188,00$ & $0,64 \%$ \\
\hline 2017 & $53.945,25$ & $7.188,00$ & $0,75 \%$ \\
\hline 2018 & $62.178,72$ & $7.188,00$ & $0,87 \%$ \\
\hline 2019 & $70.412,20$ & $7.188,00$ & $0,98 \%$ \\
\hline 2020 & $78.645,68$ & $7.188,00$ & $1,09 \%$ \\
\hline 2021 & $86.879,15$ & $7.188,00$ & $1,21 \%$ \\
\hline 2022 & $95.112,63$ & $7.188,00$ & $1,32 \%$ \\
\hline 2023 & $103.346,10$ & $7.188,00$ & $1,44 \%$ \\
\hline 2024 & $111.579,58$ & $7.188,00$ & $1,55 \%$ \\
\hline 2025 & $119.813,06$ & $7.188,00$ & $1,67 \%$ \\
\hline
\end{tabular}

Elaboración propia

$\underline{\text { Mano de obra }}$

En cuanto a mano de obra tampoco habría limitante ya que como se analizó en el punto 3.3, el porcentaje de PEA desocupada de Huaral es una de las más altas del país, por lo que se aprovecharía la disponibilidad de mano de obra con la que cuenta esta provincia.

\section{Energía eléctrica y agua}

La energía eléctrica y el agua potable tampoco son limitantes para llevar a cabo el proyecto ya que como se mencionó en el punto 3.3, Huaral cuenta con la empresa EDELNOR que brinda un servicio de energía eléctrica constante. Además no hay limitante con respecto al agua potable necesaria para la ejecución del proyecto ya que el servicio de agua potable en Huaral lo brinda la empresa Emapa Huaral S.A.

\subsection{Relación tamaño-tecnología}

En este punto se analizó la capacidad de producción de cada una de las actividades del proceso de producción y se eligió la menor, es decir el cuello de botella, ya que es esa actividad que nos indica el máximo de producción de harina de lúcuma posible. 
Nuestro proceso de producción consta de actividades con máquinas y actividades manuales. Las maquinas necesarias para el proceso y sus capacidades se indican en la tabla 4.3.

Tabla 4.3

Capacidad por máquina

\begin{tabular}{|l|c|}
\hline \multicolumn{1}{|c|}{ Máquina } & Capacidad aproximada $(\mathbf{k g} / \mathbf{h})$ \\
\hline Balanza de plataforma & 900 \\
\hline Lavadora circular & 1.000 \\
\hline Deshidratadora & 40 \\
\hline Molino de martillos & 65 \\
\hline Selladora & 36.000 \\
\hline Embolsadora & 36.000 \\
\hline
\end{tabular}

Elaboración propia

Por otro lado, las actividades manuales son las de pelado, deshuesado y trozado. Estas son las de menor capacidad de producción ya que su capacidad es aproximadamente de $12.5 \mathrm{~kg} / \mathrm{h}$. Este dato se obtuvo mediante juicio de expertos (Contacto de la empresa Complementos y Suplementos SAC - Pablo Torres). Considerando que se va a trabajar 8 horas al día, 5 días a la semana y 52 semanas al año, se puede determinar que la relación tamaño-tecnología es de 26.000 kg/año.

\subsection{Relación tamaño-inversión}

El tamaño de la planta está ligado al nivel de inversión ya que de la inversión que hagamos dependerá nuestra capacidad para cubrir nuestra demanda propuesta. La cantidad a producir el primer año será de 9.216,08 kg de harina de lúcuma, siendo nuestra inversión total de S/. 579.623,37.

\subsection{Relación tamaño-punto de equilibrio}

La relación tamaño - punto de equilibrio es el tamaño mínimo de nuestra planta en el cual nuestros ingresos igualan a nuestros costos. Es decir la cantidad a producir y comercializar debe ser mayor a este punto de equilibrio para poder empezar a obtener ganancias. Para calcularla realizamos la siguiente formula: 
Figura 4IV.1

Fórmula para el cálculo del punto de equilibrio

Dónde:

$$
\mathrm{PE}=\frac{C F}{P v-C v}
$$

- PE: Punto de equilibrio (Cantidad mínima a producir)

- CF: Costo Fijo Total

- Pv: Precio de venta unitario

- $\mathrm{Cv}$ : Costo variable unitario

Elaboración propia

Los costos fijos anuales son los que incurriremos durante un periodo de tiempo sin importar el volumen de venta. Para calcularlo consideramos los siguientes costos fijos: servicio de energía eléctrica en oficinas, servicio de agua potable en oficinas, indumentaria y herramientas, certificaciones, mano de obra indirecta, mano de obra directa y depreciación fabril.

\section{Energía eléctrica en oficinas}

En lo que refiere al costo de la energía eléctrica en las oficinas, en Huaral la empresa que provee del servicio es Edelnor. Así mismo el costo está regulado por Osinergmin en su tarifario, el cual contempla los costos de acuerdo a la tabla 4.4.

Tabla 4.4

Tarifario de luz de la empresa Edelnor para la zona de Huaral

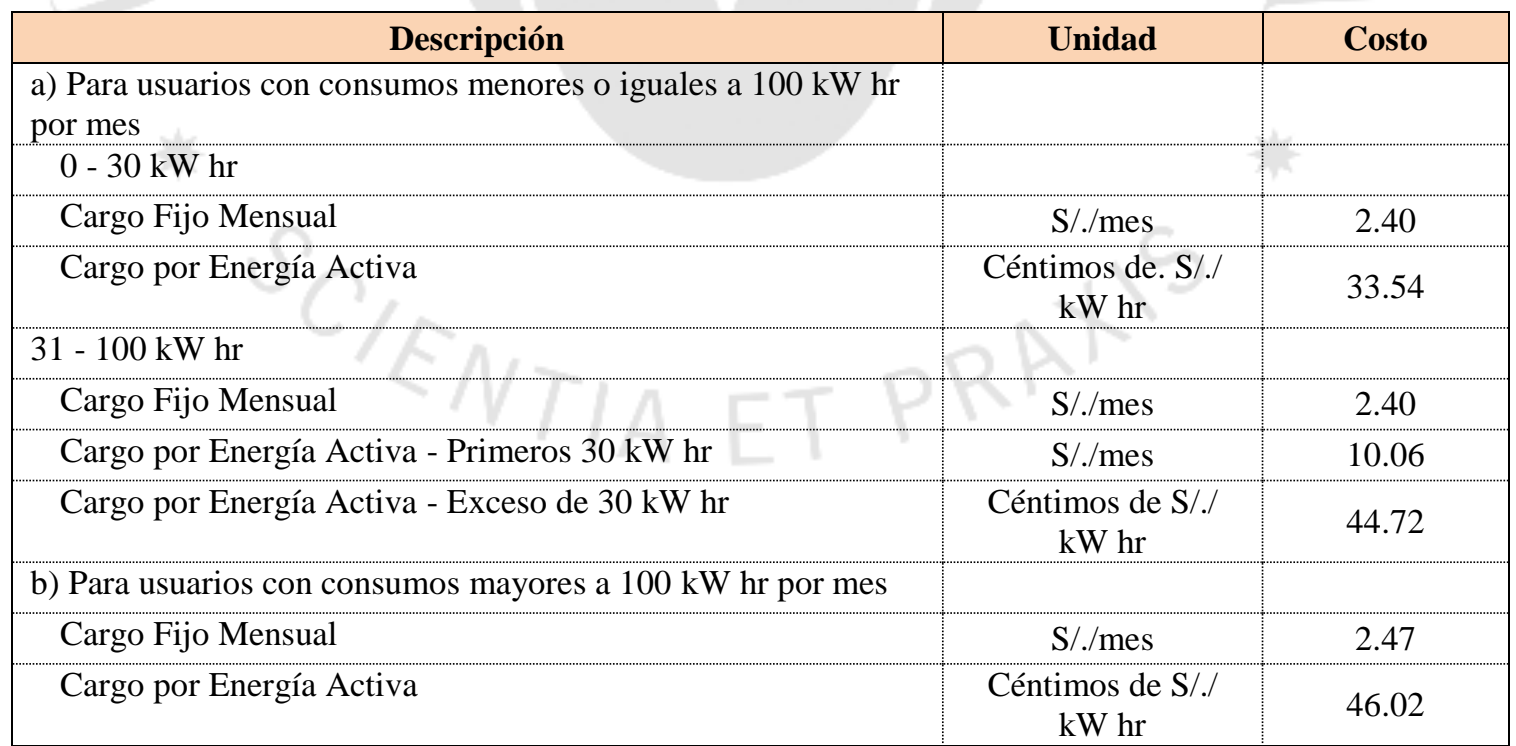

Fuente: Organismo Supervisor de la Inversión en Energía y Minería, (2015)

Se ha calculado aproximadamente un consumo de $250 \mathrm{~kW} \mathrm{hr}$ al mes. Esto incluye el consumo de computadoras (4), impresora (1) y bombillas (20) para el área de 
operaciones y para las áreas administrativas. De acuerdo a este dato y al tarifario vigente, se ha calculado un costo mensual de S/. 117,52.

\section{$\underline{\text { Agua potable en oficinas }}$}

Para el servicio de Agua en Oficinas, se ha contemplado a la empresa Emapa Huaral S.A, la cual brinda el servicio de agua potable en Huaral. Así mismo las tarifas se encuentran normadas por la SUNASS (Superintendencia Nacional de Servicios de Saneamiento). El tarifario se encuentra en la tabla 4.5.

Tabla 4.5

Tarifario de servicio de agua potable de la empresa Emapa Huaral

\begin{tabular}{|c|c|c|c|c|c|c|}
\hline \multirow{2}{*}{ Clase } & \multirow{2}{*}{ Categoría } & \multirow{2}{*}{$\begin{array}{l}\text { Rangos de } \\
\text { Consumo }\end{array}$} & \multicolumn{2}{|c|}{ Tarifas $\left(\mathrm{S} / . \mathrm{m}^{3}\right)$} & \multirow{2}{*}{$\begin{array}{c}\text { Cargo Fijo } \\
\text { (S/.) }\end{array}$} & \multirow{2}{*}{$\begin{array}{l}\text { Asignación de } \\
\text { Consumo }\end{array}$} \\
\hline & & & Agua & Alcantarillado & & \\
\hline \multirow{4}{*}{ Residencial } & Social & 0 a más & 0,602 & 0,172 & 1,70 & 10 \\
\hline & \multirow{3}{*}{ Doméstico } & 0 a 10 & 0,602 & 0,172 & 1,70 & \multirow{2}{*}{25} \\
\hline & & 10 a 25 & 0,689 & 0,197 & 1,70 & \\
\hline & & 25 a más & 1,175 & 0,336 & 1,70 & 40 \\
\hline \multirow{5}{*}{$\begin{array}{c}\text { No } \\
\text { Residencial }\end{array}$} & Estatal & 0 a más & 0,910 & 0,260 & 1,70 & 50 \\
\hline & \multirow{3}{*}{ Comercial } & 0 a 30 & 1,680 & 0,480 & 1,70 & 30 \\
\hline & & \multirow{2}{*}{30 a más } & \multirow{2}{*}{2,652} & \multirow{2}{*}{0,757} & \multirow{2}{*}{1,70} & 50 \\
\hline & & & & & & 60 \\
\hline & Industrial & 0 a más & 1,875 & 0,536 & 1,70 & 100 \\
\hline
\end{tabular}

Fuente: Emapa Huaral S.A. (2015)

Elaboración propia

De acuerdo a un estudio de la Escuela de Ingeniería de Antioquía, el consumo de agua potable por persona es de 50 litros al día. De acuerdo a estos datos y al tarifario vigente, se ha calculado un costo mensual aproximado de S/. 36,42.

El cálculo de las los costos indumentaria y herramientas, certificaciones, mano de obra directa e indirecta se encuentra detallados en los puntos 7.2.2 y 7.2 .3 respectivamente. El cálculo de las depreciaciones de máquinas e inmuebles se encuentra detallados en el punto 7.3.2.

En resumen, los costos mensual y anual de cada uno se encuentran en la tabla 4.6, siendo un Costo Fijo anual de S/. 198.845,24. 
Tabla 4.6

Costos Fijos anuales

\begin{tabular}{|c|c|c|}
\hline Categoría & Costo Fijo mensual (S/.) & Costo Fijo anual (S/.) \\
\hline Energía eléctrica (oficinas) & 117,52 & $1.410,24$ \\
\hline Agua (Oficinas) & 36,42 & 437,02 \\
\hline Indumentaria y herramientas & 46,25 & 555,00 \\
\hline Certificaciones & 220,00 & $2.640,00$ \\
\hline Mano de obra indirecta & $12.049,61$ & $144.595,33$ \\
\hline Mano de obra directa & $3.452,42$ & $41.429,00$ \\
\hline Depreciación fabril & $1.744,08$ & $20.928,93$ \\
\hline Depreciación no fabril & 525,99 & $6.311,84$ \\
\hline Total & $\begin{array}{r}18.192,28 \\
\end{array}$ & $218.307,36$ \\
\hline
\end{tabular}

Elaboración propia

Por otro lado el costo unitario variable lo hemos calculado en base a los costos de materia prima (Punto 7.2.1) y servicios relacionados al proceso de producción como agua, energía eléctrica y gas natural (Punto 7.2.3). El costo unitario se ha determinado sumando dichos costos y dividiéndolos entre la cantidad de harina de lúcuma a producir y el resultado es de S/. 11,62. El precio unitario del kilo de harina de lúcuma en el mercado internacional, como se explicó en el capítulo 2, lo hemos determinado en 12,80 dólares, a una tasa de cambio aproximada de S/. 3,20 soles por dólar. Con estos datos, obtuvimos el punto de equilibrio el cual es 6.660,92 kg de harina de lúcuma.

\subsection{Selección del tamaño de planta}

En la tabla 4.7 presentamos un resumen de los tamaños de planta calculados.

Tabla 4.7

Selección del tamaño de planta

\begin{tabular}{|l|c|}
\hline \multicolumn{1}{|c|}{ Relación } & Tamaño de Planta (kg de harina de lúcuma) \\
\hline Tamaño - mercado & $24.155,86$ \\
\hline Tamaño - recursos productivos & Sin restricción \\
\hline Tamaño - tecnología & 26.000 \\
\hline Tamaño - punto de equilibrio & $6.660,92$ \\
\hline
\end{tabular}

Elaboración propia

El tamaño de planta de nuestro proyecto es determinado por el mercado, $24.155,86 \mathrm{~kg}$ de harina de lúcuma. Además nuestro mercado es mayor al punto de equilibrio, por lo que obtendríamos ganancias desde el primer año y contamos con la tecnología y recursos necesarios para ese objetivo. 


\section{CAPÍTULO V: INGENIERÍA DEL PROYECTO}

\subsection{Definición técnica del producto}

\subsubsection{Especificaciones técnicas del producto}

Las especificaciones técnicas del producto es un documento interno que recoge información técnica del producto. En este consideramos principalmente la composición, presentación y características organolépticas.

Tabla 5.1

Ficha técnica de la harina de lúcuma

\begin{tabular}{|c|c|c|c|}
\hline \multirow{2}{*}{\multicolumn{3}{|c|}{ FICHA TECNICA DE PRODUCTO TERMINADO }} & $\begin{array}{l}\text { PROGRAMA DE BUENAS } \\
\text { PRACTICAS DE } \\
\text { MANUFACTURA BMP } \\
\end{array}$ \\
\hline & & & FT-HLUC-001 \\
\hline \multicolumn{2}{|c|}{$\begin{array}{c}\text { Elaborado por: Ximena Gutierrez } \\
\text { Joseph Rafael }\end{array}$} & Fecha: dd/mm/aa & Versión: 01 \\
\hline Nombre del producto & \multicolumn{3}{|l|}{ Harina de lúcuma } \\
\hline Descripción del producto & \multicolumn{3}{|c|}{$\begin{array}{l}\text { Polvo fino de color amarillo claro hecho a base de la pulpa de la lúcuma, } \\
\text { obtenido a través de un proceso de selección, lavado, secado y molido, } \\
\text { libre de partículas extrañas o impurezas y con una humedad no mayor a } \\
7.5 \%\end{array}$} \\
\hline Lugar de elaboración & \multicolumn{3}{|c|}{$\begin{array}{l}\text { Producto elaborado en la planta ubicada en Huaral. Temperatura promedio } \\
\text { de } 20^{\circ} \mathrm{C} \text { y a } 188 \text { m.s.n.m }\end{array}$} \\
\hline \multirow{6}{*}{$\begin{array}{l}\text { Composición nutricional } \\
\text { (por cada } 100 \text { gramos) }\end{array}$} & \multicolumn{2}{|l|}{ Proteína } & 4 gramos \\
\hline & \multicolumn{2}{|l|}{ Fibras } & 2,30 gramos \\
\hline & \multicolumn{2}{|l|}{ Carbohidratos } & 2,40 gramos \\
\hline & \multicolumn{2}{|l|}{ Lípidos } & 2,50 gramos \\
\hline & \multicolumn{2}{|l|}{ Ácido Ascórbico } & 11,60 miligramos \\
\hline & \multicolumn{2}{|l|}{ Valor energético } & 329 calorías \\
\hline $\begin{array}{l}\text { Presentación y empaques } \\
\text { comerciales }\end{array}$ & \multicolumn{3}{|c|}{ Bolsa de polietileno de 10 kilogramos } \\
\hline \multirow{4}{*}{$\begin{array}{l}\text { Características } \\
\text { organolépticas }^{8}\end{array}$} & Color & \multicolumn{2}{|c|}{ Amarillo/anaranjado pálido } \\
\hline & Olor & \multicolumn{2}{|c|}{ Característico de la lúcuma } \\
\hline & Sabor & \multicolumn{2}{|c|}{ Dulce/ característico de la lúcuma } \\
\hline & Aspecto & \multicolumn{2}{|l|}{ Polvo fino uniforme } \\
\hline Vida útil & \multicolumn{3}{|l|}{24 meses } \\
\hline
\end{tabular}

Elaboración propia 


\subsubsection{Composición del producto}

Tabla 5.2

Composición nutricional

\begin{tabular}{|c|cc|}
\hline Componente & \multicolumn{2}{|c|}{ Cantidad (Por cada 100 g) } \\
\hline Proteína & 4,00 & $\mathrm{~g}$ \\
\hline Fibras & 2,30 & $\mathrm{~g}$ \\
\hline Carbohidratos & 2,40 & $\mathrm{~g}$ \\
\hline Lípidos & 2,50 & $\mathrm{~g}$ \\
\hline Ácido Ascórbico & 11,60 & $\mathrm{mg}$ \\
\hline Valor energético & 329,00 & $\mathrm{cal}$. \\
\hline
\end{tabular}

Fuente: Del Castillo R, (2006)

\subsubsection{Diseño gráfico del producto}

Figura 5.1

Etiqueta frontal del empaque

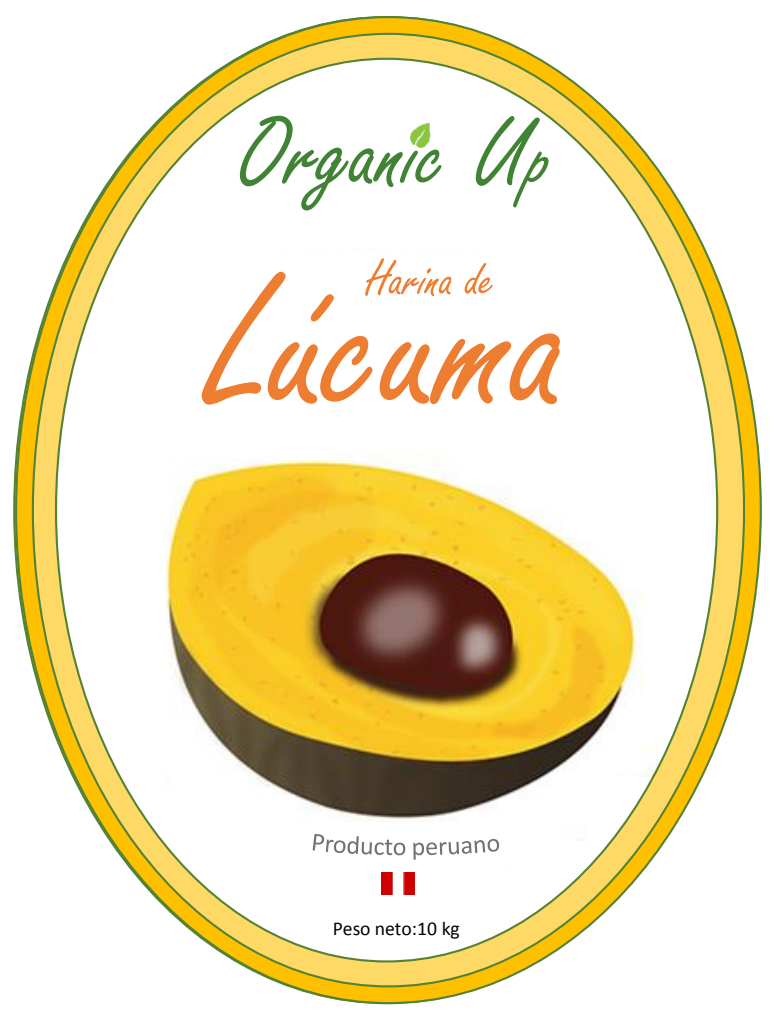

Elaboración propia 
Figura 5.2

Etiqueta posterior del empaque

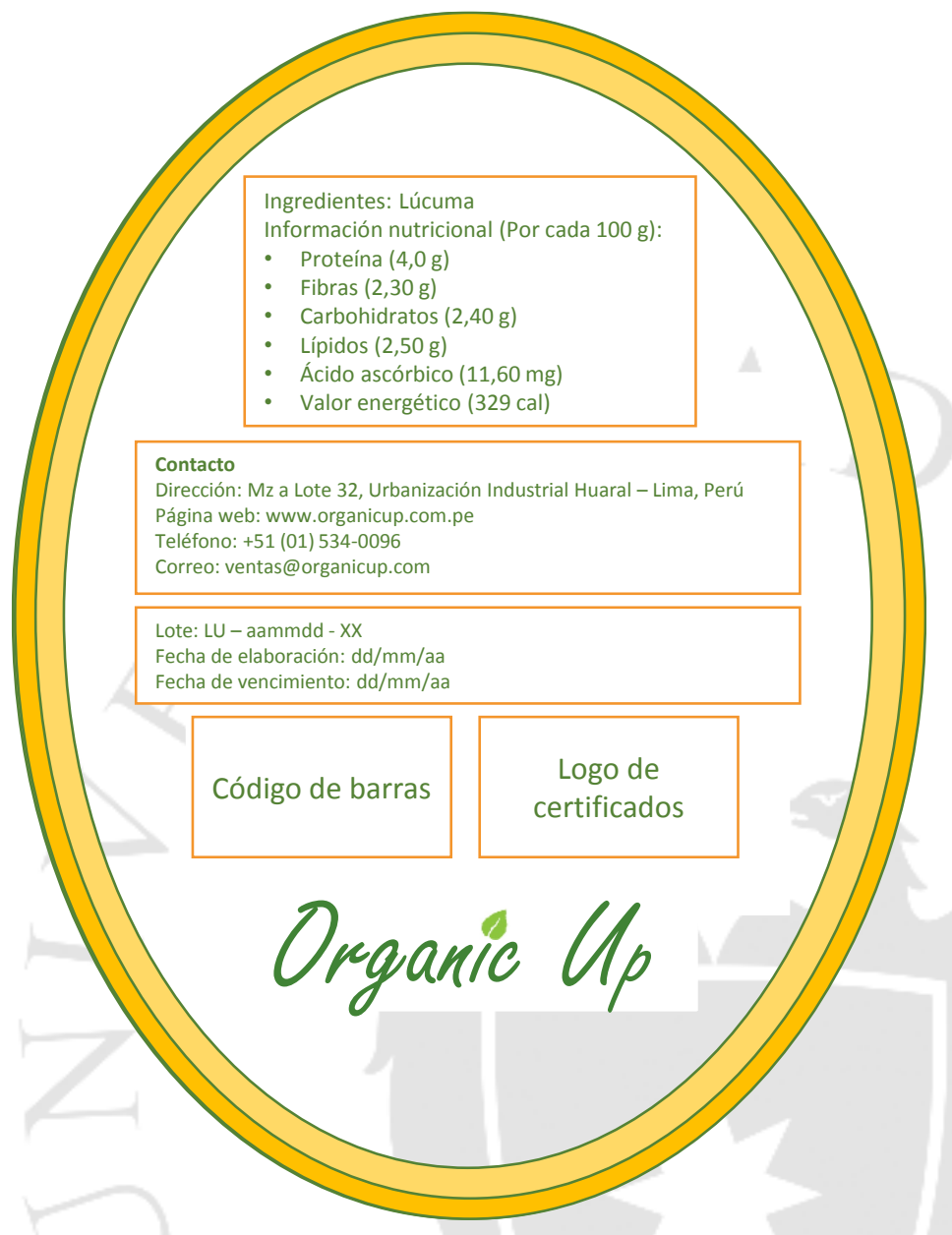

Elaboración propia

\subsubsection{Regulaciones técnicas al producto}

Para definir las regulaciones técnicas que aplican a nuestro producto nos basamos en la Guía de Requisitos Sanitarios y Fitosanitarios para Exportar Alimentos a los Estados Unido y Guía de Requisitos Sanitarios y Fitosanitarios para Exportar Alimentos a la Unión Europea elaboradas por el MINCETUR. Estas guías contienen todos los requisitos que debe cumplir todo exportador para exportar alimentos orgánicos.

Para acreditar que cumplimos con estos requisitos debemos estar certificados ante el United States Department of Agriculture (USDA) de Estados Unidos y ante la Unión Europea. Las regulaciones técnicas que debemos cumplir son las siguientes: 
- La harina de lúcuma debe ser considerada como un alimento ecológico solo si el 95\% de sus ingredientes han sido producidos de manera ecológica. Es decir nuestro proveedor de la lúcuma debe estar certificado de que produce el fruto con procedimientos e insumos orgánicos, libre de pesticidas artificiales.

- Los aditivos son restringidos al mínimo. Esta regulación se encuentra implícita ya que nuestro proceso de producción no considera aditivos.

- En la producción no se debe considerar alimentos modificados genéticamente.

- Todos los recursos utilizados para la producción de la harina de lúcuma deben estar debidamente etiquetados.

- Cumplir con los requisitos descritos en la tabla 5.3.

Tabla 5.3

Requisitos microbiológicos según DIGESA, R.M. 591 - 2008

\begin{tabular}{|l|c|}
\hline \multicolumn{1}{|c|}{ Agente microbiano } & Limite \\
\hline Mohos & $10^{5}(\mathrm{UFC} / \mathrm{g})$ \\
\hline Escherichia coli & $10^{2}(\mathrm{UFC} / \mathrm{g})$ \\
\hline Salmonella sp. & Ausencia \\
\hline
\end{tabular}

Fuente: Dirección General de Salud Ambiental, (2008)

\subsection{Tecnologías existentes y procesos de producción}

Como se explicó en el punto 4.3 (Relación tamaño-tecnología), el proceso de producción consta de las siguientes etapas: selección de la lúcuma, lavado, pelado, deshuesado, trozado, deshidratado, molido y embolsado. Dentro de las actividades críticas del proceso están las de deshidratado y molido, ya que en estas se determinan las propiedades características de la harina de lúcuma.

\subsubsection{Naturaleza de la tecnología requerida}

\subsubsection{Descripción de las tecnologías existentes}

Como ya se mencionó, las actividades críticas son las de deshidratado y molido debido a que estas determinan la calidad final de la harina en cuanto a humedad y finura.

Para las actividades de deshidratado y molido se analizó las diferentes tecnologías existentes para cada una, tomando en cuenta sus ventajas y desventajas. 


\section{Secado}

Esta etapa del proceso es crítica ya que debe asegurar una de las especificaciones más importantes de la harina de lúcuma, que la humedad no debe superar el 7.5\% (detallado en el punto 5.1). La tecnología existente comúnmente usada para el deshidratado de frutas en general es la siguiente:

1. Máquina de liofilización

La liofilización es un proceso que se basa en la congelación de un producto para luego sublimar el líquido contenido en él bajo condiciones de vacío. Para nuestro proyecto, se congelaría la lúcuma para luego ser introducida en una cámara de vacío y separar el agua por sublimación, pasando el agua de estado sólido a gaseoso, todo esto dentro de la cámara de liofilización. La maquinaria liofilizadora o equipos de liofilización (Figura 5.3) presentan las siguientes ventajas y desventajas:

Ventajas:

- Ausencia de temperaturas altas por lo que previene le daño térmico

- Conservación, fácil transporte y almacenamiento de los productos

- Mantenimiento del valor nutricional del alimento

- Inhibición del crecimiento de microorganismos, estabilidad microbiológica

Desventajas

- Largo tiempo de procesamiento

- Alto consumo de energía

- Costo de inversión alto

Figura 5.3

Máquina de liofilización

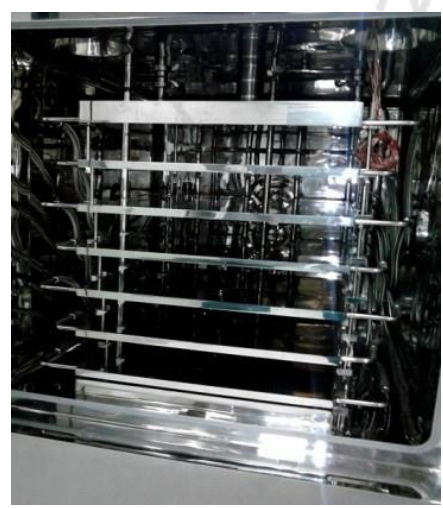

Fuente: Terroni, (2015) 
2. Secador de bandejas

Dicho secador está constituido por un armario en donde se encuentran bandejas perforadas en capas de grosor de 2-6 cm. En la parte superior se encuentra un ventilador y una serie de resistencias eléctricas que permiten generar aire caliente el cual circula a través de las bandejas deshidratando la lúcuma.

Ventajas

- Se evita el exceso de secado

- Es posible de acelerar la deshidratación

- Es económico en adquisición y funcionamiento

- Está diseñado específicamente para secar frutas y verduras

Desventajas

- La temperatura se controla con dificultad

- Se utiliza solo en pequeñas instalaciones

\section{Figura 5.4}

Secador de bandejas

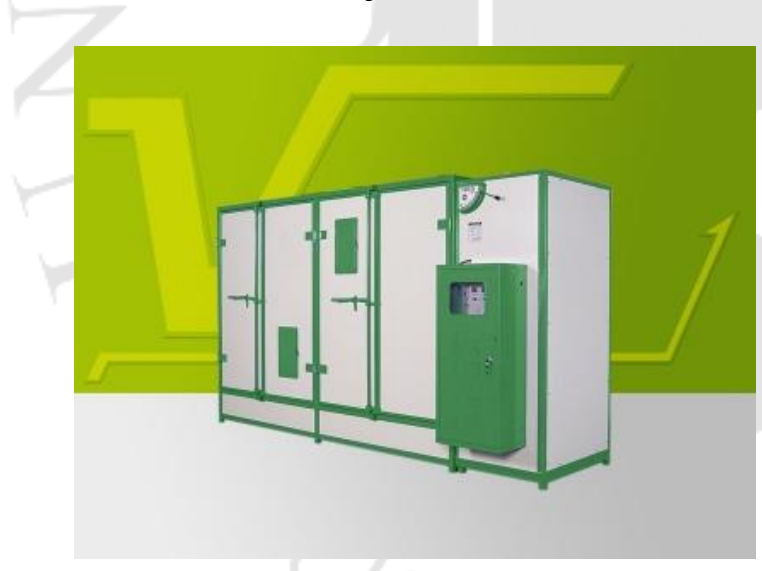

Fuente: Vulcano Tecnología Aplicada EIRL, (2015)

3. Ventaja Refractiva

Este tipo de secador está compuesto de una bañera termostática de acero inoxidable llena de agua estilada. En la superficie del agua se encuentra una cubierta de plástico (Película de Mylar) que sirve de contacto entre el agua y las rodajas de lúcuma. El agua se encuentra a $95^{\circ} \mathrm{C}$ y la transmisión de calor es a través de la película de Mylar. 
Ventajas:

- Realiza el secado en tiempos más cortos que la tecnología detallada anteriormente

- No influye significativamente en el color de la fruta

- Se logra un secado uniforme

- Es utilizado para alimentos con alta demanda de energía para su secado

Desventajas:

- Producción continua, para el proyecto hemos considerado una producción por lotes

- No es muy utilizada en la elaboración de harina de lúcuma

Figura 5.5

Esquema del secado por Ventana Refractante

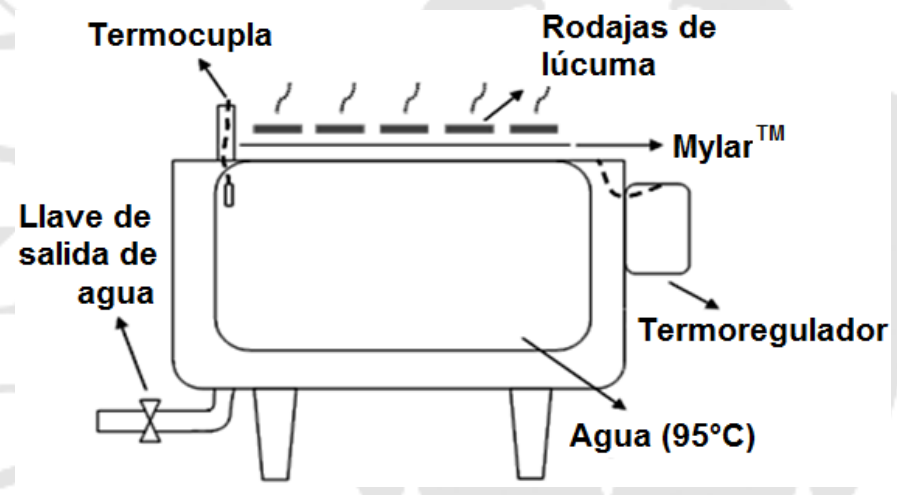

Fuente: Scientia Agropecuaria, (2014)

4. Lecho fluidizado

El proceso bajo lecho fluidizado es un proceso mediante el cual una corriente ascendente de aire caliente suspende desde el fondo de la cámara las rodajas de lúcuma. La lúcuma deshidratada al elevarse por el lateral pasa por una tubería descendente que la dirige a un separador de finos. La máquina de lecho fluidizado (Figura 5.6) tiene las siguientes ventajas y desventajas:

Ventajas

- Acelera el tiempo de deshidratado

- Mantiene constante la temperatura de secado 
Desventajas:

- Alto costo de inversión

- La capacidad de producción es mucho mayor a la requerida

Figura 5.6

Máquina de Lecho fluidizado

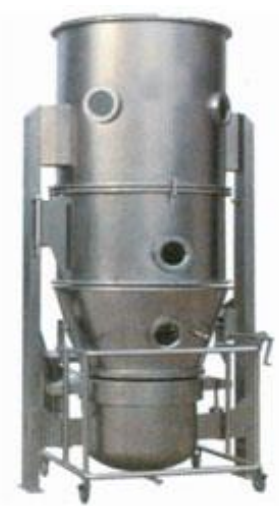

Fuente: Jiangsu Xianfeng Drying Engineering Co., (2015)

5. Secador de tambor

Consiste en un par de tambores que se encuentran girando y que son calentados por dentro mediante vapor. Las rodajas de lúcuma son colocadas sobre la superficie exterior para ser removidas mediante espátulas luego de tres cuartos de revolución. Las ventajas y desventajas del secador de tambor (Figura 5.5) se detallan a continuación:

Ventajas:

- Alta eficiencia de consumo de energía

- Facilidad de operar y mantener

- El producto de la deshidratación cuenta con buena porosidad y por ende buena rehidratación

Desventajas:

- Existe el riesgo de quemar el producto debido al contacto directo con la superficie

- El producto al contener azúcar, es posible que sea difícil de remover

- Se corre el riesgo de que altere la composición del producto 
Figura 5.7

Secador de Tambor

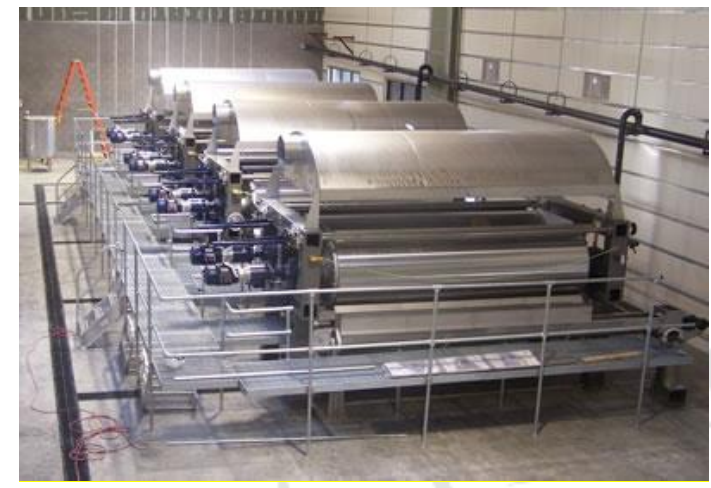

Fuente: Drum Drying Resources LLC, (2015)

\section{$\underline{\text { Molido }}$}

Esta etapa del proceso es crítica ya que debe asegurar que la harina luego pase por un tamiz con una malla de 0,5 $\mathrm{mm}$ (detallado en el punto 5.1). En esta etapa la tecnología existente es la siguiente:

- Molino de rodillos

En este tipo de molino dos cilindros giran en sentido contrario de manera que los sólidos producto del proceso de deshidratado quedan comprimidos lo que causa la reducción del tamaño.

- Molina de disco

Los molinos de disco lo que hacen es reducir el tamaño de las partículas debido a la alta velocidad de rotación de los discos. Es utilizada principalmente para lograr partículas finas en la industria de la harina.

- Molino de martillos

Esta máquina consiste en un rotor que gira en el interior de una carcasa cilíndrica. En el rotor se encuentran una serie de martillos alrededor. La disminución del tamaño de las partículas se da básicamente por el impacto con estos martillos. Son usados principalmente para la obtención de partículas finas. 


\subsubsection{Selección de la tecnología}

Luego de haber analizado las tecnologías existentes para las 2 actividades críticas del proceso de producción para la harina de lúcuma, se elige la que se adecue más al ritmo de producción de nuestro proyecto y a las condiciones del producto final:

Secado

Al diseñar nuestra producción en lotes, se descarta la máquina por ventana refractante, además de ser la de menor disponibilidad en el mercado. Adicionalmente analizando la inversión que realizaríamos al comprar la máquina y el costo en depreciación que tendríamos que asumir, descartamos la máquina de liofilización y la de lecho fluidizado, esta última por tener además una capacidad de producción muy por encima de nuestra demanda de proyecto calculada. Por la particularidad del insumo principal, es decir la lúcuma, también descartamos el secador de Tambor, ya que se corre el riesgo de que no se logre adherir la lúcuma al tambor y esta se caiga volviendo ineficiente el proceso. El secador de bandejas es el que mejor se acopla a nuestro ritmo de producción y el más usado por la mayoría de empresas.

Molido

Para poder obtener una harina que cumpla con los requisitos que hemos descrito en el punto 5.1, debemos contar con un molino que nos permita que la harina pase por una malla de $0.5 \mathrm{~mm}$. Para ello el molino de martillos es el más adecuado para obtener una harina de menos de $0.5 \mathrm{~mm}$ de espesor.

\subsubsection{Proceso de producción}

\subsubsection{Descripción del proceso}

El proceso de producción tiene 2 etapas claramente definidas, siendo la primera etapa la de acondicionamiento de la lúcuma que es en la que se recibe, selecciona, lava y troza. La segunda etapa es en la que se obtiene la lúcuma en rodajas para ser deshidratada, molida y embolsada hasta obtener el producto final que es la harina de lúcuma en bolsas de $10 \mathrm{~kg}$. 


\section{Acondicionamiento de la lúcuma}

\section{$\underline{\text { Recepción }}$}

En esta etapa se reciben y almacenan la materia prima e insumos. La materia prima se almacena momentáneamente hasta estar seguros de que las balanzas (2) y la lavadora de frutas estén disponibles para ser utilizadas. El otro insumo es la lejía, utilizado para el desinfectado de las frutas, y también es almacenado y en un almacén temporal ya que no ocupa mucho espacio y no es utilizado en grandes volúmenes.

\section{$\underline{\text { Selección }}$}

Luego de recibida la fruta esta es ingresada por una faja transportadora en donde 1 operario retira la fruta no apta para el proceso. Verifica que la fruta no presente magulladuras, que no esté en estado de descomposición y que haya alcanzado la madurez completa. Se estima tener una merma no mayor al $0,5 \%$.

\section{$\underline{\text { Pesado }}$}

Luego de la etapa de selección, la lúcuma es pesada por un operario con el fin de determinar la cantidad que ingresará al proceso productivo. También nos ayudará a determinar el rendimiento de nuestro proceso y tomar decisiones en base a los indicadores de producción.

\section{Lavado}

Seguidamente las frutas seleccionadas son lavadas por inmersión y aspersión. Para ello son ingresadas a la lavadora de frutas en la que se sumergen en agua potable (inmersión) a la que previamente se le ha diluido lejía en proporción de 4 gotas de lejía por cada litro de agua. Luego pasan por unas duchas de agua a presión que hace más eficiente el proceso de limpieza. El objetivo de esta actividad es retirar toda la mugre, tierra, hojas, tallos o cualquier objeto extraño que este adherida a la fruta. En esta actividad se pierde un $0,05 \%$ en peso del total de lúcuma lavada.

\section{$\underline{\text { Pelado }}$}

Luego del lavado la fruta limpia se coloca en cajas de madera teniendo cuidado en todo momento para que esta no se chanque o sufra golpes que la dañen. Estas cajas son colocadas en cada estación de trabajo de los operarios (4) para que las pelen. En esta actividad hay una pérdida del $15 \%$ del peso por la cáscara. 


\section{Trozado y deshuesado}

Luego de pelar la lúcuma, esta es cortada en rodajas manualmente verificando que cada rodaja tenga un grosor de entre $0,5 \mathrm{~cm}$ y $0,7 \mathrm{~cm}$ por rodaja. A medida que se va trozando, la lúcuma es deshuesada, asegurando también de no dejar restos de pulpa adheridos a la pepa.

Las rodajas son colocadas en las bandejas de plástico listas para ser ingresadas a la siguiente etapa.

\section{Deshidratado, molido y embolsado}

\section{Deshidratado}

En la actividad de deshidratado se hace uso del secador de bandejas. Las bandejas son colocadas en el interior de la máquina para dar inicio al deshidratado. El secado debe de realizarse por un periodo de 16 horas a una temperatura de $65^{\circ} \mathrm{C}$. (Lavado Soto, 2013). Las bandejas son retiradas e inmediatamente deben pasar a la actividad de molido ya que se corre el riesgo de que absorba la humedad del ambiente si se deja reposar.

\section{$\underline{\text { Molido }}$}

En la actividad de molido la lúcuma deshidratada es retirada de las bandejas con la ayuda de una espátula y es ingresada al molino de martillo, en el cuál se obtendrá el grosor requerido de la lúcuma de $0,5 \mathrm{~mm}$. La harina es tamizada para que cumpla con dicho requisito. La harina de lúcuma resultante pasa inmediatamente a la siguiente actividad de embolsado.

\section{Embolsado y etiquetado}

En esta actividad la harina de lúcuma se empaca en bolsas de $10 \mathrm{~kg}$ y etiquetada de acuerdo al formato de la etiqueta definido en el capítulo 2. Finalmente se colocan en cajas de 5 cajas cada una. 


\subsubsection{Diagrama de proceso: DOP}

Figura 5.8

Diagrama de operaciones del proceso

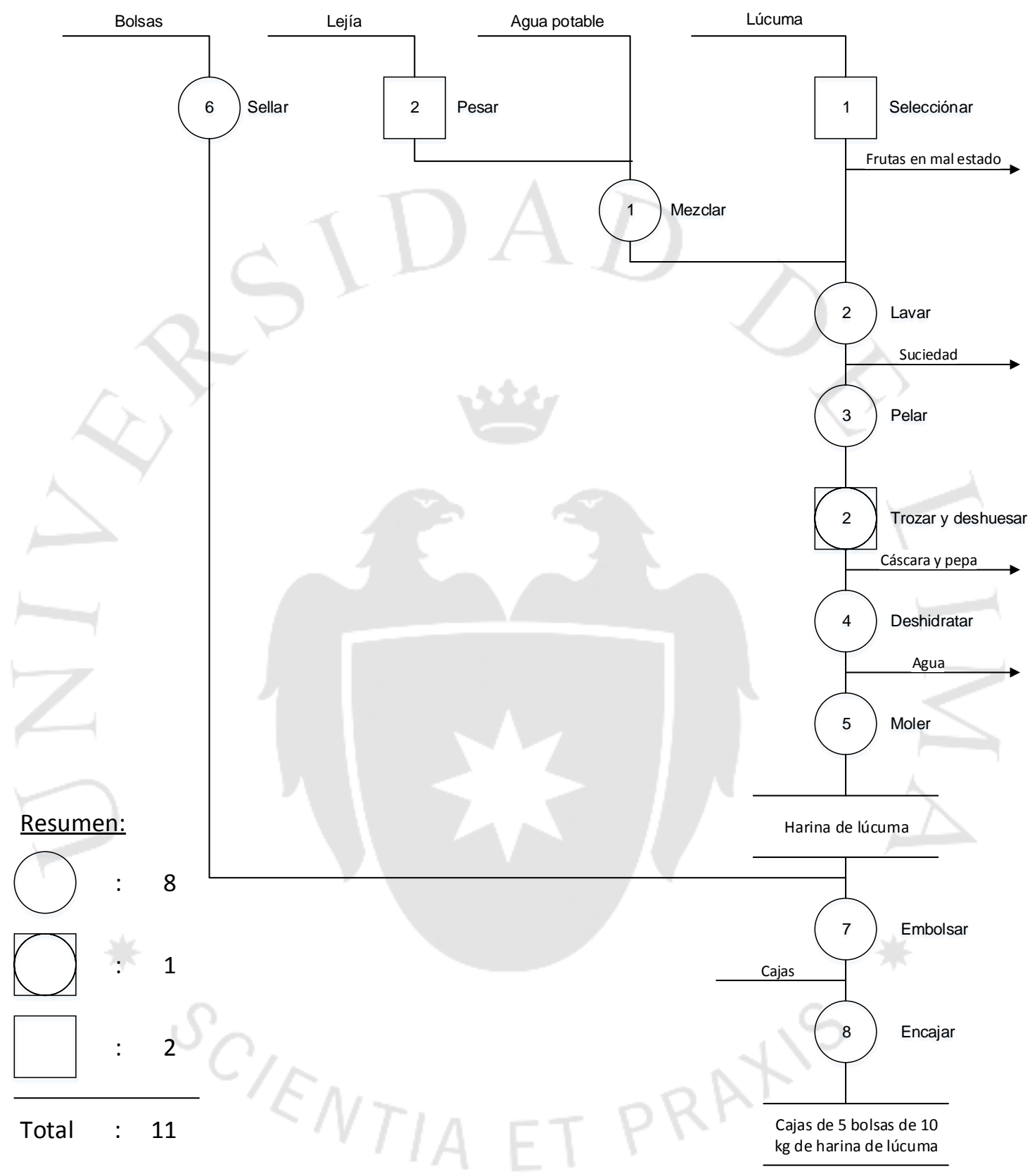

Elaboración propia 


\subsubsection{Balance de materia y energía}

En la Figura 5.9 se detalla el balance de materia para la elaboración de $24.155 \mathrm{~kg}$ de harina de lúcuma, demanda en el año 2025, es decir en el décimo año del proyecto.

Figura 5.9

Balance de materia de la producción de harina de lúcuma

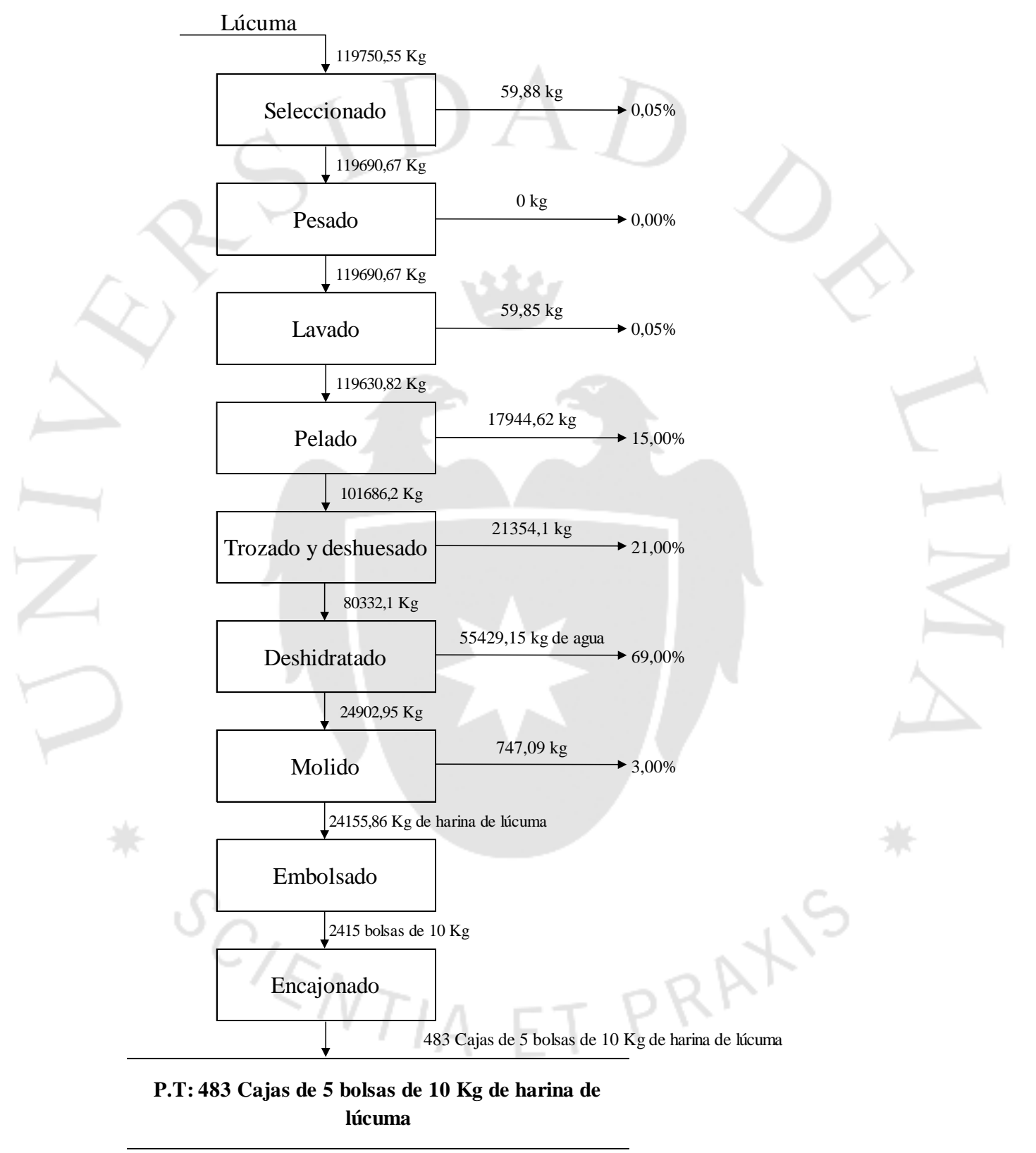

Elaboración propia 


\subsection{Características de las instalaciones y equipos}

\subsubsection{Selección de la maquinaria y equipos}

Para la selección de los equipos a utilizar en el proceso de producción de la harina de lúcuma se ha tomado en cuenta la producción por lotes ya que es la que más se adecua al ritmo de producción requerido para atender el mercado. La lista de equipos a utilizar se detalla en la tabla 5.4.

Tabla 5.4

Maquinaria por actividad

\begin{tabular}{|c|c|}
\hline Actividad & Maquinaria \\
\hline Pesado & Balanza de plataforma \\
\hline Lavado & Lavadora de Frutas \\
\hline Deshidratado & Secador de Bandejas \\
\hline Molido & Molino de martillo \\
\hline Sellado & Selladora \\
\hline Embolsado & Embolsadora \\
\hline
\end{tabular}

Elaboración propia

\subsubsection{Especificaciones de la maquinaria}

A continuación, se presentan las especificaciones de cada máquina a utilizar:

\section{$\underline{\text { Pesado }}$}

Tabla 5.5

Ficha descriptiva de la balanza de plataforma

\begin{tabular}{|c|c|}
\hline Máquina & $\begin{array}{c}\text { Balanza de } \\
\text { plataforma }\end{array}$ \\
\hline Marca & SAGAS \\
\hline Modelo & LS-30 \\
\hline Capacidad $(\mathrm{kg} / \mathrm{h})$ & $900 \mathrm{~kg}$ \\
\hline Potencia $(\mathrm{Kw})$ & 0.05 \\
\hline Largo $(\mathrm{cm})$ & 60 \\
\hline Ancho $(\mathrm{cm})$ & 46 \\
\hline Altura $(\mathrm{cm})$ & 64 \\
\hline
\end{tabular}

Fuente: Sagas, (2015) 


\section{$\underline{\text { Lavado }}$}

Tabla 5.6

Ficha descriptiva de la lavadora de frutas

\begin{tabular}{|c|c|}
\hline Máquina & Lavadora de frutas \\
Marca & CI TALSA \\
\hline Modelo & LIA -1 \\
\hline Capacidad $(\mathrm{kg} / \mathrm{h})$ & 1000 \\
\hline Potencia $(\mathrm{Kw})$ & 1.12 \\
\hline Largo $(\mathrm{cm})$ & 223 \\
\hline Ancho $(\mathrm{cm})$ & 103 \\
\hline Altura $(\mathrm{cm})$ & 174 \\
\hline
\end{tabular}

Fuente: Talsa, (2015)

\section{$\underline{\text { Deshidratado }}$}

Tabla 5.7

Ficha descriptiva del secador de bandejas

\begin{tabular}{|c|c|c|}
\hline Máquina & Secador de bandejas \\
\hline Marca & Vulcano \\
\hline Modelo & G10S \\
\hline Capacidad (kg/h) & 40 \\
\hline Potencia $(\mathrm{Kw})$ & 1.35 \\
\hline Largo $(\mathrm{cm})$ & 355 \\
\hline Ancho $(\mathrm{cm})$ & 97 \\
\hline Altura $(\mathrm{cm})$ & 240 \\
\hline
\end{tabular}

Fuente: Vulcano, (2015) 
$\underline{\text { Molido }}$

Tabla 5.8

Ficha descriptiva del molino de martillos

\begin{tabular}{|c|c|}
\hline Máquina & Molino de martillos \\
\hline Marca & Vulcano \\
\hline Modelo & MV $15-45$ \\
\hline Capacidad $(\mathrm{kg} / \mathrm{h})$ & 65 \\
\hline Potencia $(\mathrm{Kw})$ & 5.6 \\
\hline Largo $(\mathrm{cm})$ & 230 \\
\hline Ancho $(\mathrm{cm})$ & 95 \\
\hline Altura $(\mathrm{cm})$ & 170 \\
\hline
\end{tabular}

Fuente: Vulcano, (2015)

\section{Sellado}

Tabla 5.9

Ficha descriptiva de la selladora

\begin{tabular}{|c|c|c|}
\hline Máquina & Selladora \\
\hline Marca & Neumo Pack \\
\hline Modelo & SellaVac \\
\hline Capacidad $(\mathrm{kg} / \mathrm{h})$ & $36.000(60$ bolsas/min $)$ \\
\hline Potencia $(\mathrm{Kw})$ & 0.8 \\
\hline Largo $(\mathrm{cm})$ & 150 \\
\hline Ancho $(\mathrm{cm})$ & 140 & 180 \\
\hline Altura $(\mathrm{cm})$ & 150 \\
\hline
\end{tabular}

Fuente: Neumo Pack, (2015) 
$\underline{\text { Embolsado }}$

Tabla 5.10

Ficha descriptiva de la embolsadora

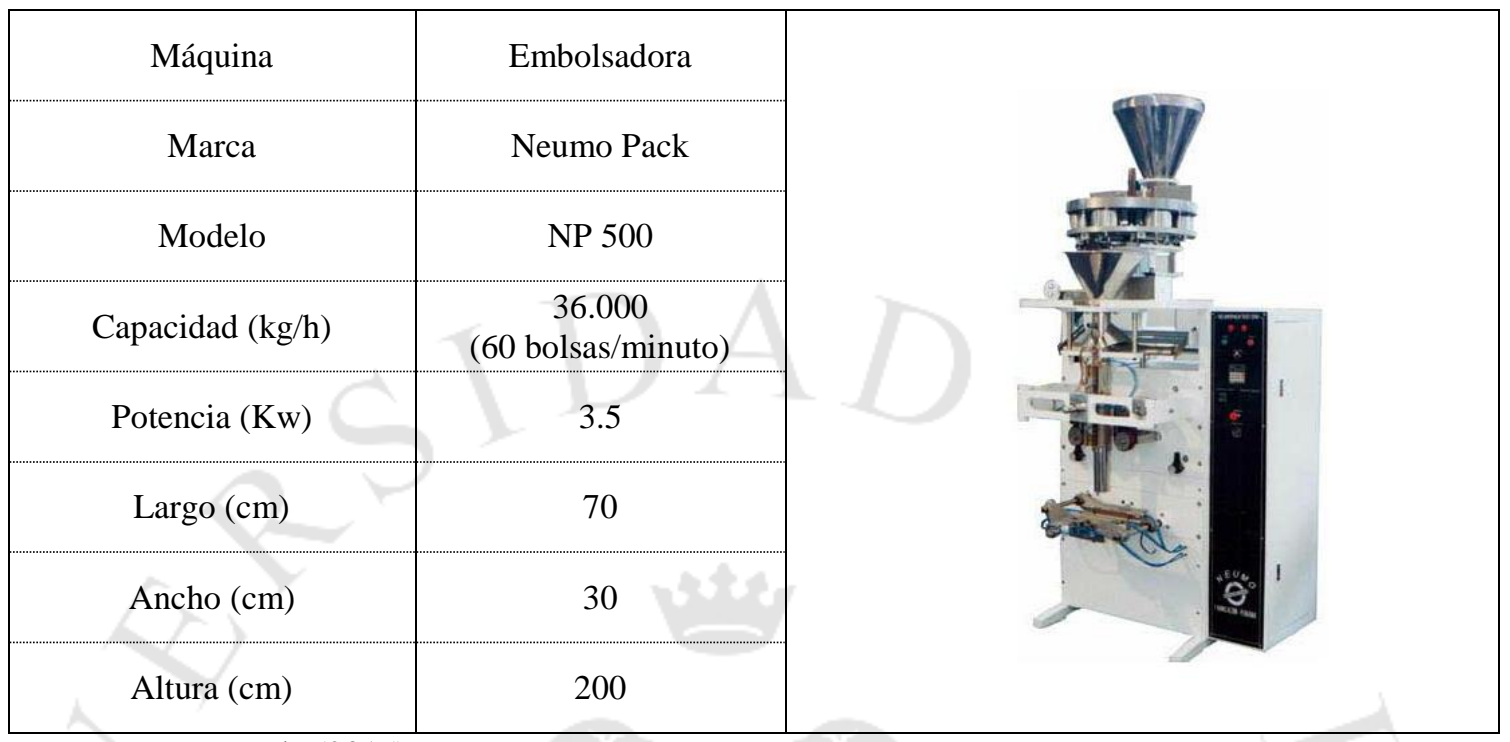

Fuente: Neuma Pack, (2015)

\subsection{Capacidad instalada}

\subsubsection{Cálculo de la capacidad instalada}

El cálculo de la capacidad instalada se determinó a partir de la actividad con menor capacidad de producción (cuello de botella) en términos de producto final (harina de lúcuma). Si bien en el punto 4.3 se determinó el cuello de botella, está no estuvo afecta a estos criterios. Para ello se consideró que la planta estará operativa 8 horas por turno, 1 turno al día, 5 días a la semana y 52 semanas al año. Adicionalmente se tuvieron en cuenta los factores de utilización y eficiencia. El factor de eficiencia se estableció en 1 para los procesos manuales y automáticos. A continuación, se muestra como se calculó el factor de utilización.

- Horario de trabajo: lunes a viernes de 8:00 a.m. a 17:45 p.m. y sábados de 8:00 a.m. a 12:00 p.m. (No se considera 1 hora de refrigerio).

- Necesidades fisiológicas y de descanso: 30 minutos en promedio al día.

- Mantenimiento de maquinaria: 2 horas cada 6 meses.

- Tiempo para la ubicación en el puesto de trabajo: 10 minutos al día. 
Cálculo del factor de utilización:

$U=\frac{8-0.68}{8}=0.91$

En base a esta información y a balance de materia, se muestra en la tabla 5.11 el cálculo de la capacidad de planta por actividad. 


\section{Tabla 5.11}

Cálculo de la capacidad instalada por actividad

\begin{tabular}{|c|c|c|c|c|c|c|c|c|c|c|c|c|c|c|}
\hline & $\mathbf{Q E}$ & & & & $\mathbf{P}$ & T/D & $\mathrm{H} / \mathrm{T}$ & $\mathrm{D} / \mathrm{S}$ & S/A & $\mathbf{U}$ & $\mathbf{E}$ & $M \times P \times T / D \times H / T \times D / S \times S / A \times U \times E$ & $\mathbf{F Q}$ & CP $\times F Q$ \\
\hline Operación & $\begin{array}{c}\text { Cantidad entrante } \\
\text { según balance de } \\
\text { materia }\end{array}$ & Und & $\begin{array}{l}\text { Nro de } \\
\text { máq/ope }\end{array}$ & $\begin{array}{c}\text { Manual / } \\
\text { Mecanizado }\end{array}$ & $\begin{array}{l}\text { Producción } \\
\text { (Und/ hora) }\end{array}$ & $\begin{array}{c}\text { Turnos } \\
\text { / día }\end{array}$ & $\begin{array}{c}\text { Horas } / \\
\text { Turno }\end{array}$ & $\begin{array}{c}\text { Días / } \\
\text { semana }\end{array}$ & $\begin{array}{c}\text { Semana } / \\
\text { Año }\end{array}$ & $\begin{array}{c}\text { Factor de } \\
\text { utilización }\end{array}$ & $\begin{array}{l}\text { Factor de } \\
\text { eficiencia }\end{array}$ & $\begin{array}{l}\text { Capacidad de procesamiento en } \\
\text { unidades de balance de materia }\end{array}$ & $\begin{array}{c}\text { Factor de } \\
\text { conversión }\end{array}$ & $\begin{array}{c}\text { Capacidad de } \\
\text { producción en } \\
\text { unidades de producto } \\
\text { terminado }\end{array}$ \\
\hline Seleccionado & $119.750,55$ & $\mathrm{~kg}$ & 1 & Manual & 80,00 & 1 & 8 & 6 & 52 & 0,91 & 1,00 & $181.708,80$ & 0,0202 & $3.664,51$ \\
\hline Pesado & $119.690,67$ & $\mathrm{~kg}$ & 1 & Mecanizado & 900,00 & 1 & 8 & 6 & 52 & 0,91 & 1,00 & $2.044 .224,00$ & 0,0202 & $41.246,33$ \\
\hline Lavado & $119.690,67$ & $\mathrm{~kg}$ & 1 & Mecanizado & $1.000,00$ & 1 & 8 & 6 & 52 & 0,91 & 1,00 & $2.271 .360,00$ & 0,0202 & $45.829,26$ \\
\hline Pelado & $119.630,82$ & $\mathrm{~kg}$ & 1 & Manual & 26,00 & 2 & 8 & 6 & 52 & 0,91 & 1,00 & $118.110,72$ & 0,0202 & $2.384,31$ \\
\hline Trozado y deshuesado & $101.686,20$ & $\mathrm{~kg}$ & 1 & Manual & 26,00 & 2 & 8 & 6 & 52 & 0,91 & 1,00 & $118.110,72$ & 0,0237 & $2.805,07$ \\
\hline Deshidratado & $80.332,10$ & $\mathrm{~kg}$ & 1 & Mecanizado & 40,00 & 1 & 8 & 6 & 52 & 0,91 & 1,00 & $90.854,40$ & 0,0301 & $2.731,33$ \\
\hline Molido & $24.902,95$ & $\mathrm{~kg}$ & 1 & Mecanizado & 65,00 & 1 & 8 & 6 & 52 & 0,91 & 1,00 & $147.638,40$ & 0,0970 & $14.317,45$ \\
\hline Sellado & 2.415 & bolsa & 1 & Mecanizado & $36.000,00$ & 1 & 8 & 6 & 52 & 0,91 & 1,00 & $81.768 .960,00$ & 1,0000 & $81.768 .960,00$ \\
\hline Embolsado & 2.415 & bolsa & 1 & Mecanizado & $36.000,00$ & 1 & 8 & 6 & 52 & 0,91 & 1,00 & $81.768 .960,00$ & 1,0000 & $81.768 .960,00$ \\
\hline Encajonado & 483 & caja & 1 & Manual & $1.000,00$ & 1 & 8 & 6 & 52 & 0,91 & 1,00 & $2.271 .360,00$ & 5,0000 & $11.356 .800,00$ \\
\hline
\end{tabular}

Elaboración propia

0

$11.356 .800,00$
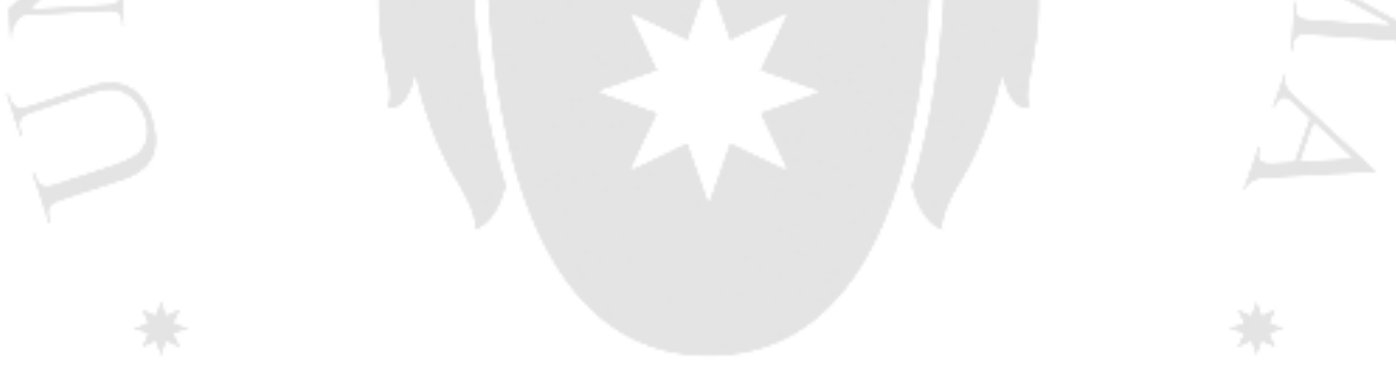
La actividad de pelado es la que tiene la menor capacidad en unidades de producto terminado (bolsas de $10 \mathrm{~kg}$ de harina de lúcuma). Por lo tanto, la capacidad instalada es de $2.384,31$ bolsas/año.

\subsubsection{Cálculo detallado del número de máquinas requeridas}

Para el cálculo detallado del número de máquinas se tomó en cuenta la siguiente fórmula: \# Máquinas $=\frac{\text { Cantidad a procesar } * \text { Tiempo estandar por maquina }}{\text { Utilización } * \text { Eficiencia } * \text { Horas disponibles al año }}$

Se tomará como referencia la necesidad de producción del último año, 2.415 bolsas de harina de lúcuma, ya que es la mayor de todos los años del proyecto. En la tabla 5.12 se muestra el cálculo del número de máquinas necesarias para el proyecto.

Tabla 5.12

Cálculo del número de máquinas

\begin{tabular}{|l|c|c|c|c|c|c|c|c|c|c|}
\hline \multicolumn{1}{|c|}{ Máquina } & $\begin{array}{c}\text { Cantidad } \\
\text { entrante según } \\
\text { balance de } \\
\text { materia }\end{array}$ & Und. & $\begin{array}{c}\text { T. } \\
\text { estándar } \\
\text { (min / } \\
\text { und.) }\end{array}$ & T/D & H/T & D/S & S/A & U & E & $\begin{array}{c}\text { Nro } \\
\text { de } \\
\text { máq. }\end{array}$ \\
\hline Balanza de plataforma & $119.690,67$ & $\mathrm{Kg}$ & 0,067 & 1 & 8 & 6 & 52 & 0,91 & 1 & 1 \\
\hline Lavadora de frutas & $119.690,67$ & $\mathrm{Kg}$ & 0,060 & 1 & 8 & 6 & 52 & 0,91 & 1 & 1 \\
\hline Secador de bandejas & $80.332,10$ & $\mathrm{Kg}$ & 1,500 & 1 & 8 & 6 & 52 & 0,91 & 1 & 1 \\
\hline Molino de martillos & $24.902,95$ & $\mathrm{Kg}$ & 0,923 & 1 & 8 & 6 & 52 & 0,91 & 1 & 1 \\
\hline Selladora & $2.415,00$ & Bolsa & 0,017 & 1 & 8 & 6 & 52 & 0,91 & 1 & 1 \\
\hline Embolsadora & $2.415,00$ & Bolsa & 0,017 & 1 & 8 & 6 & 52 & 0,91 & 1 & 1 \\
\hline
\end{tabular}

Elaboración propia

\subsection{Resguardo de la calidad y/o inocuidad del producto}

Parte fundamental del proyecto es brindar un producto con los más altos estándares de calidad y competir con otras empresas ya posicionadas que comercializan el mismo producto en el exterior. Para ello se aplicará un sistema se aseguramiento de calidad, enfocándonos en los proveedores, en la recepción de la materia prima el proceso del producto, su almacenamiento y distribución. 


\subsubsection{Calidad de la materia prima, de los insumos, del proceso y del producto}

Para determinar calidad óptima de nuestro producto se tienen en consideración varios grupos de características:

- Calidad sensorial

- Calidad fisiológica- nutritiva

- Calidad higiénica

- Calidad en el uso

Las características principales por cada uno de estos grupos se encuentras en la tabla 5.13 .

Tabla 5.13

Características de la harina de lúcuma

\begin{tabular}{|l|cl|}
\hline \multicolumn{1}{|c|}{ Grupo de Características } & \multicolumn{1}{c|}{ Características } \\
\hline Calidad sensorial & $\bullet$ & Color \\
& $\bullet$ & Aroma \\
Calidad fisiológica- nutritiva & $\bullet$ & Tamaño de partícula \\
\hline Calidad higiénica & $\bullet$ & Contenido de nutrientes \\
\hline Calidad en el uso & $\bullet$ & Cuerpos extraños \\
& $\bullet$ & Gérmenes y microbios \\
\hline
\end{tabular}

Elaboración propia

A efectos de nuestro proyecto se han determinado 2 grupos de características como los más críticos. Uno de ellos es la calidad sensorial puesto que el color y el aroma son percibidos por el consumidor fácilmente. El segundo grupo más importante es la calidad higiénica, puesto que, para todo producto dirigido al consumo humano, se debe eliminar cualquier cuerpo extraño, gérmenes y microbios.

A continuación, se detallarán los controles a tomar en cuenta para asegurar la calidad de materia prima, de los insumos y del producto final de acuerdo a las Buenas Prácticas de Manufactura.

Se puede mencionar algunas de estas:

- La lúcuma deberá estar entera, y preferentemente manteniendo la base del pedúnculo que siempre va adherida al cáliz; de contar con el pedúnculo, este no deberá ser mayor a $5 \mathrm{~mm}$. 
- La lúcuma deberá estar sana, se excluirán los productos afectados por podredumbre, moho o deterioro que hagan que no sean aptos para el consumo.

- Lúcuma limpia, y prácticamente exenta de cualquier materia extraña visible, prácticamente exenta de plagas, y daños causados por ellas, que afecten el aspecto general del producto.

- Lúcuma exenta de humedad externa anormal, salvo la condensación consiguiente a su remoción de una cámara frigorífica.

- Lúcuma exenta de cualquier olor y/o sabor extraño; así como, exenta de daños causados por bajas y/o altas temperatura.

- La lúcuma será adquirida en la provincia de Huaral, y mediante proveedores que aseguren que cuentan con una lúcuma orgánica, cultivada con productos naturales y que no utilizan pesticidas que sean perjudiciales a la salud.

- El almacenamiento de la materia prima y el producto terminado será en lugares limpios, libre de humedad y a una temperatura ambiente.

- Se tomarán muestras aleatoriamente del producto final, con el fin de asegurar que cuenten con una humedad no mayor a $7,5 \%$ y con un grosor no mayor a $0,5 \mathrm{~mm}$.

\subsubsection{Estrategias de mejora}

En el proceso de producción de la harina de lúcuma, se aplicará el Análisis de peligros y puntos críticos de control (HACCP), el cual nos ayuda a prevenir posibles contaminaciones. En este proceso se identifican los posibles riesgos de contaminación de los productos a lo largo de la cadena productiva. El objetivo principal es tomar medidas preventivas. En la figura 5.10 presentamos los pasos para la implementación de un HACCP. 
Figura 5.10

Pasos para la implementación de HACCP

Determinación de los puntos críticos de control

Establecimiento de los límites críticos para cada punto crítico de control

Establecimiento de un sistema de vigilancia para cada punto crítico de control

Establecimiento de medidas correctivas para las posibles desviaciones

Establecimiento de procedimientos de verificación

Establecimiento de un sistema de registro y documentación

Fuente: Moltimore S y Walace C, (2004)

Para la determinación de los puntos críticos de control se debe tener en cuenta la materia prima, el proceso de producción, la maquinaria, los envases, el almacenamiento y distribución.

Para la definición de los límites críticos se debe establecer para cada punto crítico de control un límite permisible. Estos límites tienen que ser medibles. Además si se supera los límites establecidos puede resultar el producto peligroso para el consumidor.

En el caso de los sistemas de vigilancia, estos sirven para verificar que el proceso se realice bajo las condiciones indicadas.

En el caso de que se detecte un punto crítico de control fuera de los rangos permitidos se debe tomar acciones correctivas; es decir, lograr que el proceso retome su estado normal bajo condiciones seguras.

Finalmente, para mantener y analizar los resultados a través del tiempo todo procedimiento debe estar documentado. En la tabla 5.14 se describen los factores más importantes a considerar para asegurar la calidad de la harina de lúcuma y en la tabla 5.15 se analizan los peligros por cada actividad del proceso. 
Tabla 5.14

Descripción del producto y uso presunto

\begin{tabular}{|c|c|}
\hline Nombre & Harina de lúcuma \\
\hline Composición & Lúcuma \\
\hline Características sensoriales & $\begin{array}{l}\text { - Color: Amarillo/ Anaranjado pálido } \\
\text { - Aroma: agradable y característico de la } \\
\text { fruta } \\
\text { - Tamaño de partícula: Debe pasar por una } \\
\text { malla de } 0,5 \mathrm{~mm} \text {. }\end{array}$ \\
\hline Características físico químicas & $\begin{array}{ll}\text { - } & \text { Humedad: máx. } 7,5 \% \\
\text { - } & \text { Solubilidad: Aprox. } 60 \%\end{array}$ \\
\hline Forma de uso de consumidores potenciales & Mezclar con agua en relación de 50/50 \\
\hline Empaque etiquetado y presentaciones & $\begin{array}{l}\text { Bolsa de polietileno de } 10 \text { kilos en cajas de } 5 \\
\text { bolsas. }\end{array}$ \\
\hline Vida útil esperada & 2 años sin abrir. \\
\hline Condiciones de manejo y conservación & Conservar en lugar seco \\
\hline
\end{tabular}

Elaboración propia 
Tabla 5.15

Análisis de los peligros en las etapas del proceso para la elaboración de harina de lúcuma

\begin{tabular}{|c|c|c|c|c|c|}
\hline $\begin{array}{l}\text { Etapa de } \\
\text { proceso }\end{array}$ & Peligros & $\begin{array}{l}\text { ¿El peligro es } \\
\text { significativo? }\end{array}$ & $\begin{array}{l}\text { Justifique su } \\
\text { decisión }\end{array}$ & $\begin{array}{l}\text { ¿Qué medidas } \\
\text { preventivas } \\
\text { pueden ser } \\
\text { aplicadas? }\end{array}$ & $\begin{array}{c}\text { ¿Es esta } \\
\text { etapa un } \\
\text { PCC? } \\
\text { (SÍ/NO) }\end{array}$ \\
\hline Selección & $\begin{array}{l}\text { BIOLÓGICO } \\
\text {-Crecimiento } \\
\text { bacteriano } \\
\text {-Descomposición }\end{array}$ & $\mathrm{NO}$ & $\begin{array}{l}\text {-Frutas que } \\
\text { pueden } \\
\text { contaminarse } \\
\text { a través de } \\
\text { gérmenes del } \\
\text { suelo } \\
\text {-Productos } \\
\text { químicos }\end{array}$ & $\begin{array}{l}\text { - Lavar y } \\
\text { desinfectar antes } \\
\text { de ser usadas } \\
\text { - Usar frutas de } \\
\text { cultivo seguro }\end{array}$ & $\mathrm{NO}$ \\
\hline Pesado & $\begin{array}{l}\text { FÍSICO } \\
\text { - Contaminación } \\
\text { por balanza con } \\
\text { suciedad u } \\
\text { oxidada }\end{array}$ & $\mathrm{NO}$ & $\begin{array}{l}\text {-Las frutas } \\
\text { son lavadas } \\
\text { inmediatame } \\
\text { nte luego del } \\
\text { pesado. }\end{array}$ & $\begin{array}{l}\text { - Brindar } \\
\text { mantenimiento } \\
\text { preventivo a la } \\
\text { balanza de } \\
\text { plataforma }\end{array}$ & $\mathrm{O}$ \\
\hline Lavado & $\begin{array}{l}\text { BIOLÓGICO } \\
\text {-Contaminación } \\
\text { microbiológica }\end{array}$ & $\mathrm{NO}$ & $\begin{array}{l}\text {-Agua de } \\
\text { calidad } \\
\text { sanitaria } \\
\text { adecuada }\end{array}$ & $\begin{array}{l}\text { - Buenas prácticas } \\
\text { de manufactura } \\
\text { - Lavado de fruta } \\
\text { con lejía }\end{array}$ & $\mathrm{NO}$ \\
\hline Pelado & $\begin{array}{l}\text { BIOLÓGICO } \\
\text { Descomposición } \\
\text { FÍSICO } \\
\text { Pedazos de metal } \\
\text { en la fruta por } \\
\text { cuchillo }\end{array}$ & $\mathrm{NO}$ & $\begin{array}{l}\text {-El proceso es } \\
\text { rápido }\end{array}$ & $\begin{array}{l}\text { - Buenas prácticas } \\
\text { de manufactura }\end{array}$ & $\mathrm{NO}$ \\
\hline $\begin{array}{l}\text { Trozado y } \\
\text { deshuesado }\end{array}$ & $\begin{array}{l}\text { BIOLÓGICO } \\
\text {-Contaminación } \\
\text { por cuerpos } \\
\text { extraños }\end{array}$ & SI & $\begin{array}{l}\text { - Frutas que } \\
\text { pueden } \\
\text { contaminarse }\end{array}$ & $\begin{array}{l}\text { - Buenas prácticas } \\
\text { de manufactura }\end{array}$ & SI \\
\hline Secado & $\begin{array}{l}\text { BIOLÓGICO } \\
\text { - Contaminación } \\
\text { de Salmonella } \\
\text { debido a un } \\
\text { secado } \\
\underline{\text { ineficiente }}\end{array}$ & SI & $\begin{array}{l}\text { - Control de } \\
\text { humedad y } \\
\text { temperatura } \\
\text { en la } \\
\text { máquina } \\
\text { deshidratador } \\
\text { a }\end{array}$ & $\begin{array}{l}\text { - Vigilancia } \\
\text { constante de } \\
\text { temperatura y } \\
\text { humedad }\end{array}$ & SI \\
\hline Envasado & $\begin{array}{l}\text { BIOLÓGICO } \\
\text {-Re } \\
\text { contaminación } \\
\text { de organismos } \\
\text { patógenos }\end{array}$ & SI & $\begin{array}{l}\text {-No existe } \\
\text { una } \\
\text { aplicación } \\
\text { adecuada } \\
\text { limpieza }\end{array}$ & $\begin{array}{l}\text { - Lavado y } \\
\text { desinfección de } \\
\text { envases ; cerrado } \\
\text { hermético en } \\
\text { caliente }\end{array}$ & $\mathrm{NO}$ \\
\hline $\begin{array}{c}\text { Almacenami } \\
\text { ento }\end{array}$ & $\begin{array}{l}\text { BIOLÓGICO } \\
\text {-Aumento de } \\
\text { microorganismos } \\
\text { patógenos }\end{array}$ & $\mathrm{NO}$ & $\begin{array}{l}\text { Podría haber } \\
\text { un descuido } \\
\text { en limpieza e } \\
\text { higiene }\end{array}$ & $\begin{array}{l}\text { - Uso de } \\
\text { temperatura } \\
\text { adecuada }\end{array}$ & $\mathrm{NO}$ \\
\hline
\end{tabular}

Elaboración propia 


\subsection{Estudio de Impacto Ambiental}

La contaminación es un tema que actualmente ha cobrado un gran interés no solo por los afectados, sino por las empresas y el estado. Para establecer el grado de impacto ambiental del proyecto en cada uno de los factores se aplicará la Matriz de Leopold.

La matriz de Leopold consiste en la relación de acciones de nuestro proyecto que puedan ocasionar impactos o alteraciones en el medio económico, social e institucional. La matriz consiste en lo siguiente:

- Estimación de la magnitud del impacto, en una escala de 1 a 9, siendo el signo (+) un impacto positivo y el signo (-) un impacto negativo.

- Identificación de las acciones del proyecto que intervienen y de los componentes del medio ambiental afectado.

En la tabla 5.16 se mostrara la matriz que nos permitió analizar los impactos ambientales que generara cada proceso y que impactos ambientales son los más significativos. 
Tabla 5.16

Matriz de Leopold

\begin{tabular}{|c|c|c|c|c|c|c|c|c|c|c|c|c|c|c|c|c|c|c|c|c|c|c|}
\hline \multirow{2}{*}{ 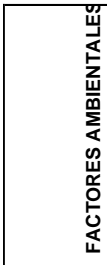 } & \multirow{2}{*}{ 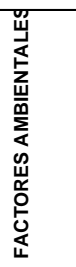 } & \multirow[b]{2}{*}{ № } & \multirow[b]{2}{*}{$\begin{array}{l}\text { ELEMENTOS AMBIENTALES / } \\
\text { IMPACTOS }\end{array}$} & \multicolumn{8}{|c|}{ ETAPAS DEL PROCESO } & \\
\hline & & & & 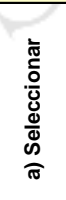 & 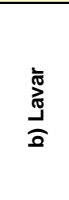 & $\begin{array}{l}\frac{\frac{1}{0}}{0} \\
\frac{0}{0}\end{array}$ & 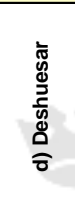 & 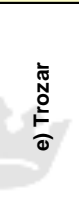 & 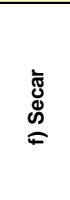 & $\frac{\bar{\omega}}{\sum_{0}^{\circ}}$ & 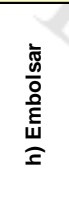 & & & & & & & & & & & \\
\hline \multirow{15}{*}{$\underset{\frac{\vec{L}}{m}}{\frac{\vec{L}}{m}}$} & \multirow{11}{*}{ 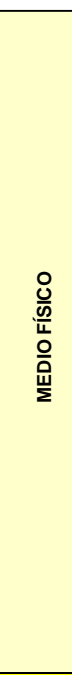 } & A & \multicolumn{9}{|l|}{ AIRE } & & m & $d$ & e & s & Total & & m & \begin{tabular}{l|l|l}
$\mathrm{d}$ & $\mathrm{e}$ \\
\end{tabular} & s & Total \\
\hline & & A.1 & $\begin{array}{l}\begin{array}{l}\text { Contaminación del aire por emisiones } \\
\text { de combustión }\end{array} \\
\end{array}$ & & & & $\Rightarrow$ & & & & & A.2/f & 3 & 4 & 3 & 0,9 & 0,59 & A.3/g & 3 & \begin{tabular}{l|l|l}
4 & 2 \\
\end{tabular} & 0,85 & 0,51 \\
\hline & & A.2 & $\begin{array}{l}\text { Contaminación del aire debido a la } \\
\text { emisión de vapor de agua }\end{array}$ & & & $\mathrm{z}$ & & & $-0,59$ & 要 & & A.3/b & 3 & 4 & 2 & 0,85 & 0,51 & & & & & \\
\hline & & A. 3 & $\begin{array}{l}\begin{array}{l}\text { Ruido generado por las máquinas } \\
\text { (contaminación sonora) }\end{array} \\
\end{array}$ & & $-0,51$ & & & $-0,51$ & & $-0,51$ & & A.2/e & 3 & 4 & 2 & 0,85 & 0,51 & & & & & \\
\hline & & AG & \multicolumn{9}{|l|}{ AGUA } & & & & & & & & & & & \\
\hline & & AG1 & Contaminación de aguas superficiales & & & & & & & & & & & & & & & & & & & \\
\hline & & AG2 & Contaminación de aguas subterráneas & & $-0,72$ & & & & & & & \multirow[t]{2}{*}{$A G 2 / b$} & 4 & 4 & 4 & 0,9 & 0,72 & & & & & \\
\hline & & s & \multicolumn{9}{|l|}{ SUELO } & & & & & & 0 & & & & & \\
\hline & & s1 & $\begin{array}{l}\text { Contaminación por residuos de } \\
\text { materiales, embalajes }\end{array}$ & $-0,60$ & & $-0,60$ & $-0,60$ & & & & $-0,57$ & s1/a & 3 & 4 & 4 & 0,85 & 0,60 & s1/h & 2 & \begin{tabular}{l|l|l}
4 & 4 \\
\end{tabular} & 0,95 & 0,57 \\
\hline & & s2 & Contaminación por vertido de efluentes & & $-0,67$ & & 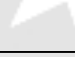 & & & & & $\mathrm{s} 1 / \mathrm{c}$ & 3 & 4 & 4 & 0,85 & 0,60 & s2/b & 3 & \begin{tabular}{l|l|}
4 & 4 \\
\end{tabular} & 0,95 & 0,67 \\
\hline & & s3 & \begin{tabular}{|l} 
Contaminación por residuos \\
peligrosos: trapos con grasa, aceites \\
residuales
\end{tabular} & & $P$ & & & & & 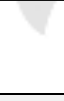 & & s1/d & 3 & 4 & 4 & 0,85 & 0,60 & & & & & \\
\hline & \multirow{4}{*}{ 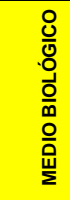 } & RL & \multicolumn{9}{|l|}{ FLORA } & & & & & & & & & & & \\
\hline & & FL1 & Eliminación de la cobertura vegetal & & & & & & & & & & & & & & & & & & & \\
\hline & & FA & \multicolumn{9}{|l|}{ FAUNA } & & & & & & & & & & & \\
\hline & & FA1 & Alteración del hábitat de la fauna & & & & & & & & 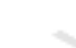 & & & & & & & & & & & \\
\hline
\end{tabular}




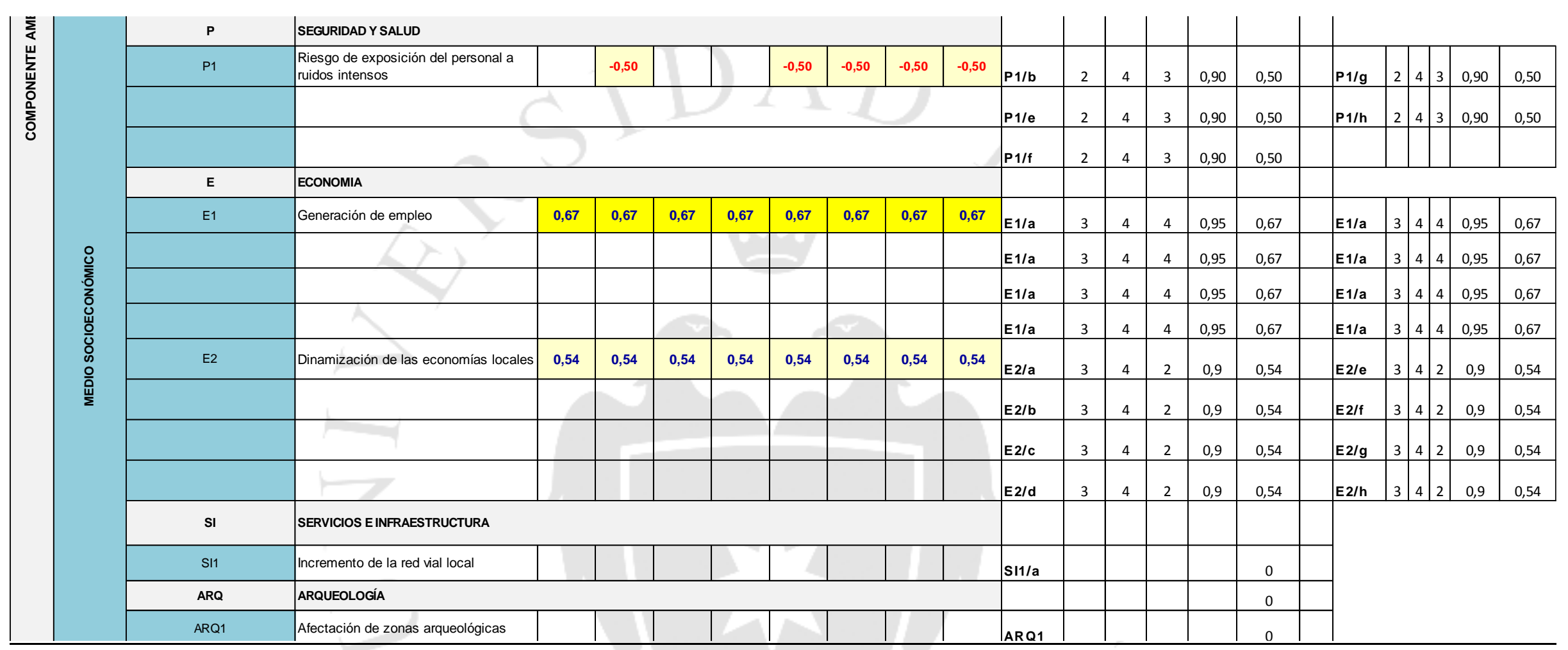

Elaboración propia 
Tabla 5.17

Cuadro de valoración

\begin{tabular}{|c|c|}
\hline Significancia & Valoración \\
\hline Muy poco significativo (1) & $0,10<0,39$ \\
\hline Poco significativo (2) & $0,40<0,49$ \\
\hline Moderadamente significativo (3) & $0,50<0,59$ \\
\hline Muy significativo (4) & $0,60<0,69$ \\
\hline Altamente significativo (5) & $0,7-1,0$ \\
\hline
\end{tabular}

Elaboración propia

Tabla 5.18

Cuadro de rangos

\begin{tabular}{|c|c|c|c|c|c|}
\hline Rangos & Magnitud (m) & Duración (d) & Extensión (e) & \multicolumn{2}{|c|}{ Sensibilidad } \\
\hline \multirow{2}{*}{1} & Muy pequeña & Días & Puntual & \multirow{2}{*}{0,8} & \multirow{2}{*}{ Nula } \\
\hline & Casi imperceptible & 1-7 días & En un punto del proyecto & & \\
\hline \multirow{2}{*}{2} & Pequeña & Semanas & Local & \multirow{2}{*}{0,85} & \multirow{2}{*}{ Baja } \\
\hline & Leve alteración & 1- 4 semanas & En una sección del proyecto & & \\
\hline \multirow{2}{*}{3} & Mediana & Meses & Área del proyecto & \multirow{2}{*}{0,9} & \multirow{2}{*}{ Media } \\
\hline & Moderada alteración & $1-12$ meses & En área del proyecto & & \\
\hline \multirow[b]{2}{*}{4} & Alta & Años & Más allá del proyecto & \multirow[b]{2}{*}{0,95} & \multirow[b]{2}{*}{ Alta } \\
\hline & $\begin{array}{c}\text { Se produce } \\
\text { modificación }\end{array}$ & $1-10$ años & Dentro del área de influencia & & \\
\hline \multirow[b]{2}{*}{5} & Muy alta & Permanente & Distrital & \multirow[b]{2}{*}{1} & \multirow[b]{2}{*}{ Extrema } \\
\hline & $\begin{array}{c}\text { Modificación } \\
\text { sustancial }\end{array}$ & Más de 10 años & Fuera del área de influencia & & \\
\hline
\end{tabular}

Elaboración propia

De la matriz realizada se puede concluir que los impactos ambientales que se deben tratar y prevenir son los siguientes: Contaminación del aire debido a la emisión de vapor de agua, Ruido generado por las máquinas (contaminación sonora), Contaminación de aguas subterráneas, Contaminación por residuos de materiales, embalajes, Contaminación por vertido de efluentes y Riesgo de exposición del personal a ruidos intensos.

La contaminación del aire por emisión de vapor de agua se da en el proceso de secado. En esta operación se desprende vapor de agua producto del secado de la pulpa de la lúcuma. Esto se puede prevenir teniendo un área con constante ventilación. El siguiente impacto ambiental, la contaminación sonora, se da en los procesos de lavado, trozado y molido. Este impacto no se considera tan perjudicial ya que las maquinas a utilizar no superan los 85 decibeles.

La contaminación de las aguas subterráneas y por vertido de efluentes se da básicamente por el desecho que se produce en la operación de lavado. Para esto se deberá 
contar con un plan de tratamiento de efluentes. Esto nos beneficiara ya que se podrá rehusar el agua tratada disminuyendo nuestros costos operativos y energéticos. Mediante empresas dedicadas al tratamiento de efluentes industriales como UNITEK SA podremos clarificar y desinfectar el agua que ya haya sido utilizada y utilizarla en la operación de lavado y para el riego de áreas verdes.

Para contrarrestar la contaminación por residuos de materiales y embalajes, la empresa contara con tachos de colores en los que se podrá separar los distintos tipos de desechos que se produzcan. En el proceso de recepción de la materia prima se separar los residuos de plástico y cartón. En el proceso de pelado y deshuesado se separan los desechos orgánicos para que estos sean desechados por separado. En el proceso de embolsado también se tratara los productos rechazados teniendo cuidado que los desechos orgánicos no vayan junto con el plástico.

\subsection{Seguridad y Salud ocupacional}

Para este estudio un tema importante es garantizar la seguridad dentro y fuera de las instalaciones, al manipular una máquina o al realizar algún proceso.

Nuestra empresa, respecto a la seguridad y salud ocupacional, estará comprometida a que se cumpla el reglamento de seguridad y salud en el trabajo. El reglamento que se debe cumplir es el Decreto Supremo $N^{\circ}$ 005-2012 TR en conjunto con la Ley 29783, Ley de Seguridad y Salud en el trabajo. Este reglamento tiene como objetivo promover una cultura de prevención de riesgos laborales en el país. Establece la implementación de un Sistema de gestión de salud y seguridad en el trabajo (SGSST) y un reglamento interno de seguridad y salud en el trabajo (RISST); siendo el Ministerio de trabajo y promoción de empleo el que se encargue de fiscalizar.

Se elaboraran charlas de capacitaciones en donde se les explicara a los operarios sobre la señalización y el uso de los equipos de protección personal.

Adicional a ello, hemos identificado los peligros que hay dentro de la planta, así como también sus respectivos riesgos, consecuencias y la medida de solución (Tabla 5.19). 
Tabla 5.19

Análisis de los peligros y riesgos en planta

\begin{tabular}{|c|c|c|c|c|}
\hline Operación & Peligro & Riesgo & Pérdida & Solución \\
\hline Seleccionar & $\begin{array}{c}\text { Mala } \\
\text { manipulación }\end{array}$ & $\begin{array}{l}\text { Intoxicación } \\
\text { del operario }\end{array}$ & $\begin{array}{l}\text { Ausencia del } \\
\text { operario }\end{array}$ & $\begin{array}{l}\text { Brindar capacitaciones sobre el } \\
\text { riesgo que se corre si no se usa } \\
\text { el equipo de protección especial } \\
\text { como mascarilla }\end{array}$ \\
\hline \multirow{2}{*}{ Lavar } & \multirow{2}{*}{$\begin{array}{l}\text { Mal manejo de } \\
\text { maquinaria }\end{array}$} & Corto circuito & \multirow{2}{*}{$\begin{array}{l}\text { Materiales y } \\
\text { humanas }\end{array}$} & \multirow{2}{*}{$\begin{array}{l}\text { Mantener aislados los circuitos } \\
\text { eléctricos }\end{array}$} \\
\hline & & Incendio & & \\
\hline Pelar & $\begin{array}{l}\text { No poner atención } \\
\text { al momento de } \\
\text { realizar el pelado }\end{array}$ & Corte & $\begin{array}{l}\text { Ausencia del } \\
\text { operario }\end{array}$ & $\begin{array}{l}\text { Brindar capacitaciones sobre el } \\
\text { correcto modo de realizar el } \\
\text { pelado }\end{array}$ \\
\hline Deshuesado & $\begin{array}{l}\text { No seguir las } \\
\text { prácticas de } \\
\text { manufacturas }\end{array}$ & Corte & $\begin{array}{l}\text { Ausencia del } \\
\text { operario }\end{array}$ & $\begin{array}{l}\text { Brindar capacitaciones sobre el } \\
\text { correcto modo de realizar el } \\
\text { deshuesado }\end{array}$ \\
\hline \multirow[t]{3}{*}{ Trozar } & $\begin{array}{l}\text { Mal manejo de } \\
\text { maquinaria }\end{array}$ & Atrapamiento & $\begin{array}{l}\text { Perdida de la } \\
\text { mano o dedo }\end{array}$ & $\begin{array}{l}\text { Poner guardas a las máquinas } \\
\text { para que el operario no pueda } \\
\text { introducir la mano }\end{array}$ \\
\hline & \multirow{2}{*}{$\begin{array}{l}\text { Mal manejo de } \\
\text { maquinaria }\end{array}$} & Quemadura & $\begin{array}{l}\text { Ausencia del } \\
\text { operario }\end{array}$ & \multirow{2}{*}{$\begin{array}{l}\text { Brindar capacitaciones sobre el } \\
\text { correcto uso de la maquina } \\
\text { secadora }\end{array}$} \\
\hline & & Corto circuito & $\begin{array}{l}\text { Materiales y } \\
\text { humanas }\end{array}$ & \\
\hline \multirow{2}{*}{ Moler } & \multirow{2}{*}{$\begin{array}{l}\text { Mal manejo de } \\
\text { maquinaria }\end{array}$} & \multirow{2}{*}{ Atrapamiento } & \multirow{2}{*}{$\begin{array}{l}\text { Perdida de la } \\
\text { mano o dedo }\end{array}$} & $\begin{array}{l}\text { Brindar capacitaciones sobre el } \\
\text { correcto uso de la máquina } \\
\text { moledora }\end{array}$ \\
\hline & & & & $\begin{array}{l}\text { Poner guardas a las máquinas } \\
\text { para que el operario no pueda } \\
\text { introducir la mano }\end{array}$ \\
\hline \multirow{2}{*}{ Embolsar } & \multirow{2}{*}{$\begin{array}{l}\text { Mal manejo de } \\
\text { maquinaria }\end{array}$} & \multirow{2}{*}{ Atrapamiento } & \multirow{2}{*}{$\begin{array}{l}\text { Ausencia del } \\
\text { operario }\end{array}$} & $\begin{array}{l}\text { Brindar capacitaciones sobre el } \\
\text { correcto uso de la máquina } \\
\text { embolsadora. }\end{array}$ \\
\hline & & & & $\begin{array}{l}\text { Poner guardas a las máquinas } \\
\text { para que el operario no pueda } \\
\text { introducir la mano }\end{array}$ \\
\hline Encajar & $\begin{array}{l}\text { Mal postura al } \\
\text { momento de } \\
\text { cargar las cajas }\end{array}$ & Lumbalgia & $\begin{array}{l}\text { Ausencia del } \\
\text { operario }\end{array}$ & $\begin{array}{l}\text { Brindar capacitaciones sobre la } \\
\text { correcta forma de cargar objetos } \\
\text { pesados }\end{array}$ \\
\hline
\end{tabular}

Elaboración propia

En la capacitación se les dará la siguiente información a los operarios:

- Riesgos potenciales para la salud

- Precauciones para prevenir la exposición

- Disposiciones en materia de higiene

- Utilización y empleo de equipos de protección personal

- Medidas a adoptar en caso de incidentes y su prevención

De forma general, para prevenir todos estos riesgos, se debe considerar lo siguiente:

- Establecer un reglamento de seguridad y salud ocupacional en el trabajo 
- Contar con un plano que muestre al detalle el flujo de producción, para así tener la información suficiente de todos los procesos.

- Contar con botiquines en toda la empresa.

Al ser el producto, harina de lúcuma, un producto comestible, se hará especial énfasis en la inocuidad y la seguridad al momento de manipular la fruta y la harina después del secado. También se dispondrá de 4 extinguidores en la planta, ubicados estratégicamente, verificando periódicamente la fecha de vencimiento y la presión. También se les capacitara a los operarios en el uso de los extinguidores en caso ocurra un incendio.

\subsection{Sistema de mantenimiento}

En una empresa, el mantenimiento de las máquinas es de gran importancia para la disponibilidad de las máquinas y equipos. Esto ayudará a proporcionar mayor calidad y productividad a la empresa.

Para el mantenimiento de las máquinas a utilizar en el proceso se aplicará un mantenimiento preventivo. En el proceso participarán los operarios, debidamente capacitados. Además se contará con manuales de uso de las máquinas, que estarán disponibles en el área de producción.

En el caso de que se presente alguna falla en la maquina aun habiendo realizado el mantenimiento preventivo, se realizará un mantenimiento correctivo

A continuación se muestra el cuadro de mantenimiento de máquinas.

Tabla 5.20

Cronograma de mantenimiento

\begin{tabular}{|l|c|c|c|}
\hline \multicolumn{1}{|c|}{ Máquina } & Tipo de mantenimiento & Veces por semestre & Responsable \\
\hline Lavadora de frutas & Preventivo & 3 & Jefe de producción \\
\hline Deshidratador & Preventivo & 2 & Jefe de producción \\
\hline Tornillo transportador & Preventivo & 2 & Jefe de producción \\
\hline Molino & Preventivo & 3 & Jefe de producción \\
\hline Envasadora & Preventivo & 2 & Jefe de producción \\
\hline
\end{tabular}

Elaboración propia 


\subsection{Programa de producción}

\subsubsection{Factores para la programación de la producción}

Para estructurar el adecuado programa de producción se deberá realizar las estimaciones de la demanda, las cuales determinarán las políticas de inventario y una óptima gestión de almacenamiento que esté de acuerdo a las necesidades del mercado.

Para el cálculo del programa de producción se tomará en cuenta la capacidad instalada calculada anteriormente, además intervendrá el stock de seguridad respectivo.

Se ha determinado una vida útil de 10 años.

\subsubsection{Programa de producción}

A continuación, en la tabla 5.21, se calculó el porcentaje de utilización de la planta. Se estableció una comparación de nuestra demanda anual con la capacidad instalada de la planta.

Tabla 5.21

Producción anual

\begin{tabular}{|c|c|c|c|}
\hline Año & Demanda del proyecto $\mathbf{( k g )}$ & Stock de seguridad (1\%) & Producción $\mathbf{( k g / \text { año) }}$ \\
\hline 2016 & $9.216,08$ & 92,16 & $9.308,24$ \\
\hline 2017 & $10.876,06$ & 108,76 & $10.984,82$ \\
\hline 2018 & $12.536,03$ & 125,36 & $12.661,39$ \\
\hline 2019 & $14.196,01$ & 141,96 & $14.337,97$ \\
\hline 2020 & $15.855,98$ & 158,56 & $16.014,54$ \\
\hline 2021 & $17.515,96$ & 175,16 & $17.691,12$ \\
\hline 2022 & $19.175,93$ & 191,76 & $19.367,69$ \\
\hline 2023 & $20.835,91$ & 208,36 & $21.044,27$ \\
\hline 2024 & $22.495,88$ & 224,96 & $22.720,84$ \\
\hline 2025 & $24.155,86$ & 241,56 & $24.397,42$ \\
\hline
\end{tabular}

Elaboración propia

Finalmente en la tabla 5.22 se muestra la producción mensual por cada año. 


\section{Tabla 5.22}

Cronograma de producción mensual

\begin{tabular}{|c|c|c|}
\hline Año & Producción (kg/año) & Producción $(\mathbf{k g} / \mathbf{m e s})$ \\
\hline 2016 & $9.308,24$ & 775,69 \\
\hline 2017 & $10.984,82$ & 915,40 \\
\hline 2018 & $12.661,39$ & $1.055,12$ \\
\hline 2019 & $14.337,97$ & $1.194,83$ \\
\hline 2020 & $16.014,54$ & $1.334,55$ \\
\hline 2021 & $17.691,12$ & $1.474,26$ \\
\hline 2022 & $19.367,69$ & $1.613,97$ \\
\hline 2023 & $21.044,27$ & $1.753,69$ \\
\hline 2024 & $22.720,84$ & $1.893,40$ \\
\hline 2025 & $24.397,42$ & $2.033,12$ \\
\hline
\end{tabular}

Elaboración propia

\subsection{Requerimiento de insumos, servicios y personal}

Para poder cumplir con la demanda de nuestro proyecto, es necesario establecer la cantidad requerida de la materia prima y de los demás insumos.

\subsubsection{Materia prima, insumos y otros materiales}

Los insumos y la materia prima que intervienen en la producción de la harina de lúcuma son los siguientes:

- Lúcuma seda

- Lejía desinfectante

- Cajas de cartón

- Bolsas de polietileno

En la tabla 5.23 se muestra el programa de abastecimiento para los 10 años del proyecto. El cálculo se realizó considerando la producción de bolsas de $10 \mathrm{~kg}$ de harina de lúcuma. 
Tabla 5.23

Programa de abastecimiento

\begin{tabular}{|c|c|c|c|c|c|}
\hline Año & $\begin{array}{c}\text { Demanda anual } \\
(\mathbf{k g})\end{array}$ & $\begin{array}{c}\text { Lúcuma seda } \\
(\mathbf{k g})\end{array}$ & $\begin{array}{c}\text { Lejía } \\
\text { desinfectante (L) }\end{array}$ & $\begin{array}{c}\text { Bolsas de } \\
\text { polietileno } \\
\text { (Unds.) }\end{array}$ & $\begin{array}{c}\text { Cajas de } \\
\text { cartón } \\
\text { (Unds.) }\end{array}$ \\
\hline 2016 & $9.216,08$ & $45.687,91$ & 91,33 & 921 & 184 \\
\hline 2017 & $10.876,06$ & $53.917,09$ & 107,78 & 1.087 & 217 \\
\hline 2018 & $12.536,03$ & $62.146,27$ & 124,23 & 1.253 & 250 \\
\hline 2019 & $14.196,01$ & $70.375,45$ & 140,68 & 1.419 & 283 \\
\hline 2020 & $15.855,98$ & $78.604,63$ & 157,13 & 1.585 & 317 \\
\hline 2021 & $17.515,96$ & $86.833,81$ & 173,58 & 1.751 & 350 \\
\hline 2022 & $19.175,93$ & $95.062,99$ & 190,03 & 1.917 & 383 \\
\hline 2023 & $20.835,91$ & $103.292,17$ & 206,48 & 2.083 & 416 \\
\hline 2024 & $22.495,88$ & $111.521,35$ & 222,93 & 2.249 & 449 \\
\hline 2025 & $24.155,86$ & $119.750,53$ & 239,38 & 2.415 & 483 \\
\hline
\end{tabular}

Elaboración propia

Por otro lado se tienen en consideración materiales que darán soporte a los procesos de mantenimiento de la maquinaria como los siguientes:

- Caja de herramientas

- Lubricantes

- Útiles de limpieza

\subsubsection{Servicios: energía eléctrica, agua, vapor, combustible, etc.}

\section{Energía eléctrica}

En cuanto al consumo de energía eléctrica, fue necesario separarlo en consumo industrial, es decir de la maquinaria, y en consumo administrativo. El consumo administrativo fue detallado en el punto 4.5 así que aquí nos centraremos en el consumo de las máquinas. En la tabla 5.24 se detalla el consumo de horas por máquina y por cada año del proyecto para luego hacer el cálculo de la potencia a utilizar. 
Tabla 5.24

Consumo de horas por máquina y por año

\begin{tabular}{|c|c|c|c|c|c|c|}
\hline Año & $\begin{array}{c}\text { Balanza de } \\
\text { plataforma }\end{array}$ & $\begin{array}{c}\text { Lavadora de } \\
\text { Frutas }\end{array}$ & $\begin{array}{c}\text { Secador de } \\
\text { bandejas }\end{array}$ & $\begin{array}{c}\text { Molino de } \\
\text { martillos }\end{array}$ & Selladora & Embolsadora \\
\hline 2016 & 55,76 & 50,18 & 841,99 & 160,63 & 0,28 & 0,28 \\
\hline 2017 & 65,80 & 59,22 & 993,65 & 189,56 & 0,33 & 0,33 \\
\hline 2018 & 75,84 & 68,26 & $1.145,31$ & 218,49 & 0,38 & 0,38 \\
\hline 2019 & 85,89 & 77,30 & $1.296,97$ & 247,42 & 0,43 & 0,43 \\
\hline 2020 & 95,92 & 86,33 & $1.448,54$ & 276,34 & 0,48 & 0,48 \\
\hline 2021 & 105,97 & 95,37 & $1.600,20$ & 305,27 & 0,53 & 0,53 \\
\hline 2022 & 116,01 & 104,41 & $1.751,86$ & 334,20 & 0,59 & 0,59 \\
\hline 2023 & 126,05 & 113,45 & $1.903,53$ & 363,13 & 0,64 & 0,64 \\
\hline 2024 & 136,09 & 122,48 & $2.055,19$ & 392,07 & 0,69 & 0,69 \\
\hline 2025 & 146,14 & 131,52 & $2.206,85$ & 421,00 & 0,74 & 0,74 \\
\hline
\end{tabular}

Elaboración propia

En la tabla 5.25 se muestra la potencia por cada máquina de manera consolidada, detallada en el punto 5.3.2.

Tabla 5.25

Potencia por máquina

\begin{tabular}{|c|c|}
\hline Operación & Potencia $(\mathbf{K w )}$ \\
\hline Balanza de plataforma & 0,05 \\
\hline Lavadora de Frutas & 1,12 \\
\hline Secador de Bandejas & 1,35 \\
\hline Molino de martillos & 5,60 \\
\hline Selladora & 0,80 \\
\hline Embolsadora & 3,50 \\
\hline
\end{tabular}

Elaboración propia

Tabla 5.26

Demanda de potencia anual por máquina en $\mathrm{kW}$ hr

\begin{tabular}{|c|c|c|c|c|c|c|}
\hline Año & $\begin{array}{c}\text { Balanza de } \\
\text { plataforma }\end{array}$ & $\begin{array}{c}\text { Lavadora de } \\
\text { Frutas }\end{array}$ & $\begin{array}{c}\text { Secador de } \\
\text { bandejas }\end{array}$ & $\begin{array}{c}\text { Molino de } \\
\text { martillos }\end{array}$ & Selladora & Embolsadora \\
\hline 2016 & 2,79 & 56,20 & $1.136,70$ & 899,51 & 0,23 & 0,98 \\
\hline 2017 & 3,29 & 66,33 & $1.341,44$ & $1.061,53$ & 0,27 & 1,16 \\
\hline 2018 & 3,79 & 76,45 & $1.546,18$ & $1.223,55$ & 0,31 & 1,34 \\
\hline 2019 & 4,29 & 86,57 & $1.750,92$ & $1.385,57$ & 0,35 & 1,52 \\
\hline 2020 & 4,80 & 96,70 & $1.955,65$ & $1.547,59$ & 0,39 & 1,69 \\
\hline 2021 & 5,30 & 106,82 & $2.160,39$ & $1.709,60$ & 0,43 & 1,87 \\
\hline 2022 & 5,80 & 116,94 & $2.365,13$ & $1.871,62$ & 0,47 & 2,05 \\
\hline 2023 & 6,30 & 127,07 & $2.569,87$ & $2.033,64$ & 0,51 & 2,23 \\
\hline 2024 & 6,80 & 137,19 & $2.774,61$ & $2.195,66$ & 0,55 & 2,40 \\
\hline 2025 & 7,31 & 147,31 & $2.979,35$ & $2.357,68$ & 0,59 & 2,58 \\
\hline
\end{tabular}

Elaboración propia 
$\underline{\text { Agua }}$

El consumo de agua dentro de la planta está definido por la operación de lavado. La cantidad requerida se encuentra en la tabla 5.27.

Tabla 5.27

Cantidad de agua requerida

\begin{tabular}{|c|c|c|}
\hline Año & $\begin{array}{c}\text { Cantidad entrante a la } \\
\text { operación de lavado (kg) }\end{array}$ & $\begin{array}{c}\text { Cantidad de agua requerida } \\
(\mathbf{L})\end{array}$ \\
\hline 2016 & $45.665,03$ & $22.832,52$ \\
\hline 2017 & $53.890,14$ & $26.945,07$ \\
\hline 2018 & $62.115,17$ & $31.057,59$ \\
\hline 2019 & $70.340,26$ & $35.170,13$ \\
\hline 2020 & $78.565,32$ & $39.282,66$ \\
\hline 2021 & $86.790,40$ & $43.395,20$ \\
\hline 2022 & $95.015,45$ & $47.507,73$ \\
\hline 2023 & $103.240,53$ & $51.620,27$ \\
\hline 2024 & $111.465,58$ & $55.732,79$ \\
\hline 2025 & $119.690,67$ & $59.845,34$ \\
\hline
\end{tabular}

Elaboración propia

Gas natural

La única máquina que consume gas natural es el Secador de Bandejas. El consumo de esta máquina es de 39,600 kilocalorías por hora. De acuerdo a la consultora APPISA, 1 metro cúbico de gas natural puede liberar 8,460 kilocalorías. En base a estos datos, en la tabla 5.28, se muestra el consumo de kilocalorías y por ende de los metros cúbicos requeridos por año.

Tabla 5.28

Consumo de Gas Natural por año

\begin{tabular}{|c|c|c|}
\hline Año & $\begin{array}{c}\text { Cantidad entrante (kg de harina } \\
\text { de lúcuma) }\end{array}$ & $\begin{array}{c}\text { Gas natural requerido } \\
\left(\mathbf{m}^{\mathbf{3}}\right)\end{array}$ \\
\hline 2016 & $30.648,48$ & 3.587 \\
\hline 2017 & $36.168,94$ & 4.233 \\
\hline 2018 & $41.689,39$ & 4.879 \\
\hline 2019 & $47.209,84$ & 5.525 \\
\hline 2020 & $52.726,97$ & 6.170 \\
\hline 2021 & $58.247,42$ & 6.816 \\
\hline 2022 & $63.767,87$ & 7.462 \\
\hline 2023 & $69.288,32$ & 8.108 \\
\hline 2024 & $74.808,77$ & 8.754 \\
\hline 2025 & $80.329,23$ & 9.400 \\
\hline
\end{tabular}

Elaboración propia 


\subsubsection{Determinación del número de operarios y trabajadores indirectos}

Mano de obra directa

Es aquella que participa directamente en la elaboración del producto. Para la producción de harina de lúcuma, el personal no necesita tener experiencia, ya que al inicio de sus labores se les dará una capacitación de cómo deben realizar la (s) operación (es) asignada (s). En la tabla 5.29 se detalla la cantidad de horas requeridas para cada actividad. Esto nos ayudará a determinar el número de operarios necesarios para cada una. Este cálculo se realizó tomando en cuenta que la capacidad de producción de cada una se ve afectada por los factores de utilidad y eficiencia.

Tabla 5.29

Requerimiento de $\mathrm{H}-\mathrm{H}$ por actividad por año

\begin{tabular}{|c|c|c|c|c|c|c|c|c|c|c|}
\hline Año & 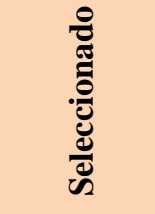 & 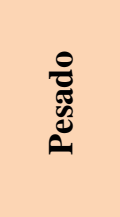 & 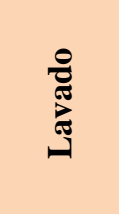 & $\frac{O}{\frac{\pi}{0}}$ & 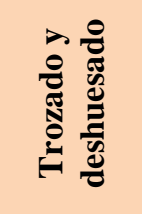 & 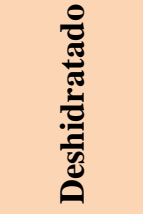 & $\frac{\stackrel{ }{\circ}}{\stackrel{0}{\circ}}$ & 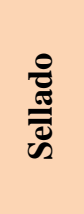 & 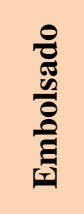 & 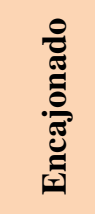 \\
\hline 2016 & 627,58 & 55,76 & 50,18 & $1.929,07$ & $1.639,71$ & 841,99 & 160,63 & 0,28 & 0,28 & 10,13 \\
\hline 2017 & 740,62 & 65,80 & 59,22 & $2.276,54$ & $1.935,06$ & 993,65 & 189,56 & 0,33 & 0,33 & 11,95 \\
\hline 2018 & 853,66 & 75,84 & 68,26 & $2.624,01$ & $2.230,40$ & $1.145,31$ & 218,49 & 0,38 & 0,38 & 13,78 \\
\hline 2019 & 966,70 & 85,89 & 77,30 & $2.971,47$ & $2.525,75$ & $1.296,97$ & 247,42 & 0,43 & 0,43 & 15,60 \\
\hline 2020 & $1.079,67$ & 95,92 & 86,33 & $3.318,73$ & $2.820,92$ & $1.448,54$ & 276,34 & 0,48 & 0,48 & 17,42 \\
\hline 2021 & $1.192,71$ & 105,97 & 95,37 & $3.666,20$ & $3.116,27$ & $1.600,20$ & 305,27 & 0,53 & 0,53 & 19,25 \\
\hline 2022 & $1.305,75$ & 116,01 & 104,41 & $4.013,67$ & $3.411,62$ & $1.751,86$ & 334,20 & 0,59 & 0,59 & 21,07 \\
\hline 2023 & $1.418,79$ & 126,05 & 113,45 & $4.361,13$ & $3.706,96$ & $1.903,53$ & 363,13 & 0,64 & 0,64 & 22,90 \\
\hline 2024 & $1.531,83$ & 136,09 & 122,48 & $4.708,60$ & $4.002,31$ & $2.055,19$ & 392,07 & 0,69 & 0,69 & 24,72 \\
\hline 2025 & $1.644,87$ & 146,14 & 131,52 & $5.056,07$ & $4.297,66$ & $2.206,85$ & 421,00 & 0,74 & 0,74 & 26,54 \\
\hline
\end{tabular}

Elaboración propia

Luego de este cálculo se determinó cuantos operarios serán necesarios tomando en cuenta que las actividades automáticas como el deshidratado y las semiautomáticas como el pesado, lavado, molido, sellado, embolsado y encajonado necesitan de un operario para su ejecución En la tabla 5.30 se determina la cantidad de operarios necesarios por año en base a las horas-hombres requeridas. Cabe indicar que en los primeros 4 años es un solo operario el que realiza y/o supervisa las actividades de seleccionado, pesado, lavado, deshidratado, molido, sellado, embolsado y encajonado, debido a las pocas horas-hombre requeridas por año. 
Tabla 5.30

Número de operarios necesarios por año

\begin{tabular}{|c|c|c|c|c|c|c|c|c|c|c|c|}
\hline Año & $\frac{\stackrel{0}{0}}{0}$ & 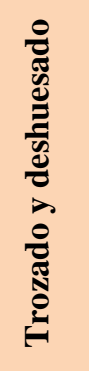 & 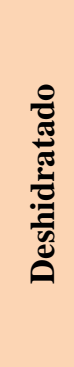 & 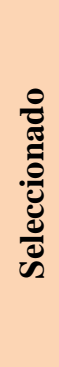 & 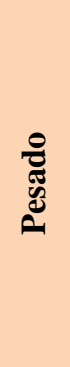 & 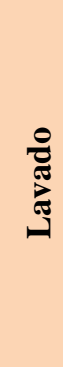 & $\frac{\circ}{\stackrel{0}{\frac{\pi}{0}}}$ & 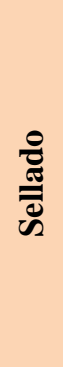 & 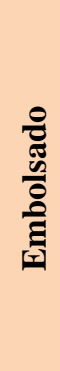 & 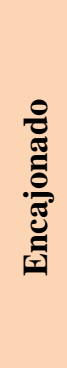 & Total \\
\hline 2016 & 1,0 & 1,0 & & & 7 & 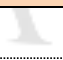 & & & & & 3 \\
\hline 2017 & 1,0 & 1,0 & 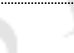 & & & & & & & & 3 \\
\hline 2018 & 2,0 & 1,0 & & & & & & & & & 4 \\
\hline 2019 & 2,0 & 2,0 & 1,0 & & & & 1,0 & & & & 6 \\
\hline 2020 & 2,0 & 2,0 & 1,0 & & 8 & & 1,0 & & & 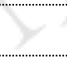 & 6 \\
\hline 2021 & 2,0 & 2,0 & 1,0 & & 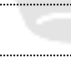 & & 1,0 & & & 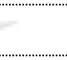 & 6 \\
\hline 2022 & 2,0 & 2,0 & 1,0 & & & & 1,0 & & & & 6 \\
\hline 2023 & 2,0 & 2,0 & 1,0 & & & & 1,0 & & & & 6 \\
\hline 2024 & 2,0 & 2,0 & 1,0 & & & & 1,0 & & & & 6 \\
\hline 2025 & 3,0 & 2,0 & 1,0 & & 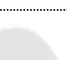 & 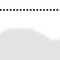 & 1,0 & & & & 7 \\
\hline
\end{tabular}

Elaboración propia

\section{$\underline{\text { Mano de obra indirecta }}$}

Para determinar el personal administrativo se tomaron en cuenta las actividades más importantes del proceso y sus controles de calidad, la necesidad de trazarnos objetivos y hacerles seguimiento, la gestión de compras, ventas, marketing y la seguridad física de la empresa. En la tabla 5.31 se detallan los cargos necesarios en la parte administrativa.

Tabla 5.31

Personal administrativo requerido

\begin{tabular}{|l|c|}
\hline \multicolumn{1}{|c|}{ Cargo } & Nro. personas \\
\hline Gerente general & 1 \\
\hline Secretaria & 1 \\
\hline Encargado de producción y logística & 1 \\
\hline Encargado del talento humano & 1 \\
\hline Encargado de Finanzas & 1 \\
\hline Total & $\mathbf{5}$ \\
\hline
\end{tabular}

Elaboración propia 


\subsubsection{Servicios de terceros}

Dentro de los servicios de terceros, para la comercialización del producto en el mercado internacional, se recurrirá a un servicio de bróker el cual nos facilitará y asegure la venta, además de recurrir los servicios de una agencia de aduanas para la operación de exportación de nuestro producto.

Por otro lado los servicios que le darán soporte a la operación de la empresa, serán la contratación del servicio de internet en las áreas administrativas, licencias de paquetes de MS Office y los servicios de vigilancia, limpieza y mantenimiento.

\subsection{Disposición de planta}

\subsubsection{Características físicas del proyecto}

\section{$\underline{\text { Factor edificio }}$}

La planta estará localizada en la región Lima, en el distrito de Huaral. La planta deberá contar con las instalaciones debidas para el total funcionamiento.

El terreno deberá ser amplio para la instalación de las máquinas. También se recomienda que el material del piso esté hecho de un conjunto homogéneo, llano y liso para evitar posibles caídas. Para este proyecto se utilizará como material del piso el cemento y para las máquinas pesadas concreto. Los pasillos tendrán como mínimo 80 centímetros según la norma de seguridad, se debe mencionar que si son rectos se aprovecha más el espacio y libres de cualquier obstáculo.

En cuanto a vías de acceso y señalización deben estar situadas correctamente para que los trabajadores puedas utilizarlas fácilmente y con seguridad.

El cableado de las instalaciones eléctricas deberá estar aislado y se contará con una caja principal.

\section{$\underline{\text { Factor Servicio }}$}

En cuanto a servicios se requiere lo siguiente:

Para el personal: La oficinas estarán equipadas con escritorio y sillas para el personal administrativo; tales como secretaria y jefes de área. Se contará con un área de comedor que se encontrará fuera del área de producción y contará con mesas, sillas y horno 
microondas. También se contará con servicios higiénicos, 2 para el área administrativa y 2 para el área de producción.

Para los materiales y productos: Se contará con dos almacenes; uno para materia prima y otro para producto terminado, cabe resaltar que la distancia del área de producción debe ser la mínima, para evitar demora y facilitar el transporte. Además se contará con un patio de descarga, área para la recepción de materia prima y para el despacho de producto terminado.

\subsubsection{Determinación de las zonas físicas requeridas}

Luego de conocer el número total de trabajadores directos e indirectos se determina que las áreas a considerar en nuestra planta serán las siguientes:

- Área de producción

- Área de administración

- Área de almacén de materia prima

- Área de almacén de producto terminado

- Servicios higiénicos

- Comedor

\subsubsection{Cálculo de áreas para cada zona}

$\underline{\text { Área de administración }}$

Más adelante se ha calculado la cantidad de personal administrativo con la que se contará.

Estos son 1 gerente general, 1 secretaria, 1 jefe de producción y logística, 1 jefe de gestión de talento humano y, 1 jefe de finanzas. Para la disposición de oficinas se tomará en cuenta la tabla 5.32, en la cual detallamos la superficie a considerar por cada puesto dentro de la empresa. 
Tabla 5.32

Área de oficinas

\begin{tabular}{|c|c|}
\hline Ambiente & Área \\
\hline Ejecutivo principal & 23 a $46 \mathrm{~m}^{2}$ \\
\hline Ejecutivo & 18 a $37 \mathrm{~m}^{2}$ \\
\hline Ejecutivo junior & 10 a $23 \mathrm{~m}^{2}$ \\
\hline Mando medio & 7,5 a $14 \mathrm{~m}^{2}$ \\
\hline Oficinista & 4,5 a $9 \mathrm{~m}^{2}$ \\
\hline Estación de trabajo mínima & $4,5 \mathrm{~m}^{2}$ \\
\hline
\end{tabular}

Fuente: Sulem D, (2011)

El área de cada oficina serán las siguientes:

- Gerente general: $28 \mathrm{~m}^{2}$

- Secretaria: $5 \mathrm{~m}^{2}$

- Encargado de producción y logística: $20 \mathrm{~m}^{2}$

- Encargado del talento humano: $20 \mathrm{~m}^{2}$

- Encargado de finanzas: $20 \mathrm{~m}^{2}$

El total del área de la zona administrativa sería de $93 \mathrm{~m}^{2}$

\section{$\underline{\text { Área de almacén de materia prima }}$}

En el caso del almacén de materia prima, el tiempo promedio que puede permanecer la lúcuma en estos es de una semana; por lo tanto si se necesitan 100.158,99 kg de lúcuma al año y cada año tiene 52 semanas; entonces se necesitan $1.926 .13 \mathrm{~kg} / \mathrm{semana}$.

Según datos se sabe que la capacidad de una jaba es de $12 \mathrm{~kg}$ de lúcuma; por lo tanto se necesitarán 161 jabas. En una parihuela entran 20 jabas; lo que nos demuestra que se necesitarían 8 parihuelas para almacenar la lúcuma. 
A continuación se mostrará la distribución de las parihuelas.

Figura 5.11

Distribución de parihuelas

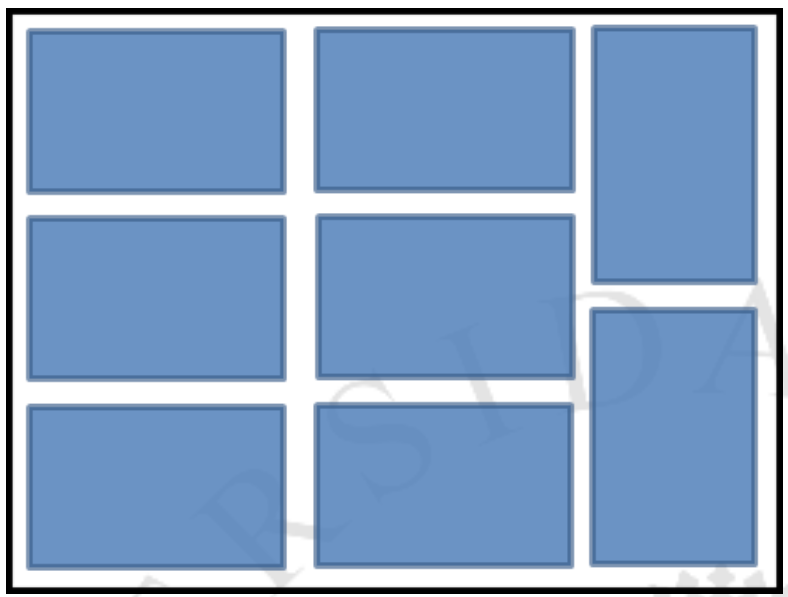

Elaboración propia

Para hallar el área requerida del almacén de materias primas se sabe que:

- Largo de parihuela: $1,2 \mathrm{~m}$

- Ancho de parihuela: $0,8 \mathrm{~m}$

Por lo tanto, el área ocupada por las parihuelas es de 7,68 $\mathrm{m}^{2}$, más un área de maniobra de $3,5 \mathrm{~m}^{2}$. El total de área del almacén sería de: $11.18 \mathrm{~m}^{2}$.

\section{Área de almacén de producto terminado}

En el caso de almacén de producto terminado, se tiene que la producción es de 20.203,89 $\mathrm{kg}$ de harina al año; lo que nos indica un total de $388,54 \mathrm{~kg}$ cada semana. La venta se realizará en bolsas de 10 kilos; por lo tanto se tendrán 39 bolsas. Se sabe que en una caja entran 2 bolsas por lo tanto por semana tendremos un total de 20 cajas. Se podrán colocar 2 cajas en una parihuela y máximo una encima de otra, por lo que se necesitara 10 parihuelas para almacenar el producto terminado.

Para hallar el área requerida del almacén de producto terminado se sabe que:

- Largo de la caja: $0,8 \mathrm{~m}$

- Ancho de la caja: $0,5 \mathrm{~m}$ 
Figura 5.12

Distribución de cajas en una parihuela

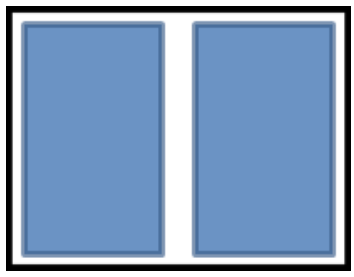

Elaboración propia

A continuación se mostrará la distribución de las parihuelas.

Figura 5.13

Distribución de parihuelas

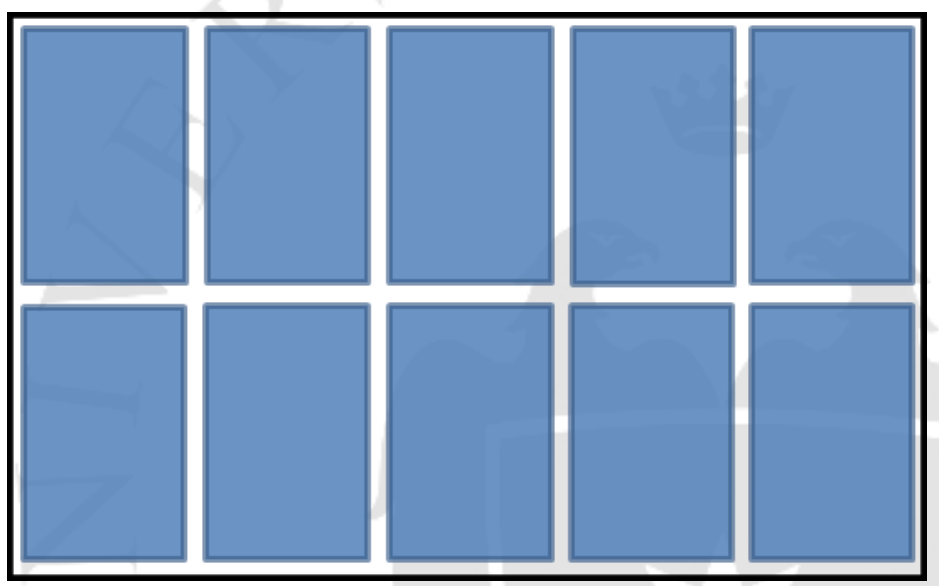

Elaboración propia

Para hallar el área requerida del almacén de producto terminado se sabe que:

- Largo de parihuela: 1,2 m

- Ancho de parihuela: $0,8 \mathrm{~m}$

Por lo tanto el área ocupada por las cajas es de $9.6 \mathrm{~m}^{2}$ más un área de maniobra de $3 \mathrm{~m}^{2}$, sería $12.6 \mathrm{~m}^{2}$ el área total requerida.

\section{$\underline{\text { Servicios higiénicos }}$}

Como ya se explicó anteriormente se contará con dos retretes para el área de producción y dos retretes para el área administrativa. El área requerida de cada servicio es de $12 \mathrm{~m}^{2}$. 
Tabla 5.33

Número de retretes

\begin{tabular}{|c|c|}
\hline Número de empleados & Número mínimo de retretes \\
\hline $1-15$ & 1 \\
\hline $16-35$ & 2 \\
\hline $36-55$ & 3 \\
\hline $56-80$ & 4 \\
\hline $81-110$ & 5 \\
\hline $111-150$ & 6 \\
\hline Más de 150 & 1 conjunto adicional por cada 40 empleados adicionales \\
\hline
\end{tabular}

Fuente: Sulem D, (2011)

Comedor

También para el área del comedor se calcula que cada trabajador ocupará un espacio de $1,58 \mathrm{~m}^{2}$, lo que nos indica que el área requerida es de $17,38 \mathrm{~m}^{2}$.

\section{Tabla 5.34}

Resumen de áreas

\begin{tabular}{|l|c|}
\hline \multicolumn{1}{|c|}{ Área } & Medida \\
\hline Área de producción & $217,08 \mathrm{~m}^{2}$ \\
\hline Área de administración & $93,00 \mathrm{~m}^{2}$ \\
\hline Servicios & $48,00 \mathrm{~m}^{2}$ \\
\hline Comedor & $17,38 \mathrm{~m}^{2}$ \\
\hline Área de almacén de MP & $11,18 \mathrm{~m}^{2}$ \\
\hline Área de almacén de PT & $12,6 \mathrm{~m}^{2}$ \\
\hline Total & $399,24 \mathrm{~m}^{2}$ \\
\hline
\end{tabular}

Elaboración propia

Finalmente para un mejor espacio de trabajo se utilizará un aproximado de $490 \mathrm{~m}^{2}$, dado que en el patio de descarga debe entrar un pequeño camión.

\subsubsection{Dispositivos de seguridad industrial y señalización}

Unas de las condiciones más importantes dentro de un plan de emergencias y seguridad son los dispositivos de seguridad y señalización. Por lo tanto toda la empresa debe estar involucrada en como desempeñarse en una situación de riesgo o emergencia.

Las áreas de la empresa tendrán carteles y señales, los cuales serán ubicados en puntos visuales estratégicos. Estas deben ser claras y simples, ayudando siempre a la visualización. 
Todas las señales deben cumplir con la Norma técnica peruana 399.10-1. A continuación se muestra en la tabla 5.35 los principales colores utilizados en la señalización.

Tabla 5.35

Significado general de colores de seguridad

\begin{tabular}{|c|c|}
\hline $\begin{array}{c}\text { Colores empleados en las señales de } \\
\text { seguridad }\end{array}$ & Significado y finalidad \\
\hline Rojo & $\begin{array}{c}\text { Prohibición, material de prevención y lucha contra } \\
\text { incendios }\end{array}$ \\
\hline Amarillo & Riesgo de peligro \\
\hline Verde & Información de emergencia \\
\hline
\end{tabular}

Fuente: Ministerio de Salud del Perú, (2004)

Además se contará con un plan de mantenimiento de la señalización.

En el tema de seguridad industrial, las actividades que realizaremos son las siguientes:

- Plan de emergencias, en el tema de simulacros y uso de extintores.

- Plan de mantenimiento de extintores.

- Elaboración de perfiles de puestos que indiquen la exposición el efecto de los factores de riesgo.

\subsubsection{Disposición general}

Para saber la disposición general de la panta se utilizará la tabla relacional de actividades y el diagrama relacional de actividades. Para la elaboración de las tablas se debe tomar en cuenta la siguiente tabla de códigos.

Tabla 5.36

Tabla de códigos de proximidades

\begin{tabular}{|c|c|c|c|}
\hline Código & Valor de proximidad & Color & $\mathbf{N}^{\circ}$ de líneas \\
\hline A & Absolutamente necesario & Rojo & 4 rectas \\
\hline E & Especialmente necesario & Amarillo & 3 rectas \\
\hline I & Importante & Verde & 1 rectas \\
\hline O & Normal & Azul & - \\
\hline U & Sin importancia & - & 1 zig - zag \\
\hline X & No deseable & Plomo & 2 zig - zag \\
\hline XX & Altamente no deseable & Negro & - \\
\hline
\end{tabular}

Fuente: Diaz B, Jarufe B y Noriega M, (2007) 
Tabla 5.37

Identificación de actividades

\begin{tabular}{|c|c|c|}
\hline Símbolo & Color & Actividad \\
\hline & Rojo & Operación (montaje o desmontaje) \\
\hline & Verde & Operación, proceso o fabricación \\
\hline & Amarillo & Transporte \\
\hline & Naranja & Almacenaje \\
\hline & Azul & Control \\
\hline & Azul & Servicios \\
\hline & Pardo & Administración \\
\hline
\end{tabular}

Fuente: Diaz B, Jarufe B y Noriega M, (2007)

Tabla 5.38

Lista de motivos

\begin{tabular}{|c|c|}
\hline Código & Motivos \\
\hline 1 & Secuencia del proceso \\
\hline 2 & Fácil traslado \\
\hline 3 & Para no contaminar el producto \\
\hline 4 & Higiene de alimentos \\
\hline 5 & Sin relación \\
\hline 6 & Necesidad de información \\
\hline 7 & Control y seguridad \\
\hline
\end{tabular}

Elaboración propia

Figura 5.14

Tabla relacional de actividades

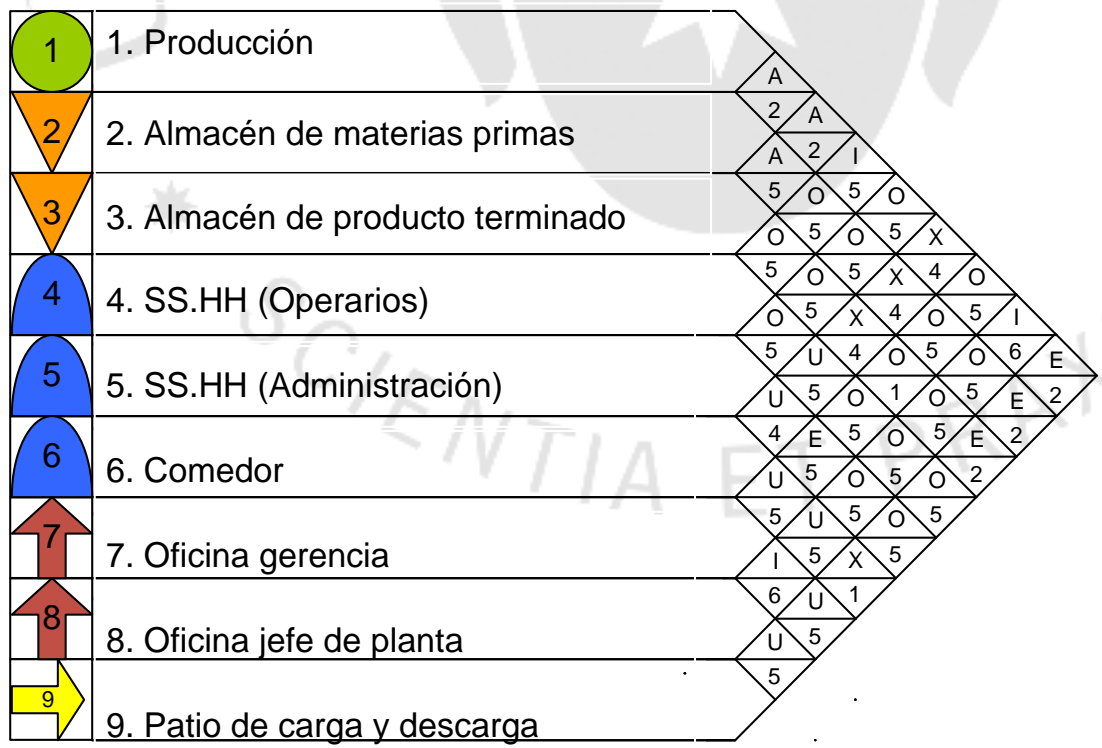

Elaboración propia 
Figura 5.15

Tabla relacional de actividades

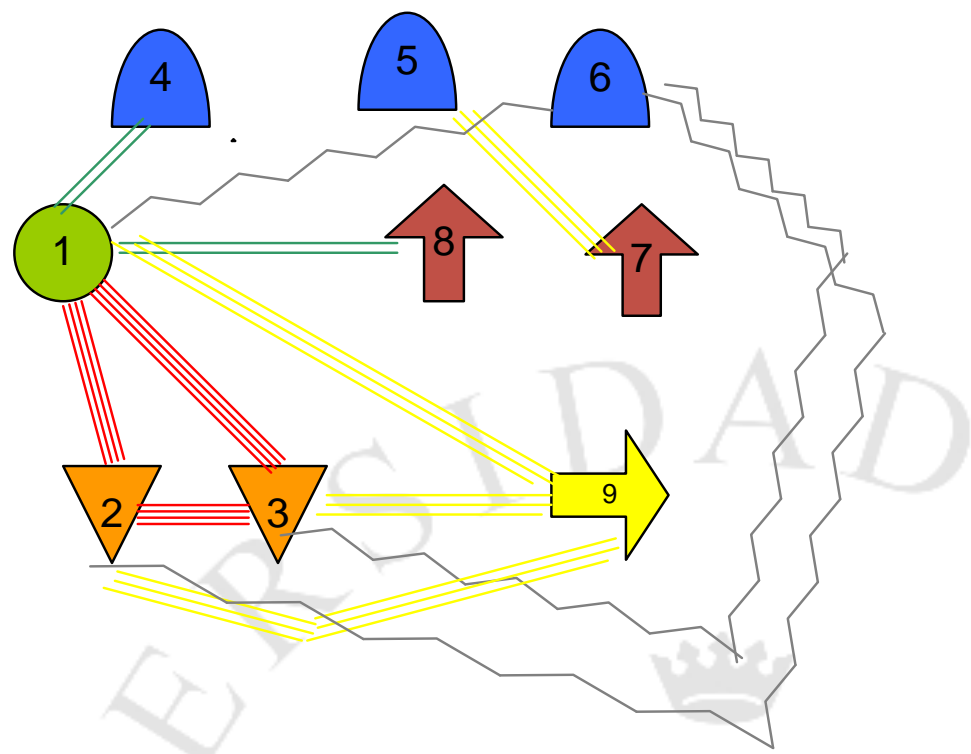

Elaboración propia

\subsubsection{Disposición de detalle}

Para determinar el área mínima de producción se realizará en análisis de Guerchet que se muestra a continuación. Es importante resaltar que lo necesario para este análisis son el largo, ancho y alto de las máquinas. Además se debe conocer el número de máquinas y lados por donde se opera.

Las fórmulas a utilizar son las siguientes:

- Superficie estática: Largo * Ancho

- Superficie gravitacional $=$ Superficie estática* Número de lados

- Superficie de evolución= $($ Superficie Estática + Superficie gravitacional $) * \mathrm{k}$

- Superficie Total $=($ Superficie estática + Superficie gravitacional + Superficie de evolución) * número de máquinas

- Coeficiente de evolución: (Altura de elementos móviles / $2 *$ Altura de Elementos estáticos)

$$
K=\frac{H * E M}{2 * H * E E}
$$

A continuación se mostrará el cuadro del área mínima requerida para la zona de producción: 
Tabla 5.39

Guerchet de elementos fijos

\begin{tabular}{|c|c|c|c|c|c|c|c|c|c|c|c|c|}
\hline Elementos estáticos & $\mathbf{n}$ & $\mathbf{N}$ & $\mathbf{L}(\mathbf{m})$ & $\mathbf{A}(\mathbf{m})$ & $\mathbf{D}(\mathbf{m})$ & $\mathbf{H}(\mathbf{m})$ & $\operatorname{Ss}\left(\mathbf{m}^{2}\right)$ & $\operatorname{Sg}\left(\mathbf{m}^{2}\right)$ & $\operatorname{Se}\left(\mathrm{m}^{2}\right)$ & St $\left(\mathrm{m}^{2}\right)$ & Ss*n & Ss*n*h \\
\hline Balanza & 1 & 3 & 0,60 & 0,46 & - & 0,64 & 0,28 & 0,83 & 1,97 & 3,07 & 0,28 & 0,18 \\
\hline Lavadora & 1 & 4 & 2,23 & 1,03 & - & 0,64 & 2,30 & 9,19 & 20,48 & 31,96 & 2,30 & 1,47 \\
\hline Secador de bandejas & 1 & 1 & 3,55 & 0,97 & & 3,56 & 3,44 & 3,44 & 12,28 & 19,17 & 3,44 & 12,26 \\
\hline Molino de martillo & 1 & 3 & 2,30 & 0,95 & & 1,70 & 2,19 & 6,56 & 15,59 & 24,33 & 2,19 & 3,71 \\
\hline Selladora & 1 & 3 & 1,50 & 1,40 & & 1,80 & 2,10 & 6,30 & 14,98 & 23,38 & 2,10 & 3,78 \\
\hline Embolsadora & 1 & 1 & 0,70 & 0,30 & & 2,00 & 0,21 & 0,21 & 0,75 & 1,17 & 0,21 & 0,42 \\
\hline Mesa de selección & 1 & 4 & 1,50 & 1,00 & & 1,10 & 1,50 & 6,00 & 13,37 & 20,87 & 1,50 & 1,65 \\
\hline Mesa de pelado, trozado y deshuesado & 1 & 4 & 1,50 & 1,00 & & 1,10 & 1,50 & 6,00 & 13,37 & 20,87 & 1,50 & 1,65 \\
\hline Mesa de encajonado & 1 & 4 & 1,50 & 1,00 & & 1,10 & 1,50 & 6,00 & 13,37 & 20,87 & 1,50 & 1,65 \\
\hline Total & & & & & & 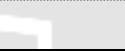 & & & & 165,71 & 15,01 & 26,77 \\
\hline
\end{tabular}

Elaboración propia 
Tabla 5.40

Guerchet de elementos móviles

\begin{tabular}{|l|c|c|c|c|c|c|c|}
\hline Elementos móviles & $\mathbf{n}$ & $\mathbf{L}(\mathbf{m})$ & $\mathbf{A}(\mathbf{m})$ & $\mathbf{h}(\mathbf{m})$ & $\mathbf{S s}\left(\mathbf{m}^{2}\right)$ & $\mathbf{S s} * \mathbf{n}$ & $\mathbf{S s} * \mathbf{n} * \mathbf{h}$ \\
\hline Operarios & 11 & - & - & 1,65 & 0,5 & 5,5 & 9,08 \\
\hline Carretillas hidráulicas & 2 & 1,5 & 0,7 & 1,2 & 0,84 & 1,68 & 2,02 \\
\hline Total & & & & & & 7,18 & 11,10 \\
\hline
\end{tabular}

Elaboración propia

Tabla 5.41

Cálculo de $\mathrm{k}$

\begin{tabular}{|l|c|}
\hline h EM & 1,55 \\
\hline h EE & 1,78 \\
\hline Coeficiente de evolución & 0,43 \\
\hline
\end{tabular}

Elaboración propia

Para hallar el coeficiente de evolución (k), se divide la altura de las máquinas o equipos móviles entre el doble de altura de máquinas o equipos fijos. Este coeficiente varía entre 0,05 y 3 .

Luego del análisis de Guerchet se obtuvo que el área mínima requerida es de $167,39 \mathrm{~m}^{2}$ debido a que la carretilla hidráulica se estacionará dentro del área productiva. 
Figura 5.16

Plano tentativo de la empresa

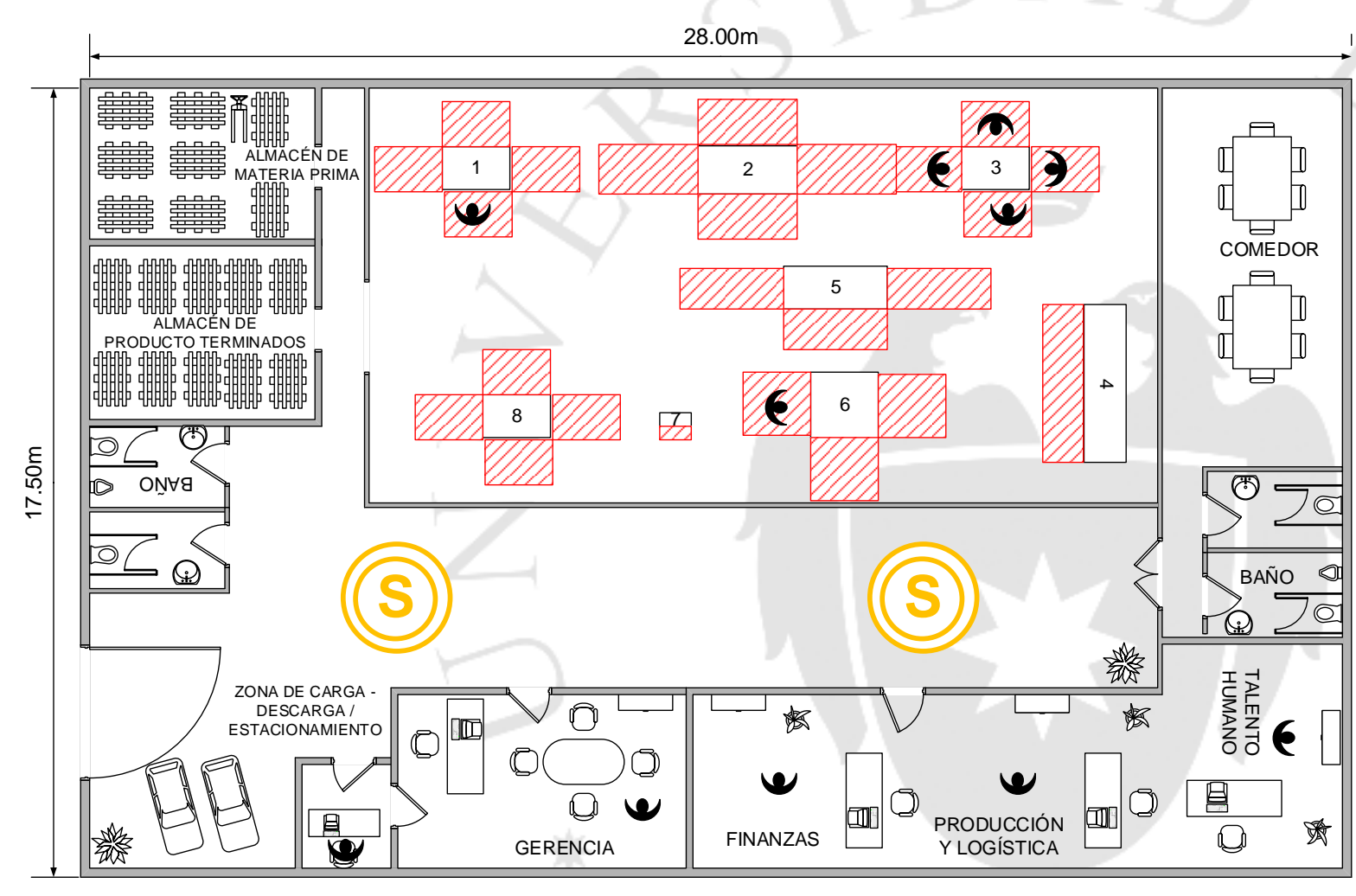

1. MESA DE SELECCIÓN
2. LAVADORADE FRUTAS
3. MESADE PELADO, TROZADO Y DESHUESADO
4. EECADOR DE BANDJAS
5. MOLINO DE MARTLLLO
6. ELLLADORA
7. EMBOLSADORA
8. MESA DE ENCAJONADO

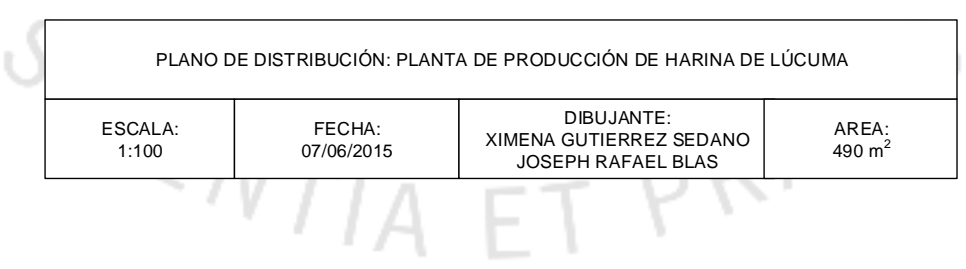




\subsection{Cronograma de implementación del proyecto}

La implementación de nuestro proyecto requerirá de un sistema de gestión que planifique y ejecute todas las actividades.

La dirección de este proyecto se realizará tomando en base el PMBOK. Esta metodología describe los procesos, herramientas y técnica de la dirección de proyectos.

Las áreas de conocimiento comprendidas en el PMBOK que son: Integración, Alcance, Tiempo, Costos, Calidad, Recursos Humanos, Comunicación, Riesgo y Adquisiciones. Además se incluirá los grupos de procesos tales como: de Iniciación, Planificación, Ejecución, Seguimiento y Control y Cierre.

Para la implementación del proyecto el planeamiento se realizará con la Estructura de Desglose de Trabajo (EDT) o WBS sus siglas en inglés.

Tabla 5.42

Estructura de desglose de trabajo

\begin{tabular}{|l|l|l|}
\hline \multicolumn{1}{|c|}{ Fase } & \multicolumn{1}{|c|}{ Entregable } & \multicolumn{1}{c|}{ Paquete de trabajo } \\
\hline Inicio & Estudios preliminares & $\begin{array}{l}\text {-Estudio de Pre factibilidad } \\
\text {-Estudio de Factibilidad } \\
\text {-Constitución de la empresa }\end{array}$ \\
\hline Planificación & Ingeniería básica & $\begin{array}{l}\text {-Ingeniería básica } \\
\text {-Estudios de Seguridad y Medio } \\
\text { Ambiente } \\
\text {-Estimación de costos } \\
\text {-Preparación de presupuesto }\end{array}$ \\
\hline Ejecución & -Aprobación de presupuesto \\
\hline Seguimiento y & Permisos y registros & $\begin{array}{l}\text {-Permiso de construcción } \\
\text {-Registro de producción }\end{array}$ \\
\hline Control & Ingeniería, procura y & $\begin{array}{l}\text {-Ingeniería de detalle } \\
\text {-Procura } \\
\text {-Construcción de planta en Huaral }\end{array}$ \\
\hline Cierre & construcción & -Puesta en marcha \\
\hline
\end{tabular}

Fuente: Project Management Institute, (2008)

Para realizar el cronograma general de implementación nos guiaremos de la estructura de desglose de trabajo, en el que se muestran los paquetes de trabajo.

Desarrollando un escenario optimista se requerirán 236 días iniciando el 2016. 
Figura 5.17

Cronograma de implementación del proyecto

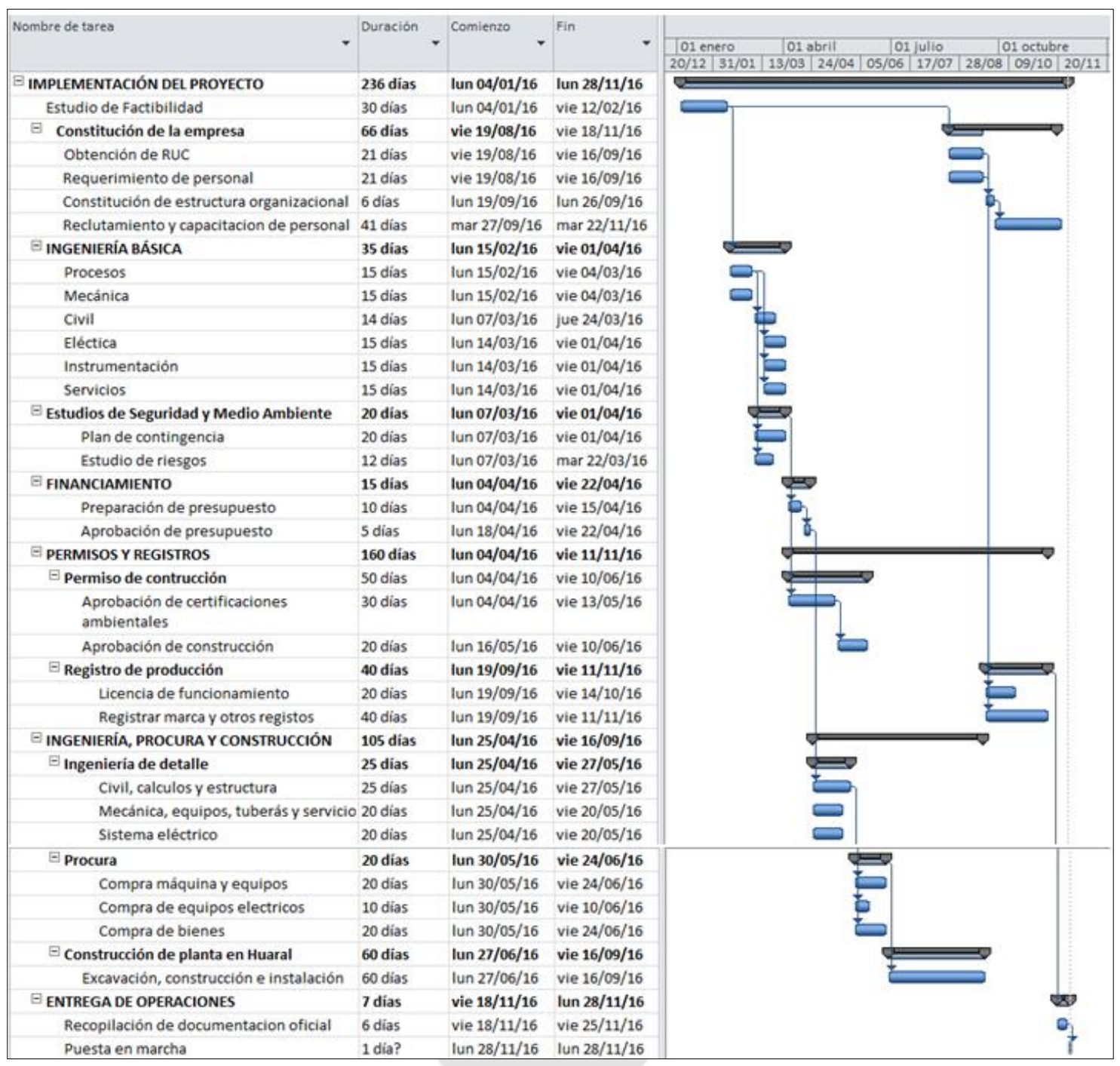

Elaboración propia 


\section{CAPÍTULO VI: ORGANIZACIÓN Y ADMINISTRACIÓN}

\subsection{Formación de la Organización empresarial}

Para el desarrollo de nuestro proyecto, la organización y administración de la implementación de este tiene como objetivo lograr el mejor manejo conforme las etapas del proyecto se vayan desarrollando.

Para poder tener una administración correcta se han definido cuatro elementos básicos administrativos, estos son:

- Planificación: consiste en el proceso de realizar previsiones y planificaciones, establecer metas y alcanzarlas.

- Organización: brindar a la empresa todos lo viene necesarios para que eta pueda funcionar; útiles, herramientas, personal y capital.

- Coordinación: para que todas las partes de las empresas estén en constante comunicación.

- Dirección: para que las metas y objetivos se alcancen.

- Control: para la continuidad de las actividades que se realicen dentro de la empresa.

Para la ejecución de nuestro proyecto se ha establecido dos etapas:

1. Etapa de formulación

- Formular la razón social y crear el nombre de la empresa, para este proyecto se ha elegido por una empresa sociedad anónima cerrada, ya que estará constituida por un grupo de 2 socios.

- Creación del nombre que llevará la empresa.

- Determinar el giro de nuestra empresa: industrial.

- Definir los aportes de capital. Estos pueden ser en dinero en efectivo, asi como en bienes inmuebles o muebles.

- Fijar el domicilio legal de la empresa.

- Decidir los principales proveedores de los activos fijos tangibles y las que nos brindarán el servicio de obra civil. 
2. Etapa de realización

- Elaborar la minuta de constitución social de la empresa, esta deberá ser firmada por los dos socios y por un abogado. Esta deberá ser llevada a un notario para inscribirla en registros públicos.

- Depositar el dinero del capital social en el banco.

- Registrar el RUC, para este procedimiento el representante legal deberá llevar su documento de identidad así como una carta de representación.

- Obtener permiso para emitir boletas y facturas.

- Obtener registro patronal en ESSALUD

- Adquirir y legalizar libros contables.

- Obtener licencia de funcionamiento

\subsection{Requerimientos de personal directivo, administrativo y de servicios}

La tabla 6.1 muestra el requerimiento de personal en las áreas administrativas.

Tabla 6.1

Requerimiento de personal para actividades administrativas

\begin{tabular}{|l|c|}
\hline \multicolumn{1}{|c|}{ Cargo } & Nro. Personas \\
\hline Gerente general & 1 \\
\hline Secretaria & 1 \\
\hline Encargado de producción y logística & 1 \\
\hline Encargado del talento humano & 1 \\
\hline Encargado de Finanzas & 1 \\
\hline Total & $\mathbf{5}$ \\
\hline
\end{tabular}

Elaboración propia

Gerente general: Responsable legal de la empresa y el principal encargado del correcto funcionamiento esta. Además será responsable de comercializar la harina de lúcuma. Es decir de colocar nuestro producto, para que este alcance el plan de ventas estipulado.

- Representar a la empresa.

- Proponer, dirigir y supervisar la misión, visión y objetivos generales y políticas de la empresa.

- Revisar y aprobar los presupuestos e informes económicos y financieros.

- Establecer reuniones con las demás áreas para evaluar indicadores de gestión y evaluar los informes que presentan las demás áreas. 
- Planificar visitas a potenciales de compradores a la empresa.

- Establecer relaciones con clientes, buscando la distribución de nuestro producto.

- Comunicar acerca de las ferias alimentarias, donde podemos ofertar nuestro producto.

- Búsqueda de opciones de negocio adicionales.

- Establecer y administrar canales de comercialización

Secretaria: Responsable de brindar apoyo a la gerencia general. Redactar, clasificar y distribuir documentación de la gerencia.

- Atender los requerimientos efectuados por la gerencia,

- Organizar las teleconferencias.

- Programar reuniones del gerente general con clientes o proveedores.

- Preparar, recibir y distribuir la correspondencia de la empresa.

- Atender diariamente la agenda de la Gerencia.

- Recibir llamada, mensajes telefónicos de gerencia.

- Actualizar archivos físicos, bases de datos y facturas generadas de la empresa.

Encargado de producción y logística: Responsable de controlar la producción y del abastecimiento oportuno de insumos y materia prima requeridos por la empresa. Además debe tener un control de existencias del almacén de producto terminado. Contará con un asistente de producción.

- Supervisar todo el proceso productivo de la empresa

- Cumplir con programa de producción, así como de órdenes de pedido como fecha de entrega.

- Establecer controles para medir eficiencia de los procesos productivos.

- Supervisar el desempeño de los operarios.

- Verificar los insumos recibidos

- Velar por la buena conservación de los productos del almacén.

- Realizar los despachos de acuerdo a las órdenes de compra.

Encargado de gestión del talento humano: Responsable de dirigir el proceso de selección de personal, inducir y capacitar, sea este ejecutivo, empleado u obrero.

- Registrar y controlar el personal. Guardando el historial del personal.

- Definir el perfil y diseño de puestos. 
- Realizar el proceso de reclutamiento y selección del personal.

- Gestionar la estructura y política salarial; así como del adecuada administración de los beneficios sociales.

- Velar por el cumplimiento del rol vacacional.

Encargado de área de finanzas: Responsable de temas contables, económicos y aspectos legales de la empresa.

- Tener la información contable actualizada.

- Archivar los comprobantes de compras, recibo de honorarios.

- Realizar asientos en el libro diario

- Preparar el informe mensual de pagos y efectuarlos.

\subsection{Estructura organizacional}

A continuación en la físura 6.1 se presenta el organigrama de la empresa.

Figura 6.1

Organigrama de la empresa

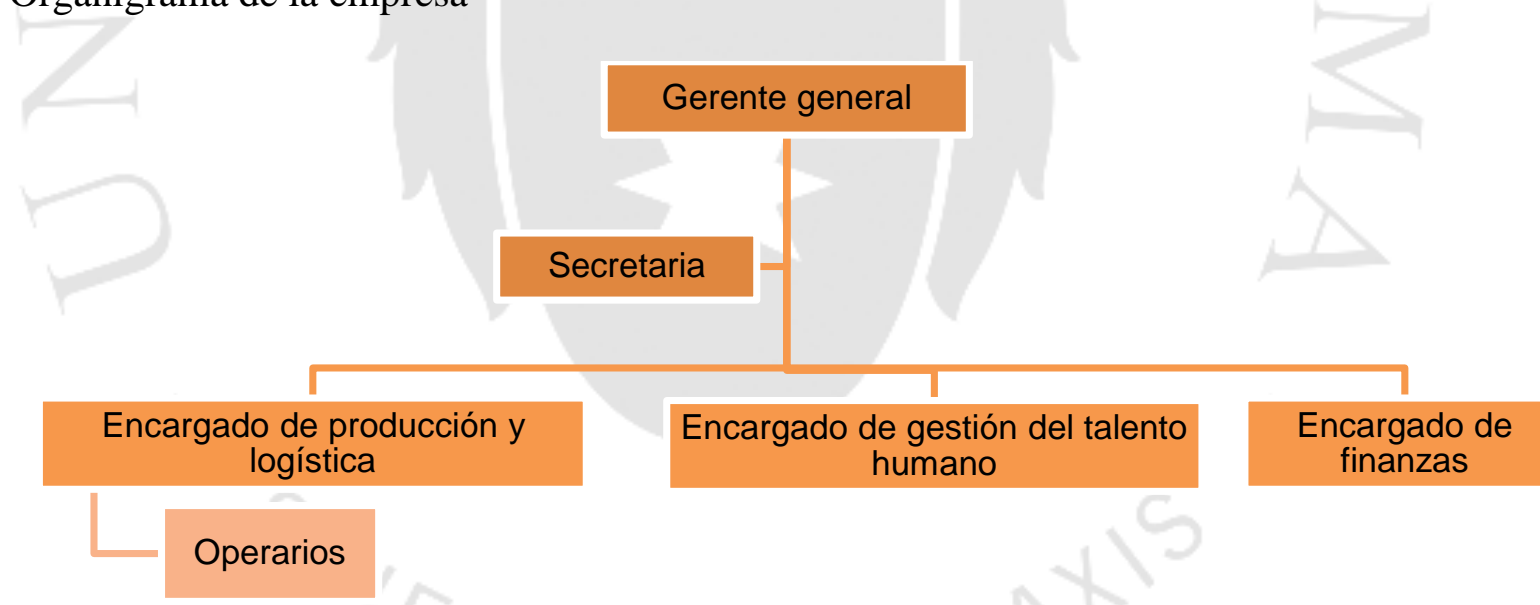

Elaboración propia

De acuerdo al decreto legislativo N 854, Ley de jornada de trabajo. El articulo uno indica que la jornada laboral para varones y mujeres mayores de edad es de ocho horas diarias o cuarenta y ocho horas a la semana como máximo.

Dadas estas consideraciones se ha establecido el horario de trabajo, detallado en la tabla 6.2. 
Tabla 6.2

Horario de trabajo

\begin{tabular}{|c|c|}
\hline Días & Horario \\
\hline Lunes a Viernes & $8: 00 \mathrm{am}-17: 45 \mathrm{pm}$ \\
\hline Sábado & $8: 00 \mathrm{am}-12: 00 \mathrm{pm}$ \\
\hline Refrigerio & $12: 30 \mathrm{pm}-1: 30 \mathrm{pm}$ \\
\hline
\end{tabular}

Elaboración propia

La vestimenta es importante en una empresa de producción de alimentos, ya que ayuda a prevenir contaminaciones. El uniforme de trabajo para el área de producción es el siguiente:

- Polo blanco de la empresa

- Jean

- Toca o gorro

- Cubre boca

- Guantes

- Zapatos ( botas blancas antideslizantes)

- Delantal impermeable

Además, el uniforme de forma obligatoria para las personas que ingresen a la zona productiva es el siguiente:

- Guardapolvo blanco

- Toca o gorro

- Cubre boca

- Zapatos apropiados 


\section{CAPÍTULO VII: ASPECTOS ECONÓMICOS Y FINANCIEROS}

\subsection{Inversiones}

Las inversiones a considerar para el proyecto, están relacionados a las adquisiciones de los activos tangibles necesarios para la puesta en marcha del proyecto.

\subsubsection{Estimación de las inversiones de largo plazo}

Dentro de la inversión a considerar para el proyecto están contempladas todas las compras de la maquinaria y mobiliario necesario para el funcionamiento de la empresa. Así mismo están incluidas las inversiones relacionadas al terreno y a las edificaciones necesarias para la instalación de la planta. Los rubros a considerar para la inversión tangible son los siguientes:

a) Terreno

El costo del terreno en Huaral es en promedio de S/. 300 por $\mathrm{m}^{2}$. Será necesario adquirir un terreno de $504 \mathrm{~m}^{2}$ (Punto 5.11.3) lo que dará un total de inversión en terreno aproximado de S/.151.200,00.

b) Edificaciones

Para calcular el costo en edificaciones, se tomó como referencia el Cuadro de Valores Unitarios Oficiales de Edificaciones para la Costa vigente (Octubre 2015) promulgado por el Ministerio de Vivienda, Construcción y Saneamiento. Los valores son multiplicados por cada área para determinar el costo total en edificaciones. 
Tabla 7.1

Inversión en edificaciones de oficinas administrativas, almacenes y comedor

\begin{tabular}{|l|c|c|c|c|c|c|}
\cline { 2 - 7 } \multicolumn{1}{c|}{} & \multicolumn{2}{c|}{ Oficinas administrativas } & \multicolumn{2}{c|}{ Almacenes } & \multicolumn{2}{c|}{ Comedor } \\
\cline { 2 - 7 } \multicolumn{1}{c|}{} & Tipo & Costo (S/.) & Tipo & Costo (S/.) & Tipo & Costo (S/.) \\
\hline Muros y columnas & $\mathrm{C}$ & 201,91 & $\mathrm{C}$ & 201,91 & $\mathrm{C}$ & 201,91 \\
\hline Techos & $\mathrm{C}$ & 148,94 & $\mathrm{C}$ & 148,94 & $\mathrm{C}$ & 148,94 \\
\hline Pisos & $\mathrm{E}$ & 56,90 & $\mathrm{E}$ & 56,90 & $\mathrm{E}$ & 56,90 \\
\hline Puertas y ventanas & $\mathrm{E}$ & 63,04 & $\mathrm{~F}$ & 47,33 & $\mathrm{~F}$ & 47,33 \\
\hline Revestimientos & $\mathrm{E}$ & 78,96 & $\mathrm{E}$ & 78,96 & $\mathrm{E}$ & 78,96 \\
\hline Baños & $\mathrm{F}$ & 11,07 & $\mathrm{~F}$ & 11,07 & $\mathrm{~F}$ & 11,07 \\
\hline $\begin{array}{l}\text { Instalaciones eléctricas } \\
\text { y sanitarias }\end{array}$ & $\mathrm{F}$ & 31,91 & $\mathrm{~F}$ & 31,91 & $\mathrm{~F}$ & 31,91 \\
\hline Costo (S/./ m2) & & 592,73 & & 577,02 & & 577,02 \\
\hline Área (m2) & & 141,00 & & 23,78 & 17,38 \\
\hline Total (S/.) & & $\mathbf{8 3 . 5 7 4 , 9 3}$ & & $\mathbf{1 3 . 7 2 1 , 5 4}$ & $\mathbf{1 0 . 0 2 8 , 6 1}$ \\
\hline
\end{tabular}

Elaboración propia

Adicionalmente a ello, para el área de producción se ha considerado una inversión de \$15.000,00 más IGV para la construcción de la nave industrial.

Con esta información, a continuación se muestra el resumen de la inversión en edificaciones.

Tabla 7.2

Inversión total en edificaciones

\begin{tabular}{|c|c|}
\hline Zona & Total (S/.) \\
\hline Área de Producción & $56.640,00$ \\
\hline Almacenes & $13.721,54$ \\
\hline Oficinas administrativas & $83.574,93$ \\
\hline Comedor & $10.028,61$ \\
\hline $\begin{array}{r}\text { Total } \\
\end{array}$ & $163.965,07$ \\
\hline
\end{tabular}

Elaboración propia

c) Muebles para la zona administrativa, almacenes y comedor

A continuación se muestra la inversión en muebles necesarios para las zonas administrativas, almacenes y el comedor. 
Tabla 7.3

Inversión en muebles

\begin{tabular}{|l|c|c|c|}
\hline \multicolumn{1}{|c|}{ Muebles } & Cantidad & Costo Unitario (S/.) & Costo Total (S/.) \\
\hline Computadoras & 5.00 & $1,279.00$ & $6,395.00$ \\
\hline Impresora & 1.00 & 200.00 & 200.00 \\
\hline Telefonía & 5.00 & 545.33 & $2,726.65$ \\
\hline Escritorios de oficina & 5.00 & 350.00 & $1,750.00$ \\
\hline Sillas giratorias & 12.00 & 175.00 & $2,100.00$ \\
\hline Juego de comedor (4 personas) & 3.00 & 325.00 & 975.00 \\
\hline Mesas de trabajo & 3.50 & 620.00 & $2,170.00$ \\
\hline Total & & & $\mathbf{1 6 , 3 1 6 . 6 5}$ \\
\hline
\end{tabular}

Elaboración propia

d) Maquinaria

En esta sección se muestra la inversión estimada para la maquinaria necesaria para el proceso de producción.

Tabla 7.4

Inversión en maquinaria

\begin{tabular}{|l|c|c|c|}
\hline \multicolumn{1}{|c|}{ Maquinaria } & Cantidad & Costo Unitario (S/.) & Costo Total (S/.) \\
\hline Lavadora de frutas (Ver anexo 1) & 1.00 & $77.832,80$ & $77.832,80$ \\
\hline Secador de bandejas (Ver anexo 2) & 1.00 & $53.100,00$ & $53.100,00$ \\
\hline Selladora & 1.00 & $15.000,00$ & $15.000,00$ \\
\hline Molino de martillos (Ver anexo 2) & 1.00 & $10.974,00$ & $10.974,00$ \\
\hline Embolsadora & 1.00 & $13.000,00$ & $13.000,00$ \\
\hline Total & & & $\mathbf{1 6 9 . 9 0 6 , 8 0}$ \\
\hline
\end{tabular}

Elaboración propia

e) Herramientas de control y medición

A continuación se detalla la inversión en instrumentos de control y medición:

Tabla 7.5

Inversión en instrumentos de control y medición

\begin{tabular}{|l|c|c|c|}
\hline \multicolumn{1}{|c|}{ Instrumentos de control y medición } & Cantidad & Costo Unitario (S/.) & Costo Total (S/.) \\
\hline Balanza de plataforma & 1.00 & 950,00 & 950,00 \\
\hline Carretilla hidráulica (Ver anexo 3) & 2.00 & $1.350,85$ & $2.701,71$ \\
\hline Medidor de humedad para granos & 1.00 & 550,00 & 550,00 \\
\hline Total & & & $\mathbf{4 . 2 0 1 , 7 1}$ \\
\hline
\end{tabular}

Elaboración propia 


\subsubsection{Estimación de las inversiones de corto plazo (Capital de trabajo)}

El capital de trabajo son el conjunto de costos y gastos a incurrir para el funcionamiento de la empresa una vez que esta empiece a operar. Esta inversión es necesaria para cubrir los desembolsos antes de que se produzcan los ingresos. Los rubros a cubrir los siguientes:

- Materia prima

- Mano de obra directa e indirecta

- Servicios

A efectos del presente proyecto hemos calculado el capital de trabajo para un periodo de 3 meses. En la tabla 7.6 se muestra el resumen del capital de trabajo necesario para dicho periodo.

Tabla 7.6

Capital de trabajo

\begin{tabular}{|l|c|c|}
\hline \multicolumn{1}{|c|}{ Concepto } & Costo anual (S/.) & Capital de trabajo(S/.) \\
\hline Materia prima & $105.550,20$ & $26.387,55$ \\
\hline Indumentaria y herramientas & 555,00 & 138,75 \\
\hline Mano de obra directa & $41.429,00$ & $10.357,25$ \\
\hline Mano de obra indirecta & $144.595,33$ & $36.148,83$ \\
\hline Agua (Planta) & 612,21 & 153,05 \\
\hline Energía eléctrica (Planta) & 994,40 & 248,60 \\
\hline Gas natural & 549,14 & 137,29 \\
\hline Agua (oficinas) & 437,02 & 109,26 \\
\hline Luz (oficinas) & $1.410,24$ & 352,56 \\
\hline \multicolumn{1}{|c|}{ Total } & $\mathbf{2 9 6 . 1 3 2 , 5 5}$ & $\mathbf{7 4 . 0 3 3 , 1 4}$ \\
\hline
\end{tabular}

Elaboración propia

\subsection{Costos de producción}

Los costos de producción son los que están relacionados directamente con la elaboración del producto, tales como materia prima, insumos y las remuneraciones de los trabajadores de la empresa. 


\subsubsection{Costos de la materia prima}

Tabla 7.7

Costo unitario de materia prima

\begin{tabular}{|l|c|c|}
\hline \multicolumn{1}{|c|}{ Materia prima } & Costo & Unidad \\
\hline Lúcuma seda & 2.30 & S/./kg \\
\hline Lejía desinfectante & 2.10 & S/./L \\
\hline Bolsas de polietileno & 0.20 & S/./und. \\
\hline Cajas de cartón & 0.50 & S/./und. \\
\hline
\end{tabular}

Elaboración propia

Tabla 7.8

Costos de materia prima

\begin{tabular}{|c|c|c|c|c|c|}
\hline Año & Lúcuma seda & Lejía desinfectante & Bolsas de polietileno & Cajas de cartón & Total (S/.) \\
\hline 2016 & $105.082,20$ & 191,79 & 184,20 & 92,00 & $105.550,20$ \\
\hline 2017 & $124.009,32$ & 226,34 & 217,40 & 108,50 & $124.561,55$ \\
\hline 2018 & $142.936,43$ & 260,88 & 250,60 & 125,00 & $143.572,91$ \\
\hline 2019 & $161.863,54$ & 295,43 & 283,80 & 141,50 & $162.584,27$ \\
\hline 2020 & $180.790,65$ & 329,97 & 317,00 & 158,50 & $181.596,13$ \\
\hline 2021 & $199.717,76$ & 364,52 & 350,20 & 175,00 & $200.607,48$ \\
\hline 2022 & $218.644,87$ & 399,06 & 383,40 & 191,50 & $219.618,84$ \\
\hline 2023 & $237.571,99$ & 433,61 & 416,60 & 208,00 & $238.630,20$ \\
\hline 2024 & $256.499,10$ & 468,16 & 449,80 & 224,50 & $257.641,55$ \\
\hline 2025 & $275.426,21$ & 502,70 & 483,00 & 241,50 & $276.653,41$ \\
\hline
\end{tabular}

Elaboración propia

\subsubsection{Costo de la mano de obra directa}

Para el cálculo de los costos por mano de obra directa, se tomó en consideración el número de operarios por cada año, hallado en el punto 5.10.3. Luego se consideraron contratos a plazo determinado (Renta 5ta categoría) con renovaciones semestrales. El costo total en mano de obra directa se encuentra en la tabla 7.9. 
Tabla 7.9

Costos de mano de obra directa

\begin{tabular}{|c|c|c|c|c|c|c|}
\hline Año & $\begin{array}{c}\text { Número de } \\
\text { operarios }\end{array}$ & $\begin{array}{c}\text { Remuneración } \\
\text { básica por } \\
\text { operario }\end{array}$ & $\begin{array}{c}\text { EsSalud (9\%) } \\
\text { por operario }\end{array}$ & $\begin{array}{c}\text { Gratificación } \\
\text { por operario }\end{array}$ & $\begin{array}{c}\text { CTS por } \\
\text { operario }\end{array}$ & Total (S/.) \\
\hline 2016 & 3 & 850,00 & 76,50 & $1.700,00$ & 991,67 & $41.429,00$ \\
\hline 2017 & 3 & 900,00 & 81,00 & $1.800,00$ & $1.050,00$ & $43.866,00$ \\
\hline 2018 & 4 & 950,00 & 85,50 & $1.900,00$ & $1.108,33$ & $61.737,33$ \\
\hline 2019 & 6 & $1.000,00$ & 90,00 & $2.000,00$ & $1.166,67$ & $97.480,00$ \\
\hline 2020 & 6 & $1.050,00$ & 94,50 & $2.100,00$ & $1.225,00$ & $102.354,00$ \\
\hline 2021 & 6 & $1.100,00$ & 99,00 & $2.200,00$ & $1.283,33$ & $107.228,00$ \\
\hline 2022 & 6 & $1.150,00$ & 103,50 & $2.300,00$ & $1.341,67$ & $112.102,00$ \\
\hline 2023 & 6 & $1.200,00$ & 108,00 & $2.400,00$ & $1.400,00$ & $116.976,00$ \\
\hline 2024 & 6 & $1.250,00$ & 112,50 & $2.500,00$ & $1.458,33$ & $121.850,00$ \\
\hline 2025 & 7 & $1.300,00$ & 117,00 & $2.600,00$ & $1.516,67$ & $147.844,67$ \\
\hline
\end{tabular}

Elaboración propia

\subsubsection{Costo Indirecto de Fabricación (materiales indirectas, mano de obra indirecta} y costos generales de planta)

Tabla 7.10

Remuneraciones de puestos administrativos

\begin{tabular}{|l|c|}
\hline \multicolumn{1}{|c|}{ Puesto } & Remuneración mensual (S/.) \\
\hline Gerente general & $3.500,00$ \\
\hline Secretaria & $1.500,00$ \\
\hline Encargado de producción y logística & $1.800,00$ \\
\hline Encargado del talento humano & $1.800,00$ \\
\hline Encargado de Finanzas & $1.800,00$ \\
\hline \multicolumn{1}{|c|}{ Total } & $\mathbf{1 0 . 4 0 0 , 0 0}$ \\
\hline
\end{tabular}

Elaboración propia 
Tabla 7.11

Costos de mano de obra indirecta

\begin{tabular}{|c|c|c|c|c|c|}
\hline Año & $\begin{array}{c}\text { Remuneración } \\
\text { mensual MOI (S/.) }\end{array}$ & $\begin{array}{c}\text { EsSalud (9\%) } \\
(\mathbf{S} / .)\end{array}$ & $\begin{array}{c}\text { Gratificaciones } \\
\text { (S/.) }\end{array}$ & CTS (S/.) & Total (S/.) \\
\hline 2016 & $8.900,00$ & 801,00 & $17.800,00$ & $10.383,33$ & $144.595,33$ \\
\hline 2017 & $10.920,00$ & 982,80 & $21.840,00$ & $12.740,00$ & $177.413,60$ \\
\hline 2018 & $11.466,00$ & $1.031,94$ & $22.932,00$ & $13.377,00$ & $186.284,28$ \\
\hline 2019 & $12.039,30$ & $1.083,54$ & $24.078,60$ & $14.045,85$ & $195.598,49$ \\
\hline 2020 & $12.641,27$ & $1.137,71$ & $25.282,53$ & $14.748,14$ & $205.378,42$ \\
\hline 2021 & $13.273,33$ & $1.194,60$ & $26.546,66$ & $15.485,55$ & $215.647,34$ \\
\hline 2022 & $13.936,99$ & $1.254,33$ & $27.873,99$ & $16.259,83$ & $226.429,71$ \\
\hline 2023 & $14.633,84$ & $1.317,05$ & $29.267,69$ & $17.072,82$ & $237.751,19$ \\
\hline 2024 & $15.365,54$ & $1.382,90$ & $30.731,07$ & $17.926,46$ & $249.638,75$ \\
\hline 2025 & $16.133,81$ & $1.452,04$ & $32.267,63$ & $18.822,78$ & $262.120,69$ \\
\hline
\end{tabular}

Elaboración propia

Tabla 7.12

Costo del agua potable, energía eléctrica y gas natural en planta

\begin{tabular}{|c|c|c|c|c|c|c|}
\hline \multirow{2}{*}{ Año } & \multicolumn{2}{|c|}{ Agua potable } & \multicolumn{2}{|c|}{ Energía eléctrica } & \multicolumn{2}{|c|}{ Gas natural } \\
\cline { 2 - 8 } & $\begin{array}{c}\text { Cantidad } \\
\text { requerida } \\
\left(\mathbf{m}^{\mathbf{3}}\right)\end{array}$ & $\begin{array}{c}\text { Costo total } \\
\mathbf{( S / . )}\end{array}$ & $\begin{array}{c}\text { Cantidad } \\
\text { requerida } \\
(\mathbf{K W} \mathbf{~ h r})\end{array}$ & $\begin{array}{c}\text { Costo total } \\
\mathbf{( S / . )}\end{array}$ & $\begin{array}{c}\text { Cantidad } \\
\text { requerida } \\
\left(\mathbf{m}^{\mathbf{3}}\right)\end{array}$ & $\begin{array}{c}\text { Costo total } \\
\mathbf{( S / . )}\end{array}$ \\
\hline 2016 & 22,83 & 612,21 & $2.096,39$ & 994,40 & 298,88 & 549,14 \\
\hline 2017 & 26,94 & 718,81 & $2.474,00$ & $1.168,17$ & 352,71 & 634,19 \\
\hline 2018 & 31,06 & 825,41 & $2.851,61$ & $1.341,95$ & 406,55 & 719,24 \\
\hline 2019 & 35,17 & 932,01 & $3.229,21$ & $1.515,72$ & 460,38 & 804,29 \\
\hline 2020 & 39,28 & $1.038,54$ & $3.606,59$ & $1.689,39$ & 514,18 & 889,28 \\
\hline 2021 & 43,39 & $1.145,14$ & $3.984,20$ & $1.863,17$ & 568,02 & 974,33 \\
\hline 2022 & 47,51 & $1.251,74$ & $4.361,80$ & $2.036,94$ & 621,85 & $1.059,38$ \\
\hline 2023 & 51,62 & $1.358,34$ & $4.739,41$ & $2.210,72$ & 675,68 & $1.144,43$ \\
\hline 2024 & 55,73 & $1.464,94$ & $5.117,01$ & $2.384,49$ & 729,52 & $1.229,48$ \\
\hline 2025 & 59,84 & $1.571,54$ & $5.494,62$ & $2.558,26$ & 783,35 & $1.314,53$ \\
\hline
\end{tabular}

Elaboración propia 


\subsection{Presupuestos Operativos}

\subsubsection{Presupuesto de ingreso por ventas}

Tabla 7.13

Presupuesto de ingreso por ventas

\begin{tabular}{|c|c|c|c|}
\hline Año & Demanda & Precio unitario (S/./kg) & Ingreso (S/.) \\
\hline 2016 & $9.216,08$ & 12,80 & $401.083,93$ \\
\hline 2017 & $10.876,06$ & 12,80 & $473.326,05$ \\
\hline 2018 & $12.536,03$ & 12,80 & $545.568,16$ \\
\hline 2019 & $14.196,01$ & 12,80 & $617.810,27$ \\
\hline 2020 & $15.855,98$ & 12,80 & $690.052,39$ \\
\hline 2021 & $17.515,96$ & 12,80 & $762.294,50$ \\
\hline 2022 & $19.175,93$ & 12,80 & $834.536,61$ \\
\hline 2023 & $20.835,91$ & 12,80 & $906.778,72$ \\
\hline 2024 & $22.495,88$ & 12,80 & $979.020,84$ \\
\hline 2025 & $24.155,86$ & 12,80 & $1.051 .262,95$ \\
\hline
\end{tabular}

Elaboración propia 


\subsubsection{Presupuesto operativo de costos}

Tabla 7.14

Presupuesto operativo de costos (en nuevos soles)

\begin{tabular}{|l|c|c|c|c|c|c|c|c|c|c|}
\hline \multicolumn{1}{|c|}{ Rubro } & $\mathbf{2 0 1 6}$ & $\mathbf{2 0 1 7}$ & $\mathbf{2 0 1 8}$ & $\mathbf{2 0 1 9}$ & $\mathbf{2 0 2 0}$ & $\mathbf{2 0 2 1}$ & $\mathbf{2 0 2 2}$ & $\mathbf{2 0 2 3}$ & $\mathbf{2 0 2 4}$ & $\mathbf{2 0 2 5}$ \\
\hline Materia prima & $105.550,20$ & $124.561,55$ & $143.572,91$ & $162.584,27$ & $181.596,13$ & $200.607,48$ & $219.618,84$ & $238.630,20$ & $257.641,55$ & $276.653,41$ \\
\hline Mano de obra directa & $41.429,00$ & $43.866,00$ & $61.737,33$ & $97.480,00$ & $102.354,00$ & $107.228,00$ & $112.102,00$ & $116.976,00$ & $121.850,00$ & $147.844,67$ \\
\hline CIF & $2.155,75$ & $2.521,18$ & $2.886,60$ & $3.252,02$ & $3.617,22$ & $3.982,64$ & $4.348,06$ & $4.713,48$ & $5.078,90$ & $5.444,32$ \\
\hline Depreciación fabril & $20.928,93$ & $20.928,93$ & $20.928,93$ & $20.928,93$ & $20.928,93$ & $20.928,93$ & $20.928,93$ & $20.928,93$ & $20.928,93$ & $20.928,93$ \\
\hline Total & $\mathbf{1 7 0 . 0 6 3 , 8 8}$ & $\mathbf{1 9 1 . 8 7 7 , 6 6}$ & $\mathbf{2 2 9 . 1 2 5 , 7 7}$ & $\mathbf{2 8 4 . 2 4 5 , 2 1}$ & $\mathbf{3 0 8 . 4 9 6 , 2 7}$ & $\mathbf{3 3 2 . 7 4 7 , 0 5}$ & $\mathbf{3 5 6 . 9 9 7 , 8 3}$ & $\mathbf{3 8 1 . 2 4 8 , 6 1}$ & $\mathbf{4 0 5 . 4 9 9 , 3 8}$ & $\mathbf{4 5 0 . 8 7 1 , 3 3}$ \\
\hline
\end{tabular}

Elaboración propia

\subsubsection{Presupuesto operativo de gastos}

Tabla 7.15

Presupuesto operativo de gastos (en nuevos soles)

\begin{tabular}{|c|c|c|c|c|c|c|c|c|c|c|c|}
\hline Rubro & 2015 & 2016 & 2017 & 2018 & 2019 & 2020 & 2021 & 2022 & 2023 & 2024 & 2025 \\
\hline Mano de obra indirecta & 0,00 & $144.595,33$ & $177.413,60$ & $186.284,28$ & $195.598,49$ & $205.378,42$ & $215.647,34$ & $226.429,71$ & $237.751,19$ & $249.638,75$ & $262.120,69$ \\
\hline Indumentaria y herramientas & 0,00 & 555,00 & 555,00 & 740,00 & $1.110,00$ & $1.110,00$ & $1.110,00$ & $1.110,00$ & $1.110,00$ & $1.110,00$ & $1.295,00$ \\
\hline Depreciación No fabril & 0,00 & $6.311,84$ & $6.311,84$ & $6.311,84$ & $6.311,84$ & $6.311,84$ & $6.311,84$ & $6.311,84$ & $6.311,84$ & $6.311,84$ & $6.311,84$ \\
\hline Certificaciones & 0,00 & $2.640,00$ & $2.640,00$ & $2.640,00$ & $2.640,00$ & $2.640,00$ & $2.640,00$ & $2.640,00$ & $2.640,00$ & $2.640,00$ & $2.640,00$ \\
\hline Servicios & 0,00 & $1.847,26$ & $1.847,26$ & $1.847,26$ & $1.847,26$ & $1.847,26$ & $1.847,26$ & $1.847,26$ & $1.847,26$ & $1.847,26$ & $1.847,26$ \\
\hline Constitución y asesoría legal & $6.600,00$ & 0,00 & 0,00 & 0,00 & 0,00 & 0,00 & 0,00 & 0,00 & 0,00 & 0,00 & 0,00 \\
\hline Total & $6.600,00$ & $155.949,44$ & $188.767,70$ & \begin{tabular}{|l|}
$197.823,38$ \\
\end{tabular} & $207.507,60$ & \begin{tabular}{|l|}
$217.287,52$ \\
\end{tabular} & $227.556,44$ & \begin{tabular}{|l|}
$238.338,81$ \\
\end{tabular} & $249.660,29$ & $261.547,85$ & \begin{tabular}{|l|}
$274.214,79$ \\
\end{tabular} \\
\hline
\end{tabular}

Elaboración propia 


\subsection{Presupuestos Financieros}

\subsubsection{Presupuesto de Servicio de Deuda}

La inversión total requerida para el proyecto es de S/. 579,623.37 (Cuadro 7.16). El financiamiento será compartido entre accionistas y préstamo. Para el proyecto se ha considerado un capital propio del $20 \%$ mientras que el otro $80 \%$ será financiado mediante préstamo. El préstamo que se obtendrá será en COFIDE, mediante su programa PROBID, el cuál es específico para proyectos de pequeñas y medianas empresas exportadoras el cual ofrece una tasa de $14 \%$. El pago del préstamo a lo largo del proyecto con cuotas crecientes se puede ver en la tabla 7.16.

Tabla 7.16

Resumen de inversión total

\begin{tabular}{|l|c|}
\hline \multicolumn{1}{|c|}{ Tipo de inversión } & (S/.) \\
\hline Terreno & $151.200,00$ \\
\hline Edificaciones & $163.965,07$ \\
\hline Maquinaria y muebles & $190.425,16$ \\
\hline Capital de trabajo & $74.033,14$ \\
\hline \multicolumn{1}{|c|}{ Inversión total } & $\mathbf{5 7 9 . 6 2 3 , 3 7}$ \\
\hline
\end{tabular}

Elaboración propia

Tabla 7.17

Cuadro de Servicio de deuda (en nuevos soles)

\begin{tabular}{|c|c|c|c|c|}
\hline Año & Principal & Amortización & Intereses & Cuota \\
\hline 2015 & $463.698,69$ & - & - & - \\
\hline 2016 & $463.698,69$ & $16.560,67$ & $64.917,82$ & $81.478,48$ \\
\hline 2017 & $447.138,03$ & $33.121,34$ & $62.599,32$ & $95.720,66$ \\
\hline 2018 & $414.016,69$ & $49.682,00$ & $57.962,34$ & $107.644,34$ \\
\hline 2019 & $364.334,69$ & $66.242,67$ & $51.006,86$ & $117.249,53$ \\
\hline 2020 & $298.092,02$ & $82.803,34$ & $41.732,88$ & $124.536,22$ \\
\hline 2021 & $215.288,68$ & $99.364,01$ & $30.140,42$ & $129.504,42$ \\
\hline 2022 & $115.924,67$ & $115.924,67$ & $16.229,45$ & $132.154,13$ \\
\hline
\end{tabular}

Elaboración propia

Para el cálculo del Costo Promedio Ponderado de Capital (CPPC), primero se determinó el valor del COK. Para su cálculo se utilizó el modelo CAPM (Modelo de Evaluación de Activos de Capital), el cual nos devuelve la tasa requerida de retorno de los accionistas, en este caso nosotros. La fórmula a aplicar es la siguiente: 
Figura 7.1

Fórmula para el cálculo del COK

$C O K_{\text {proy }}=r_{f}+\beta_{\text {proy }} \times\left[r_{m}-r_{f}\right]+$ Riesgo País

Fuente: Diario Gestión

Los datos para el cálculo del COK son los siguientes:

- $r_{f}=2.241 \%$

- $\beta_{\text {proy }}=\beta_{\mu} *\left(1+\frac{D}{E} *(1-T)\right)=0.8(1+0.2721 *(1-0.3))=0.9524$

(Aswath Damodaran, Enero 2015)

- $r_{m}-r_{f}=8.45 \%$ (Diario Gestión, 2015)

- Riesgo país $=\lambda * 2.29 \%=1.5 * 2.29=3.44 \%$ (Diario Gestión, 2015)

Con estos datos el COK del proyecto es $13.72 \%$. Con este valor hallado, a continuación (Tabla 7.18) presentamos el cálculo del CPPC.

Tabla 7.18

Distribución de la inversión

\begin{tabular}{|c|c|c|c|c|}
\hline & Financiamiento $(\boldsymbol{\%})$ & Monto $(\mathbf{S} /)$. & Costo dinero & Tasa de descuento \\
\hline Capital propio & 20,00 & $115.924,67$ & $13,72 \%$ & $2,74 \%$ \\
\hline Préstamo & 80,00 & $463.698,69$ & $14,00 \%$ & $7,84 \%$ \\
\hline Total & 100,00 & $579.623,37$ & & $10,58 \%$ \\
\hline
\end{tabular}

Elaboración propia 


\subsubsection{Presupuesto de Estado Resultados}

Tabla 7.19

Presupuesto de Estado de Resultados (en nuevos soles)

\begin{tabular}{|c|c|c|c|c|c|c|c|c|c|c|}
\hline Rubro & 2016 & 2017 & 2018 & 2019 & 2020 & 2021 & 2022 & 2023 & 2024 & 2025 \\
\hline Ingreso por ventas & $401.083,93$ & $473.326,05$ & $545.568,16$ & $617.810,27$ & $690.052,39$ & $762.294,50$ & $834.536,61$ & $906.778,72$ & $979.020,84$ & $1.051 .262,95$ \\
\hline (-) Costo de ventas & $170.063,88$ & $191.877,66$ & $229.125,77$ & $284.245,21$ & $308.496,27$ & $332.747,05$ & $356.997,83$ & $381.248,61$ & \begin{tabular}{|l|}
$405.499,38$ \\
\end{tabular} & $450.871,33$ \\
\hline (=) Utilidad bruta & $231.020,05$ & $281.448,39$ & $316.442,39$ & $333.565,06$ & $381.556,11$ & $429.547,45$ & $477.538,78$ & $525.530,12$ & $573.521,45$ & $600.391,62$ \\
\hline (-) Gastos administrativos & $155.949,44$ & $188.767,70$ & $197.823,38$ & $207.507,60$ & $217.287,52$ & $227.556,44$ & $238.338,81$ & $249.660,29$ & $261.547,85$ & $274.214,79$ \\
\hline$=$ Utilidad Operativa & $75.070,62$ & $92.680,69$ & $118.619,01$ & $126.057,46$ & $164.268,59$ & $201.991,01$ & $239.199,97$ & $275.869,82$ & $311.973,60$ & $326.176,83$ \\
\hline (-) Gastos financieros & $64.917,82$ & $62.599,32$ & $57.962,34$ & $51.006,86$ & $41.732,88$ & $30.140,42$ & $16.229,45$ & 0,00 & 0,00 & 0,00 \\
\hline$=$ Utilidad antes de part. e impuestos & $10.152,80$ & $30.081,36$ & $60.656,67$ & $75.050,61$ & $122.535,71$ & $171.850,59$ & $222.970,52$ & $275.869,82$ & $311.973,60$ & $326.176,83$ \\
\hline (-) Participaciones $(10 \%)$ & $1.015,28$ & $3.008,14$ & $6.065,67$ & $7.505,06$ & $12.253,57$ & $17.185,06$ & $22.297,05$ & $27.586,98$ & $31.197,36$ & $32.617,68$ \\
\hline (-) Impuesto a la renta (27\%) & $2.741,26$ & $8.121,97$ & $16.377,30$ & $20.263,66$ & $33.084,64$ & $46.399,66$ & $60.202,04$ & $74.484,85$ & $84.232,87$ & $88.067,74$ \\
\hline (=) Utilidad Neta & $6.396,26$ & $18.951,26$ & $38.213,70$ & $47.281,88$ & $77.197,50$ & $108.265,87$ & $140.471,43$ & $173.797,99$ & $196.543,37$ & $205.491,40$ \\
\hline
\end{tabular}

Elaboración propia
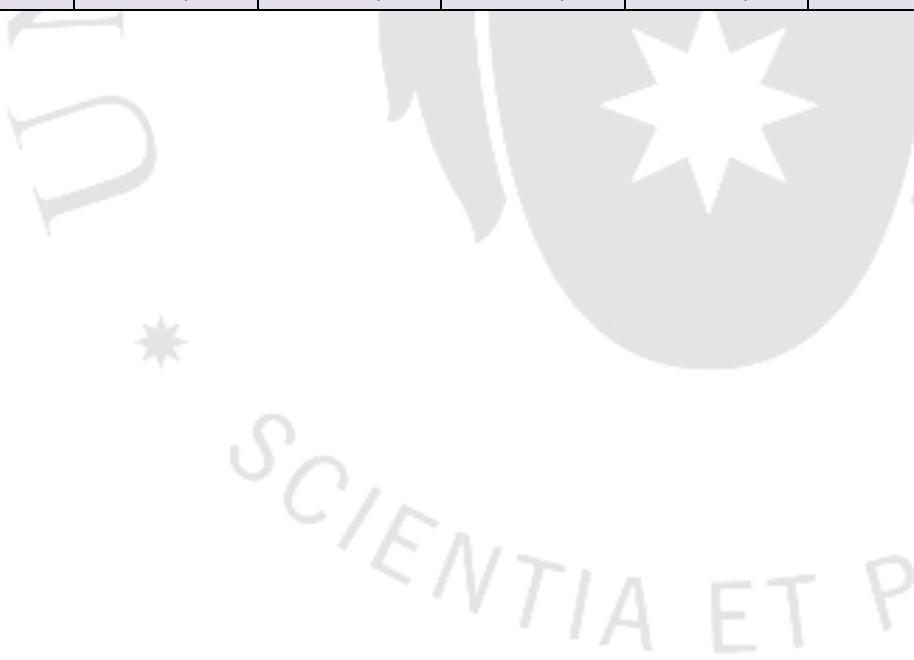


\subsubsection{Presupuesto de Estado de Situación Financiera}

Tabla 7.20

Presupuesto de Estado de Situación Financiera (en nuevos soles)

\begin{tabular}{|c|c|c|c|c|c|c|c|c|c|c|c|}
\hline \multicolumn{12}{|c|}{$\begin{array}{l}\text { Estado de Situación Financiera } \\
\text { Empresa "Organic up" } \\
\text { diciembre de cada año (Expresado en Nuevos Soles) }\end{array}$} \\
\hline Año & 2015 & 2016 & 2017 & 2018 & 2019 & 2020 & 2021 & 2022 & 2023 & 2024 & 2025 \\
\hline \multicolumn{12}{|l|}{ Activo } \\
\hline Corriente & & & & & & & & & & & \\
\hline Caja y Bancos & $67.433,14$ & $82.249,78$ & $95.214,14$ & $102.264,59$ & $76.572,99$ & $67.411,89$ & $43.519,91$ & $4.872,30$ & $83.928,74$ & $146.189,65$ & $186.550,02$ \\
\hline Inventarios (3\%) & 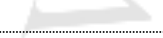 & $12.032,52$ & $14.199,78$ & $16.367,04$ & $18.534,31$ & $20.701,57$ & $22.868,83$ & $25.036,10$ & $27.203,36$ & $29.370,63$ & $31.537,89$ \\
\hline Total Activo Corriente & $67.433,14$ & $94.282,30$ & $109.413,93$ & $118.631,63$ & $95.107,30$ & $88.113,46$ & $66.388,74$ & $29.908,40$ & $111.132,10$ & $175.560,28$ & $218.087,91$ \\
\hline \multicolumn{12}{|l|}{ No Corriente } \\
\hline Valor en libros Activo Tangible & $505.590,23$ & $478.349,46$ & $451.108,69$ & $423.867,92$ & $396.627,15$ & $369.386,38$ & $342.145,61$ & $314.904,84$ & $287.664,08$ & $260.423,31$ & 233.182,54 \\
\hline Total Activo No Corriente & $505.590,23$ & $478.349,46$ & $451.108,69$ & $423.867,92$ & $396.627,15$ & $369.386,38$ & $342.145,61$ & $314.904,84$ & $287.664,08$ & $260.423,31$ & $233.182,54$ \\
\hline Total Activo & $573.023,37$ & $572.631,76$ & $560.522,62$ & $542.499,55$ & $491.734,45$ & $457.499,85$ & $408.534,36$ & $344.813,24$ & $398.796,18$ & $435.983,58$ & $451.270,45$ \\
\hline \multicolumn{12}{|l|}{ Pasivo } \\
\hline \multicolumn{12}{|l|}{ Pasivo Corriente } \\
\hline Préstamo Corto plazo & $16.560,67$ & $33.121,34$ & $49.682,00$ & $66.242,67$ & $82.803,34$ & $99.364,01$ & $115.924,67$ & 0,00 & 0,00 & 0,00 & 0,00 \\
\hline Participaciones & 0,00 & $1.015,28$ & $3.008,14$ & $6.065,67$ & $7.505,06$ & $12.253,57$ & $17.185,06$ & $22.297,05$ & $27.586,98$ & $31.197,36$ & $32.617,68$ \\
\hline Impuesto a la Renta $(27 \%)$ & 0,00 & $2.741,26$ & $8.121,97$ & $16.377,30$ & $20.263,66$ & $33.084,64$ & $46.399,66$ & $60.202,04$ & $74.484,85$ & $84.232,87$ & $88.067,74$ \\
\hline IGV por pagar & 0,00 & $6.016,26$ & $7.099,89$ & $8.183,52$ & $9.267,15$ & $10.350,79$ & $11.434,42$ & $12.518,05$ & $13.601,68$ & $14.685,31$ & $15.768,94$ \\
\hline Total Pasivo Corriente & $16.560,67$ & $42.894,13$ & $67.912,00$ & $96.869,16$ & $119.839,22$ & $155.053,00$ & $190.943,81$ & $95.017,14$ & $115.673,52$ & $130.115,54$ & $136.454,37$ \\
\hline Deuda a largo plazo & $447.138,03$ & $414.016,69$ & $364.334,69$ & $298.092,02$ & $215.288,68$ & $115.924,67$ & 0,00 & 0,00 & 0,00 & 0,00 & 0,00 \\
\hline Total Pasivo No Corriente & $447.138,03$ & $414.016,69$ & $364.334,69$ & $298.092,02$ & $215.288,68$ & $115.924,67$ & 0,00 & 0,00 & 0,00 & 0,00 & 0,00 \\
\hline Total Pasivo & $463.698,69$ & $456.910,82$ & $432.246,69$ & $394.961,18$ & $335.127,90$ & $270.977,68$ & $190.943,81$ & $95.017,14$ & $115.673,52$ & $130.115,54$ & $136.454,37$ \\
\hline \multicolumn{12}{|l|}{ Patrimonio } \\
\hline Capital social & $109.324,67$ & $109.324,67$ & $109.324,67$ & $109.324,67$ & $109.324,67$ & $109.324,67$ & $109.324,67$ & $109.324,67$ & $109.324,67$ & $109.324,67$ & $109.324,67$ \\
\hline Utilidad del ejercicio & 0,00 & $6.396,26$ & $18.951,26$ & $38.213,70$ & $47.281,88$ & $77.197,50$ & $108.265,87$ & $140.471,43$ & $173.797,99$ & $196.543,37$ & $205.491,40$ \\
\hline Total Patrimonio & $109.324,67$ & $115.720,94$ & $128.275,93$ & $147.538,38$ & $156.606,55$ & $186.522,17$ & $217.590,55$ & $249.796,10$ & $283.122,66$ & $305.868,04$ & $314.816,08$ \\
\hline Total Pasivo y Patrimonio & $573.023,37$ & $572.631,76$ & $560.522,62$ & $542.499,55$ & $491.734,45$ & $457.499,85$ & $408.534,36$ & $344.813,24$ & $398.796,18$ & $435.983,58$ & $451.270,45$ \\
\hline
\end{tabular}

Elaboración propia 


\subsubsection{Flujo de caja de corto plazo}

Tabla 7.21

Flujo de Caja de Corto Plazo (en nuevos soles)

\begin{tabular}{|c|c|c|c|c|c|c|c|c|c|c|c|}
\hline & 2015 & 2016 & 2017 & 2018 & 2019 & 2020 & 2021 & 2022 & 2023 & 2024 & 2025 \\
\hline Saldo inicial & $579.623,37$ & $67.433,14$ & $82.249,78$ & $95.214,14$ & $102.264,59$ & $76.572,99$ & $67.411,89$ & $43.519,91$ & $4.872,30$ & $83.928,74$ & $146.189,65$ \\
\hline Ingresos & & $\lambda$ & & 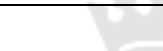 & +1 & & & & & & \\
\hline Ventas & 0,00 & $389.051,42$ & $471.158,78$ & $543.400,90$ & $615.643,01$ & $687.885,12$ & $760.127,24$ & $832.369,35$ & $904.611,46$ & $976.853,57$ & $1.049 .095,69$ \\
\hline IGV $(18 \%)$ & 0,00 & $72.195,11$ & $85.198,69$ & $98.202,27$ & $111.205,85$ & $124.209,43$ & $137.213,01$ & $150.216,59$ & $163.220,17$ & $176.223,75$ & $189.227,33$ \\
\hline Total ingresos & $579.623,37$ & $528.679,66$ & $638.607,25$ & $736.817,31$ & $829.113,45$ & $888.667,54$ & $964.752,14$ & $1.026 .105,84$ & $1.072 .703,93$ & $1.237 .006,06$ & $1.384 .512,67$ \\
\hline Egresos & & & 4 & 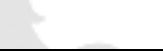 & 2 & & & & & & \\
\hline Adquisición de activo fijo & $505.590,23$ & 0,00 & 0,00 & 0,00 & 0,00 & 0,00 & 0,00 & 0,00 & 0,00 & 0,00 & 0,00 \\
\hline IGV $(18 \%)$ & & $66.178,85$ & $84.115,06$ & $97.118,64$ & $110.122,22$ & $123.125,80$ & $136.129,38$ & $149.132,96$ & $162.136,54$ & $175.140,12$ & $188.143,70$ \\
\hline Mano de obra directa & 0,00 & $41.429,00$ & $43.866,00$ & $61.737,33$ & $97.480,00$ & $102.354,00$ & $107.228,00$ & $112.102,00$ & $116.976,00$ & $121.850,00$ & $147.844,67$ \\
\hline Material directo & 0,00 & $105.550,20$ & $124.561,55$ & $143.572,91$ & $162.584,27$ & $181.596,13$ & $200.607,48$ & $219.618,84$ & $238.630,20$ & $257.641,55$ & $276.653,41$ \\
\hline Costo indirecto de fabricación & 0,00 & $2.155,75$ & $2.521,18$ & $2.886,60$ & $3.252,02$ & $3.617,22$ & $3.982,64$ & $4.348,06$ & $4.713,48$ & $5.078,90$ & $5.444,32$ \\
\hline Gastos administrativos & $6.600,00$ & $149.637,59$ & $182.455,86$ & $191.511,54$ & $201.195,75$ & $210.975,68$ & $221.244,60$ & $232.026,97$ & $243.348,45$ & $255.236,01$ & $267.902,95$ \\
\hline Gastos financieros & 0,00 & $64.917,82$ & $62.599,32$ & $57.962,34$ & $51.006,86$ & $41.732,88$ & $30.140,42$ & $16.229,45$ & 0,00 & 0,00 & 0,00 \\
\hline Amortización préstamo & 0,00 & $16.560,67$ & $33.121,34$ & $49.682,00$ & $66.242,67$ & $82.803,34$ & $99.364,01$ & $115.924,67$ & 0,00 & 0,00 & 0,00 \\
\hline Participaciones (10\%) & 0,00 & 0,00 & $1.015,28$ & $3.008,14$ & $6.065,67$ & $7.505,06$ & $12.253,57$ & $17.185,06$ & $22.297,05$ & $27.586,98$ & $31.197,36$ \\
\hline Impuesto a la renta $(27 \%)$ & 0,00 & 0,00 & $2.741,26$ & $8.121,97$ & $16.377,30$ & $20.263,66$ & $33.084,64$ & $46.399,66$ & $60.202,04$ & $74.484,85$ & $84.232,87$ \\
\hline Pago a accionistas & 0,00 & 0,00 & $6.396,26$ & $18.951,26$ & $38.213,70$ & $47.281,88$ & $77.197,50$ & $108.265,87$ & $140.471,43$ & $173.797,99$ & $196.543,37$ \\
\hline Total egresos & $512.190,23$ & $446.429,88$ & $543.393,11$ & $634.552,72$ & $752.540,46$ & $821.255,65$ & $921.232,23$ & $1.021 .233,55$ & $988.775,19$ & $1.090 .816,41$ & $1.197 .962,65$ \\
\hline Saldo de Caja & $67.433,14$ & $82.249,78$ & $95.214,14$ & $102.264,59$ & 76.572,99 & $67.411,89$ & $43.519,91$ & $4.872,30$ & $83.928,74$ & $146.189,65$ & $186.550,02$ \\
\hline
\end{tabular}

Elaboración propia 
7.5 Flujo de fondos netos

7.5.1. Flujo de fondos económicos

Tabla 7.22

Flujo de fondos económicos (en nuevos soles)

\begin{tabular}{|c|c|c|c|c|c|c|c|c|c|c|c|}
\hline & 2015 & 2016 & 2017 & 2018 & 2019 & 2020 & 2021 & 2022 & 2023 & 2024 & 2025 \\
\hline Inversión total & $-579.623,37$ & 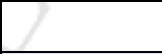 & & & 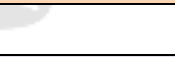 & & & & & & \\
\hline Utilidad después de impuestos & & $6.396,26$ & $18.951,26$ & $38.213,70$ & $47.281,88$ & $77.197,50$ & $108.265,87$ & $140.471,43$ & $173.797,99$ & $196.543,37$ & $205.491,40$ \\
\hline (+) Depreciación fabril & & $20.928,93$ & $20.928,93$ & $20.928,93$ & $20.928,93$ & $20.928,93$ & $20.928,93$ & $20.928,93$ & $20.928,93$ & $20.928,93$ & $20.928,93$ \\
\hline (+) Depreciación no fabril & & $6.311,84$ & $6.311,84$ & $6.311,84$ & $6.311,84$ & $6.311,84$ & $6.311,84$ & $6.311,84$ & $6.311,84$ & $6.311,84$ & $6.311,84$ \\
\hline (+) Gastos financieros & & $64.917,82$ & $62.599,32$ & $57.962,34$ & $51.006,86$ & $41.732,88$ & $30.140,42$ & $16.229,45$ & 0,00 & 0,00 & 0,00 \\
\hline (+) Valor residual (V. en libros) & & & & & & & & & & & $19.042,52$ \\
\hline Flujo neto de fondos económico & $-579.623,37$ & $98.554,85$ & $108.791,35$ & $123.416,81$ & $125.529,51$ & $146.171,15$ & $165.647,06$ & $183.941,65$ & $201.038,76$ & $223.784,14$ & $251.774,69$ \\
\hline
\end{tabular}

Elaboración propia
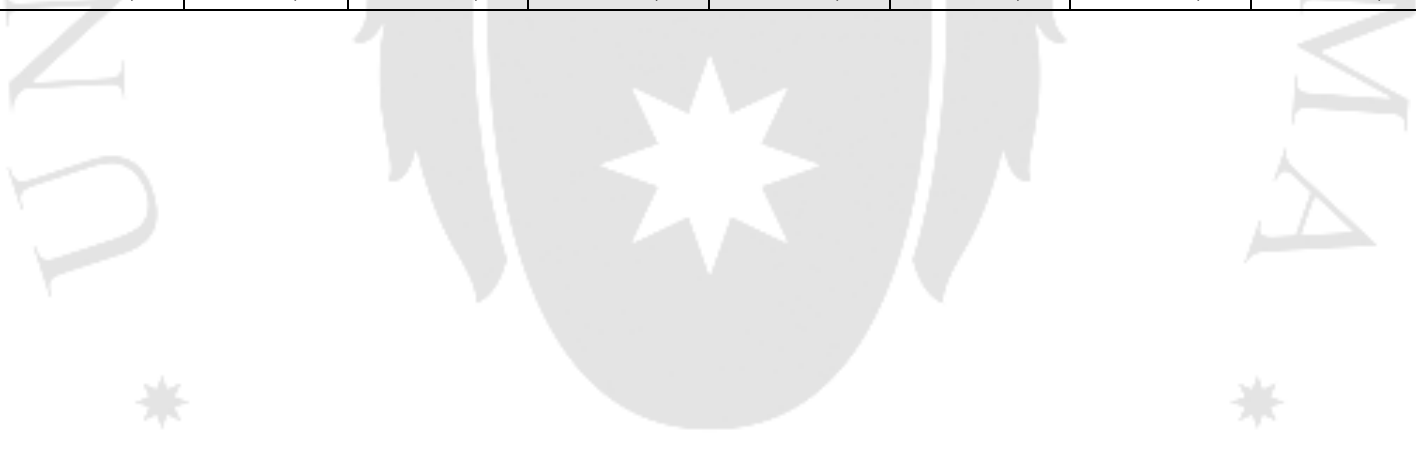
7.5.2. Flujo de fondos financieros

Tabla 7.23

Flujo de fondos financieros (en nuevos soles)

\begin{tabular}{|l|c|c|c|c|c|c|c|c|c|c|c|}
\hline \multicolumn{1}{|c|}{ Rubro } & $\mathbf{2 0 1 5}$ & $\mathbf{2 0 1 6}$ & $\mathbf{2 0 1 7}$ & $\mathbf{2 0 1 8}$ & $\mathbf{2 0 1 9}$ & $\mathbf{2 0 2 0}$ & $\mathbf{2 0 2 1}$ & $\mathbf{2 0 2 2}$ & $\mathbf{2 0 2 3}$ & $\mathbf{2 0 2 4}$ & $\mathbf{2 0 2 5}$ \\
\hline Inversión total & $-579.623,37$ & & & & & & & & & & \\
\hline Préstamo & $463.698,69$ & & & & & & & & & \\
\hline Utilidad después de impuestos & & $6.396,26$ & $18.951,26$ & $38.213,70$ & $47.281,88$ & $77.197,50$ & $108.265,87$ & $140.471,43$ & $173.797,99$ & $196.543,37$ & $205.491,40$ \\
\hline (+) Depreciación fabril & & $20.928,93$ & $20.928,93$ & $20.928,93$ & $20.928,93$ & $20.928,93$ & $20.928,93$ & $20.928,93$ & $20.928,93$ & $20.928,93$ & $20.928,93$ \\
\hline (+) Depreciación no fabril & & $6.311,84$ & $6.311,84$ & $6.311,84$ & $6.311,84$ & $6.311,84$ & $6.311,84$ & $6.311,84$ & $6.311,84$ & $6.311,84$ & $6.311,84$ \\
\hline (-) Amortización del préstamo & & $16.560,67$ & $33.121,34$ & $49.682,00$ & $66.242,67$ & $82.803,34$ & $99.364,01$ & $115.924,67$ & 0,00 & 0,00 & 0,00 \\
\hline (+) Valor residual (V. en libros) & & & & & & & & & & & $19.042,52$ \\
\hline Flujo neto de fondos financiero & $-115.924,67$ & $17.076,37$ & $13.070,69$ & $15.772,47$ & $8.279,98$ & $21.634,93$ & $36.142,64$ & $51.787,52$ & $201.038,76$ & $223.784,14$ & $251.774,69$ \\
\hline
\end{tabular}




\section{CAPÍTULO VIII: EVALUACIÓN ECONÓMICA Y FINANCIERA DEL PROYECTO}

\subsection{Evaluación económica: VAN, TIR, B/C, PR}

La evaluación económica considera que toda la inversión requerida es aportada por los accionistas. Para esta evaluación, la tasa a utilizar será el costo de oportunidad del accionista, es decir $13.72 \%$ (Punto 7.4.1). Se calcularon los siguientes indicadores económicos: Valor Actual Neto (VAN), Tasa Interna de Retorno (TIR), Tasa beneficio/costo (B/C) y Periodo de Recupero (PR).

Los indicadores producto de la evaluación económica se encuentran en la tabla 8.1.

Tabla 8.1

Indicadores económicos del proyecto

\begin{tabular}{|c|c|}
\hline Indicador & Valor \\
\hline VAN & S/. $190.075,32$ \\
\hline TIR & $20,27 \%$ \\
\hline B/C & 1,33 \\
\hline PR & 5 años \\
\hline
\end{tabular}

Elaboración propia

\subsection{Evaluación financiera: VAN, TIR, B/C, PR}

La evaluación financiera, por otro lado, muestra los indicadores tomando en cuenta el financiamiento del $80 \%$ respecto de la inversión total. A diferencia de la evaluación económica la tasa a utilizar es el Costo promedio ponderado de Capital (CPPC) calculado en el punto 7.4.1, que es de $10.58 \%$. Se calcularon los siguientes indicadores financieros: Valor Actual Neto (VAN), Tasa Interna de Retorno (TIR), Tasa beneficio/costo (B/C) y Periodo de Recupero (PR). 
Tabla 8.2

Indicadores financieros del proyecto

\begin{tabular}{|c|c|}
\hline Indicador & Valor \\
\hline VAN & $258.290,05$ \\
\hline TIR & $30,10 \%$ \\
\hline B/C & 3,23 \\
\hline PR & 7 años \\
\hline
\end{tabular}

Elaboración propia

\subsection{Análisis de ratios (liquidez, solvencia, rentabilidad) e indicadores económicos y}

\section{financieros del proyecto}

\section{$\underline{\text { Aspecto económico y financiero }}$}

Bajo el aspecto económico el proyecto es considerado rentable por la siguiente justificación:

- VAN > 0: Al ser el VAN mayor a 0 en ambos casos, nos indica que el proyecto generaría ganancias y por lo tanto debe aceptarse.

- TIR > tasa de descuento: En ambos casos, económico y financiero, el TIR es mayor a la tasa de descuento de cada uno. Esto quiere decir que la rentabilidad del proyecto es mayor a la mínima requerida (costo de oportunidad).

- B/C: La relación beneficio costo en ambos casos es mayor a 1, lo que significa que por cada sol invertido, obtendremos una ganancia de 1,33 y 3,23 en el aspecto económico y financiero respectivamente.

- PR: En ambos casos el periodo de recupero es de 7 años, tiempo menor a lo que dura el proyecto, 10 años.

\section{$\underline{\text { Ratios de rentabilidad por año }}$}

Los ratios de rentabilidad son los indicadores que nos permiten determinar si nuestro proyecto generara las ganancias suficientes para cubrir nuestros costos y poder obtener una rentabilidad para los accionistas. Como se puede observar en la tabla 8.3, la rentabilidad del proyecto se mantiene positiva en todos los años del proyecto. 
Tabla 8.3

Ratios de rentabilidad por año

\begin{tabular}{|l|c|c|c|c|c|c|c|c|c|c|}
\hline \multicolumn{1}{|c|}{ Ratio } & $\mathbf{2 0 1 6}$ & $\mathbf{2 0 1 7}$ & $\mathbf{2 0 1 8}$ & $\mathbf{2 0 1 9}$ & $\mathbf{2 0 2 0}$ & $\mathbf{2 0 2 1}$ & $\mathbf{2 0 2 2}$ & $\mathbf{2 0 2 3}$ & $\mathbf{2 0 2 4}$ & $\mathbf{2 0 2 5}$ \\
\hline Margen Bruto & $57,60 \%$ & $59,46 \%$ & $58,00 \%$ & $53,99 \%$ & $55,29 \%$ & $56,35 \%$ & $57,22 \%$ & $57,96 \%$ & $58,58 \%$ & $57,11 \%$ \\
\hline Margen Operativo & $32,50 \%$ & $32,93 \%$ & $37,49 \%$ & $37,79 \%$ & $43,05 \%$ & $47,02 \%$ & $50,09 \%$ & $52,49 \%$ & $54,40 \%$ & $54,33 \%$ \\
\hline Margen Neto & $8,52 \%$ & $20,45 \%$ & $32,22 \%$ & $37,51 \%$ & $46,99 \%$ & $53,60 \%$ & $58,73 \%$ & $63,00 \%$ & $63,00 \%$ & $63,00 \%$ \\
\hline Margen EBITDA & $41,55 \%$ & $40,37 \%$ & $44,10 \%$ & $44,07 \%$ & $48,54 \%$ & $51,90 \%$ & $54,47 \%$ & $56,48 \%$ & $58,05 \%$ & $57,81 \%$ \\
\hline ROE & $5,85 \%$ & $16,38 \%$ & $29,79 \%$ & $32,05 \%$ & $49,29 \%$ & $58,04 \%$ & $64,56 \%$ & $69,58 \%$ & $69,42 \%$ & $67,18 \%$ \\
\hline ROA & $13,11 \%$ & $16,53 \%$ & $21,87 \%$ & $25,64 \%$ & $35,91 \%$ & $49,44 \%$ & $69,37 \%$ & $69,18 \%$ & $71,56 \%$ & $72,28 \%$ \\
\hline
\end{tabular}

Elaboración propia

$\underline{\text { Ratios de liquidez por año }}$

Los ratios de liquidez son los indicadores que nos permiten determinar nuestra capacidad para hacer frente a nuestras deudas de corto plazo. Como se puede observar en la tabla 8.4, nuestra capacidad en todos los años se mantiene por encima de 1 , Por ejemplo en el año 2016 nuestra razón corriente es de 2,20, esto quiere decir que por cada sol adeudado en un plazo máximo de 1 año, contamos con 2,20 soles para cubrir dicho pago.

Tabla 8.4

Ratios de liquidez por año

\begin{tabular}{|l|c|c|c|c|c|c|c|c|c|c|}
\hline \multicolumn{1}{|c|}{ Ratio } & $\mathbf{2 0 1 6}$ & $\mathbf{2 0 1 7}$ & $\mathbf{2 0 1 8}$ & $\mathbf{2 0 1 9}$ & $\mathbf{2 0 2 0}$ & $\mathbf{2 0 2 1}$ & $\mathbf{2 0 2 2}$ & $\mathbf{2 0 2 3}$ & $\mathbf{2 0 2 4}$ & $\mathbf{2 0 2 5}$ \\
\hline Razón corriente & 2,20 & 1,61 & 1,22 & 0,79 & 0,57 & 0,35 & 0,31 & 0,96 & 1,35 & 1,60 \\
\hline Liquidez inmediata & 1,92 & 1,40 & 1,06 & 0,64 & 0,43 & 0,23 & 0,05 & 0,73 & 1,12 & 1,37 \\
\hline
\end{tabular}

Elaboración propia

\subsection{Análisis de sensibilidad del proyecto}

El análisis de sensibilidad busca poder plantearnos 2 tipos de escenarios (optimista y pesimista), ante el cambio de las variables más importantes del proyecto. Las variables a considerar para este análisis fueron precio de venta y costos de producción.

\section{$\underline{\text { Variación en el Precio de venta }}$}

El precio de la harina de lúcuma con el que se pretende entrar al mercado (precio de introducción) es de S/. 12,80 por kilogramo. El escenario optimista plantea que podamos subir el precio en un 5\%, mientras que el escenario pesimista nos plantea un precio reducido en un 5\%. En la tabla 8.5 se detalla cómo se verían afectados nuestros indicadores para cada caso. 


\section{Tabla 8.5}

Análisis de sensibilidad por variación del precio

\begin{tabular}{|l|c|c|c|c|c|c|c|c|c|}
\hline \multirow{2}{*}{ Escenario } & \multirow{2}{*}{ Variación } & \multicolumn{2}{|c|}{ VANE } & \multicolumn{2}{c|}{ VANF } & \multicolumn{2}{c|}{ TIRE } & \multicolumn{2}{c|}{ TIRF } \\
\cline { 3 - 10 } & & $\operatorname{Var}(\mathbf{S} /)$. & $\operatorname{Var}(\%)$ & $\operatorname{Var}(\mathbf{S} /)$. & $\operatorname{Var}(\%)$ & $\operatorname{Var}(\mathbf{S} /$ ) & Var (\%) & Var (S/.) & Var (\%) \\
\hline Optimista & $5,00 \%$ & $357.480,42$ & $88,07 \%$ & $462.546,16$ & $79,08 \%$ & $24,77 \%$ & $22,21 \%$ & $41,64 \%$ & $38,33 \%$ \\
\hline Probable & & $190.075,32$ & $0,00 \%$ & $258.290,05$ & $0,00 \%$ & $20,27 \%$ & $0,00 \%$ & $30,10 \%$ & $0,00 \%$ \\
\hline Pesimista & $-5,00 \%$ & $137.811,54$ & $-27,50 \%$ & $207.315,11$ & $-19,74 \%$ & $18,20 \%$ & $-10,21 \%$ & $23,54 \%$ & $-21,81 \%$ \\
\hline
\end{tabular}

Elaboración propia

Se puede concluir del análisis que de aumentar el precio en un 5\%, el VANE aumentaría en un $88,07 \%$, el VANF en un $79,08 \%$, el TIRE en un $22,21 \%$ y el TIRF en un $38,33 \%$.

\section{Variación en el Costos de producción}

Tabla 8.6

Análisis de sensibilidad por variación de costos de producción

\begin{tabular}{|l|c|c|c|c|c|c|c|c|c|}
\hline \multirow{2}{*}{ Escenario } & \multirow{2}{*}{ Variación } & \multicolumn{2}{|c|}{ VANE } & \multicolumn{2}{c|}{ VANF } & \multicolumn{2}{c|}{ TIRE } & \multicolumn{2}{c|}{ TIRF } \\
\cline { 3 - 10 } & & $\operatorname{Var}(\mathbf{S} /)$. & $\operatorname{Var}(\%)$ & $\operatorname{Var}(\mathbf{S} /)$. & $\operatorname{Var}(\%)$ & $\operatorname{Var}(\mathbf{S} /)$. & $\operatorname{Var}(\%)$ & Var (S/.) & Var (\%) \\
\hline Optimista & $-10,00 \%$ & $342.059,12$ & $79,96 \%$ & $444.599,23$ & $72,13 \%$ & $24,33 \%$ & $20,02 \%$ & $40,28 \%$ & $33,80 \%$ \\
\hline Probable & $0 \%$ & $190.075,32$ & $0,00 \%$ & $258.290,05$ & $0,00 \%$ & $20,27 \%$ & $0,00 \%$ & $30,10 \%$ & $0,00 \%$ \\
\hline Pesimista & $10,00 \%$ & $154.224,44$ & $-18,86 \%$ & $226.281,80$ & $-12,39 \%$ & $18,72 \%$ & $-7,66 \%$ & $24,83 \%$ & $-17,51 \%$ \\
\hline
\end{tabular}

Elaboración propia

Se puede concluir del análisis que de reducir el costo de producción en un 10\%, el VANE aumentaría en un 79,96\%, el VANF en un 72,13\%, el TIRE en un 20,02\% y el TIRF en un $33,80 \%$.

Bajo estos criterios se concluye que la variable más sensible es el precio de venta, ya que de esta variable depende que nuestro proyecto continúe siendo rentable. 


\section{CAPÍTULO IX: EVALUACIÓN SOCIAL DEL PROYECTO}

\subsection{Identificación de las zonas y comunidades de influencia del proyecto}

Para el presente proyecto se está considerando la ubicación de la planta de harina de lúcuma en la provincia de Huaral. Por lo tanto nuestra dicha provincia será nuestra zona de influencia.

A continuación determinaremos las comunidades de influencia en este proyecto. La comunidad campesina con la que se trabajará es la de Huayopampa. San Agustín de Huayopampa, es la capital del distrito de Atavillos Bajo, el cual pertenece a la Provincia de Huaral, se ubica sobre los 1800 m.s.n.m., asentada al margen derecho del Río Añasmayo, afluente del río Chancay.

Según el INEI en el censo del año 2009, la población era de 850 personas; de los cuales 448 son hombres y 402 son mujeres.

Figura 9.1

Mapa del departamento de Lima

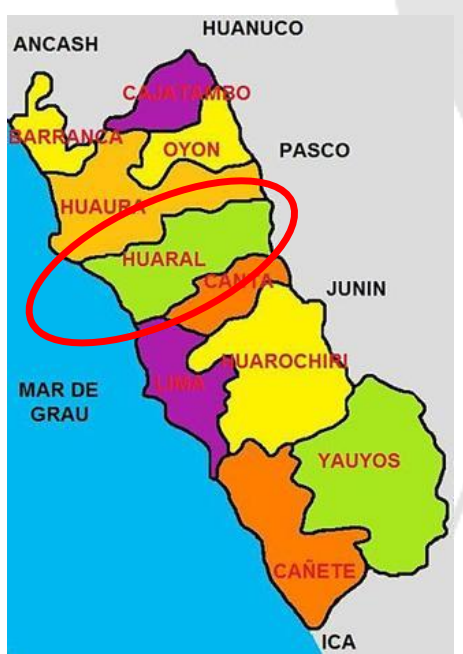

Fuente: Inversión pública de calidad, (2016)

En esta zona se siembra melocotón, chirimoya y lúcuma. Es una zona conocida como pionera en sembríos de frutas. 


\subsection{Análisis de indicadores sociales (valor agregado, densidad de capital, intensidad de capital, generación de divisas)}

Al trabajar con la comunidad de Huayompampa se generará un valor agregado a esta, debido a que afectaremos de una manera directa.

El objetivo social que define nuestro proyecto es el de contribuir con la balanza comercial y el PBI, además de crear empleo.

Los agricultores de la zona se verán beneficiados, se dictarán capacitaciones acerca de mejores técnicas de cultivo, que no afecten al medio ambiente. Se aplicará la regla de comercio justo, en el cual se paga al agricultor a un precio que le permita cubrir sus costos de producción.

Por otro lado, se generará oportunidades laborales en la zona de Huaral, esto debido a que nuestra mano de obra proviene de los alrededores.

A continuación analizaremos algunos indicadores sociales:

a) Densidad de capital: Definido como la relación entre el Activo fijo neto y el Personal ocupado censal. Con este indicador se determina la inversión que se necesita para crear un puesto de trabajo.

Tabla 9.1

Densidad de capital

\begin{tabular}{|l|c|}
\hline \multicolumn{1}{|c|}{ Rubro } & Importe (S/.) \\
\hline Inversión total & $579.623,37$ \\
\hline Puestos de trabajo & 8 \\
\hline Total & $\mathbf{7 2 . 4 5 2 , 9 2}$ \\
\hline
\end{tabular}

Elaboración propia

Para este proyecto tenemos una densidad de capital de 72.452,92 soles por puesto de trabajo.

b) Valor agregado: Definido como la suma de sueldos y salarios, depreciación, intereses, utilidades e impuestos. 
Tabla 9.2

Valor agregado en el año 2016

\begin{tabular}{|l|c|}
\hline \multicolumn{1}{|c|}{ Rubro } & Importe (S/.) \\
\hline Sueldo y salarios & $181.150,33$ \\
\hline Pago al capital & $88.894,51$ \\
\hline Depreciación & $14.847,65$ \\
\hline Intereses & $66.881,21$ \\
\hline Utilidades & $5.512,04$ \\
\hline Impuestos & $1.653,61$ \\
\hline Total & $\mathbf{2 7 0 . 0 4 4 , 8 4}$ \\
\hline Elaboración propia & \\
\hline
\end{tabular}

Se generan en el 2016, S/.270.044,84 nuevos soles gracias a este proyecto.

Tabla 9.3

Valor agregado en el año 2025

\begin{tabular}{|l|c|}
\hline \multicolumn{1}{|c|}{ Rubro } & Importe (S/.) \\
\hline Sueldo y salarios & $398.592,69$ \\
\hline Pago al capital & $373.867,61$ \\
\hline Depreciación & $14.847,65$ \\
\hline Intereses & $12.160,22$ \\
\hline Utilidades & $266.815,18$ \\
\hline Impuestos & $80.044,55$ \\
\hline Total & $\mathbf{7 7 2 . 4 6 0 , 3 0}$ \\
\hline
\end{tabular}

Elaboración propia

Se generan en el 2025, S/.772.460,30 nuevos soles gracias a este proyecto.

c) Intensidad de capital:

Tabla 9.4

Intensidad de capital en el 2016

\begin{tabular}{|l|c|}
\hline \multicolumn{1}{|c|}{ Rubro } & Importe(S/.) \\
\hline Inversión total & $579.623,37$ \\
\hline Valor agregado & $270.044,84$ \\
\hline Total & $\mathbf{2 , 1 4}$ \\
\hline
\end{tabular}

Elaboración propia

Nota: Cálculo de intensidad de capital en soles

Con este resultado se obtiene que para el 2016 se requiere 2,14 soles de inversión por cada nuevo sol de valor agregado generado. 
Tabla 9.5

Intensidad de capital en el 2025

\begin{tabular}{|c|c|}
\hline Rubro & Importe(S/.) \\
\hline Inversión total & $579.623,37$ \\
\hline Valor agregado & $772.460,30$ \\
\hline Total & $\mathbf{0 , 7 5}$ \\
\hline
\end{tabular}

Elaboración propia

Sin embargo, para el año 2025 se requiere 0,75 soles de inversión por cada nuevo sol de valor agregado generado. 


\section{CONCLUSIONES}

- El proyecto es viable a nivel de mercado, ya que existe una demanda en crecimiento en los países de Estados Unidos y los principales consumidores de harina de lúcuma en la Unión Europea. En estos países es considerado como un alimento saludable gracias a que no contiene aditivos y es un producto orgánico.

- Se cuenta con un proceso de producción claramente definido, la tecnología y herramientas adecuadas y la mano de obra calificada para elaborar la harina de lúcuma que cumpla con los más altos estándares exigidos por el mercado internacional. Estos factores nos permitirán obtener las certificaciones necesarias para poder comercializar nuestro producto fuera del país.

- La ubicación geográfica más adecuada del proyecto es en el departamento de Lima, específicamente en Huaral.

- El proyecto es económica y financieramente viable ya que los ratios de rentabilidad, los de liquidez así como los indicadores económicos y financieros, nos indican que se generarían ganancias a partir del primer año y que recuperaríamos el total invertido en un periodo de 5 años.

- Desde el punto de vista social, el proyecto generaría ganancias no solamente para los accionistas, sino para los trabajadores debido a las nuevas oportunidades de empleo generadas. También se demuestra un impacto positivo en los proveedores de la materia prima, ya que se les abrirá mayores oportunidades de comercializar su producto. 


\section{RECOMENDACIONES}

- Llevar a cabo revisiones periódicas del proceso de producción para poder obtener mediciones y aplicar una mejora continua.

- Realizar capacitaciones y programas de concienciación en los que el personal pueda obtener los conocimientos y desarrollar las competencias necesarias para realizar mejor su trabajo.

- Formar una alianza estratégica con los productores de lúcuma para de esa manera apoyarlos en mejorar la calidad de su producto, lo que repercutirá en la calidad de la harina de lúcuma.

- Capacitar al personal administrativo en temas relacionados al comercio internacional para que la empresa tenga esa orientación de mercado.
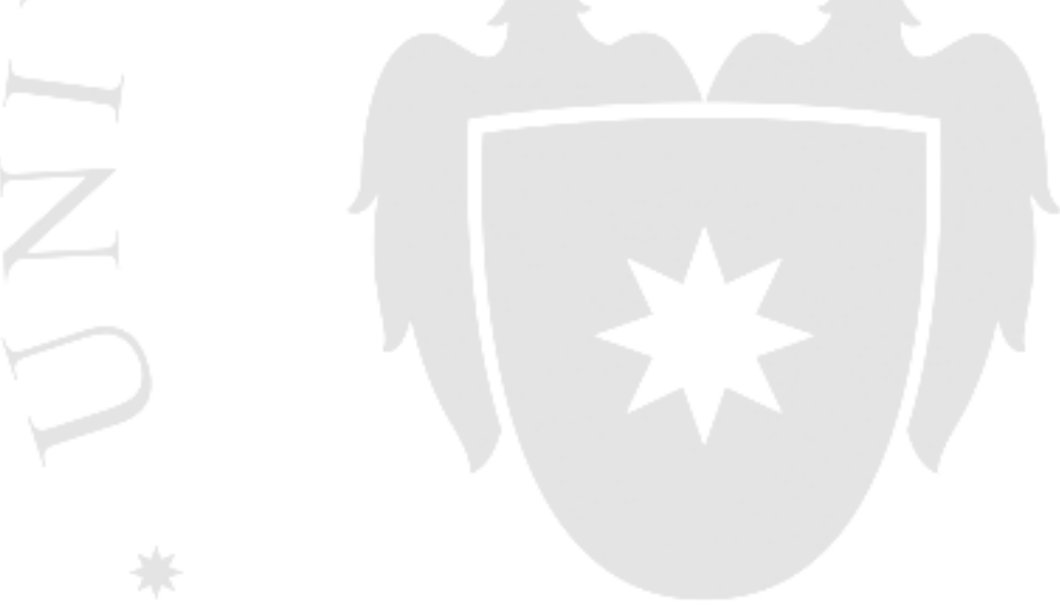


\section{REFERENCIAS}

Alibaba. (2015). Máquina de liofilización. Recuperado de http://www.alibaba.com

Alitecno Perú. (2015). Lavadora de frutas. Recuperado de http://www.alitecnoperu.com/

Centro De Investigación y Capacitación Agrícola Universidad Federico Villareal. (2015).

Comunidad de Huayopampar de

https://taller4unfv2014.files.wordpress.com/2014/05/centro-de-investigacion.pdf

CENTRUM al día. (2013). Proceso de compra de un comprador estadounidense. Recuperado de http://www.centrum.pucp.edu.pe/centrumaldia/mercado

Díaz, B.; Jarufe, B y Noriega, M. (2007). Disposición de planta. Lima: Universidad de Lima, Fondo editorial.

Dirección General de Salud Ambiental Digesa. (2008). Requisitos microbiológicos según DIGESA, R.M. 591 - 2008. Recuperado de http://www.senasa.gob.pe/senasa/wpcontent/uploads/2015/07/CRITERIOS-MICROBIOLOGICOS-RM-591-2008-

MINSA.pdf

Emapa Huaral S.A. (2015). Tarifario de servicio de agua potable. Recuperado de http://www.sunass.gob.pe/websunass/index.php/eps/tarifas-vigentes

Instituto Nacional de Estadística e Informática. (2014). Población económicamente inactiva. Recuperado de http://www.inei.gob.pe/estadisticas/indicetematico/economically-inactive-population/

Instituto Nacional de Estadística e Informática. (2015). Crecimiento del Perú. Recuperado de www.inei.com.pe 
Instituto Nacional de Estadística e Informática. (2015). Densidad de capital. Recuperado de

http://www.inei.gob.pe/media/MenuRecursivo/publicaciones_digitales/Est/Lib0961/ane xo06.pdf

Inversión pública de calidad, (2016). Mapa de Lima. Recuperado de http://www.snip.gob.pe/mapas/index.php

Málaga Del Castillo, R. (2006). Estudio Técnico de la Producción de Harina de Lúcuma en la Sierra de Piura (Tesis para optar título de Ingeniero Industrial). Recuperado de http://dspace.udep.edu.pe/bitstream/handle/123456789/1486/ING_443.pdf?sequence=1

Ministerio de Agricultura y Riego. (2015). Precio de la lúcuma. Anuario Hortofrutícola. Recuperado de http://www.minagri.gob.pe/portal/reporte-gran-mercado-mayorista-delima/la-parada-2015

Ministerio de Agricultura y Riego. (2015). Producción, superficie cosechada, rendimiento de Lúcuma del año 2014. Recuperado de http://siea.minag.gob.pe/siea/?q=actividades-estad\%C3\%ADsticas-delsistema/agr\%C3\%ADcola

Ministerio de Comercio Exterior y Turismo. (2010). Guía de Requisitos Sanitarios y Fitosanitarios para Exportar Alimentos a la Unión Europea. Recuperado de http://www.siicex.gob.pe/siicex/resources/calidad/req_ue.pdf

Ministerio de Comercio Exterior y Turismo. (2010). Guía de Requisitos Sanitarios y Fitosanitarios para Exportar Alimentos a los Estados Unidos. Recuperado de http://www.siicex.gob.pe/siicex/resources/calidad/req_usa.pdf

Ministerio de Salud del Perú. (2015). Significado general de los colores de seguridad. Recuperado de http://www.minsa.gob.pe/ogdn/cd1/pdf/ERI_06/contenido.pdf

Neumo Pack. (2015). Embolsadora. Recuperado de http://www.neumopack.com/ 
Neumo Pack. (2015). Selladora. Recuperado de http://www.neumopack.com/

Organismo Supervisor de la Inversión en Energía y Minería. (2015). Acceso a la Energía en el Perú: Balance y Opciones de Política. Recuperado de http://www.osinergmin.gob.pe/newweb/pages/Publico/CongresoInternacional/archivos/ JUEVES_30/CTI/AccesoalaEnergiaenelPeru-JulioSalvador.pdf

PROLÚCUMA. (2001). Proyecto de inversión de una planta de harina de lúcuma. Lima.

QUI Company. (2015). Máquina de lecho fluidizado. Recuperado de http://asiacentrifuge.es/3-fluid-bed-dryer-3.html

Quiminet. (2015). Secador de tambor. Recuperado de http://www.quiminet.com/articulos

Sagas. (2015). Balanza de plataforma. Recuperado de http://www.sagas.com.pe/

Sulem, D. (2001). Instalaciones de manufactura: ubicación, planeación y diseño. México, D.F.: International Thomson.

Superintendencia Nacional de Aduanas y de Administración Tributaria. (2015). Exportación e Importación de Harina de Lúcuma. Recuperado de http://www.aduanet.gob.pe/cl-aditconsultadwh/ieITS01Alias?accion=consultar\&CG_consulta=2

Universidad Nacional de Trujillo. (2015). Esquema del secado por Ventana Refractante. Scientia Agropecuaria 5. Recuperado de http://revistas.unitru.edu.pe/index.php/scientiaagrop/issue/archive

Vulcanotec. (2015). Secador de bandejas. Recuperado de http://www.vulcanotec.com/ Vulcanotec. (2015). Molino de martillos. Recuperado de http://www.vulcanotec.com/ 
Zebra Organics, Healthy Living Foods \& Products. (2015). Harina de Lúcuma. Recuperado de http://www.zebraorganics.com 


\section{BIBLIOGRAFÍA}

Diario Gestión. (10 de agosto del 2015). Terrenos en Ayacucho. Recuperado de http://gestion.pe/inmobiliaria

Instituto Nacional de Defensa de la Competencia y de la Protección de la Propiedad Intelectual. (2012). NTP 011 .042.Norma Técnica Peruana de Harina de Lúcuma.

Mortimore, S y Wallace, C. (2004). HACCP, Un enfoque práctico. Acribia. ISBN 9788420010359

Project Management Institute. (2008). Guía de los Fundamentos para la dirección de Proyectos. Cuarta Edición.

PYMEX. (2015). El atractivo internacional de la lúcuma. Recuperado de http://pymex.pe/emprendedores/productos-estrella/el-atractivo-internacional-de-lalucuma

Terrones, N. (2008). Plan de negocios para la puesta en marcha de una empresa productora/comercializadora de harina, pulpa y demás derivados de la lúcuma EXPROPAK S.R. L. - para el mercado nacional e internacional. Lima.

Zamora, F. (1999). Tesis para la implementación de una empresa productora y exportadora de harina de lúcuma a los países de Estados Unidos y Chile (Tesis para optar el título de Ingeniero Industrial). Universidad Nacional de Ingeniería, Lima. 


\section{ANEXOS}

\section{Anexo 1 - Propuesta económica - Lavadora de frutas}

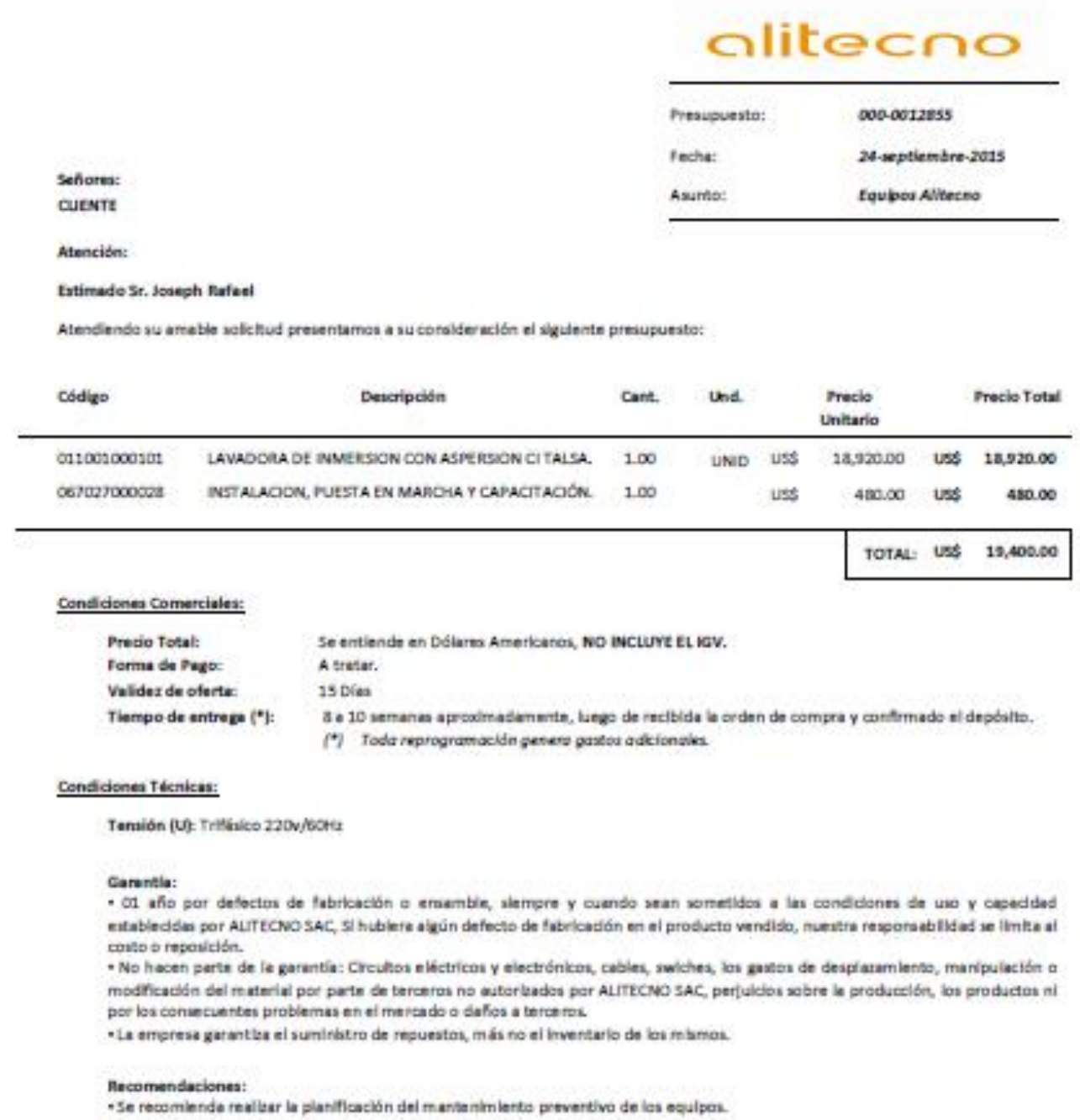

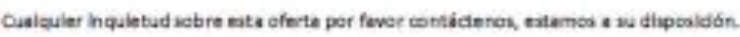

Cerdiemente.

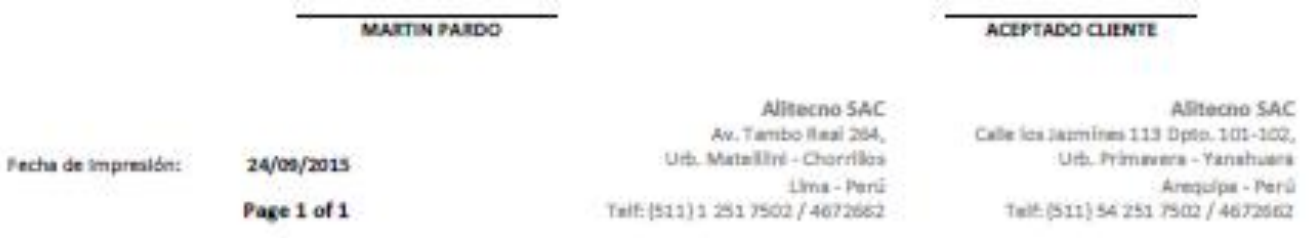

Fuente: Alitecno SAC, (2015) 
Anexo 2 - Propuesta económica - Secador de bandejas y Molino de martillos

\section{Vulcano Tecnología Aplicada E.I.R.L.}

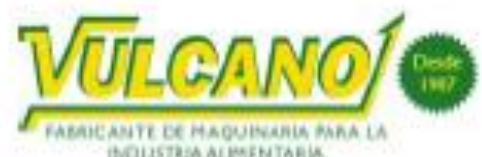

Huancayo, 26 Sefiembre del 2015

Ctz. $641-15$

Señores.

JOSEPH RAFAEL.

e-mai: ieseon.rafoeg2@gmaileom

Tif. 944206186

Lima.

Por medio de la presente le envio cotzación, por lo la siguiente.

\section{Deshidratador A Gas \\ G10 S}
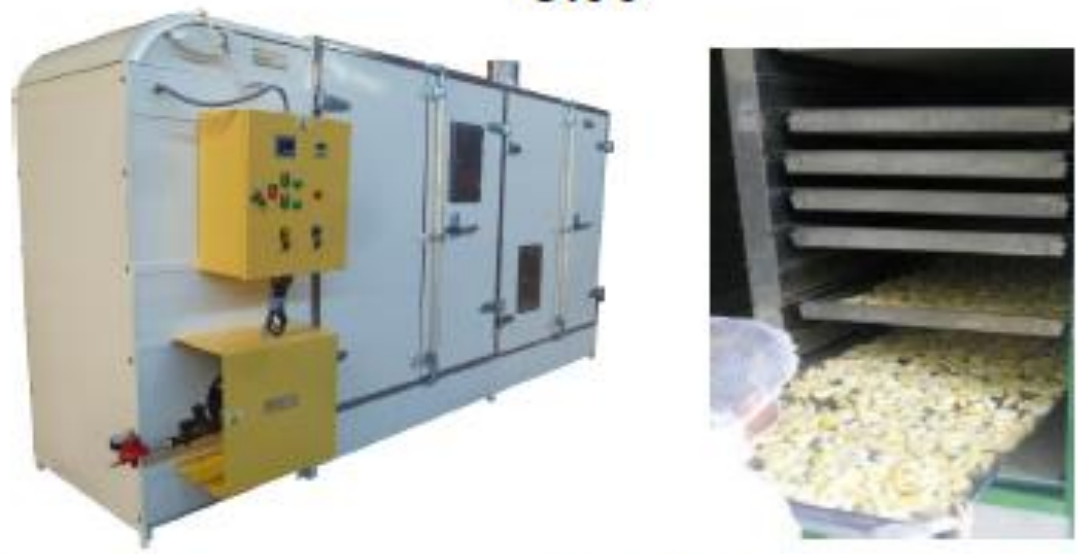

\section{Aplicación}

- Deshidratación de hierbas aromáticas, especias, frutas condimentos, raíces fubérculos, y nortalizas

\begin{tabular}{|c|c|}
\hline $\begin{array}{l}\text { ndad de la cabina } \\
\text { n la parte frontal para toma } \\
\text { mbiador de calor automátic } \\
\text { pano } \\
\text { ador con alarma de segurid } \\
\text { de provisión de corto circui }\end{array}$ & $\begin{array}{l}\text { Especificaciones } \\
\text { - Bandejas } 56 \text { unid. } 600 \times 885 \mathrm{~mm} \\
\text { - Área de secado } 30 \mathrm{~m} 2 \\
\text { - Molor de } 1.35 \mathrm{kw} \text {. } 220 \mathrm{~V} \text { monofásico } \\
\text { - Capacidad calońfica referencial: } 39600 \\
\text { (Kcal/hr). } \\
\text { - Tablero De Control. } \\
\text { Visualización e temperatura actual } \\
\text { Temperatura programable requerida } \\
\text { Luces de quemador y del ventiador } \\
\text { Tiempo programable de trabajo } \\
\text { Sensor de sobre calentamiento }\end{array}$ \\
\hline
\end{tabular}

\section{SEDE CENTRAL:}

Av. Brigida Siva de Ochos 3 se

San Mrguel - Lima

-51.1. 5661001 intogmulcanotec.com
vulcanoteo.eom
PLANTA:

Av. Coronel Parra 107 Plicomayo - Haancayo $+\$ 1.64 .261224$

Fuente: Vulcano Tecnología Aplicada E.I.R.L.,(2015) 


\section{Vulcano Tecnología Aplicada E.I.R.L.}

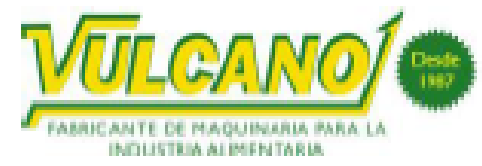

- Flexbilidad de operación garantizada. (termostato digital

- Disponibilidad de repuestos Alarma de sobre calentamiento etc.

- Material acero inoxidable de contacto cd. Peso aprox. $830 \mathrm{~kg}$

producto/acero al carbono en estructurd. Medidas exteriores Aprox.

A: $970-\mathrm{L} 3550-2400 \mathrm{~mm} \mathrm{~m}$ Consumo de gas $1.7 \mathrm{~K}$

Inversión: S/. 45,000.00 Nuevos Soles + IGV

\section{Molino de Martillos $\mathrm{MV} \cdot 15 \cdot 45 \mathrm{I} / \mathrm{C}$}

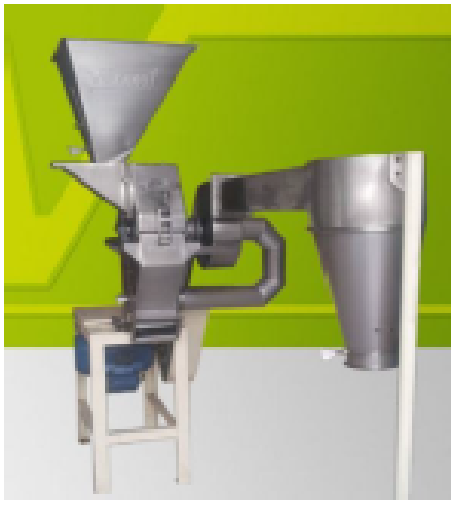

\section{Aplicación}

- Maquina diseñada para pulverizar y fragmentar todo tipo de Cereales como: cebada, avena, maíz, arroz, trigo, quinua, etc.

- Leguminosas: frejol, lentejas. palares, etc.

- Condimentos: Aj́ paprika, orégano, palilo, etc.

- para azúcar impalpable

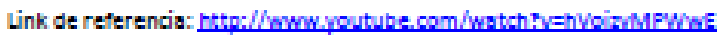

\begin{tabular}{|c|c|}
\hline $\begin{array}{l}\text { Descripción } \\
\text { - Tolva de alimentación constante con } \\
\text { sistema de dosificación } \\
\text { cámara de molienda formado por } \\
\text { paquete de trituración con eje, } \\
\text { martilos, pines,tamices } \\
\text { - Tolva frontal para descarga de } \\
\text { quebrados } \\
\text { - Sistema de aspiración con rotor, ductos } \\
\text { Ciclón como receptor de producto en } \\
\text { polvo } \\
\text { Estructura que fia máquina, motor con } \\
\text { protector de seguridad. } \\
\text { Fácil manterimiento . limpieza, } \\
\text { instalacióny operación }\end{array}$ & $\begin{array}{l}\text { Especificaciones } \\
\text { - Producción de } 60-\mathrm{kg} / \mathrm{h} \\
\text { - Motor de } 7.5 \mathrm{HP} \text { - trifásico } 220 \mathrm{v} 60 \mathrm{~Hz} \\
\text { - Tamices } 0.6-3.0 \mathrm{~mm} \\
\text { - Medida exteriores aprox. } \\
\text { A:-900, l: } 2300-1700 \mathrm{~mm} \\
\text { - Peso de } 110 \mathrm{Kg} \text {. } \\
\text { - Martillos de } 4 \text { vidas. } \\
\text { - Polea mixta de doble velocidades. } \\
\text { - Material construida en acero inoxidable } \\
\text { Alsl } 304 \text { (material en contacto con el } \\
\text { - producto/ acero al carbono en estructura } \\
\text { - Acabado sanitario }\end{array}$ \\
\hline & \\
\hline
\end{tabular}

SEDE CENTRAL:

Av. Brigida Stiva de Ochos 384

San Miguel - Lima

+51.1.5661001 infoemulcanotec.com vulcanoteo.com

\section{PLANTA:}

Av. Coronel Parra 107 Plicomayo - Huancayo $+51.64 .261224$

Fuente: Vulcano Tecnología Aplicada E.I.R.L. 


\section{Vulcano Tecnología Aplicada E.I.R.L.}

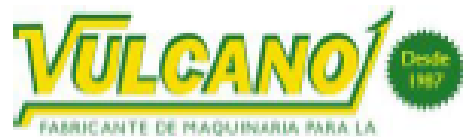

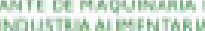

Condiciones Comerciales

\begin{tabular}{|l|l|}
\hline Observaciones & En todos los casos el flete es asumido por el Comprador. \\
\hline Forma de Pago & $\begin{array}{l}\text { Inicial } 50 \% \text { del monto total } \\
\text { Cancelación al aviso de equipo listo previo a la entrega }\end{array}$ \\
\hline Tiempo de entrega & 30 días laborales luego de la orden y la inicial \\
\hline Lugar de Entrega & Av. Brígida Silva de Ocho 384 San Miguel \\
\hline Garantía & $\begin{array}{l}\text { La garantía es de } 12 \text { meses desde Ia entrega de los equipos por } \\
\text { defectos de fabricación y en condiciones regulares de uso, no } \\
\text { atribuibles a malos manejos, traslado de trasporte, ni } \\
\text { afecciones por la naturaleza. }\end{array}$ \\
\hline $\begin{array}{l}\text { Instalación y Puesta en } \\
\text { Marcha }\end{array}$ & $\begin{array}{l}\text { Instalación, capacitación previa coordinación y pago de } \\
\text { salida de técnico a razón de S/.150 .00 N. Soles por día este } \\
\text { costo no incluye ( viáticos de pasajes alimentación ni } \\
\text { nospedaje) } \\
\text { Ecomprador se compromete a disponer los equipos en el lugar } \\
\text { del trabajo, realizar las conexiones eléctricas y dejar todo } \\
\text { dispuesto para la llegada del técrico }\end{array}$ \\
\hline Validez de la propuesta & \begin{tabular}{l}
10 dias. \\
\hline
\end{tabular}
\end{tabular}

En espera de vernos favorecido por su elección de compra quedo de Ud.

Aft.

Lide Acuña Munive

Vulcano Tecnología Aplicada

Tel: +51.64 .261224$

RPM: $\$ 575703$

info@vulcanotec.com

wuw vulcanotec.cem

\section{SEDE CENTRAL:}

Av. Brigida Stiva de Ochos 384

San Mrguel - Lima

+51.1.5661001 infogmulcanctec.com vulcanoteo. $00 m$

Fuente: Vulcano Tecnología Aplicada E.I.R.L., (2015) 


\section{Anexo 3 - Propuesta económica - Carretilla hidráulica}

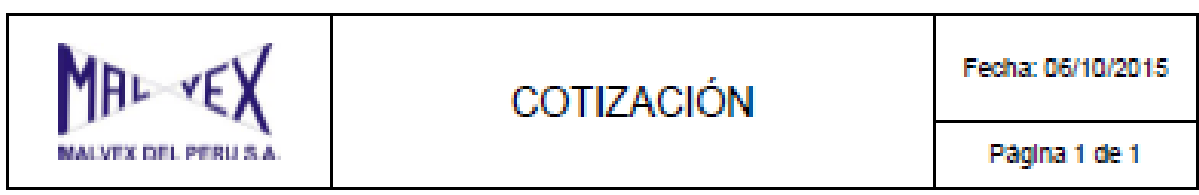

DATOS DEL CUENTE

$N^{*}$ PROFORMA: 8025-0-13907/15

\begin{tabular}{|c|c|}
\hline RAZON SOCIAL: & JOSEPH RAFAEL BLAS \\
\hline CONTACTO: & Or. Jozeph Ratsal \\
\hline TELEFONO: & 944206185 \\
\hline E-MAAL: & Joseph rafael92 fAgmall.com \\
\hline
\end{tabular}

\section{ESPECIFCACIONES TECNCAS}

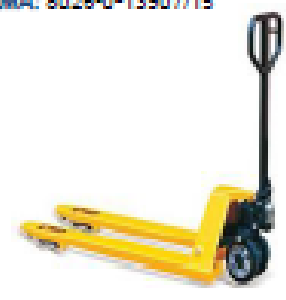

Carretla hidraulca de operacion manual marca MALVEX ECONOMY

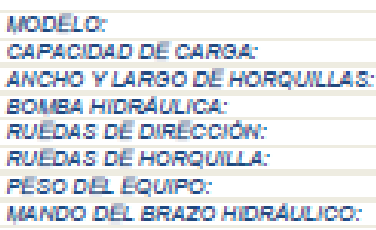

\begin{tabular}{|c|c|}
\hline WEF26 686X1220TNN & WEF25 $560 \times 1150 T N N$ \\
\hline $2,500 \mathrm{~kg}$ & $2,500 \mathrm{~kg}$. \\
\hline $685 / 1,220 \mathrm{~mm}$ & $550 / 1,150 \mathrm{~mm}$ \\
\hline Con platon cromado & Con platen cromado \\
\hline Nolion & Nylon \\
\hline Nylon, dobiez & Nylon, dobies \\
\hline $78 \mathrm{~kg}$. & $75 \mathrm{kgz}$. \\
\hline Con arco protector y poalelon n & Con arto protector y \\
\hline
\end{tabular}

DEMÁS ESPECIFICACIONES SEGÛN EL FOLETO ADUUNTO

CORTESIA:

\& Mantenimiento preventho dentro de los primeros $04-06$ meses.

\begin{tabular}{|c|c|c|c|}
\hline PRECIO STOCK LIUA & Us\$ 415.00 & Usะ & 370.00 \\
\hline PRECIO ESPECIAL & Ust 377.86 & Us: & 338.70 \\
\hline MAS: $18 \%$ L.Q.V. & 67.88 & & $60-81$ \\
\hline PRECIO TOTAL STOCK LIMA & Ust 445.83 & ust & 397.31 \\
\hline
\end{tabular}

CONONCIONES GENERALES

FORULA DE PAQC: TIEMPO DE ENTREQA:

A tratar. Cta. Cte Dolsres BCP 183-0817373-1-02

Dentro de los tres (03) dlas utlles contados a partir del dia sigulente de recibida su Orden de Compra

GARANTIA DEL EQUNPO. Doce (12) meses, contra eventusies defectoe de fabricacion

VRUDEZ DELA OFERTA: 30 dI:

SERMCIO POST-VENTA:

Con 49 affos de solida trayectoris en el mercado penusno representando diverass marcas de reconocido preatglo a nive mundial, Malvex del Peru se caractertza por ofrecer un servicio poat-venta eficiente en cualquier lugar del pala, con tecricos eapecislzadoa y atock permanente de repueatoa.

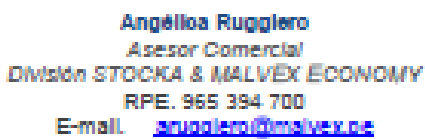

MALVEX DEL PERU S. A.

Av. Javier Prado Este 1169, LIma 13 T $2248560 / 4751512$ F 2248479 E servicloalcllentegmalwex.pe wom.malvex.pe

Fuente: Malvex del Peru S.A., (2015) 